NIST IR 8163

\title{
Dietary Supplement Laboratory Quality Assurance Program: Exercise G Final Report
}

Melissa M. Phillips Catherine A. Rimmer

Laura J. Wood 
NIST IR 8163

\title{
Dietary Supplement Laboratory Quality Assurance Program: Exercise G Final Report
}

\author{
Melissa M. Phillips \\ Catherine A. Rimmer \\ Laura J. Wood \\ Chemical Sciences Division \\ Material Measurement Laboratory
}

This publication is available free of charge from: https://doi.org/10.6028/NIST.IR.8163

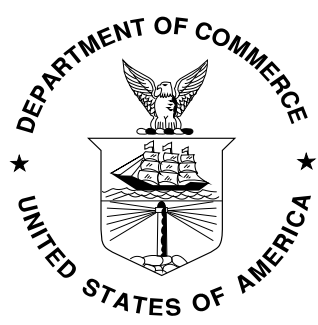

U.S. Department of Commerce Penny Pritzker, Secretary 


\section{TABLE OF CONTENTS}

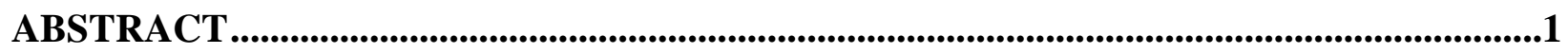

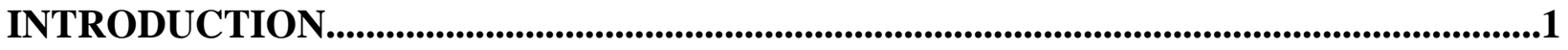

OVERVIEW OF DATA TREATMENT AND REPRESENTATION ......................................

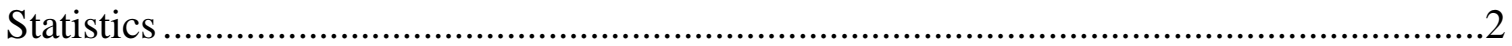

Individualized Data Table...........................................................................................

Summary Data Table …………………….................................................................

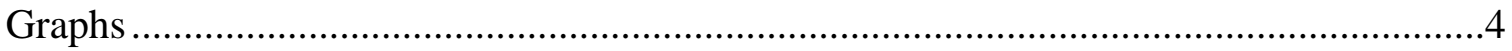

Data Summary View (Method Comparison Data Summary View) .........................4

Sample/Sample Comparison View ………………………………………………....

NUTRITIONAL ELEMENTS (Na) IN POWDERED MATRICES .......................................6

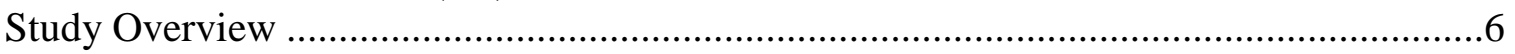

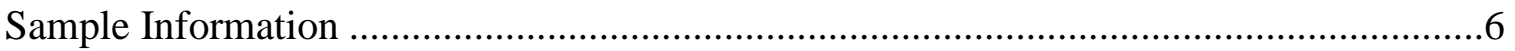

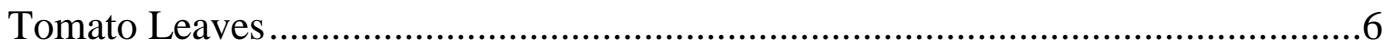

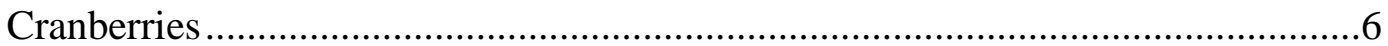

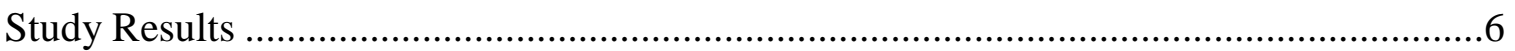

Technical Recommendations ......................................................................................

Table 1. Individual data table (NIST) for sodium in foods and dietary supplements .........9

Table 2. Data summary table for sodium in foods and dietary supplements ...................10

Figure 1. Sodium in SRM 1573a Tomato Leaves (data summary view - digestion method) …….....................................................................................................11

Figure 2. Sodium in SRM 3281 Cranberry (Fruit) (data summary view - digestion

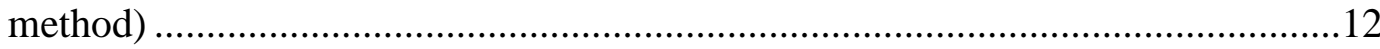

Figure 3. Sodium in SRM 1573a Tomato Leaves (data summary view - instrumental

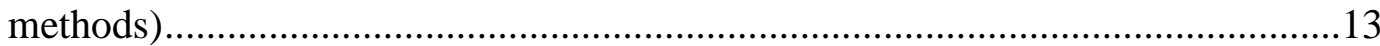

Figure 4. Sodium in SRM 3281 Cranberry (Fruit) (data summary view - instrumental methods)..........................................................................................................

Figure 5. Sodium in SRM 1573a Tomato Leaves and SRM 3281 Cranberry (Fruit) (sample/sample comparison view) .......................................................................15

TOXIC ELEMENTS (Pb) IN DIETARY SUPPLEMENTS .......................................................16

Study Overview ……………………………………………………………....16

Sample Information ......................................................................................................16

Ephedra-Containing Tablets ..............................................................................16

Multivitamin/Multielement Tablets ....................................................................16

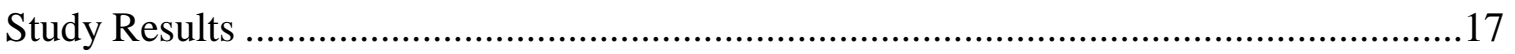

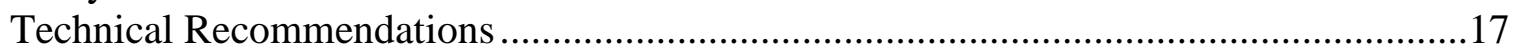

Table 3. Individual data table (NIST) for lead in dietary supplements............................19

Table 4. Data summary table for lead in dietary supplements .........................................20

Figure 6. Lead in SRM 3243 Ephedra-Containing Tablets (data summary view -

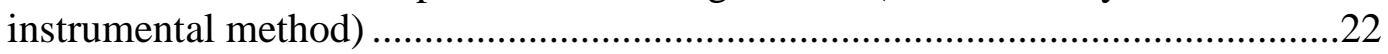

Figure 7. Lead in SRM 3280 Multivitamin/Multielement Tablets (data summary view - 
instrumental method)

Figure 8. Lead in SRM 3243 Ephedra-Containing Tablets and SRM 3280

Multivitamin/Multielement Tablets (sample/control comparison view) ................24

FOLIC ACID IN FOOD MATRICES ……….......................................................................25

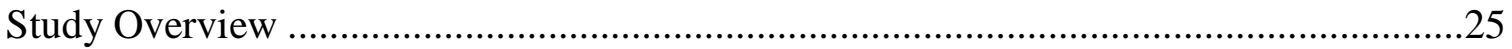

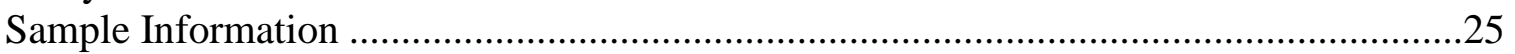

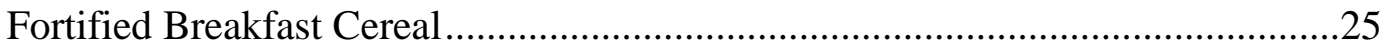

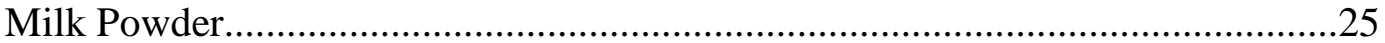

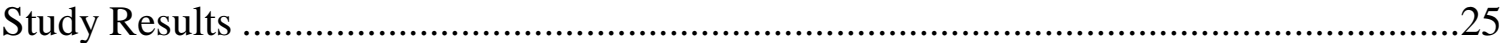

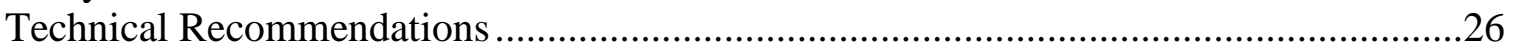

Table 5. Individual data table (NIST) for folic acid in foods.........................................27

Table 6. Data summary table for folic acid in dietary supplements..................................28

Figure 9. Folic acid in SRM 3233 Fortified Breakfast Cereal (data summary view sample preparation method).......................................................................29

Figure 10. Folic acid in Fortified Milk Powder (data summary view - sample

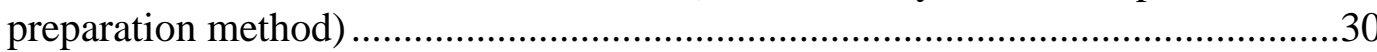

Figure 11. Folic acid in SRM 3233 Fortified Breakfast Cereal (data summary view instrumental method) ..........................................................................................31

Figure 12. Folic acid in Fortified Milk Powder (data summary view - instrumental

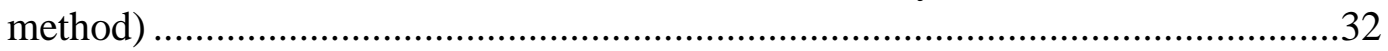

Figure 13. Folic acid in SRM 3233 Fortified Breakfast Cereal and Fortified Milk Powder (sample/sample comparison view) ............................................................33

$\beta$-CAROTENE IN SOLUTIONS AND DIETARY SUPPLEMENTS .....................................34

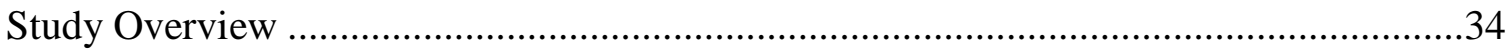

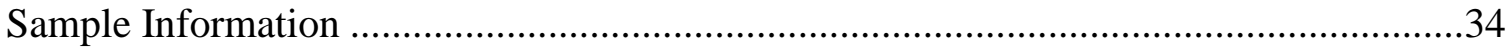

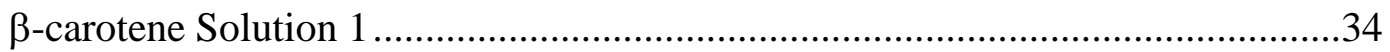

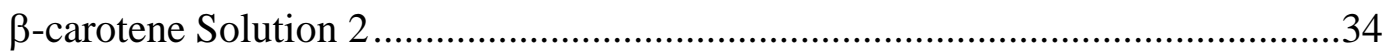

Saw Palmetto Extract......................................................................................34

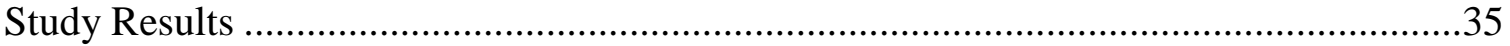

Technical Recommendations .........................................................................................35

Table 7. Individual data table (NIST) for $\beta$-carotene in solutions and dietary supplements.......................................................................................................

Table 8. Data summary table for trans- $\beta$-carotene in solutions and dietary supplements.

Table 9. Data summary table for 9-cis- $\beta$-carotene in solutions and dietary supplements.

Table 10. Data summary table for 13 -cis- $\beta$-carotene in solutions and dietary supplements

Table 11. Data summary table for 15 -cis- $\beta$-carotene in solutions and dietary supplements.

Table 12. Data summary table for total $\beta$-carotene in solutions and dietary supplements.

Figure 14. Total $\beta$-carotene in Solution 1 (data summary view - sample preparation method) 
Figure 15. Total $\beta$-carotene in Solution 2 (data summary view - sample preparation method)

Figure 16. Total $\beta$-carotene in SRM 3251 Serenoa repens Extract (data summary view - sample preparation method).............................................................................45

Figure 17. Total $\beta$-carotene in Solution 1 (data summary view - instrumental method)

Figure 18. Total $\beta$-carotene in Solution 2 (data summary view - instrumental method)

Figure 19. Total $\beta$-carotene in SRM 3251 Serenoa repens Extract (data summary view - instrumental method)

Figure 20. trans- $\beta$-carotene in Solution 1 (data summary view) .......................................49

Figure 21. trans- $\beta$-carotene in Solution 2 (data summary view) ......................................50

Figure 22. trans- $\beta$-carotene in SRM 3251 Serenoa repens Extract (data summary

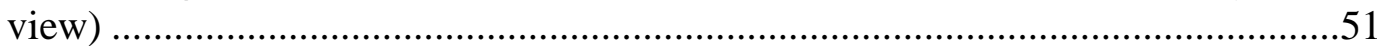

Figure 23. 9-cis- $\beta$-carotene in Solution 2 (data summary view).....................................52

Figure 24. 9-cis- $\beta$-carotene in SRM 3251 Serenoa repens Extract (data summary view) ...........................................................................................................53

Figure 25. Total $\beta$-carotene in Solution 1 and Solution 2 (sample/sample comparison view) …................................................................................................54

Figure 26. Total $\beta$-carotene in Solution 1 and SRM 3251 Serenoa repens Extract (sample/sample comparison view)........................................................................55

Figure 27. Total $\beta$-carotene in Solution 2 and SRM 3251 Serenoa repens Extract (sample/sample comparison view).........................................................................56

\section{ANTHOCYANINS \& ANTHOCYANIDINS IN DIETARY SUPPLEMENTS .....................57}

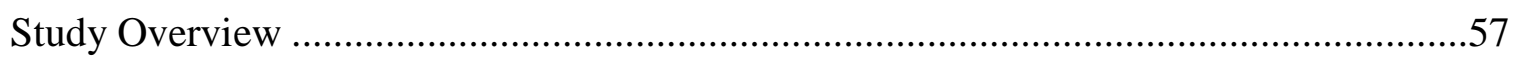

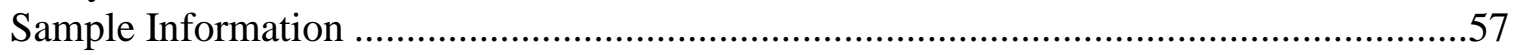

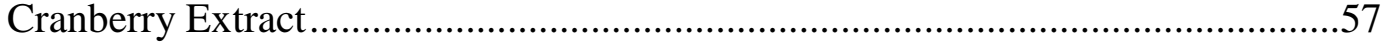

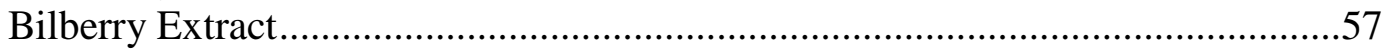

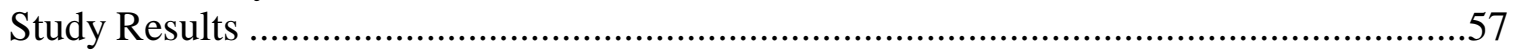

Technical Recommendations ...................................................................................58

Table 13. Individual data table (NIST) for anthocyanins and anthocyanidins in dietary

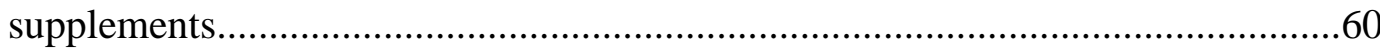

Table 14. Data summary table for cyanidin in dietary supplements .................................61

Table 15. Data summary table for cyanidin-3-arabinoside in dietary supplements.........62

Table 16. Data summary table for cyanidin-3-galactoside in dietary supplements .........63

Table 17. Data summary table for cyanidin-3-glucoside in dietary supplements .............64

Table 18. Data summary table for cyanidin equivalents in dietary supplements..............65

Table 19. Data summary table for delphinidin in dietary supplements ...........................66

Table 20. Data summary table for delphinidin-3-arabinoside in dietary supplements ....67

Table 21. Data summary table for delphinidin-3-galactoside in dietary supplements.....68

Table 22. Data summary table for delphinidin-3-glucoside in dietary supplements .......69

Table 23. Data summary table for delphinidin equivalents in dietary supplements .........70

Table 24. Data summary table for malvidin in dietary supplements ................................71

Table 25. Data summary table for malvidin-3-arabinoside in dietary supplements .........72

Table 26. Data summary table for malvidin-3-galactoside in dietary supplements..........73 
Table 27. Data summary table for malvidin-3-glucoside in dietary supplements .74

Table 28. Data summary table for malvidin equivalents in dietary supplements .............75

Table 29. Data summary table for peonidin in dietary supplements.................................76

Table 30. Data summary table for peonidin-3-arabinoside in dietary supplements..........77

Table 31. Data summary table for peonidin-3-galactoside in dietary supplements ..........78

Table 32. Data summary table for peonidin-3-glucoside in dietary supplements.............79

Table 33. Data summary table for peonidin equivalents in dietary supplements .............80

Table 34. Data summary table for petunidin in dietary supplements................................81

Table 35. Data summary table for petunidin-3-arabinoside in dietary supplements ........82

Table 36. Data summary table for petunidin-3-galactoside in dietary supplements.........83

Table 37. Data summary table for petunidin-3-glucoside in dietary supplements............84

Table 38. Data summary table for petunidin equivalents in dietary supplements ............85

Table 39. Data summary table for total anthocyanins in dietary supplements .................86

Figure 28. Cyanidin in SRM 3283 Cranberry Extract (data summary view) ....................87

Figure 29. Cyanidin in SRM 3291 Bilberry Extract (data summary view) .......................88

Figure 30. Cyanidin-3-arabinoside in SRM 3283 Cranberry Extract (data summary view)

Figure 31. Cyanidin-3-arabinoside in SRM 3291 Bilberry Extract (data summary view)

Figure 32. Cyanidin-3-galactoside in SRM 3283 Cranberry Extract (data summary

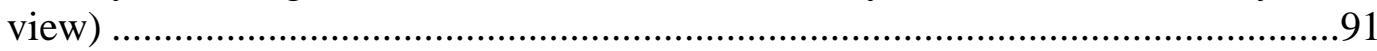

Figure 33. Cyanidin-3-galactoside in SRM 3291 Bilberry Extract (data summary view)

Figure 34. Cyanidin-3-glucoside in SRM 3283 Cranberry Extract (data summary view)

Figure 35. Cyanidin-3-glucoside in SRM 3291 Bilberry Extract (data summary view) .94

Figure 36. Cyanidin equivalents in SRM 3283 Cranberry Extract (data summary

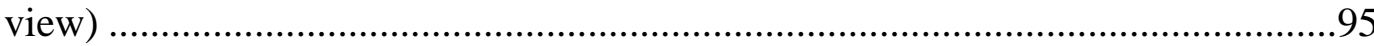

Figure 37. Cyanidin equivalents in SRM 3291 Bilberry Extract (data summary view)..96

Figure 38. Delphinidin in SRM 3283 Cranberry Extract (data summary view)...............97

Figure 39. Delphinidin in SRM 3291 Bilberry Extract (data summary view)..................98

Figure 40. Delphinidin-3-arabinoside in SRM 3291 Bilberry Extract (data summary

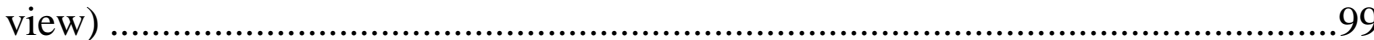

Figure 41. Delphinidin-3-galactoside in SRM 3291 Bilberry Extract (data summary

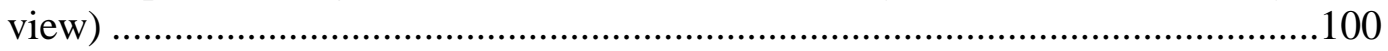

Figure 42. Delphinidin-3-glucoside in SRM 3291 Bilberry Extract (data summary view)

Figure 43. Delphinidin equivalents in SRM 3283 Cranberry Extract (data summary view)

Figure 44. Delphinidin equivalents in SRM 3291 Bilberry Extract (data summary view)

Figure 45. Malvidin in SRM 3291 Bilberry Extract (data summary view)

Figure 46. Malvidin-3-arabinoside in SRM 3291 Bilberry Extract (data summary view)

Figure 47. Malvidin-3-galactoside in SRM 3283 Cranberry Extract (data summary view) 106 
Figure 48. Malvidin-3-galactoside in SRM 3291 Bilberry Extract (data summary view)

Figure 49. Malvidin-3-glucoside in SRM 3291 Bilberry Extract (data summary view)

Figure 50. Malvidin equivalents in SRM 3283 Cranberry Extract (data summary view)

Figure 51. Malvidin equivalents in SRM 3291 Bilberry Extract (data summary view) 110

Figure 52. Peonidin in SRM 3283 Cranberry Extract (data summary view)..................111

Figure 53. Peonidin in SRM 3291 Bilberry Extract (data summary view).....................112

Figure 54. Peonidin-3-arabinoside in SRM 3283 Cranberry Extract (data summary view)

Figure 55. Peonidin-3-arabinoside in SRM 3291 Bilberry Extract (data summary view)

Figure 56. Peonidin-3-galactoside in SRM 3283 Cranberry Extract (data summary view)

Figure 57. Peonidin-3-galactoside in SRM 3291 Bilberry Extract (data summary view)

Figure 58. Peonidin-3-glucoside in SRM 3283 Cranberry Extract (data summary view)

Figure 59. Peonidin-3-glucoside in SRM 3291 Bilberry Extract (data summary view)118

Figure 60. Peonidin equivalents in SRM 3283 Cranberry Extract (data summary view)

Figure 61. Peonidin equivalents in SRM 3291 Bilberry Extract (data summary view) 120

Figure 62. Petunidin in SRM 3291 Bilberry Extract (data summary view) ..................121

Figure 63. Petunidin-3-arabinoside in SRM 3291 Bilberry Extract (data summary view)

Figure 64. Petunidin-3-galactoside in SRM 3291 Bilberry Extract (data summary view)

Figure 65. Petunidin-3-glucoside in SRM 3283 Cranberry Extract (data summary view)

Figure 66. Petunidin-3-glucoside in SRM 3291 Bilberry Extract (data summary view)

Figure 67. Petunidin equivalents in SRM 3283 Cranberry Extract (data summary view)

Figure 68. Petunidin equivalents in SRM 3291 Bilberry Extract (data summary view)

Figure 69. Total anthocyanins in SRM 3283 Cranberry Extract (data summary view sample preparation method).

Figure 70. Total anthocyanins in SRM 3291 Bilberry Extract (data summary view sample preparation method).

Figure 71. Total anthocyanins in SRM 3283 Cranberry Extract (data summary view instrumental method)

Figure 72. Total anthocyanins in SRM 3291 Bilberry Extract (data summary view instrumental method)

Figure 73. Total anthocyanins in SRM 3283 Cranberry Extract and SRM 3291 Bilberry Extract (sample/sample comparison view) 


\begin{abstract}
The NIST Dietary Supplement Laboratory Quality Assurance Program (DSQAP) was established in collaboration with the National Institutes of Health (NIH) Office of Dietary Supplements (ODS) in 2007 to enable members of the dietary supplements community to improve the accuracy of measurements made in compliance with various regulations including the dietary supplement current good manufacturing practices (cGMPs). Exercise $\mathrm{G}$ of this program offered the opportunity for laboratories to assess their in-house measurements of nutritional elements (Na), contaminants $(\mathrm{Pb})$, water-soluble vitamins (folic acid), fat-soluble vitamins (ß-carotene), and anthocyanins in foods and/or botanical dietary supplement ingredients and finished products.
\end{abstract}

\title{
INTRODUCTION
}

The dietary supplement industry in the U.S. is booming, with two-thirds of adults considering themselves to be supplement users. ${ }^{1}$ Consumption of dietary supplements, which includes vitamin and mineral supplements, represents an annual US expenditure of more than $\$ 25$ billion. These figures represent an increasing American trend, and as a result, it is critically important that both the quality and safety of these products are verified and maintained.

The Dietary Supplement Health and Education Act of 1994 (DSHEA) amended the Federal Food, Drug and Cosmetic Act to create the regulatory category called dietary supplements. The DSHEA also gave the FDA authority to write current Good Manufacturing Practices (cGMPs) that require manufacturers to evaluate the identity, purity, and composition of their ingredients and finished products. In addition, the DSHEA authorized the establishment of the Office of Dietary Supplements at the National Institutes of Health (NIH ODS). To enable members of the dietary supplements community to improve the accuracy of the measurements made in compliance with these and other regulations, NIST established the Dietary Supplement Laboratory Quality Assurance Program (DSQAP) in collaboration with the NIH ODS in 2007.

The program offers the opportunity for laboratories to assess their in-house measurements of active or marker compounds, nutritional elements, contaminants (toxic elements, pesticides, mycotoxins), and fat- and water-soluble vitamins in foods as well as botanical dietary supplement ingredients and finished products. Reports and certificates of participation are provided and can be used to demonstrate compliance with the cGMPs. In addition, NIST and the DSQAP assist the ODS Analytical Methods and Reference Materials program (AMRM) at the NIH in supporting the development and dissemination of analytical tools and reference materials. In the future, results from DSQAP exercises could be used by ODS to identify problematic matrices and analytes for which an AOAC INTERNATIONAL Official Method of Analysis would benefit the dietary supplement community

NIST has experience in the area of quality assurance programs, but the DSQAP takes a unique approach. In other NIST quality assurance programs, a set of analytes is measured repeatedly over time in the same or similar matrices to demonstrate laboratory performance. In contrast, the wide range of matrices and analytes under the "dietary supplement" umbrella means that not every

\footnotetext{
${ }^{1}$ Walsh, T. (2012) Supplement Usage, Consumer Confidence Remain Steady According to New Annual Survey from CRN. Council for Responsible Nutrition, Washington, DC.
} 
laboratory is interested in every sample or analyte. The constantly changing dietary supplement market, and the enormous diversity of finished products, makes repeated determinations of a few target compounds in a single matrix of little use to participants. Instead, participating laboratories are interested in testing in-house methods on a wide variety of challenging, real-world matrices to demonstrate that their performance is comparable to that of the community. In an area where there are few standard methods, the DSQAP offers a unique tool for assessment of the quality of measurements, provides feedback about performance, and can assist participants in improving laboratory operations.

This report contains the results from the seventh exercise of the DSQAP, Exercise G. Seventyeight laboratories responded to the call for participants distributed in May 2011. Samples were shipped to participants in July 2011, and results were returned to NIST by October 2011. The information and data contained in this report was disseminated to the participants in June 2011.

\section{OVERVIEW OF DATA TREATMENT AND REPRESENTATION}

Individualized data tables and certificates are provided to the participants that have submitted data in each study, in addition to this report. Examples of the data tables using NIST data are also included in each section of this report. Community tables and graphs are provided using randomized laboratory codes, with identities known only to NIST and individual laboratories. The statistical approaches are outlined below for each type of data representation.

\section{$\underline{\text { Statistics }}$}

Data tables and graphs throughout this report contain information about the performance of each laboratory relative to that of the other participants in this study and relative to a target around the expected result, if available. The consensus mean and standard deviation are calculated according to the robust algorithm outlined in ISO 13528:2005(E), Annex C. ${ }^{2}$ The algorithm is summarized here in simplified form.

Initial values of the consensus mean, $x^{*}$, and consensus standard deviation, $s^{*}$, are estimated as

$$
\begin{array}{ll}
x^{*}=\text { median of } x_{i} & (i=1,2, \ldots, n) \\
s^{*}=1.483 \times \text { median of }\left|x_{i}-x^{*}\right| & (i=1,2, \ldots, n) .
\end{array}
$$

These initial values for $x^{*}$ and $s^{*}$ are updated by first calculating the expanded standard deviation, $\delta$, as

$$
\delta=1.5 \times s^{*} .
$$

Then each $x_{i}$ is compared to the expanded range and adjusted to $x_{i}{ }^{*}$ as described below to reduce the effect of outliers.

$$
\begin{aligned}
& \text { If } x_{i}<x^{*}-\delta \text {, then } x_{i}^{*}=x^{*}-\delta \text {. } \\
& \text { If } x_{i}>x^{*}+\delta \text {, then } x_{i}^{*}=x^{*}+\delta .
\end{aligned}
$$

${ }^{2}$ ISO 13528:2005(E), Statistical methods for use in proficiency testing by interlaboratory comparisons, pp. 14-15. 
Otherwise, $x_{i}^{*}=x_{i}$.

New values of $x^{*}, s^{*}$, and $\delta$ are calculated iteratively until the process converges. Convergence is taken as no change from one iteration to the next in the third significant figure of $s^{*}$ and in the equivalent digit in $x^{*}$ :

$$
\begin{aligned}
& x^{*}=\frac{\sum_{i=1}^{n} x_{i}^{*}}{n} \\
& S^{*}=1.134 \times \sqrt{\frac{\sum_{i=1}^{n}\left(x_{i}^{*}-x^{*}\right)}{n-1}} .
\end{aligned}
$$

Individualized Data Table

The data in this table is individualized to each participating laboratory and is provided to allow participants to directly compare their data to the summary statistics (consensus or community data as well as NIST certified, reference, or estimated values). The upper left of the data table includes the randomized laboratory code. Tables included in this report are generated using NIST data to protect the identity and performance of participants.

Section 1 of the data table contains the laboratory results as reported, including the mean and standard deviation when multiple values were reported. A blank indicates that NIST does not have data on file for that laboratory for a particular analyte or matrix. An empty box for standard deviation indicates that only a single value was reported and therefore that value was not included in the calculation of the consensus data. ${ }^{2}$

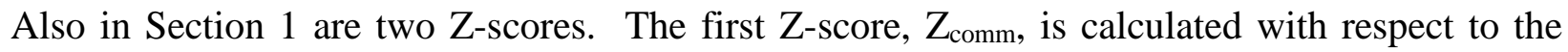
community consensus value, using $x^{*}$ and $s^{*}$ :

$$
Z_{\text {comm }}=\frac{x_{i}-x *}{s *}
$$

The second Z-score, $Z_{\text {NIST, }}$ is calculated with respect to the target value (NIST certified, reference, or estimated value), using $\mathrm{X}_{\mathrm{NIST}}$ and $U_{95}$ (the expanded uncertainty) or SNIST (the standard deviation of NIST measurements):

$$
Z_{N I S T}=\frac{x_{i}-x_{N I S T}}{U_{95}}
$$

or

$$
Z_{N I S T}=\frac{x_{i}-x_{N I S T}}{s_{N I S T}}
$$

The significance of the Z-score is as follows:

- $|\mathrm{Z}|<2$ indicates that the laboratory result is considered to be within the community consensus range (for $\mathrm{Z}_{\text {comm }}$ ) or NIST target range (for $\mathrm{Z}_{\mathrm{NIST}}$ ).

- $\quad 2<|\mathrm{Z}|<3$ indicates that the laboratory result is considered to be marginally different from the community consensus value (for $\mathrm{Z}_{\text {comm) }}$ or NIST target value (for $\mathrm{Z}_{\mathrm{NIST}}$ ). 
- $|\mathrm{Z}|>3$ indicates that the laboratory result is considered to be significantly different from the community consensus value (for $\mathrm{Z}_{\mathrm{comm}}$ ) or NIST target value (for $\mathrm{Z}_{\mathrm{NIST}}$ ).

Section 2 of the data table contains the community results, including the number of laboratories reporting more than a single value for a given analyte ${ }^{1}$, the mean value determined for each analyte, and a robust estimate of the standard deviation of the reported values. ${ }^{3}$ Consensus means and standard deviations are calculated using the laboratory means; if a laboratory reported a single value, the reported value is not included. ${ }^{3}$ Additional information on calculation of the consensus mean and standard deviation can be found in the previous section.

Section 3 of the data table contains the target values for each analyte. When possible, the target value is a certified or reference value determined at NIST. Certified values and the associated expanded uncertainty $\left(U_{95}\right)$ have been determined with two independent analytical methods at NIST, by collaborating laboratories, or in some combination. Reference values are assigned using NIST values obtained from the average and standard deviation of measurements made using a single analytical method or by measurements obtained from collaborating laboratories. For both certified and reference values, at least six samples have been tested and duplicate preparations from the sample package have been included, allowing the uncertainty to encompass variability due to inhomogeneity within and between packages. For samples in which a NIST certified or reference value is not available, the analytes are measured at NIST using an appropriate method. The NIST-assessed value represents the mean of at least three replicates. For materials acquired from another proficiency testing program, the consensus value and uncertainty from the completed round is used as the target range.

Summary Data Table

This data table includes a summary of all reported data for a particular analyte in a particular study. Participants can compare the raw data for a single laboratory to data reported by the other participating laboratories or to the consensus data. A blank indicates that the laboratory signed up and received samples for that particular analyte and matrix, but NIST does not have data on file for that laboratory.

\section{Graphs}

\section{Data Summary View (Method Comparison Data Summary View)}

In this view, individual laboratory data are plotted with the individual laboratory standard deviation (error bars). Data points that are unfilled represent laboratories that reported a single value for that analyte and therefore were not included in the consensus mean. The black solid line represents the consensus mean, and the black dotted lines represent the consensus variability calculated as one standard deviation about the consensus mean. Where appropriate, two consensus means may be calculated for the same sample if bimodality is identified in the data. In this case, two consensus means and ranges will be displayed in the data summary view. The gray shaded region represents the target zone for "acceptable" performance, which encompasses the NIST certified, reference, or estimated value bounded by twice its uncertainty $\left(U_{95}\right)$ or standard deviation. For the purpose of the DSQAP, a target range spanning twice the uncertainty in the NIST value is selected because participants are only asked to make a limited number of

\footnotetext{
${ }^{3}$ ISO 13528:2005(E), Statistical methods for use in proficiency testing by interlaboratory comparisons, Annex C.
} 
observations. The size of the y-axis on the data summary view graph represents the consensus mean bounded by $2 \delta$. In this view, the relative locations of individual laboratory data and consensus zones with respect to the target zone can be compared easily. In most cases, the target zone and the consensus zone overlap, which is the expected result. The major program goals are to reduce the size of the consensus zone and center the consensus zone about the target value. Analysis of an appropriate reference material as part of a quality control scheme can help to identify sources of bias for laboratories reporting results that are significantly different from the target zone. In the case in which a method comparison is relevant, different colored data points may be used to indicate laboratories that used a specific approach to sample preparation, analysis, or quantitation.

\section{Sample/Sample Comparison View}

In this view, the individual laboratory results for one sample (NIST SRM with a certified or reference value) are compared to the results for another sample (another NIST SRM with a more challenging matrix, a commercial sample, etc.). The error bars represent the individual laboratory standard deviation. The solid red box represents the target zone for the first sample (x-axis) and the second sample (y-axis). The dotted blue box represents the consensus zone for the first sample (x-axis) and the second sample (y-axis). The axes of this graph are centered about the consensus mean values for each sample or control, to a limit of zero and twice the consensus mean. Depending on the variability in the data, the axes may be scaled proportionally to better display the individual data points for each laboratory. In some cases, when the consensus and target ranges have limited overlap, the solid red box may only appear partially on the graph. If the variability in the data is high (greater than $100 \%$ relative standard deviation (RSD)), the dotted blue box may also only appear partially on the graph. This view emphasizes trends in the data that may indicate potential calibration issues or method biases. One program goal is to identify such calibration or method biases and assist participants in improving analytical measurement capabilities. In some cases, when two equally challenging materials are provided, the same view (sample/sample comparison) can be helpful in identifying commonalities or differences in the analysis of the two materials. 


\section{NUTRITIONAL ELEMENTS (Na) IN POWDERED MATRICES}

\section{Study Overview}

In this study, participants were provided with two NIST SRMs, SRM 1573a Tomato Leaves and SRM 3281 Cranberry (Fruit). Participants were asked to use in-house analytical methods to determine the mass fraction of sodium in each matrix and report values on an as-received basis.

\section{Sample Information}

Tomato Leaves. Participants were provided with one bottle containing approximately $50 \mathrm{~g}$ of dried, powdered tomato leaves. The material was prepared from tomato leaves collected in Pennsylvania that had been picked from an untreated area, rinsed, then dried at $60{ }^{\circ} \mathrm{C}$ to $70{ }^{\circ} \mathrm{C}$. The dried leaves were ground and sieved prior to packaging. Before use, participants were instructed to thoroughly mix the contents of the bottle and use a sample size of at least $0.5 \mathrm{~g}$. Participants were asked to store the material at controlled room temperature, $20{ }^{\circ} \mathrm{C}$ to $25{ }^{\circ} \mathrm{C}$, and to prepare three samples and report three values from the single bottle provided. Prior to the study, the approximate analyte level was given as $100 \mathrm{mg} / \mathrm{kg}$ to $200 \mathrm{mg} / \mathrm{kg}$. The certified value for sodium in SRM 1573a was determined at NIST using instrumental neutron activation analysis (INAA) and flame atomic emission spectrometry (FAES). The certified values and uncertainties for $\mathrm{Na}$ are provided in the table below, both on a dry-mass basis and on an as-received basis accounting for moisture of the material $(0.97 \%)$.

\begin{tabular}{cccc} 
& \multicolumn{2}{l}{$\begin{array}{l}\text { Certified Mass Fraction in SRM 1573a (mg/kg) } \\
\text { (dry-mass basis) }\end{array}$} \\
Sodium $(\mathrm{Na})$ & $136 \pm 4$ & $132 \pm 4$
\end{tabular}

Cranberries. Participants were provided with one packet containing approximately $6 \mathrm{~g}$ of freezedried, powdered cranberries. The cranberry powder was blended, aliquotted, and heat-sealed inside 4 mil polyethylene bags, which were then sealed inside nitrogen-flushed aluminized plastic bags along with two packets of silica gel. Before use, participants were instructed to thoroughly mix the contents of each packet and use a sample size of at least $0.5 \mathrm{~g}$. Participants were asked to store the material at controlled room temperature, $20^{\circ} \mathrm{C}$ to $25^{\circ} \mathrm{C}$, and to prepare three samples and report three values from the single packet provided. Prior to the study, the approximate analyte level was given as $200 \mathrm{mg} / \mathrm{kg}$ to $300 \mathrm{mg} / \mathrm{kg}$. The reference value for sodium in SRM 3281 Cranberry (Fruit) was determined at NIST using inductively coupled plasma optical emission spectroscopy (ICP-OES). The reference values and uncertainties for $\mathrm{Na}$ are provided in the table below, both on a dry-mass basis and on an as-received basis accounting for moisture of the material (2.39\%).

$\begin{aligned} & \text { Reference Mass Fraction in SRM } 3281 \text { (mg/kg) } \\ & \text { (dry-mass basis) } \\ & 259 \pm 3\end{aligned}$
$\frac{\text { (as-received basis) }}{253 \pm 3}$

$\underline{\text { Study Results }}$

- Thirty-seven laboratories enrolled in this study and received samples. Twenty-four laboratories reported results for both the samples (65 \% participation). 
- For both samples, the consensus ranges were wide but encompassed the NIST target ranges.

- The consensus mean for sodium in tomato leaves was on the upper edge of the target range.

- The consensus mean for sodium in the cranberries was above the target range.

- The between-laboratory variability for was high in both materials (29\% and $28 \%$ RSD for the tomato leaves and cranberries, respectively).

- A majority of the laboratories reported using either open-beaker digestion (48\%) or microwave digestion (32\% to $36 \%$ ) for sample preparation. The remaining laboratories reported using hot block digestion, dry ashing, or dilution. One laboratory did not report the type of sample preparation technique that was used.

- A majority of the laboratories reported using either ICP-OES (56 \%) or ICP-MS (28 \%) as their analytical method. Two laboratories reported using atomic absorption spectroscopy, and one laboratory reported using ion chromatography with conductivity detection. One laboratory did not report the type of analytical technique that was used.

- A majority of the laboratories reported using an external standard approach to calibration (88 \%). One laboratory reported using a standard addition approach, and one laboratory reported using an internal standard approach. One laboratory did not report the type of calibration approach that was used.

Technical Recommendations

The following recommendations are based on results obtained from the participants in this study.

- A significant difference was apparent between results obtained using open beaker and those using microwave digestion. Too few results were reported by other methods to identify any additional trends.

- As shown in Figure 1 and Figure 2, laboratories that reported high sodium values also reported using open beaker digestion. This trend may indicate contamination of samples with sodium from the environment during digestion.

- To minimize contamination, work areas should be cleaned prior to sample preparation, glassware should be cleaned by acid wash prior to use, and exposure of samples to the laboratory environment should be limited.

- If a soap solution is used for cleaning, sodium levels in blank solutions must be checked, as some soaps will give high sodium blank levels.

- Extra procedural reagent blanks should be prepared along with samples to know the extent of sodium contamination from the analysis.

- No difference was apparent in the sodium results based on analytical method used (ICPOES or ICP-MS). Too few results were reported by other methods to identify any additional trends.

- Additional sources for potential error in the final results may be errors in calibration and dilution.

- Samples with very low sodium levels may be inadvertently diluted below the calibration range and possibly out of the quantification or detection range of the instrument. Care should be taken to evaluate a more concentrated sample if the signal appears to be lower than expected or is below the lowest calibration point. 
- Many of the calibration curves reported by participants extended far above the reported working range of sodium in the solutions to be analyzed. While the calibration curve may appear linear over a wide concentration range, a measured value near an end of the calibration curve may have significant bias. For the most accurate results, use calibration points closely surrounding the expected solution concentration, and ensure that the calibration curve is linear along the region of your expected solution concentrations.

- The sample/sample comparison graph does not reflect an obvious calibration error. Some laboratories reported values that were high for one sample but were within range for the second sample. This type of trend may indicate individualized problems with the digestion of one matrix compared to another.

- Quality assurance samples should always be used. These can be commercially available reference materials (CRMs, SRMs, or RMs) or prepared in-house, but need to be of known concentration.

- They are used to ensure that the method is performing as expected.

- They are useful in finding where errors are occurring, including calculation errors.

- After checking for calculation errors, make sure results are reported correctly. 
Table 1. Individual data table (NIST) for sodium in foods and dietary supplements.

\section{National Institute of Standards \& Technology}

\begin{tabular}{|c|c|c|c|c|c|c|c|c|c|c|c|}
\hline \multicolumn{12}{|c|}{ Exercise G - July 2011 - Nutritional Elements } \\
\hline & \multirow{2}{*}{$\begin{array}{l}\text { Lab Code: } \\
\text { Sample }\end{array}$} & \multirow{2}{*}{$\frac{\text { NIST }}{\text { Units }}$} & \multicolumn{4}{|c|}{ 1. Your Results } & \multicolumn{3}{|c|}{ 2. Community Results } & \multicolumn{2}{|c|}{ 3. Target Value } \\
\hline & & & Mean & $S_{\text {total }}$ & $\mathrm{Z}_{\text {comm }}$ & $\mathrm{Z}_{\mathrm{NIST}}$ & $\mathrm{N}$ & Mean & Std Dev & Value & $U_{95}$ \\
\hline $\mathrm{Na}$ & Tomato Leaves & $\mathrm{mg} / \mathrm{kg}$ & 132 & 3.9 & -0.1 & 0.1 & 24 & 134 & 40 & 132 & 3.9 \\
\hline $\mathrm{Na}$ & Cranberry (Fruit) & $\mathrm{mg} / \mathrm{kg}$ & 253 & 2.9 & -0.2 & 0.1 & 24 & 265 & 73 & 253 & 2.9 \\
\hline
\end{tabular}

Mean Average of reported values

$s_{\text {total }}$ Standard deviation of reported values

$\mathrm{Z}_{\text {comm }}$ Z-score: (Lab Mean - Consensus Mean)/

Consensus Standard Deviation

$\mathrm{Z}_{\text {NIST }}$ Z-score: (Lab Mean - NIST Value or Label Claim)/

NIST or Label Claim Standard Deviation

NR No data reported
$\mathrm{N}$ Number of quantitative values reported

Mean Robust mean of the reported values

Std Dev Robust standard deviation

Value NIST-assessed value

$U_{95} \pm 95 \%$ confidence interval about the assessed value 
Table 2. Data summary table for sodium in foods and dietary supplements.

\begin{tabular}{|c|c|c|c|c|c|c|c|c|c|c|c|}
\hline & \multirow[b]{3}{*}{ Lab } & \multicolumn{10}{|c|}{ Sodium } \\
\hline & & \multicolumn{10}{|c|}{ SRM 3281 Cranberry (Fruit) (mg/kg) } \\
\hline & & A & $\mathbf{B}$ & C & Avg & SD & A & B & $\mathrm{C}$ & Avg & SD \\
\hline \multirow{38}{*}{ 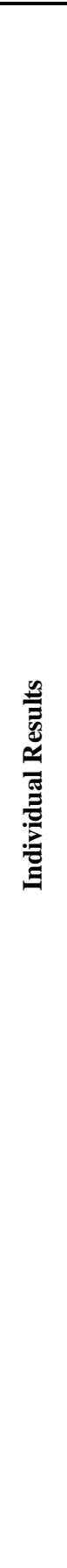 } & NIST & & & & 132 & 4 & & & & 253 & 3 \\
\hline & G701 & 80 & 79 & 77 & 79 & 1 & 210 & 215 & 215 & 213 & 3 \\
\hline & G703 & 113 & 106 & 111 & 110 & 4 & 139 & 146 & 136 & 140 & 5 \\
\hline & G704 & & & & & & & & & & \\
\hline & G709 & & & & & & & & & & \\
\hline & G710 & 112 & 113 & 116 & 114 & 2 & 233 & 234 & 240 & 236 & 4 \\
\hline & G711 & 103 & 106 & 103 & 104 & 1 & 214 & 214 & 148 & 192 & 38 \\
\hline & G714 & 151 & 140 & 133 & 142 & 9 & 231 & 223 & 243 & 232 & 10 \\
\hline & G720 & & & & & & & & & & \\
\hline & G721 & 707 & 391 & 452 & 517 & 167 & 911 & 902 & 889 & 901 & 11 \\
\hline & G723 & 119 & 116 & 118 & 117 & 2 & 232 & 230 & 224 & 229 & 4 \\
\hline & G724 & 130 & 131 & 142 & 134 & 7 & 260 & 252 & 248 & 253 & 6 \\
\hline & G728 & & & & & & & & & & \\
\hline & G729 & & & & & & & & & & \\
\hline & G734 & 219 & 220 & 218 & 219 & 1 & 572 & 573 & 554 & 566 & 11 \\
\hline & G735 & 157 & 162 & 166 & 162 & 5 & 418 & 410 & 432 & 420 & 11 \\
\hline & G736 & 194 & 181 & 187 & 187 & 6 & 403 & 436 & 416 & 418 & 17 \\
\hline & G737 & 163 & 163 & 169 & 165 & 3 & 502 & 491 & 485 & 493 & 9 \\
\hline & G738 & 138 & 138 & 139 & 138 & 1 & & & & & \\
\hline & G739 & & & & & & & & & & \\
\hline & G741 & 107 & 109 & 108 & 108 & 1 & 240 & 238 & 239 & 239 & 1 \\
\hline & G742 & & & & & & & & & & \\
\hline & G743 & 180 & 175 & 200 & 185 & 13 & 299 & 286 & 296 & 294 & 7 \\
\hline & G747 & 305 & 245 & 271 & 274 & 30 & 228 & 229 & 225 & 227 & 2 \\
\hline & G749 & 116 & 130 & & 123 & 9 & 294 & 314 & & 304 & 14 \\
\hline & G752 & 122 & 122 & 117 & 120 & 3 & 287 & 257 & 263 & 269 & 16 \\
\hline & G754 & & & & & & & & & & \\
\hline & G755 & & & & & & & & & & \\
\hline & G756 & & & & & & 260 & 233 & 246 & 246 & 14 \\
\hline & G757 & 111 & 113 & 110 & 111 & 2 & 223 & 232 & 230 & 228 & 5 \\
\hline & G758 & & & & & & & & & & \\
\hline & G759 & 122 & 122 & 118 & 121 & 2 & 263 & 262 & 265 & 263 & 1 \\
\hline & G761 & & & & & & & & & & \\
\hline & G762 & 113 & 113 & 112 & 113 & 1 & 237 & 237 & 238 & 237 & 1 \\
\hline & G763 & 105 & 100 & 102 & 102 & 2 & 230 & 232 & 230 & 231 & 1 \\
\hline & G764 & & & & & & & & & & \\
\hline & G770 & 128 & 123 & 120 & 124 & 4 & 183 & 184 & 181 & 183 & 1 \\
\hline & G778 & & & & & & & & & & \\
\hline 离 & & \multicolumn{3}{|c|}{$\begin{array}{l}\text { Consensus Mean } \\
\text { Consensus Standard Deviation } \\
\text { Maximum } \\
\text { Minimum } \\
\mathrm{N}\end{array}$} & $\begin{array}{c}136 \\
39 \\
517 \\
79 \\
23\end{array}$ & & \multicolumn{3}{|c|}{$\begin{array}{l}\text { Consensus Mean } \\
\text { Consensus Standard Deviation } \\
\text { Maximum } \\
\text { Minimum } \\
\mathrm{N}\end{array}$} & $\begin{array}{c}268 \\
83 \\
901 \\
140 \\
23\end{array}$ & \\
\hline
\end{tabular}




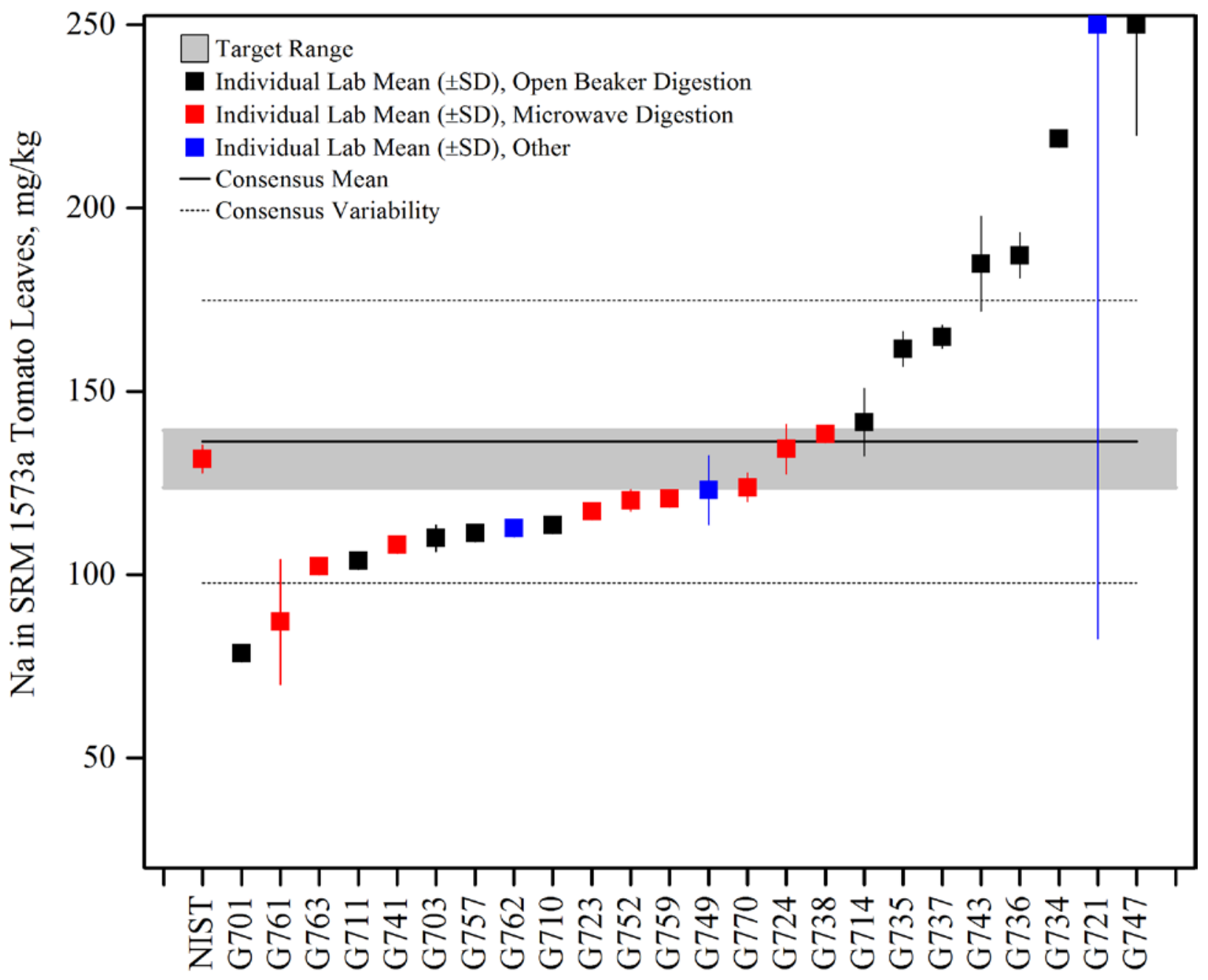

Figure 1. Sodium in SRM 1573a Tomato Leaves (data summary view - digestion method). In this view, individual laboratory data are plotted with the individual laboratory standard deviation (error bars). The color of the data point represents the sample preparation (digestion) procedure employed. The black solid line represents the consensus mean, and the black dotted lines represent the consensus variability calculated as one standard deviation about the consensus mean. The gray shaded region represents the target zone for "acceptable" performance, which encompasses the NIST reference value bounded by twice its uncertainty $\left(U_{95}\right)$. 


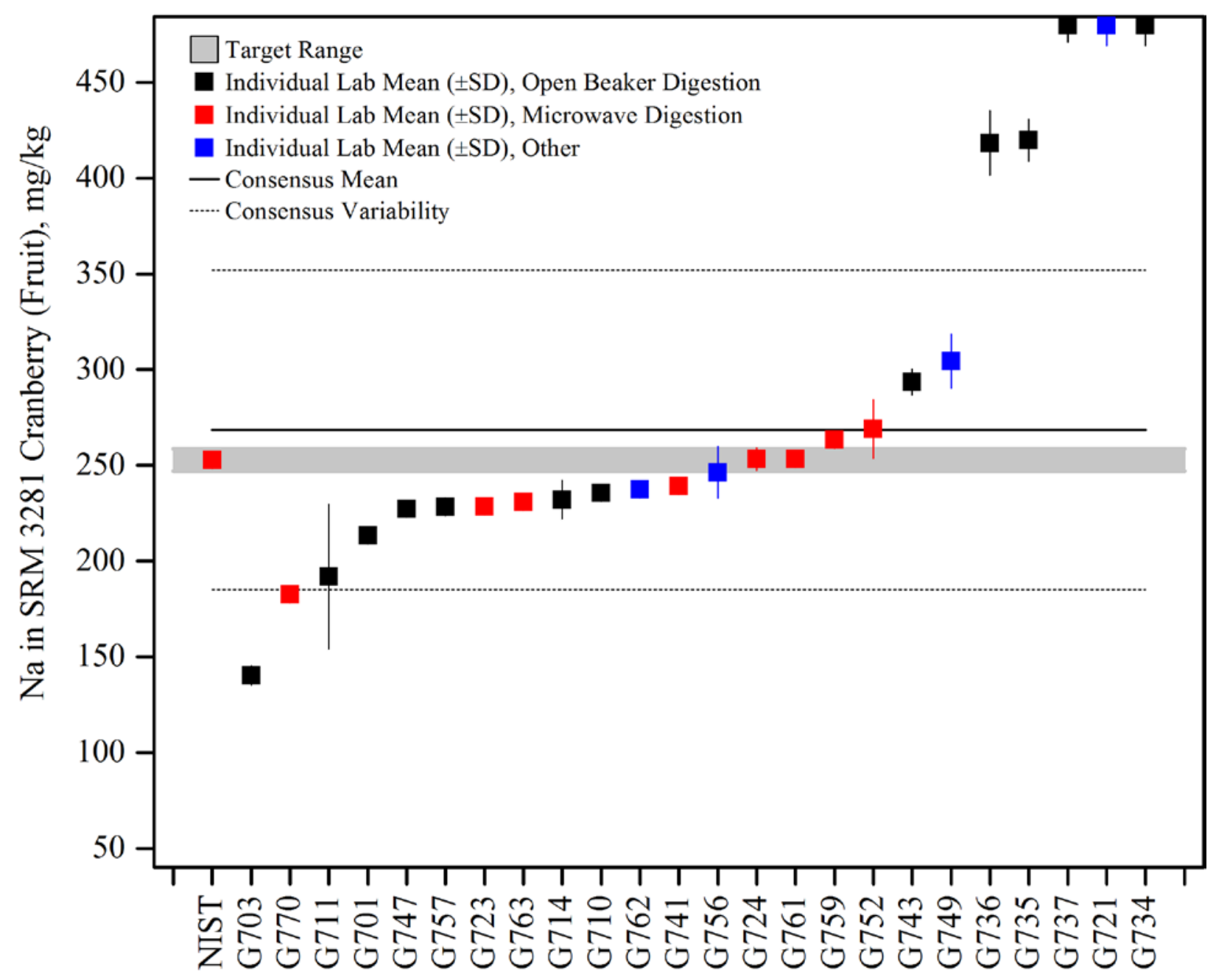

Figure 2. Sodium in SRM 3281 Cranberry (Fruit) (data summary view - digestion method). In this view, individual laboratory data are plotted with the individual laboratory standard deviation (error bars). The data are identified by digestion method in this graph. The black solid line represents the consensus mean, and the black dotted lines represent the consensus variability calculated as one standard deviation about the consensus mean. The gray shaded region represents the target zone for "acceptable" performance, which encompasses the NIST certified value bounded by twice its uncertainty $\left(U_{95}\right)$. 


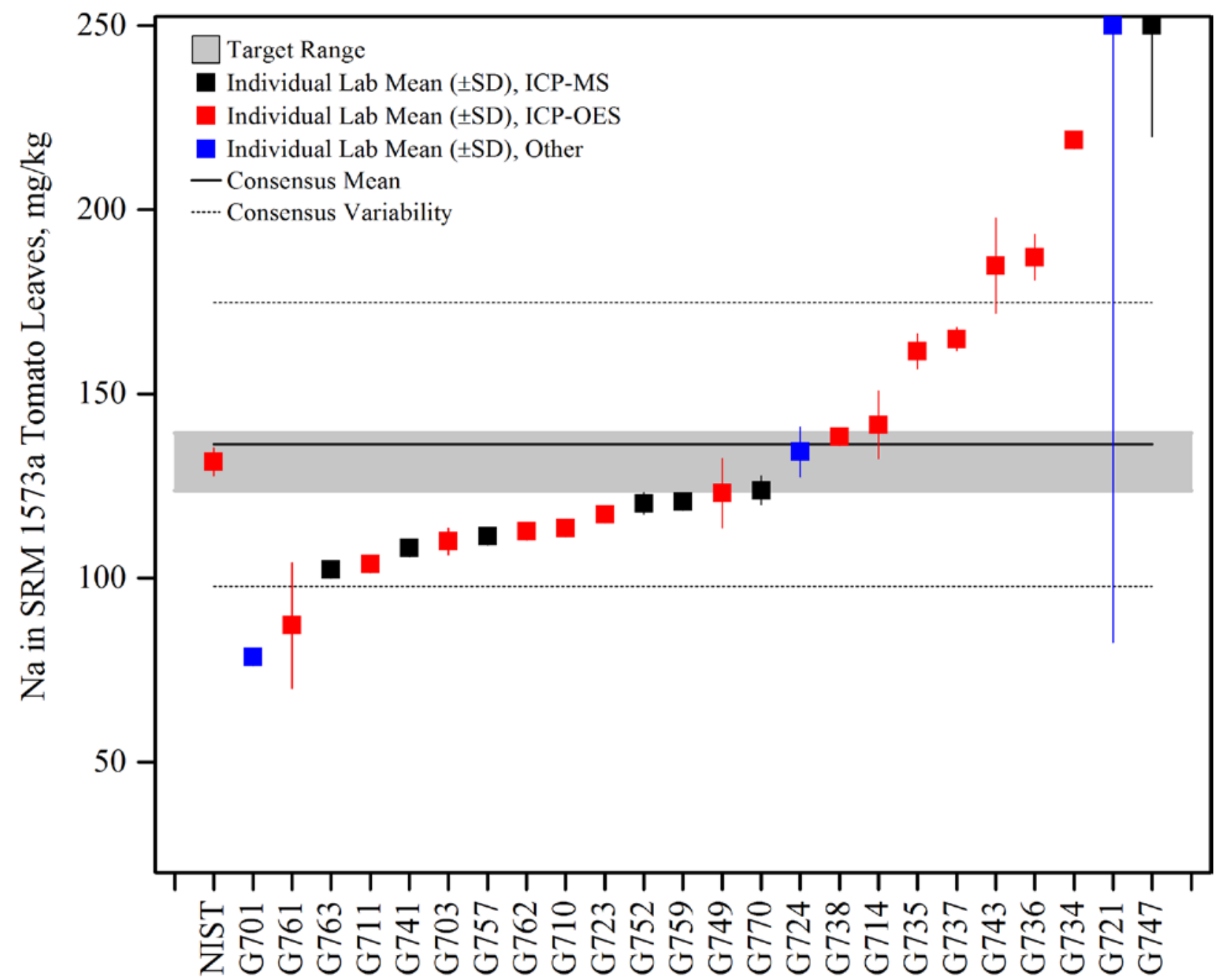

Figure 3. Sodium in SRM 1573a Tomato Leaves (data summary view - instrumental methods). In this view, individual laboratory data are plotted with the individual laboratory standard deviation (error bars). The data are identified by instrumental method in this graph. The black solid line represents the consensus mean, and the black dotted lines represent the consensus variability calculated as one standard deviation about the consensus mean. The gray shaded region represents the target zone for "acceptable" performance, which encompasses the NIST certified value bounded twice by its uncertainty $\left(U_{95}\right)$. 


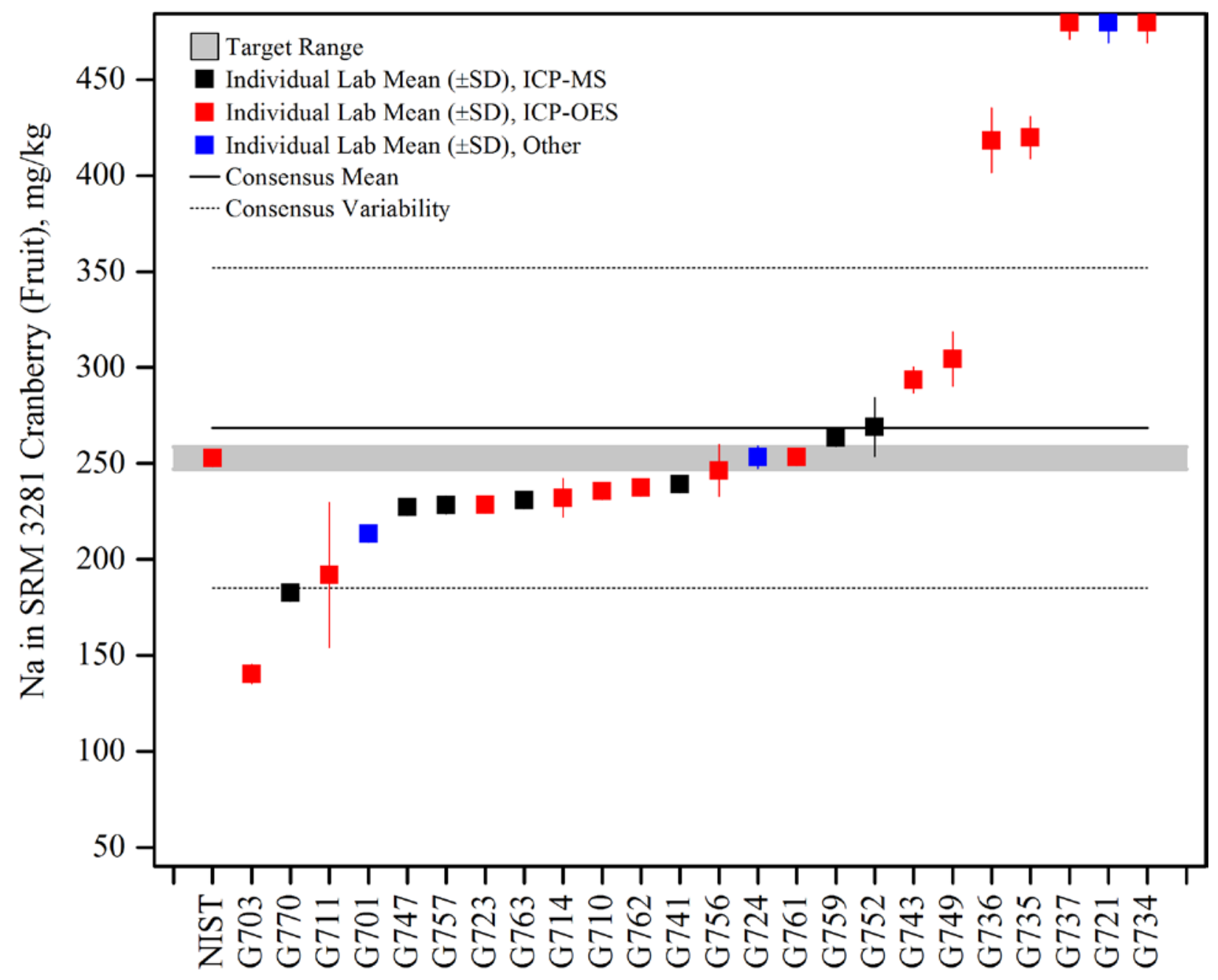

Figure 4. Sodium in SRM 3281 Cranberry (Fruit) (data summary view - instrumental methods). In this view, individual laboratory data are plotted with the individual laboratory standard deviation (error bars). The data are identified by instrumental method in this graph. The black solid line represents the consensus mean, and the black dotted lines represent the consensus variability calculated as one standard deviation about the consensus mean. The gray shaded region represents the target zone for "acceptable" performance, which encompasses the NIST certified value bounded by twice its uncertainty $\left(U_{95}\right)$. 


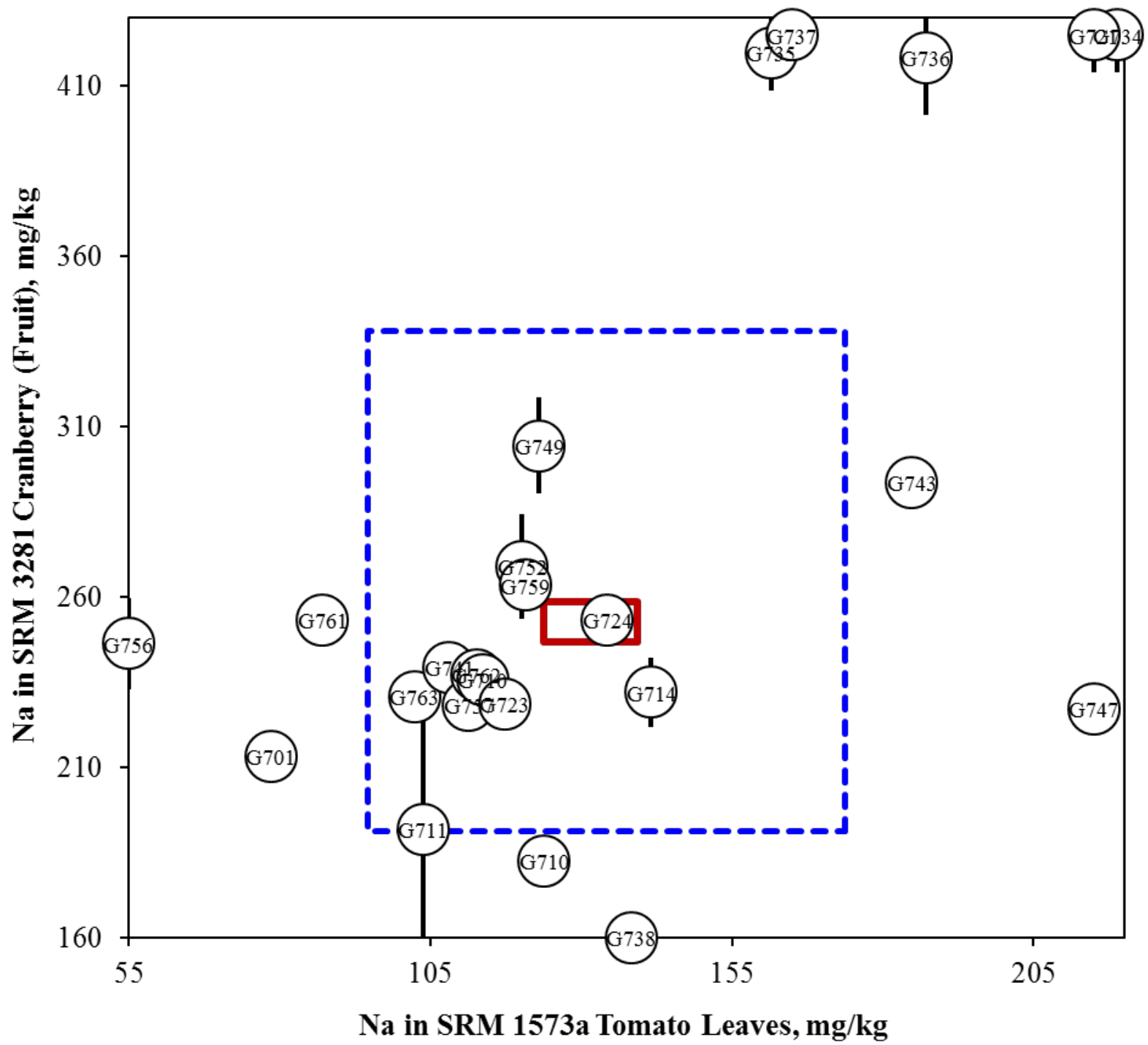

Figure 5. Sodium in SRM 1573a Tomato Leaves and SRM 3281 Cranberry (Fruit) (sample/sample comparison view). In this view, the individual laboratory results for one sample (tomato leaves) are compared to the results for a second sample (cranberry). The solid red box represents the target zone for the two samples, tomato leaves (x-axis) and cranberry (y-axis). The dotted blue box represents the consensus zone for tomato leaves (x-axis) and cranberry (y-axis). 


\section{TOXIC ELEMENTS (Pb) IN DIETARY SUPPLEMENTS}

\section{Study Overview}

In this study, participants were provided with two NIST SRMs, SRM 3243 Ephedra-Containing Solid Oral Dosage Form and SRM 3280 Multivitamin/Multielement Tablets. Participants were asked to use in-house analytical methods to determine the mass fractions of lead $(\mathrm{Pb})$ in each of the matrices and report values on an as-received basis.

Sample Information

Ephedra-Containing Tablets. Participants were provided with three bottles containing approximately $2.5 \mathrm{~g}$ of dried, powdered ephedra-containing tablets. The ephedra tablets were ground, homogenized, and packaged in amber high-density polyethylene bottles. Before use, participants were asked to thoroughly mix the contents of the bottles and use a sample size of at least 1.0 g. Participants were asked to store the material at controlled room temperature, $20{ }^{\circ} \mathrm{C}$ to $25{ }^{\circ} \mathrm{C}$, and to prepare one sample and report one value from each bottle provided. Prior to the study, the approximate analyte level was given as $600 \mathrm{ng} / \mathrm{g}$ to $800 \mathrm{ng} / \mathrm{g}$. The certified value for lead in SRM 3243 was determined at NIST using isotope dilution inductively coupled plasma mass spectrometry (ID-ICP-MS), in combination with data from two collaborating laboratories. The certified value and uncertainty for $\mathrm{Pb}$ are provided in the table below, both on a dry-mass basis and on an as-received basis accounting for moisture of the material (4.63\%).

$\begin{array}{ccc}\text { Analyte } & \begin{array}{c}\text { Certified Mass Fraction in SRM } 3243 \text { (ng/g) } \\ \text { (dry-mass basis) }\end{array} & \begin{array}{c}\text { (as-received basis) } \\ \text { Lead }(\mathrm{Pb})\end{array} \\ 692 \pm 56 & 660 \pm 53\end{array}$

Multivitamin/Multielement Tablets. Participants were provided with three vials containing approximately 2.5 g of ground multivitamin/multielement tablets. The multivitamin/multielement tablets were ground, sieved, and packaged in amber glass vials. Before use, participants were asked to thoroughly mix the contents of the vial and to use a sample size of at least $0.25 \mathrm{~g}$. Participants were asked to store the material at controlled room temperature, $20^{\circ} \mathrm{C}$ to $25^{\circ} \mathrm{C}$, and to prepare one sample and report one value from each of the vials provided. Prior to the study, the approximate analyte level was given as $200 \mathrm{ng} / \mathrm{g}$ to $300 \mathrm{ng} / \mathrm{g}$. The certified value for lead in SRM 3280 was determined at NIST using isotope dilution inductively coupled plasma mass spectrometry (ID-ICP-MS). The certified values and uncertainties are reported in the table below, both on a dry-mass basis and on an as-received basis accounting for moisture of the material (1.37\%).

\begin{tabular}{|c|c|c|}
\hline & Certified Mass & SRM 3280 (ng/g) \\
\hline Analyte & (dry-mass basis) & (as-received basis) \\
\hline Lead (Pb) & 273 & 269 \\
\hline
\end{tabular}




\section{Study Results}

- Forty-eight laboratories enrolled in this exercise and received samples. Thirty-six laboratories reported results for lead in Ephedra tablets (75 \% participation). Thirty-seven laboratories reported results for lead in multivitamin tablets (77 \% participation).

- The consensus means for lead in both matrices were within the target ranges. The betweenlaboratory variability for lead in the Ephedra tablets was acceptable (13\% RSD), but variability for lead in the multivitamin tablets was high (23\% RSD).

- A majority of the laboratories reported using microwave digestion (58 \%) or open beaker digestion (36 \%) for sample preparation. Hot block digestion was also reported as a method of sample preparation by two laboratories (6 \%). One laboratory did not report the sample preparation technique used.

- Most laboratories reported using ICP-MS as their analytical method for analysis (78 \%). Laboratories also reported using ICP-OES (17 \%) and AAS (6 \%). One laboratory did not report the analytical method used.

- A majority of the laboratories reported using an external standard approach to calibration (89 \%). One laboratory reported using a standard addition approach (6 \%), and one laboratory reported using an internal standard approach (6 \%). One laboratory did not report the type of calibration approach that was used.

\section{Technical Recommendations}

The following recommendations are based on results obtained from the participants in this study.

- Lead is generally easily digested, and digestion with $\mathrm{HNO}_{3}$ is recommended. Digestion with $\mathrm{HCl}$ may form a $\mathrm{PbCl}_{2}$ precipitate that is difficult to dissolve. While the sample solution may look clear, results may be biased low if solid $\mathrm{PbCl}_{2}$ remains. The $\mathrm{Cl}$ can be removed by repeatedly drying the sample solution using $\mathrm{HNO}_{3}$.

- Some laboratories reported high values for one sample, but not both, which may indicate more difficulty in digestion of one matrix over the other. Because each matrix is different, some may digest more readily, and the digestion quality must be evaluated for each sample prior to analysis. A quality assurance sample of a similar matrix prepared alongside unknown samples will help to determine if the digestion method is appropriate for the determination of lead in these matrices.

- ICP-OES has low sensitivity for lead, making it difficult to measure low-level samples. The concentration of lead in solutions prepared from the multivitamin samples may be near the method detection limit of many ICP-OES systems, leading to inaccurate results. Sufficient procedural reagent blanks should be prepared along with samples to determine the method detection limit for lead.

- Many of the calibration curves reported by participants extended far below the reported working range of lead in the solutions to be analyzed. While the calibration curve may appear linear over a wide concentration range, a measured value outside of the calibration curve may have significant bias. For the most accurate results, use calibration points closely surrounding the expected solution concentration, and ensure that the calibration curve is linear along the region of your expected solution concentrations.

- The sample/sample comparison graph does not reflect an obvious calibration error. Some laboratories reported values that were high for one sample but were within range for the second sample. This type of trend may indicate individualized problems with the digestion of one matrix compared to another. 
- Quality assurance samples should always be used. These can be commercially available reference materials (CRMs, SRMs, or RMs) or prepared in-house, but need to be of known concentration.

- $\quad$ They are used to ensure that the method is performing as expected.

- They are useful in finding where errors are occurring, including calculation errors.

- After checking for calculation errors, make sure results are reported correctly. 
Table 3. Individual data table (NIST) for lead in dietary supplements.

\section{National Institute of Standards \& Technology}

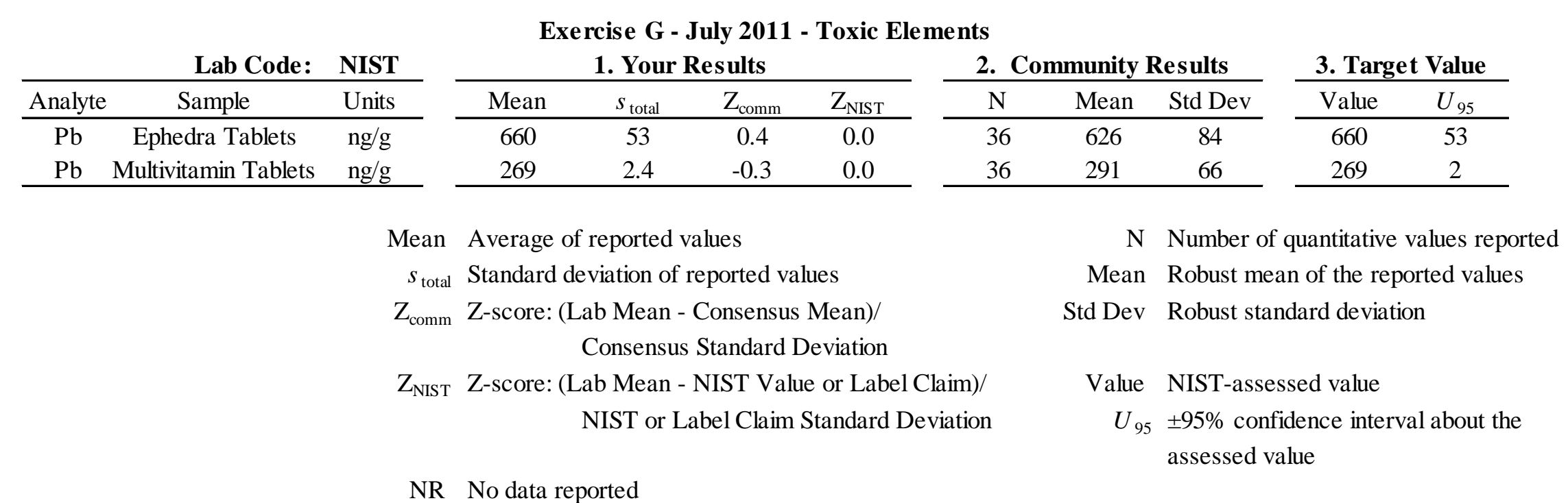


[Type here]

Table 4. Data summary table for lead in dietary supplements.

\begin{tabular}{|c|c|c|c|c|c|c|c|c|c|c|c|}
\hline & \multirow[b]{3}{*}{ Lab } & \multicolumn{10}{|c|}{ Lead } \\
\hline & & \multicolumn{5}{|c|}{ SRM 3243 EphedraTablets (ng/g) } & \multicolumn{5}{|c|}{ SRM 3280 Multivitamin Tablets (ng/g) } \\
\hline & & A & B & C & Avg & SD & A & B & C & Avg & SD \\
\hline \multirow{49}{*}{ 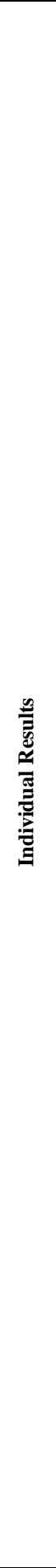 } & NIST & & & & 660 & 53 & & & & 269 & 2 \\
\hline & G703 & 661 & 678 & 621 & 653 & 29 & 279 & 288 & 275 & 281 & 7 \\
\hline & G706 & 690 & 717 & 728 & 712 & 20 & 228 & 232 & 240 & 233 & 6 \\
\hline & G709 & 636 & 641 & 627 & 634 & 7 & 265 & 253 & 273 & 264 & 10 \\
\hline & G710 & 665 & 644 & 584 & 631 & 42 & 282 & 277 & 277 & 279 & 3 \\
\hline & G711 & & & & & & & & & & \\
\hline & G713 & 620 & 649 & 624 & 631 & 16 & 271 & 283 & 280 & 278 & 6 \\
\hline & G714 & & & & & & 219 & 235 & 341 & 265 & 66 \\
\hline & G718 & 587 & 601 & 549 & 579 & 27 & 319 & 297 & 269 & 295 & 25 \\
\hline & G719 & 500 & 559 & 549 & 536 & 32 & 210 & 225 & 214 & 216 & 8 \\
\hline & G720 & & & & & & & & & & \\
\hline & G723 & 704 & 687 & 664 & 685 & 20 & 226 & 229 & 226 & 227 & 2 \\
\hline & G724 & 711 & 681 & 674 & 689 & 20 & 258 & 257 & 252 & 256 & 3 \\
\hline & G725 & 682 & 615 & 614 & 637 & 39 & 279 & 288 & 287 & 285 & 5 \\
\hline & G726 & 711 & 672 & 693 & 692 & 20 & 324 & 328 & 292 & 315 & 20 \\
\hline & G728 & & & & & & & & & & \\
\hline & G729 & & & & & & & & & & \\
\hline & G734 & 472 & 466 & 505 & 481 & 21 & 616 & 627 & 658 & 634 & 22 \\
\hline & G735 & 538 & 569 & 522 & 543 & 24 & 618 & 554 & 554 & 576 & 37 \\
\hline & G736 & 659 & 489 & 553 & 567 & 86 & 769 & 818 & 811 & 799 & 27 \\
\hline & G737 & 960 & 678 & 946 & 861 & 159 & 657 & 628 & 638 & 641 & 15 \\
\hline & G738 & 670 & 610 & 680 & 653 & 38 & 290 & 280 & 290 & 287 & 6 \\
\hline & G739 & & & & & & & & & & \\
\hline & G742 & & & & & & & & & & \\
\hline & G743 & 531 & 546 & 524 & 534 & 11 & 233 & 230 & 225 & 230 & 4 \\
\hline & G745 & 667 & 560 & 576 & 601 & 58 & 275 & 285 & 272 & 277 & 7 \\
\hline & G746 & 614 & 614 & 614 & 614 & 0 & 326 & 370 & 360 & 352 & 23 \\
\hline & G747 & 606 & 596 & 573 & 592 & 17 & 242 & 245 & 222 & 236 & 13 \\
\hline & G748 & 699 & 644 & 736 & 693 & 46 & 299 & 200 & 333 & 277 & 69 \\
\hline & G749 & 1610 & & 3400 & 2505 & 1266 & 530 & & & 530 & \\
\hline & G750 & 757 & 658 & 634 & 683 & 65 & 211 & 208 & 213 & 211 & 3 \\
\hline & G751 & 614 & 689 & 589 & 631 & 52 & 267 & 270 & 267 & 268 & 2 \\
\hline & G752 & 1042 & 718 & 849 & 870 & 163 & 649 & 706 & 824 & 727 & 89 \\
\hline & G754 & 532 & 562 & 543 & 546 & 15 & 328 & 305 & 324 & 319 & 12 \\
\hline & G755 & & & & & & & & & & \\
\hline & G756 & 574 & 534 & 521 & 543 & 28 & 233 & 239 & 243 & 238 & 5 \\
\hline & G757 & 647 & 601 & 614 & 621 & 24 & 249 & 257 & 249 & 252 & 5 \\
\hline & G758 & & & & & & & & & & \\
\hline & G759 & 637 & 646 & 642 & 642 & 4 & 281 & 280 & 280 & 280 & 0 \\
\hline & G762 & 640 & 630 & 650 & 640 & 10 & 280 & 280 & 290 & 283 & 6 \\
\hline & G763 & 606 & 627 & 645 & 626 & 19 & 365 & 327 & 299 & 330 & 33 \\
\hline & G764 & & & & & & & & & & \\
\hline & G766 & 549 & 538 & 567 & 551 & 15 & 239 & 246 & 238 & 241 & 4 \\
\hline & G769 & 163 & 153 & 504 & 273 & 200 & 467 & 456 & 389 & 437 & 42 \\
\hline & G770 & 667 & 689 & 689 & 682 & 13 & 298 & 302 & 300 & 300 & 2 \\
\hline & G771 & 421 & 507 & 391 & 440 & 60 & 94 & 91 & 83 & 89 & 5 \\
\hline & G773 & 929 & 778 & 774 & 827 & 88 & 392 & 357 & 443 & 397 & 43 \\
\hline & G774 & & & & & & & & & & \\
\hline & G778 & & & & & & & & & & \\
\hline \multirow{5}{*}{ 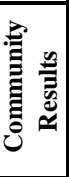 } & & \multirow{5}{*}{\multicolumn{3}{|c|}{$\begin{array}{l}\text { Consensus Mean } \\
\text { Consensus Standard Deviation } \\
\text { Maximum } \\
\text { Minimum } \\
\mathrm{N} \\
\end{array}$}} & 626 & & \multirow{5}{*}{\multicolumn{3}{|c|}{$\begin{array}{l}\text { Consensus Mean } \\
\text { Consensus Standard Deviation } \\
\text { Maximum } \\
\text { Minimum } \\
\mathrm{N}\end{array}$}} & 291 & \\
\hline & & & & & 84 & & & & & & \\
\hline & & & & & 2505 & & & & & 799 & \\
\hline & & & & & 273 & & & & & 89 & \\
\hline & & & & & 36 & & & & & 36 & \\
\hline
\end{tabular}


[Type here]

\begin{tabular}{|c|c|c|c|c|c|c|c|c|c|c|c|}
\hline & \multirow[b]{3}{*}{ Lab } & \multicolumn{10}{|c|}{ Lead } \\
\hline & & \multicolumn{5}{|c|}{ SRM 3243 EphedraTablets (ng/g) } & \multicolumn{5}{|c|}{ SRM 3280 Multivitamin Tablets (ng/g) } \\
\hline & & A & B & C & Avg & SD & A & B & C & Avg & SD \\
\hline \multirow{49}{*}{ 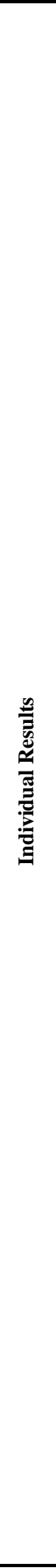 } & NIST & & & & 660 & 53 & & & & 269 & 2 \\
\hline & G703 & 661 & 678 & 621 & 653 & 29 & 279 & 288 & 275 & 281 & 7 \\
\hline & G706 & 690 & 717 & 728 & 712 & 20 & 228 & 232 & 240 & 233 & 6 \\
\hline & G709 & 636 & 641 & 627 & 634 & 7 & 265 & 253 & 273 & 264 & 10 \\
\hline & G710 & 665 & 644 & 584 & 631 & 42 & 282 & 277 & 277 & 279 & 3 \\
\hline & \multicolumn{11}{|l|}{ G711 } \\
\hline & G713 & 620 & 649 & 624 & 631 & 16 & 271 & 283 & 280 & 278 & 6 \\
\hline & G714 & & & & & & 219 & 235 & 341 & 265 & 66 \\
\hline & G718 & 587 & 601 & 549 & 579 & 27 & 319 & 297 & 269 & 295 & 25 \\
\hline & G719 & 500 & 559 & 549 & 536 & 32 & 210 & 225 & 214 & 216 & 8 \\
\hline & \multicolumn{11}{|l|}{ G720 } \\
\hline & G723 & 704 & 687 & 664 & 685 & 20 & 226 & 229 & 226 & 227 & 2 \\
\hline & G724 & 711 & 681 & 674 & 689 & 20 & 258 & 257 & 252 & 256 & 3 \\
\hline & G725 & 682 & 615 & 614 & 637 & 39 & 279 & 288 & 287 & 285 & 5 \\
\hline & G726 & 711 & 672 & 693 & 692 & 20 & 324 & 328 & 292 & 315 & 20 \\
\hline & \multicolumn{11}{|l|}{ G728 } \\
\hline & \multicolumn{11}{|l|}{ G729 } \\
\hline & G734 & 472 & 466 & 505 & 481 & 21 & 616 & 627 & 658 & 634 & 22 \\
\hline & G735 & 538 & 569 & 522 & 543 & 24 & 618 & 554 & 554 & 576 & 37 \\
\hline & G736 & 659 & 489 & 553 & 567 & 86 & 769 & 818 & 811 & 799 & 27 \\
\hline & G737 & 960 & 678 & 946 & 861 & 159 & 657 & 628 & 638 & 641 & 15 \\
\hline & G738 & 670 & 610 & 680 & 653 & 38 & 290 & 280 & 290 & 287 & 6 \\
\hline & G739 & & & & & & & & & & \\
\hline & G742 & & & & & & & & & & \\
\hline & G743 & 531 & 546 & 524 & 534 & 11 & 233 & 230 & 225 & 230 & 4 \\
\hline & G745 & 667 & 560 & 576 & 601 & 58 & 275 & 285 & 272 & 277 & 7 \\
\hline & G746 & 614 & 614 & 614 & 614 & 0 & 326 & 370 & 360 & 352 & 23 \\
\hline & G747 & 606 & 596 & 573 & 592 & 17 & 242 & 245 & 222 & 236 & 13 \\
\hline & G748 & 699 & 644 & 736 & 693 & 46 & 299 & 200 & 333 & 277 & 69 \\
\hline & G749 & 1610 & & 3400 & 2505 & 1266 & 530 & & & 530 & \\
\hline & G750 & 757 & 658 & 634 & 683 & 65 & 211 & 208 & 213 & 211 & 3 \\
\hline & G751 & 614 & 689 & 589 & 631 & 52 & 267 & 270 & 267 & 268 & 2 \\
\hline & G752 & 1042 & 718 & 849 & 870 & 163 & 649 & 706 & 824 & 727 & 89 \\
\hline & G754 & 532 & 562 & 543 & 546 & 15 & 328 & 305 & 324 & 319 & 12 \\
\hline & \multicolumn{11}{|l|}{ G755 } \\
\hline & G756 & 574 & 534 & 521 & 543 & 28 & 233 & 239 & 243 & 238 & 5 \\
\hline & G757 & 647 & 601 & 614 & 621 & 24 & 249 & 257 & 249 & 252 & 5 \\
\hline & \multicolumn{11}{|l|}{ G758 } \\
\hline & G759 & 637 & 646 & 642 & 642 & 4 & 281 & 280 & 280 & 280 & 0 \\
\hline & G762 & 640 & 630 & 650 & 640 & 10 & 280 & 280 & 290 & 283 & 6 \\
\hline & G763 & 606 & 627 & 645 & 626 & 19 & 365 & 327 & 299 & 330 & 33 \\
\hline & \multicolumn{11}{|l|}{ G764 } \\
\hline & G766 & 549 & 538 & 567 & 551 & 15 & 239 & 246 & 238 & 241 & 4 \\
\hline & G769 & 163 & 153 & 504 & 273 & 200 & 467 & 456 & 389 & 437 & 42 \\
\hline & G770 & 667 & 689 & 689 & 682 & 13 & 298 & 302 & 300 & 300 & 2 \\
\hline & G771 & 421 & 507 & 391 & 440 & 60 & 94 & 91 & 83 & 89 & 5 \\
\hline & G773 & 929 & 778 & 774 & 827 & 88 & 392 & 357 & 443 & 397 & 43 \\
\hline & G774 & & & & & & & & & & \\
\hline & \multirow{6}{*}{ G778 } & & & & & & & & & & \\
\hline \multirow{5}{*}{ حُّ } & & & & & 626 & & Consen & Mean & & 291 & \\
\hline & & Consen & Standar & Peviation & 84 & & Consen & Standa & eviation & & \\
\hline & & Maximu & & & 2505 & & Maxim! & & & 799 & \\
\hline & & Minimu & & & 273 & & Minimu & & & 89 & \\
\hline & & $\mathrm{N}$ & & & 36 & & $\mathrm{~N}$ & & & 36 & \\
\hline
\end{tabular}




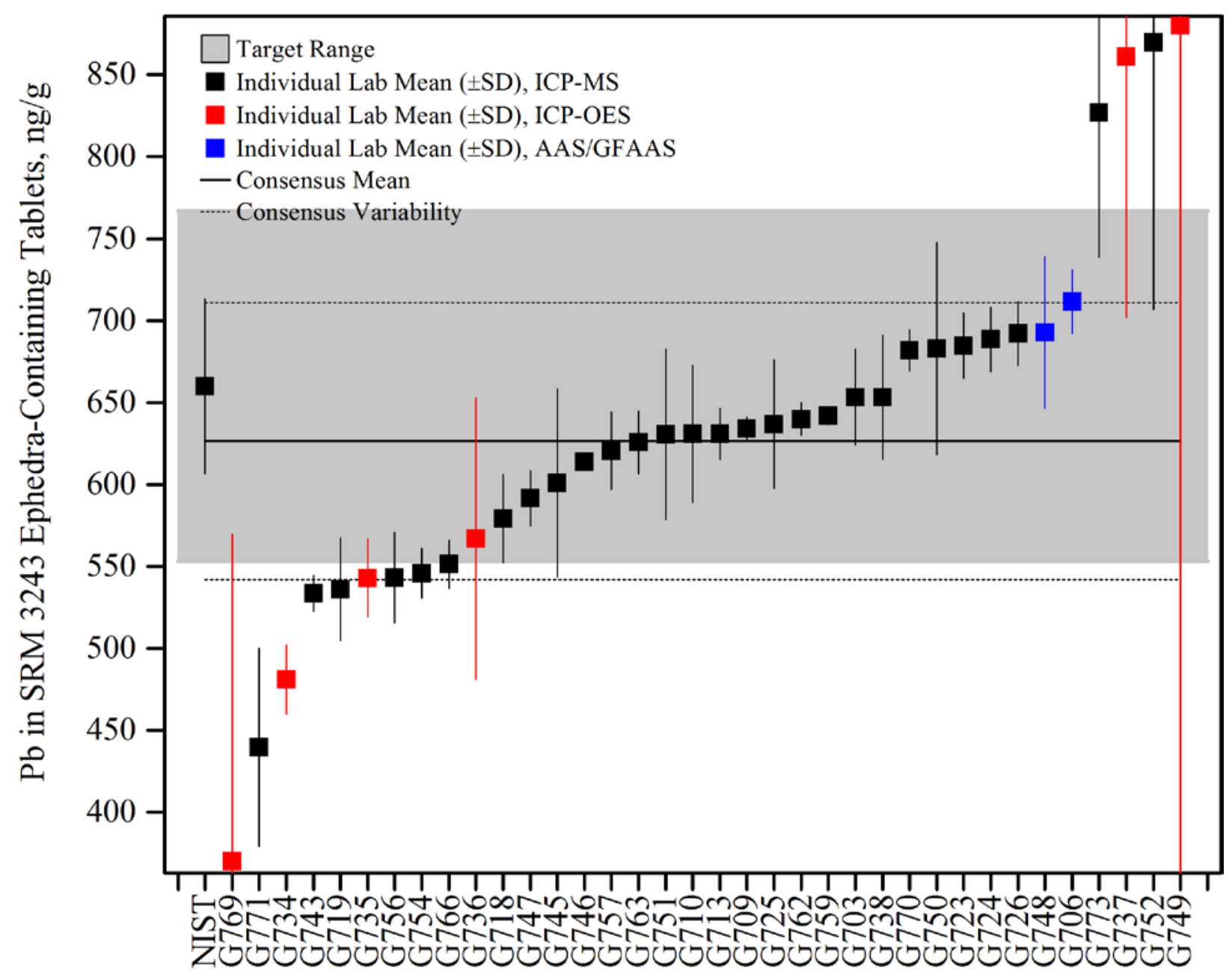

Figure 6. Lead in SRM 3243 Ephedra-Containing Tablets (data summary view - instrumental method). In this view, individual laboratory data are plotted with the individual laboratory standard deviation (error bars). The data are identified by instrumental method in this graph. The black solid line represents the consensus mean, and the black dotted lines represent the consensus variability calculated as one standard deviation about the consensus mean. The gray shaded region represents the target zone for "acceptable” performance, which encompasses the NIST certified value bounded by twice its uncertainty $\left(U_{95}\right)$. 


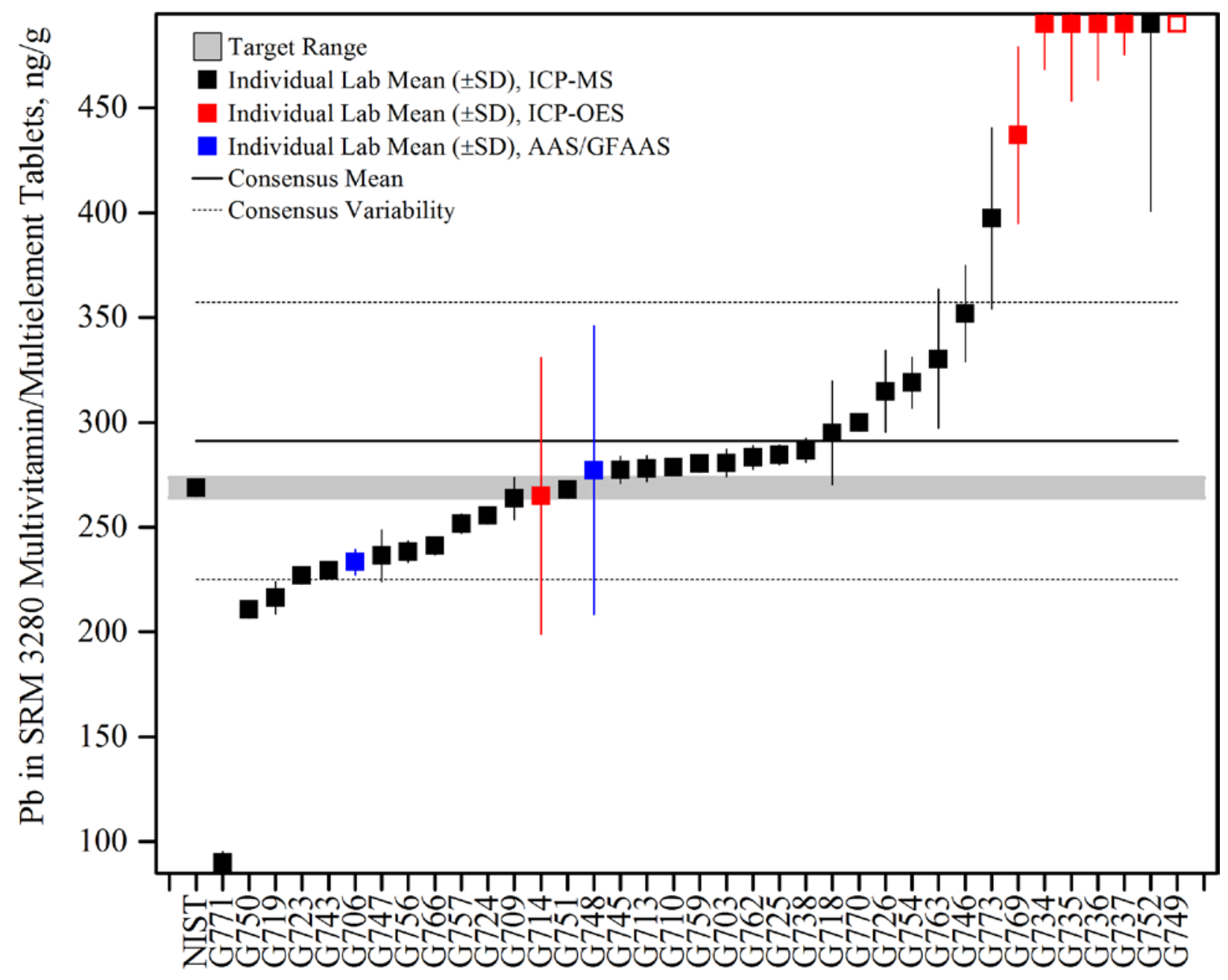

Figure 7. Lead in SRM 3280 Multivitamin/Multielement Tablets (data summary view instrumental method). In this view, individual laboratory data are plotted with the individual laboratory standard deviation (error bars). The data are identified by instrumental method in this graph. The black solid line represents the consensus mean, and the black dotted lines represent the consensus variability calculated as one standard deviation about the consensus mean. The gray shaded region represents the target zone for "acceptable" performance, which encompasses the NIST certified value bounded by twice its uncertainty $\left(U_{95}\right)$. 


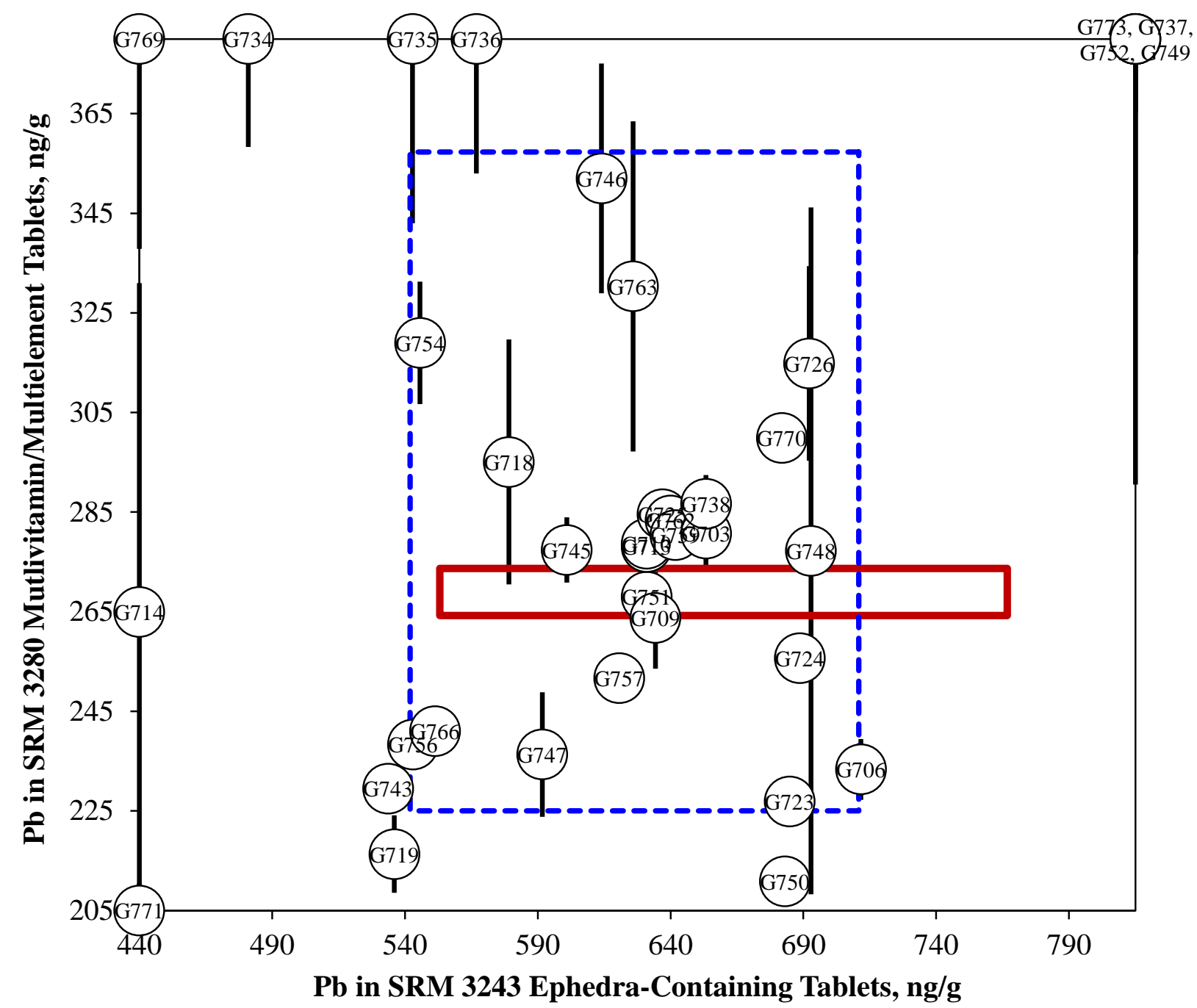

Figure 8. Lead in SRM 3243 Ephedra-Containing Tablets and SRM 3280 Multivitamin/Multielement Tablets (sample/control comparison view). In this view, the individual laboratory results for the one sample (SRM 3243 Ephedra-Containing Tablets) are compared to the results for a second sample (SRM 3280 Multivitamin/Multielement Tablets). The solid red box represents the target zone for the two samples, ephedra tablets (x-axis) and multivitamin (yaxis). The dotted blue box represents the consensus zone for the ephedra tablets (x-axis) and the multivitamin (y-axis). 


\section{FOLIC ACID IN FOOD MATRICES}

\section{$\underline{\text { Study Overview }}$}

In this study, participants were provided with one NIST SRM, SRM 3233 Fortified Breakfast Cereal, and a well-characterized fortified milk powder sample. Participants were asked to use inhouse analytical methods to determine the mass fraction of folic acid in each of the matrices and report values on an as-received basis.

Sample Information

Fortified Breakfast Cereal. Participants were provided with one bottle containing approximately $60 \mathrm{~g}$ of dried, powdered breakfast cereal. The cereal flakes were ground, homogenized, and packaged in amber glass bottles, and the bottles were capped, sealed with heat-shrink tape, and individually sealed in mylar bags. Before use, participants were instructed to thoroughly mix the contents of the bottle and use a sample size of at least $1.0 \mathrm{~g}$. Participants were asked to store the material at controlled room temperature, $20{ }^{\circ} \mathrm{C}$ to $25{ }^{\circ} \mathrm{C}$, and to prepare three samples and report three values from the single bottle provided. Prior to the study, the approximate analyte level was given as $15 \mathrm{mg} / \mathrm{kg}$. The certified value for folic acid in SRM 3233 was determined at NIST by ID-LC-MS/MS following solvent extraction, in combination with data from numerous collaborating laboratories. The certified values and uncertainties are reported in the table below, both on a dry-mass basis and on an as-received basis accounting for moisture of the material $(1.7 \%)$.

Certified Mass Fraction in SRM 3233 (mg/kg)

\begin{tabular}{|c|c|c|}
\hline Analyte & (dry-mass basis) & (as-received basis) \\
\hline Folic Acid & $15.1 \pm 1.2$ & $14.8 \pm 1.2$ \\
\hline
\end{tabular}

Milk Powder. Participants were provided with three packets containing approximately $10 \mathrm{~g}$ of freeze-dried, powdered milk. The fortified milk powder was homogenized and packaged in nitrogen-flushed foil pouches with a paper over-wrap. Before use, participants were instructed to thoroughly mix the contents of the packet and use a sample size of at least $1.0 \mathrm{~g}$. Participants were asked to store the material at $-20^{\circ} \mathrm{C}$, and to prepare one sample and report one value from each packet of milk powder provided. Prior to the study, the approximate analyte level was given as $2.4 \mathrm{mg} / \mathrm{kg}$. The target value for folic acid in the fortified milk powder was determined at NIST by ID-LC-MS/MS following solvent extraction and hydrolysis, in combination with data from two collaborating laboratories. The NIST-determined values and uncertainties are reported in the table below, both on a dry-mass basis and on an as-received basis accounting for moisture of the material (1.6\%).

$\begin{array}{ccc}\text { Analyte } & \begin{array}{c}\text { Mass Fraction in Milk Powder (mg/kg) } \\ \text { (dry-mass basis) }\end{array} & \text { (as-received basis) } \\ \text { Folic Acid } & 2.35 \pm 0.06 & 2.31 \pm 0.06\end{array}$

Study Results

- Twenty-three laboratories enrolled in this exercise and received samples. Eleven laboratories reported results for folic acid in both the breakfast cereal and the milk powder 
(48 \% participation). One laboratory reported a single value for folic acid in the breakfast cereal and was therefore excluded from calculation of summary statistics. ${ }^{2}$

- The consensus ranges for folic acid in both matrices were wide but contained the target ranges. The consensus means for folic acid in both matrices were slightly above the target ranges.

- For folic acid in the breakfast cereal, the between-laboratory variability was high (32 \% RSD).

- For folic acid in the milk powder, the between-laboratory variability was acceptable (15\% RSD).

- A majority of the laboratories reported using an enzymatic hydrolysis approach (50 \%). A solvent extraction approach (25\%) and a shaking or sonication extraction approach (25\%) were also reported as methods of sample preparation.

- Most laboratories reported using LC with absorbance detection as the analytical method for analysis (67\%). Laboratories also reported using microbiological assay (17 \%), LCMS (8\%), and protein binding assay (8\%) as the instrumental approach.

- All participating laboratories reported the use of an external standard approach to quantitation.

Technical Recommendations

The following are recommendations based on results obtained from the participants in this study.

- No sample preparation approach or analytical method was identified as exceptionally good or problematic.

- Some high values were reported for either the sample or control (but not both). This may indicate chromatographic coelutions with matrix components. Because each matrix is different, the chromatographic method should be evaluated to confirm any potential biases from coeluting matrix components.

- NIST values in SRM 3233 and the fortified milk powder were determined using a gentle extraction procedure designed for determination of fortified folic acid in foods. As a result, the consensus means may be slightly higher than the NIST target ranges, reflecting the small fraction of endogenous folic acid that could be extracted by participating laboratories using more extensive extraction procedures such as enzymatic treatments. This contribution is expected to be relatively small, perhaps only $2 \%$ of the total folic acid present in these highly fortified samples. 
Table 5. Individual data table (NIST) for folic acid in foods.

\section{National Institute of Standards and Technology}

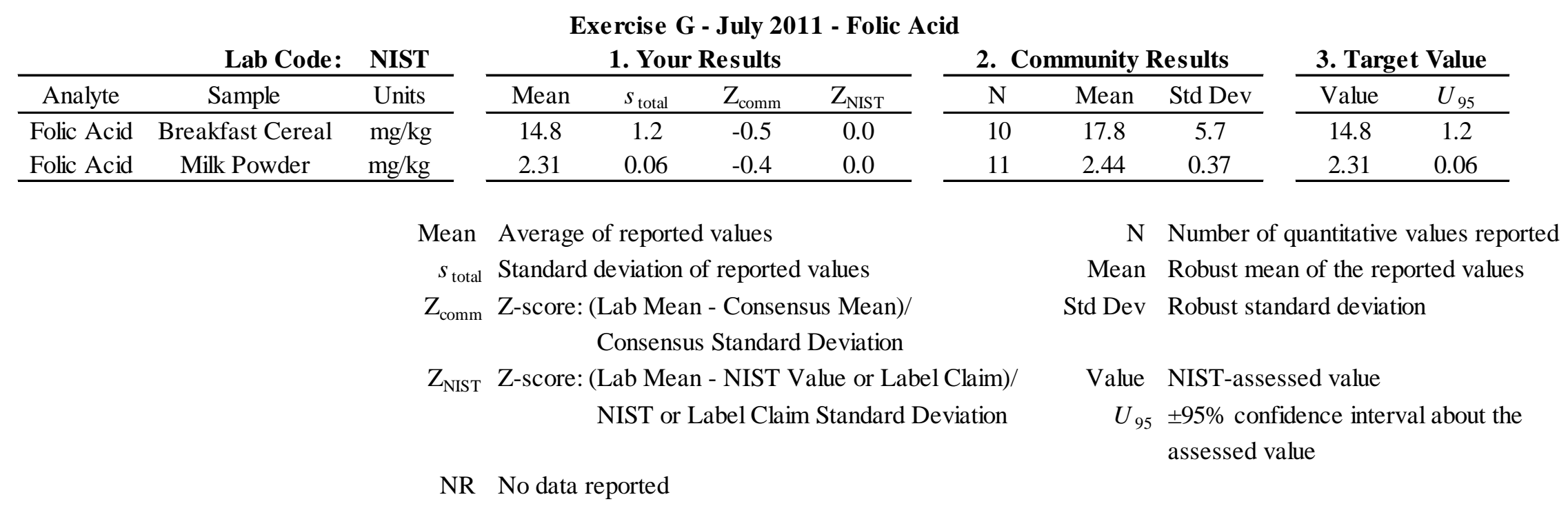


Table 6. Data summary table for folic acid in dietary supplements.

\begin{tabular}{|c|c|c|c|c|c|c|c|c|c|c|c|}
\hline & \multirow[b]{3}{*}{ Lab } & \multicolumn{10}{|c|}{ Folic Acid } \\
\hline & & \multicolumn{5}{|c|}{ SRM 3233 Fortified Breakfast Cereal (mg/kg) } & \multicolumn{5}{|c|}{ Fortified Milk Powder (mg/kg) } \\
\hline & & $\mathbf{A}$ & B & $\mathbf{C}$ & Avg & SD & A & B & $\mathrm{C}$ & Avg & SD \\
\hline \multirow{24}{*}{ 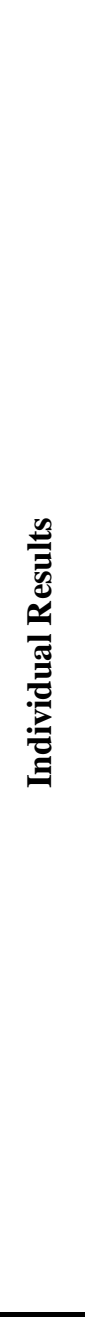 } & NIST & & & & 14.8 & 1.2 & & & & 2.31 & 0.06 \\
\hline & G703 & 13.1 & 13.1 & 13.9 & 13.4 & 0.5 & 2.33 & 2.22 & 2.32 & 2.29 & 0.06 \\
\hline & \multicolumn{11}{|l|}{ G705 } \\
\hline & \multicolumn{11}{|l|}{ G706 } \\
\hline & G709 & 24.6 & 26.2 & 26.0 & 25.6 & 0.9 & & & & & \\
\hline & \multicolumn{11}{|l|}{ G711 } \\
\hline & \multicolumn{11}{|l|}{ G721 } \\
\hline & G727 & 14.0 & 13.9 & 13.6 & 13.8 & 0.2 & 2.20 & 2.14 & 2.15 & 2.16 & 0.03 \\
\hline & \multicolumn{11}{|l|}{ G728 } \\
\hline & G729 & 15.8 & 15.5 & 14.8 & 15.4 & 0.5 & 2.61 & 1.90 & 2.72 & 2.41 & 0.44 \\
\hline & G738 & 16.1 & & & 16.1 & & 3.10 & 3.20 & 3.20 & 3.17 & 0.06 \\
\hline & \multicolumn{11}{|l|}{ G739 } \\
\hline & \multicolumn{11}{|l|}{ G740 } \\
\hline & G744 & 14.9 & 15.6 & 14.1 & 14.9 & 0.8 & 2.97 & 2.70 & 2.59 & 2.75 & 0.20 \\
\hline & G746 & 24.4 & 22.5 & 22.3 & 23.1 & 1.2 & 5.00 & 4.90 & 4.80 & 4.90 & 0.10 \\
\hline & G749 & 40.6 & 44.4 & 51.6 & 45.5 & 5.6 & 1.23 & 1.59 & 3.65 & 2.16 & 1.31 \\
\hline & \multicolumn{11}{|l|}{ G752 } \\
\hline & G753 & 15.2 & 15.0 & 14.9 & 15.0 & 0.1 & 2.19 & 1.93 & 2.16 & 2.09 & 0.14 \\
\hline & G754 & 14.8 & 15.6 & 15.2 & 15.2 & 0.4 & 2.27 & 2.28 & 2.29 & 2.28 & 0.01 \\
\hline & \multicolumn{11}{|l|}{ G758 } \\
\hline & G759 & 15.5 & 15.7 & 15.4 & 15.5 & 0.2 & 2.02 & 2.33 & 2.28 & 2.21 & 0.16 \\
\hline & \multicolumn{11}{|l|}{ G767 } \\
\hline & G768 & & & & & & 2.74 & 2.72 & 2.24 & 2.57 & 0.28 \\
\hline & G778 & & & & & & & & & & \\
\hline \multirow{5}{*}{ 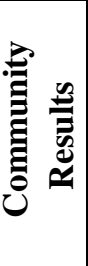 } & & \multicolumn{3}{|c|}{ Consensus Mean } & \multicolumn{2}{|l|}{17.8} & \multicolumn{3}{|c|}{ Consensus Mean } & \multicolumn{2}{|l|}{2.44} \\
\hline & & \multicolumn{3}{|c|}{ Consensus Standard Deviation } & \multicolumn{2}{|l|}{5.7} & \multicolumn{3}{|c|}{ Consensus Standard Deviation } & 0.37 & \\
\hline & & \multicolumn{3}{|c|}{ Maximum } & \multicolumn{2}{|l|}{45.5} & \multicolumn{3}{|c|}{ Maximum } & 4.9 & \\
\hline & & Minimu & & & 13.4 & & Minimu & & & 2.1 & \\
\hline & & $\mathrm{N}$ & & & 10 & & $\mathrm{~N}$ & & & 11 & \\
\hline
\end{tabular}




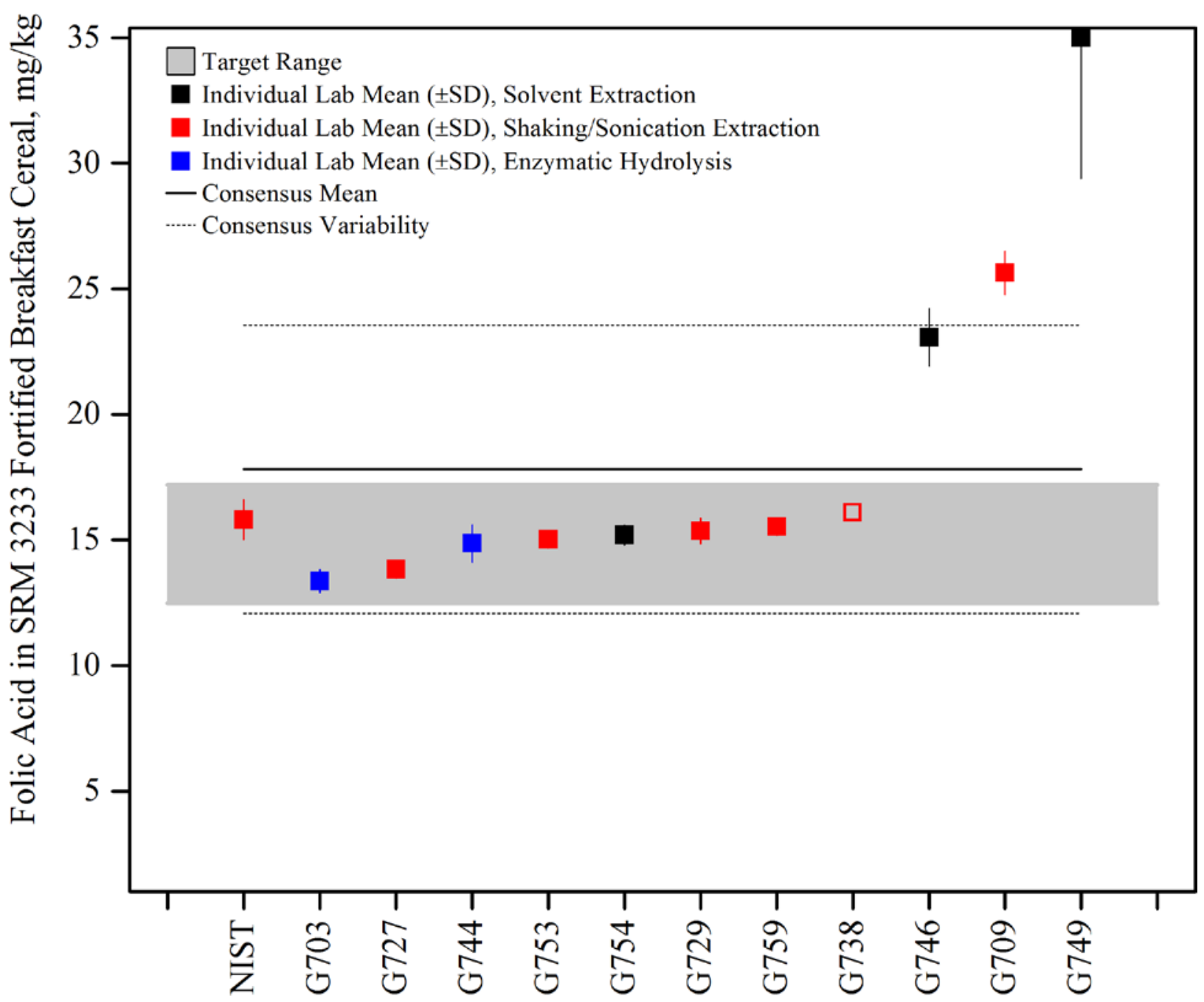

Figure 9. Folic acid in SRM 3233 Fortified Breakfast Cereal (data summary view - sample preparation method). In this view, individual laboratory data are plotted with the individual laboratory standard deviation (error bars). The data are identified by sample preparation method in this graph. The black solid line represents the consensus mean, and the black dotted lines represent the consensus variability calculated as one standard deviation about the consensus mean. The gray shaded region represents the target zone for "acceptable" performance, which encompasses the NIST certified value bounded by twice its uncertainty $\left(U_{95}\right)$. 


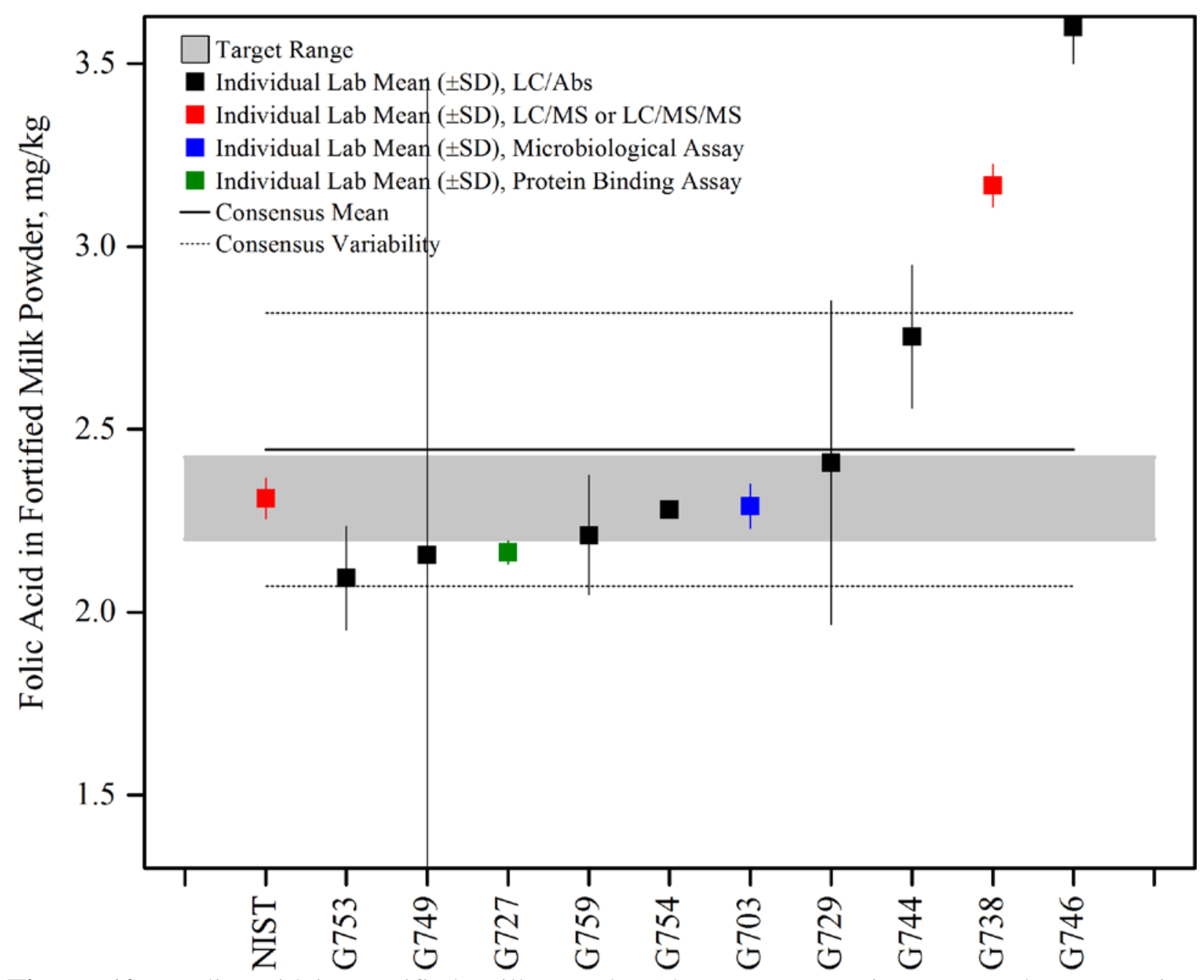

Figure 10. Folic acid in Fortified Milk Powder (data summary view - sample preparation method). In this view, individual laboratory data are plotted with the individual laboratory standard deviation (error bars). The data are identified by sample preparation method in this graph. The black solid line represents the consensus mean, and the black dotted lines represent the consensus variability calculated as one standard deviation about the consensus mean. The gray shaded region represents the target zone for "acceptable" performance, which encompasses the NIST assigned value bounded by twice its standard deviation. 


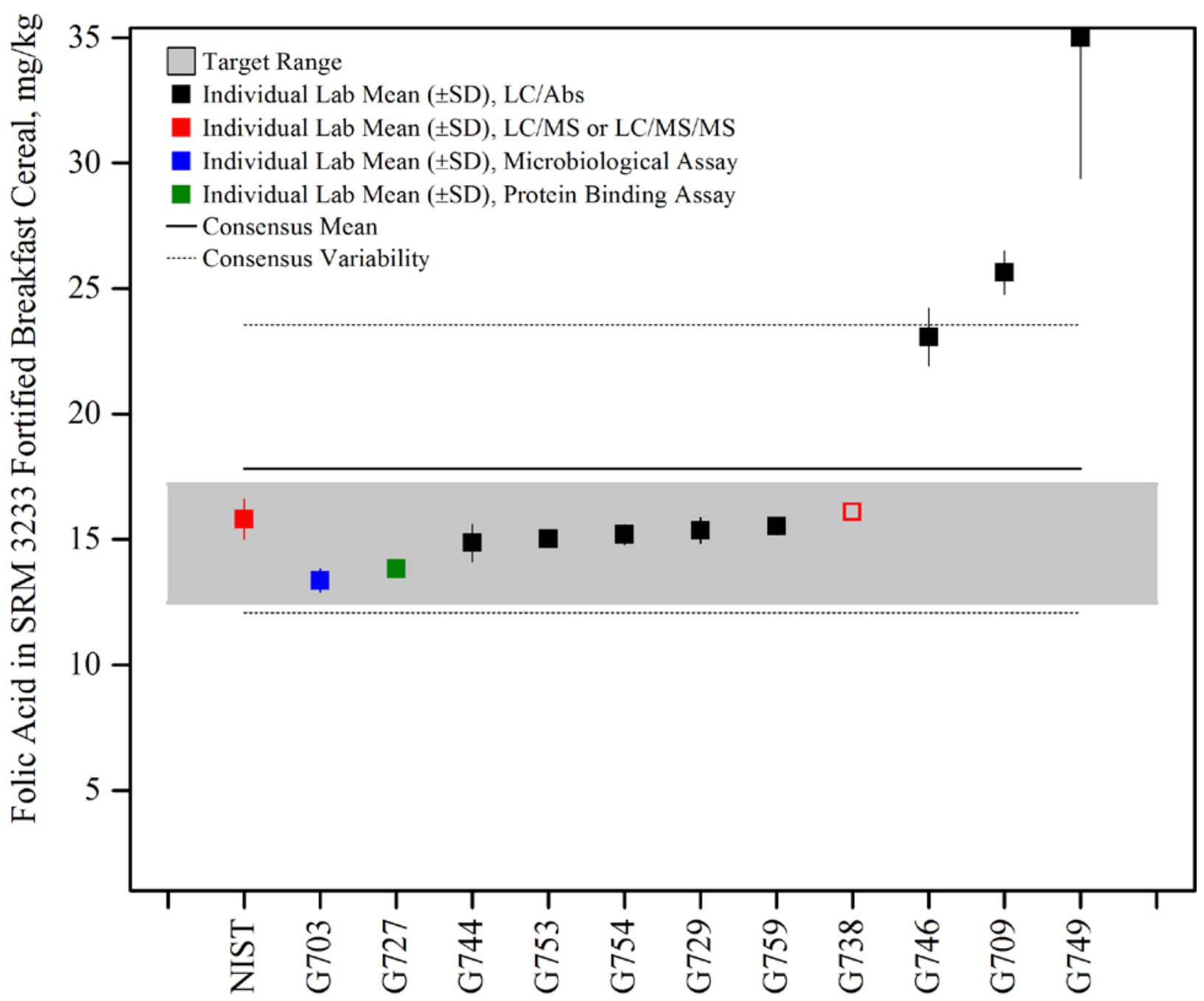

Figure 11. Folic acid in SRM 3233 Fortified Breakfast Cereal (data summary view - instrumental method). In this view, individual laboratory data are plotted with the individual laboratory standard deviation (error bars). The data are identified by instrumental method in this graph. The black solid line represents the consensus mean, and the black dotted lines represent the consensus variability calculated as one standard deviation about the consensus mean. The gray shaded region represents the target zone for "acceptable" performance, which encompasses the NIST certified value bounded by twice its uncertainty $\left(U_{95}\right)$. 


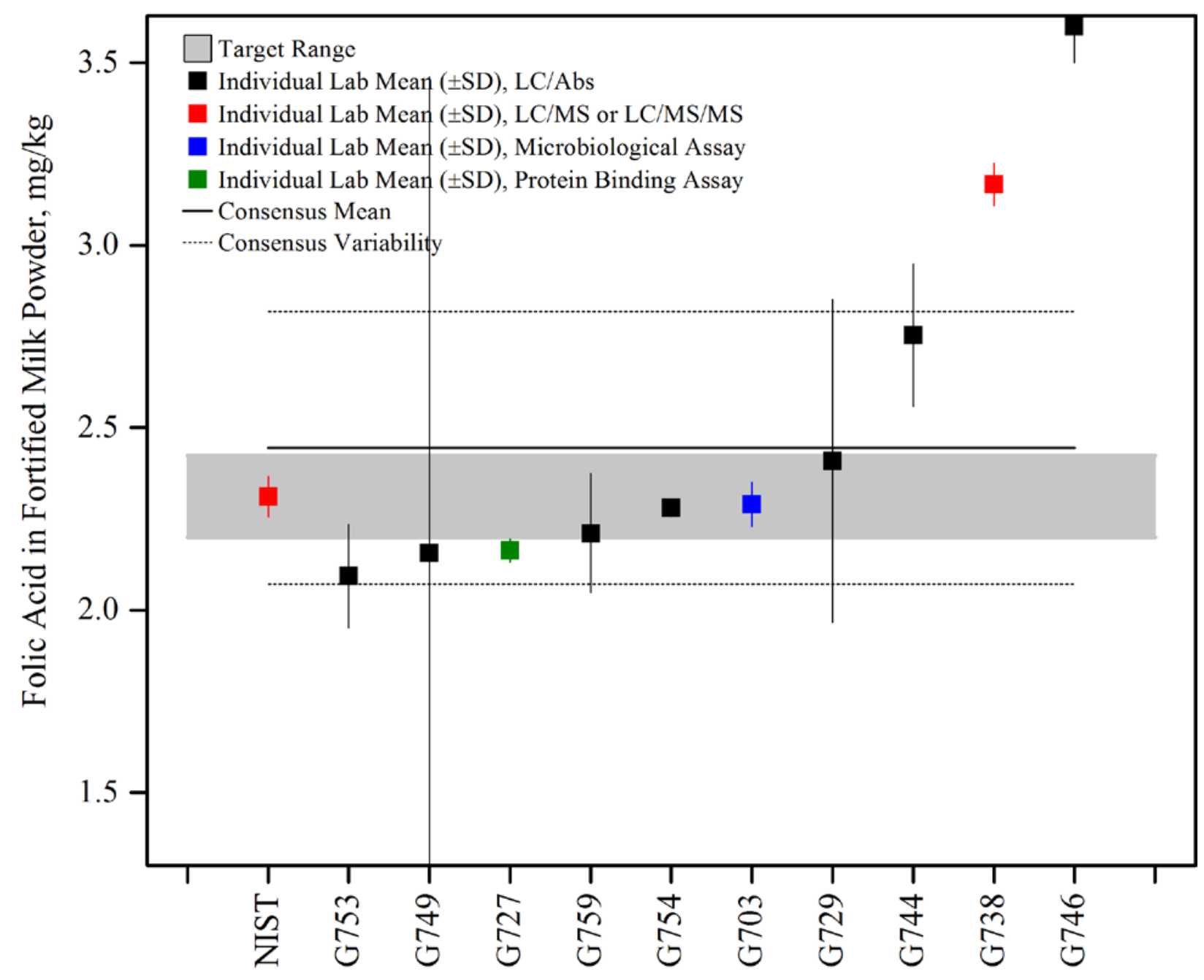

Figure 12. Folic acid in Fortified Milk Powder (data summary view - instrumental method). In this view, individual laboratory data are plotted with the individual laboratory standard deviation (error bars). The data are identified by instrumental method in this graph. The black solid line represents the consensus mean, and the black dotted lines represent the consensus variability calculated as one standard deviation about the consensus mean. The gray shaded region represents the target zone for "acceptable" performance, which encompasses the NIST assigned value bounded by twice its standard deviation. 


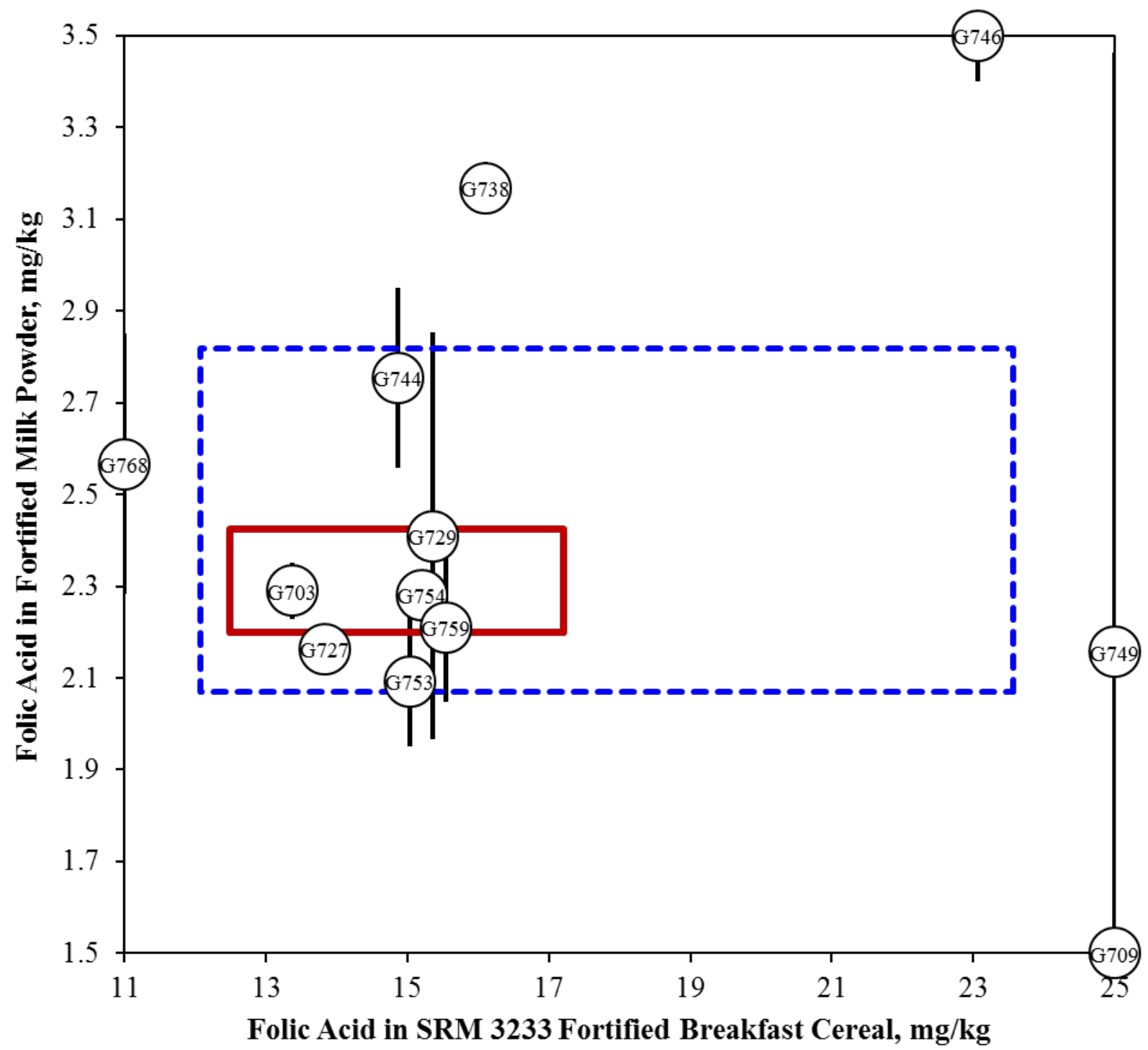

Figure 13. Folic acid in SRM 3233 Fortified Breakfast Cereal and Fortified Milk Powder (sample/sample comparison view). In this view, the individual laboratory results for one sample (SRM 3233 Fortified Breakfast Cereal) are compared to the results for a second sample (Fortified Milk Powder). The solid red box represents the target zone for the breakfast cereal (x-axis) and the milk powder (y-axis). The dotted blue box represents the consensus zone for the breakfast cereal (x-axis) and the milk powder (y-axis). 


\section{$\beta$-CAROTENE IN SOLUTIONS AND DIETARY SUPPLEMENTS}

\section{Study Overview}

In this study, participants were provided with one NIST SRM, SRM 3251 Serenoa repens Extract, and two ethanolic solutions of $\beta$-carotene. Participants were asked to use in-house analytical methods to determine the mass fraction of total $\beta$-carotene and isomers in each of the matrices and report values on an as-received basis.

\section{Sample Information}

$\beta$-carotene Solution 1. Participants were provided with three vials containing approximately $2 \mathrm{~mL}$ of all-trans- $\beta$-carotene dissolved in ethanol containing 30 ppm BHT. Solution 1 did not contain significant amounts of cis- $\beta$-carotene isomers. Before use, participants were instructed to thoroughly mix the contents of the vials and use a sample size of at least $50 \mathrm{mg}$. Participants were asked to store the material in a freezer at $-20{ }^{\circ} \mathrm{C}$, and to prepare one sample and report one value per analyte from each vial provided. Prior to the study, the approximate level of total $\beta$-carotene was given as $0.9 \mathrm{mg} / \mathrm{kg}$. The NIST value and uncertainty for total $\beta$-carotene in solution 1 were determined spectrophotometrically in ethanol with a molar absorptivity of $2620 \mathrm{dLg}^{-1} \mathrm{~cm}^{-1}$, and the $\beta$-carotene concentration decreased approximately $10 \%$ from July 2011 until February 2012. The NIST-determined values and uncertainties are reported in the table below.

$\beta$-carotene Solution 2. Participants were provided with three vials containing approximately $2 \mathrm{~mL}$ of Dunaliella extract dissolved in ethanol containing $30 \mathrm{ppm}$ BHT. In solution 2, approximately $30 \%$ of the total $\beta$-carotene was in the form of the 9 -cis- $\beta$-carotene isomer. Before use, participants were instructed to thoroughly mix the contents of the vials and use a sample size of at least $50 \mathrm{mg}$. Participants were asked to store the material in a freezer at $-20{ }^{\circ} \mathrm{C}$, and to prepare one sample and report one value per analyte from each vial provided. Prior to the study, the approximate level of total $\beta$-carotene was given as $4 \mathrm{mg} / \mathrm{kg}$. The NIST value and uncertainty for total $\beta$-carotene in solution 2 were determined spectrophotometrically in ethanol with a molar absorptivity of $2620 \mathrm{dLg}^{-1} \mathrm{~cm}^{-1}$; the total $\beta$-carotene content of solution 2 was stabile throughout the time period of the study. The NIST-determined values and uncertainties are reported in the table below.

Saw Palmetto Extract. Participants were provided with three ampoules, each containing approximately $1 \mathrm{~mL}$ of Serenoa repens extract. The extract was packaged under nitrogen in amber glass ampoules. Before use, participants were instructed to thoroughly mix the contents of the ampoules and use a sample size of at least $50 \mathrm{mg}$. Participants were asked to store the material at controlled room temperature, $20^{\circ} \mathrm{C}$ to $25{ }^{\circ} \mathrm{C}$, and to prepare one sample and report one value per analyte from each ampoule provided. Prior to the study, the approximate level of total $\beta$-carotene was given as $50 \mathrm{mg} / \mathrm{kg}$. The NIST certified values and uncertainties for trans- $\beta$-carotene, 9-cis$\beta$-carotene, and total $\beta$-carotene in SRM 3251 were determined at NIST by LC-absorbance and LC-fluorescence (using different column chemistries), following gravimetric dilution and addition of an internal standard. The NIST-determined values and uncertainties are reported in the table below. 


\begin{tabular}{|c|c|c|c|c|}
\hline Analyte & $\begin{array}{c}\text { Mass Fraction } \\
\text { in Solution } 1(\mathrm{mg} / \mathrm{kg})\end{array}$ & $\begin{array}{c}\text { Mass Fraction } \\
\text { in Solution } 2(\mathrm{mg} / \mathrm{kg})\end{array}$ & \multicolumn{2}{|c|}{$\begin{array}{l}\text { Mass Fraction } \\
\frac{\text { in SRM } 3251}{(\mathrm{mg} / \mathrm{kg})}\end{array}$} \\
\hline trans- $\beta$-carotene & & & 36.4 & 5.6 \\
\hline 9-cis- $\beta$-carotene & & & $10.40 \pm$ & 1.20 \\
\hline Total $\beta$-carotene & $0.900 \pm 0.045$ & $4.000 \pm 0.200$ & 46.8 & 4.6 \\
\hline
\end{tabular}

Study Results

- Forty-one laboratories enrolled in this exercise and received samples. Twenty-three laboratories reported results for total $\beta$-carotene in both of the $\beta$-carotene solutions (56 \% participation). Twenty-four laboratories reported results for total $\beta$-carotene in the saw palmetto extract (59\% participation). One laboratory reported a single value for total $\beta$ carotene in the saw palmetto extract and was therefore excluded from calculation of summary statistics. ${ }^{2}$

- Few laboratories (6 or fewer) reported values for cis and trans isomers of $\beta$-carotene in any sample.

- The consensus ranges for total $\beta$-carotene in both solutions were wide (21\% to $23 \%$ relative standard deviation, (RSD) respectively) but overlapped with the target ranges. The consensus means for total $\beta$-carotene in both solutions were significantly above the target ranges.

- The consensus range for total $\beta$-carotene in SRM 3251 was excellent (10 \% RSD) and overlapped with the target range. The consensus mean for total $\beta$-carotene was within the target range.

- The consensus range for trans- $\beta$-carotene in SRM 3251 was excellent (7 \% RSD) and overlapped with the target range. The consensus mean for trans- $\beta$-carotene was within the target range.

- The consensus range for 9-cis- $\beta$-carotene in SRM 3251 was reasonable (17 \% RSD) and overlapped with the target range. The consensus mean for 9 -cis- $\beta$-carotene was within the target range.

- A majority of the laboratories reported using simple dilution (48\%) or saponification with extraction (40\%). Other solvent extraction approaches (8 \%) and hydrolysis extraction approaches (4\%) were also reported as methods of sample preparation.

- Most laboratories reported using LC with absorbance detection as the analytical method for analysis (92\%). Laboratories also reported using LC-MS or LC-MS/MS (4 \%) and spectrophotometry (4\%) as the instrumental approach.

- All participating laboratories reported the use of an external standard approach to quantitation.

Technical Recommendations

The following are recommendations based on results obtained from the participants in this study.

- No sample preparation approach or analytical method was identified as exceptionally good or problematic.

- Although no sample pretreatment was necessary for the $\beta$-carotene solutions, many laboratories subjected the samples to saponification, enzymatic hydrolysis, and solvent extraction. Sample preparation can isomerize the $\beta$-carotene, which would not be evident 
in the total $\beta$-carotene measurements, but would affect the ratio of the cis/trans isomers observed.

- As shown in Figure 25, Figure 26, and Figure 27, calibration errors may be possible. Laboratories tended to report consistently biased results for the samples and solutions. The most common calibration error in the measurement of carotenoids is caused by either neglecting to assign the concentration spectrophotometrically (carotenoid measurements are traceable to molar absorptivity) or using the wrong molar absorption coefficient (wrong solvent or temperature). 
Table 7. Individual data table (NIST) for $\beta$-carotene in solutions and dietary supplements.

\section{National Institute of Standards \& Technology}

\begin{tabular}{|c|c|c|}
\hline & Lab Code: & NIST \\
\hline Analyte & Sample & Units \\
\hline trans $-\beta$-carotene & Solution 1 & $\mathrm{mg} / \mathrm{kg}$ \\
\hline trans $-\beta$-carotene & Solution 2 & $\mathrm{mg} / \mathrm{kg}$ \\
\hline trans $-\beta$-carotene & Saw Palmetto Extract & $\mathrm{mg} / \mathrm{kg}$ \\
\hline 9-cis- $\beta$-carotene & Solution 1 & $\mathrm{mg} / \mathrm{kg}$ \\
\hline 9-cis- $\beta$-carotene & Solution 2 & $\mathrm{mg} / \mathrm{kg}$ \\
\hline 9 -cis - $\beta$-carotene & Saw Palmetto Extract & $\mathrm{mg} / \mathrm{kg}$ \\
\hline 13 -cis - $\beta$-carotene & Solution 1 & $\mathrm{mg} / \mathrm{kg}$ \\
\hline 13 -cis $-\beta$-carotene & Solution 2 & $\mathrm{mg} / \mathrm{kg}$ \\
\hline 13 -cis - $\beta$-carotene & Saw Palmetto Extract & $\mathrm{mg} / \mathrm{kg}$ \\
\hline 15 -cis - $\beta$-carotene & Solution 1 & $\mathrm{mg} / \mathrm{kg}$ \\
\hline 15 -cis $-\beta$-carotene & Solution 2 & $\mathrm{mg} / \mathrm{kg}$ \\
\hline 15 -cis $-\beta$-carotene & Saw Palmetto Extract & $\mathrm{mg} / \mathrm{kg}$ \\
\hline Total $\beta$-carotene & Solution 1 & $\mathrm{mg} / \mathrm{kg}$ \\
\hline Total $\beta$-carotene & Solution 2 & $\mathrm{mg} / \mathrm{kg}$ \\
\hline Total $\beta$-carotene & Saw Palmetto Extract & $\mathrm{mg} / \mathrm{kg}$ \\
\hline
\end{tabular}

Exercise G - July 2011 - $\beta$-carotene

\begin{tabular}{cccc}
\multicolumn{4}{c}{ 1. Your Results } \\
\hline Mean & $s_{\text {total }}$ & $\mathrm{Z}_{\text {comm }}$ & $\mathrm{Z}_{\mathrm{NIST}}$ \\
\hline & & & \\
36.4 & 5.6 & 0.6 & 0.0 \\
\hline & & & \\
10.4 & 1.2 & -0.7 & 0.0 \\
\hline
\end{tabular}

\begin{tabular}{ccc}
\multicolumn{3}{c}{ 2. Community Results } \\
\hline $\mathrm{N}$ & Mean & Std Dev \\
\hline 6 & 1.05 & 0.227
\end{tabular}

3. Target Value

\begin{tabular}{cccccc}
6 & 2.48 & 0.548 & & NR & NR \\
7 & 34.9 & 2.35 & & 36.4 & 5.6 \\
\cline { 1 - 3 } \cline { 5 - 6 } 2 & 0.0113 & 0.00135 & & NR &
\end{tabular}

\begin{tabular}{llll}
10.4 & 1.2 & -0.7 & 0.0 \\
\hline
\end{tabular}

\begin{tabular}{ccc}
6 & 2.21 & 0.74 \\
6 & 11.8 & 2.04 \\
\hline 1 & 0.0364 & \\
3 & 0.199 & 0.0427 \\
4 & 2.59 & 2.33
\end{tabular}

NR NR

\begin{tabular}{cc}
10.4 & 1.2 \\
\hline NR & NR \\
NR & NR \\
NR & NR \\
\hline NR & NR \\
NR & NR \\
NR & NR \\
\hline 0.900 & 0.045 \\
4.00 & 0.20 \\
46.8 & 4.6 \\
\hline
\end{tabular}

Mean Average of reported values

$s_{\text {total }}$ Standard deviation of reported values

$\mathrm{Z}_{\text {comm }}$ Z-score: (Lab Mean - Consensus Mean)/

Consensus Standard Deviation

$Z_{\text {NIST }}$ Z-score: (Lab Mean - NIST Value or Label Claim)/

NIST or Label Claim Standard Deviation

Value NIST-assessed value

$U_{95} \pm 95 \%$ confidence interval about the assessed value

NR No data reported 
Table 8. Data summary table for trans- $\beta$-carotene in solutions and dietary supplements.

\begin{tabular}{|c|c|c|c|c|c|c|c|c|c|c|c|c|c|c|c|c|}
\hline & \multirow[b]{3}{*}{ Lab } & \multicolumn{15}{|c|}{ trans- $\beta$-carotene } \\
\hline & & \multicolumn{5}{|c|}{ Solution 1 (mg/kg) } & \multicolumn{5}{|c|}{ Solution 2 (mg/kg) } & \multicolumn{5}{|c|}{ SRM 3251 Saw Palmetto Extract (mg/kg) } \\
\hline & & $\mathbf{A}$ & B & $\mathbf{C}$ & Avg & SD & A & B & C & Avg & SD & A & B & C & Avg & SD \\
\hline \multirow{42}{*}{ 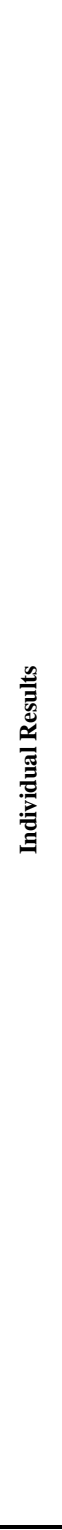 } & NIST & & & & & & & & & & & & & & 36.4 & 5.6 \\
\hline & G703 & 1.34 & 1.60 & 1.17 & 1.37 & 0.22 & 2.98 & 3.23 & 3.26 & 3.16 & 0.15 & 35.8 & 34.4 & 34.4 & 34.9 & 0.8 \\
\hline & \multicolumn{16}{|l|}{ G705 } \\
\hline & \multicolumn{16}{|l|}{ G706 } \\
\hline & \multicolumn{16}{|l|}{ G707 } \\
\hline & G709 & 1.13 & 1.00 & 0.95 & 1.03 & 0.10 & 3.48 & 2.51 & 2.26 & 2.75 & 0.64 & 33.0 & 33.8 & 34.0 & 33.6 & 0.5 \\
\hline & \multicolumn{16}{|l|}{ G710 } \\
\hline & \multicolumn{16}{|l|}{ G711 } \\
\hline & \multicolumn{16}{|l|}{ G712 } \\
\hline & \multicolumn{16}{|l|}{ G714 } \\
\hline & G716 & 0.75 & 0.92 & 1.00 & 0.89 & 0.13 & 1.33 & 2.16 & 1.78 & 1.76 & 0.42 & 34.8 & 34.7 & 41.8 & 37.1 & 4.1 \\
\hline & \multicolumn{16}{|l|}{ G717 } \\
\hline & \multicolumn{16}{|l|}{ G721 } \\
\hline & G722 & & & & & & & & & & & & & & & \\
\hline & G724 & & & & & & & & & & & & & & & \\
\hline & G727 & 18.61 & 22.90 & 17.56 & 19.69 & 2.83 & 53.80 & 47.72 & 50.17 & 50.56 & 3.06 & & 37.2 & 37.5 & 37.4 & 0.2 \\
\hline & G728 & & & & & & & & & & & & & & & \\
\hline & G729 & & & & & & & & & & & & & & & \\
\hline & G730 & & & & & & & & & & & & & & & \\
\hline & G731 & & & & & & & & & & & & & & & \\
\hline & G732 & & & & & & & & & & & & & & & \\
\hline & G733 & & & & & & & & & & & & & & & \\
\hline & G738 & & & & & & & & & & & & & & & \\
\hline & G739 & & & & & & & & & & & & & & & \\
\hline & G740 & & & & & & & & & & & & & & & \\
\hline & G742 & & & & & & & & & & & & & & & \\
\hline & G744 & & & & & & & & & & & & & & & \\
\hline & G746 & & & & & & & & & & & & & & & \\
\hline & G749 & & & & & & & & & & & & & & & \\
\hline & G752 & & & & & & & & & & & & & & & \\
\hline & G753 & 1.06 & 1.11 & 1.09 & 1.09 & 0.03 & 2.48 & 2.54 & 2.67 & 2.56 & 0.10 & 35.0 & 35.5 & 37.0 & 35.8 & 1.0 \\
\hline & G755 & & & & & & & & & & & & & & & \\
\hline & G758 & & & & & & & & & & & & & & & \\
\hline & G760 & & & & & & & & & & & & & & & \\
\hline & G762 & & & & & & & & & & & & & & & \\
\hline & G764 & & & & & & & & & & & & & & & \\
\hline & G766 & 0.78 & 0.75 & 0.85 & 0.79 & 0.05 & 2.18 & 2.03 & 2.25 & 2.15 & 0.11 & 28.4 & 29.0 & 28.1 & 28.5 & 0.4 \\
\hline & G767 & & & & & & & & & & & & & & & \\
\hline & G770 & & & & & & & & & & & & & & & \\
\hline & G773 & & & & & & & & & & & & & & & \\
\hline & G774 & & & & & & & & & & & & & & & \\
\hline & G775 & & & & & & & & & & & & & & & \\
\hline & & Consen & Mean & & 1.14 & & Consens & Mean & & 2.76 & & Consen & Mean & & 35.0 & \\
\hline$\ddot{\Xi}$ & & Consen & Standarc & Deviation & 0.37 & & Consens & Standar & Deviation & 0.96 & & Consen & Standa & Deviation & 2.6 & \\
\hline Eี & & Maximı & & & 19.69 & & Maximu & & & 50.56 & & Maximı & & & 37.4 & \\
\hline ن & & Minimu & & & 0.79 & & Minimur & & & 1.76 & & Minimu & & & 28.5 & \\
\hline & & $\mathrm{N}$ & & & 6 & & $\mathrm{~N}$ & & & 6 & & $\mathrm{~N}$ & & & 6 & \\
\hline
\end{tabular}


Table 9. Data summary table for 9-cis- $\beta$-carotene in solutions and dietary supplements.

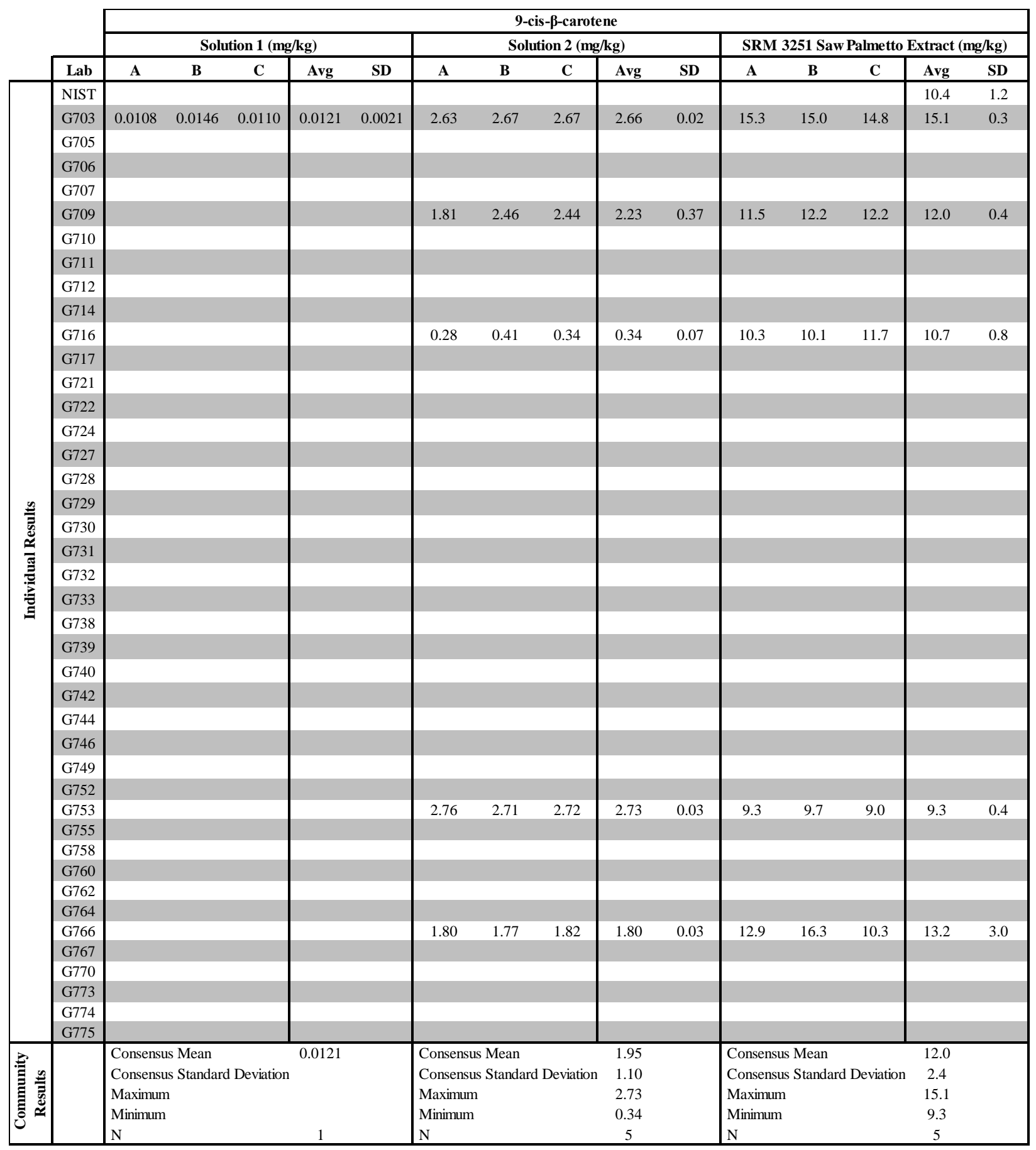


Table 10. Data summary table for 13 -cis- $\beta$-carotene in solutions and dietary supplements.

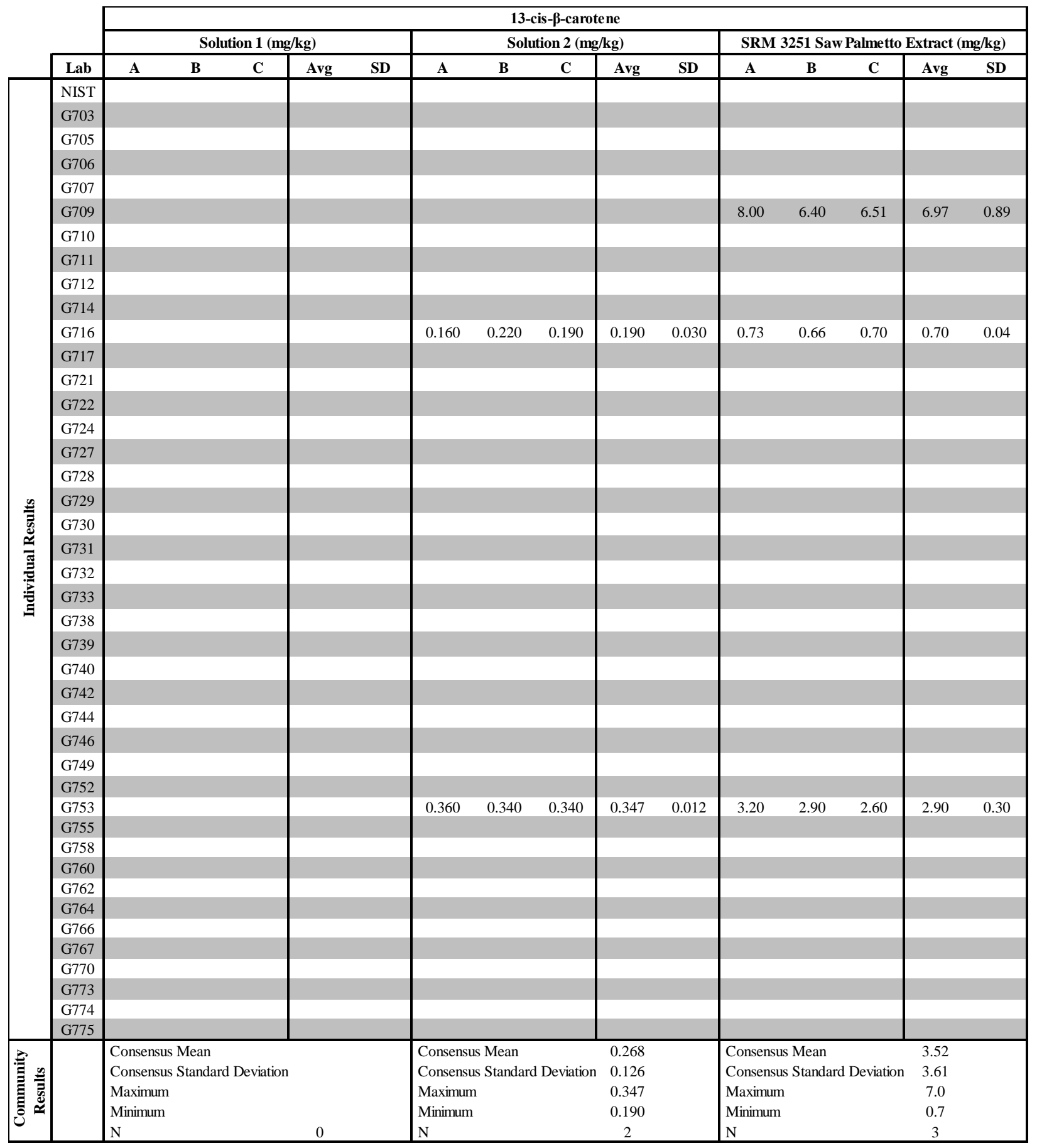


Table 11. Data summary table for 15 -cis- $\beta$-carotene in solutions and dietary supplements.

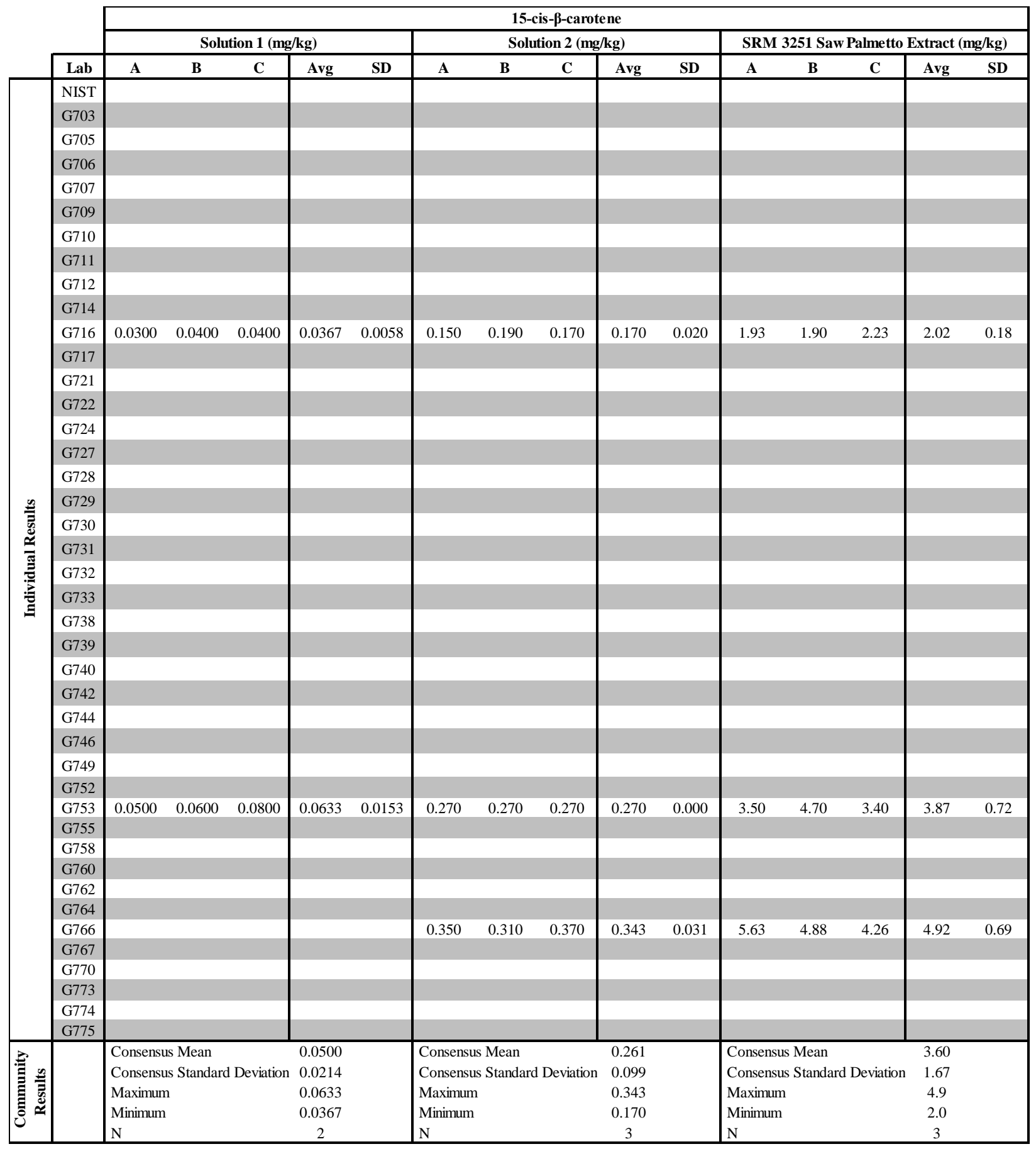


Table 12. Data summary table for total $\beta$-carotene in solutions and dietary supplements.

\begin{tabular}{|c|c|c|c|c|c|c|c|c|c|c|c|c|c|c|c|c|}
\hline & \multirow[b]{3}{*}{ Lab } & \multicolumn{15}{|c|}{ Total $\beta$-carotene } \\
\hline & & \multicolumn{9}{|c|}{ SRM 3251 Saw Palmetto Extract (mg/kg) } & & \multicolumn{2}{|c|}{ SRM 3251 Saw Palmetto Extract (mg/kg) } & & & \\
\hline & & $\mathbf{A}$ & B & C & Avg & SD & $\mathbf{A}$ & B & C & Avg & SD & A & B & C & Avg & SD \\
\hline \multirow{42}{*}{ 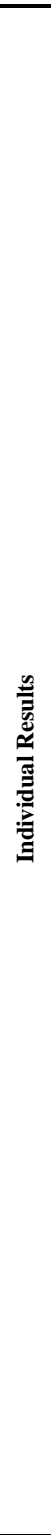 } & NIST & & & & 0.90 & 0.05 & & & & 4.00 & 0.20 & & & & 46.8 & 4.6 \\
\hline & G703 & 1.46 & 1.73 & 1.27 & 1.48 & 0.24 & 6.47 & 6.76 & 6.79 & 6.67 & 0.18 & 57.7 & 55.4 & 54.5 & 55.9 & 1.7 \\
\hline & G705 & & & & & & & & & & & & & & & \\
\hline & G706 & 0.88 & 1.13 & 1.02 & 1.01 & 0.13 & 4.91 & 5.19 & 4.68 & 4.93 & 0.26 & 46.2 & 46.0 & 46.5 & 46.2 & 0.3 \\
\hline & G707 & & & & & & & & & & & & & & & \\
\hline & G709 & 1.13 & 1.00 & 0.95 & 1.03 & 0.10 & 5.29 & 4.97 & 4.69 & 4.98 & 0.30 & 52.5 & 52.4 & 52.7 & 52.6 & 0.2 \\
\hline & G710 & & & & & & & & & & & & & & & \\
\hline & G711 & 1.13 & 0.94 & 0.91 & 0.99 & 0.12 & 4.81 & 4.60 & 5.58 & 5.00 & 0.52 & 48.3 & 47.8 & 51.5 & 49.2 & 2.0 \\
\hline & G712 & & & & & & & & & & & & & & & \\
\hline & G714 & 0.94 & 0.77 & 1.18 & 0.96 & 0.21 & 4.33 & 6.44 & 6.74 & 5.84 & 1.31 & & & & & \\
\hline & G716 & 0.78 & 0.96 & 1.04 & 0.93 & 0.13 & 1.92 & 2.98 & 2.48 & 2.46 & 0.53 & 47.8 & 47.4 & 56.4 & 50.5 & 5.1 \\
\hline & G717 & & & & & & & & & & & & & & & \\
\hline & G721 & & & & & & & & & & & & & & & \\
\hline & G722 & 2.82 & 2.87 & 2.76 & 2.82 & 0.06 & 8.74 & 9.84 & 8.82 & 9.13 & 0.61 & 163.3 & 176.9 & 182.5 & 174.2 & 9.9 \\
\hline & G724 & 1.16 & 1.28 & 1.43 & 1.29 & 0.14 & 6.28 & 6.68 & 6.16 & 6.38 & 0.27 & 50.8 & 49.3 & 49.9 & 50.0 & 0.8 \\
\hline & G727 & & & & & & & & & & & & & & & \\
\hline & G728 & & & & & & & & & & & & & & & \\
\hline & G729 & 1.16 & 0.79 & 0.69 & 0.88 & 0.25 & 5.13 & 5.04 & 3.66 & 4.61 & 0.82 & 62.3 & 38.8 & 57.6 & 52.9 & 12.4 \\
\hline & G730 & 1.50 & 1.30 & 1.30 & 1.37 & 0.12 & 6.30 & 6.10 & 6.20 & 6.20 & 0.10 & 57.5 & 56.9 & 58.4 & 57.6 & 0.8 \\
\hline & G731 & 1.19 & 1.63 & 1.20 & 1.34 & 0.25 & 5.56 & 5.57 & 5.44 & 5.52 & 0.07 & 54.5 & 53.5 & 53.2 & 53.7 & 0.6 \\
\hline & G732 & 1.18 & 1.25 & 1.15 & 1.19 & 0.05 & 5.67 & 5.88 & 5.65 & 5.73 & 0.13 & 49.8 & 50.7 & 51.8 & 50.7 & 1.0 \\
\hline & G733 & 1.31 & 1.45 & 1.35 & 1.37 & 0.07 & 5.95 & 6.39 & 6.23 & 6.19 & 0.22 & 52.8 & 55.5 & 51.5 & 53.3 & 2.0 \\
\hline & G738 & 2.40 & 1.30 & 1.10 & 1.60 & 0.70 & 6.20 & 7.30 & 7.00 & 6.83 & 0.57 & 89.0 & 119.0 & 150.0 & 119.3 & 30.5 \\
\hline & G739 & & & & & & & & & & & & & & & \\
\hline & G740 & & & & & & & & & & & & & & & \\
\hline & G742 & & & & & & & & & & & & & & & \\
\hline & G744 & 1.04 & 0.86 & 0.85 & 0.92 & 0.11 & 4.50 & 4.20 & 4.20 & 4.30 & 0.17 & 55.5 & 42.0 & 45.8 & 47.8 & 7.0 \\
\hline & G746 & 1.20 & 1.90 & 1.20 & 1.43 & 0.40 & 3.40 & 3.30 & 4.90 & 3.87 & 0.90 & 69.6 & 45.8 & 56.7 & 57.4 & 11.9 \\
\hline & G749 & 2.22 & & & 2.22 & & 8.33 & 5.83 & 6.27 & 6.81 & 1.33 & 113.6 & 106.4 & 124.3 & 114.8 & 9.0 \\
\hline & G752 & & & & & & & & & & & & & & & \\
\hline & G753 & 1.11 & 1.17 & 1.17 & 1.15 & 0.03 & 6.35 & 6.37 & 6.50 & 6.41 & 0.08 & 51.0 & 52.8 & 52.0 & 51.9 & 0.9 \\
\hline & G755 & & & & & & & & & & & & & & & \\
\hline & G758 & & & & & & & & & & & & & & & \\
\hline & G760 & 1.05 & 1.30 & 1.15 & 1.16 & 0.12 & 4.89 & 5.09 & 4.97 & 4.98 & 0.10 & 64.5 & & & 64.5 & \\
\hline & G762 & 1.32 & 1.19 & 1.08 & 1.20 & 0.12 & 6.37 & 6.29 & 6.25 & 6.30 & 0.06 & 56.2 & 54.5 & 55.6 & 55.4 & 0.9 \\
\hline & G764 & & & & & & & & & & & & & & & \\
\hline & G766 & & & & & & & & & & & 47.0 & 50.1 & 42.7 & 46.6 & 3.7 \\
\hline & G767 & & & & & & & & & & & & & & & \\
\hline & G770 & & & & & & & & & & & 49.4 & 43.6 & 43.3 & 45.4 & 3.4 \\
\hline & G773 & 0.10 & 0.11 & 0.08 & 0.10 & 0.02 & 3.90 & 3.83 & 3.68 & 3.80 & 0.11 & 0.1 & 0.1 & 0.1 & 0.1 & 0.0 \\
\hline & G774 & & & & & & & & & & & & & & & \\
\hline & G775 & 0.90 & 0.95 & & 0.93 & 0.04 & 6.29 & 5.91 & 6.60 & 6.27 & 0.35 & 54.2 & 52.0 & 51.4 & 52.5 & 1.5 \\
\hline 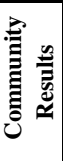 & & \multicolumn{3}{|c|}{$\begin{array}{l}\text { Consensus Mean } \\
\text { Consensus Standard Deviation } \\
\text { Maximum } \\
\text { Minimum } \\
\text { N }\end{array}$} & $\begin{array}{c}1.17 \\
0.28 \\
2.82 \\
0.88 \\
19\end{array}$ & & \multicolumn{3}{|c|}{$\begin{array}{l}\text { Consensus Mean } \\
\text { Consensus Standard Deviation } \\
\text { Maximum } \\
\text { Minimum } \\
\text { N }\end{array}$} & $\begin{array}{c}5.58 \\
1.22 \\
9.13 \\
2.46 \\
20\end{array}$ & & \multicolumn{3}{|c|}{$\begin{array}{l}\text { Consensus Mean } \\
\text { Consensus Standar } \\
\text { Maximum } \\
\text { Minimum } \\
\mathrm{N}\end{array}$} & $\begin{array}{c}52.5 \\
5.3 \\
174.2 \\
46.2 \\
19\end{array}$ & \\
\hline
\end{tabular}




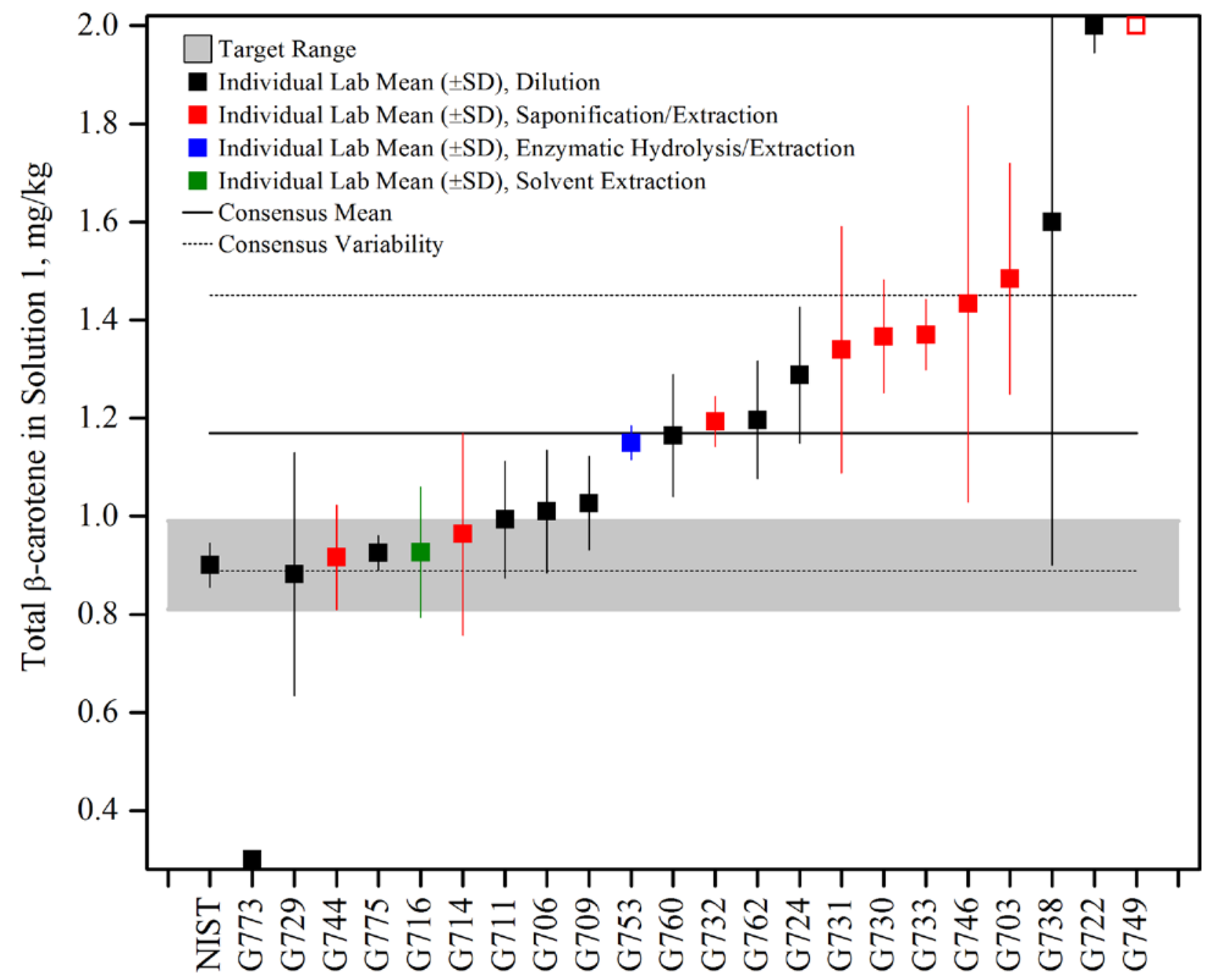

Figure 14. Total $\beta$-carotene in Solution 1 (data summary view - sample preparation method). In this view, individual laboratory data are plotted with the individual laboratory standard deviation (error bars). The data are identified by sample preparation method in this graph. The black solid line represents the consensus mean, and the black dotted lines represent the consensus variability calculated as one standard deviation about the consensus mean. The gray shaded region represents the target zone for "acceptable" performance, which encompasses the NIST assigned value bounded by twice its standard deviation. 


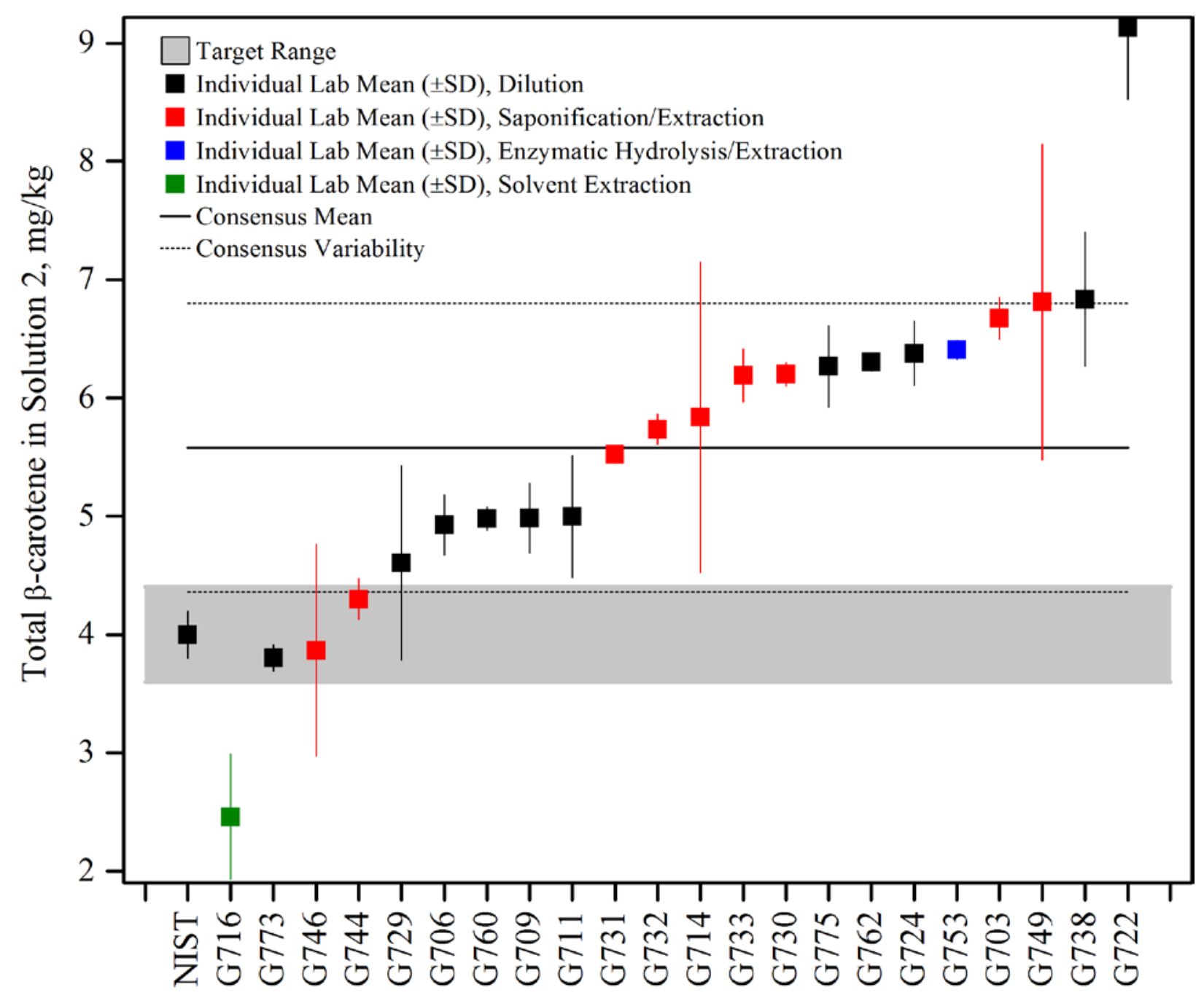

Figure 15. Total $\beta$-carotene in Solution 2 (data summary view - sample preparation method). In this view, individual laboratory data are plotted with the individual laboratory standard deviation (error bars). The data are identified by sample preparation method in this graph. The black solid line represents the consensus mean, and the black dotted lines represent the consensus variability calculated as one standard deviation about the consensus mean. The gray shaded region represents the target zone for "acceptable" performance, which encompasses the NIST assigned value bounded by twice its standard deviation. 


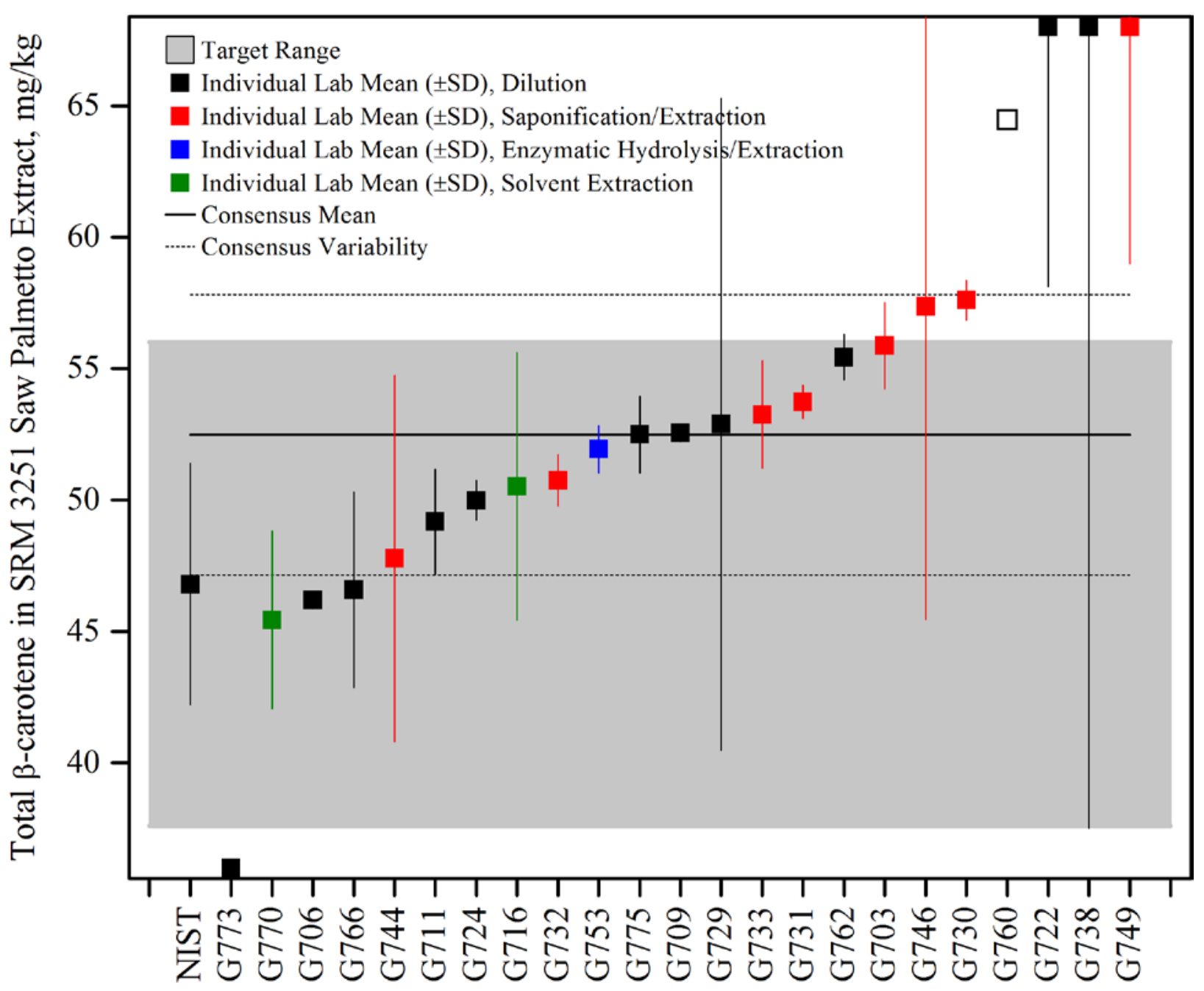

Figure 16. Total $\beta$-carotene in SRM 3251 Serenoa repens Extract (data summary view - sample preparation method). In this view, individual laboratory data are plotted with the individual laboratory standard deviation (error bars). The data are identified by sample preparation method in this graph. The black solid line represents the consensus mean, and the black dotted lines represent the consensus variability calculated as one standard deviation about the consensus mean. The gray shaded region represents the target zone for "acceptable" performance, which encompasses the NIST certified value bounded by twice its uncertainty $\left(U_{95}\right)$. 


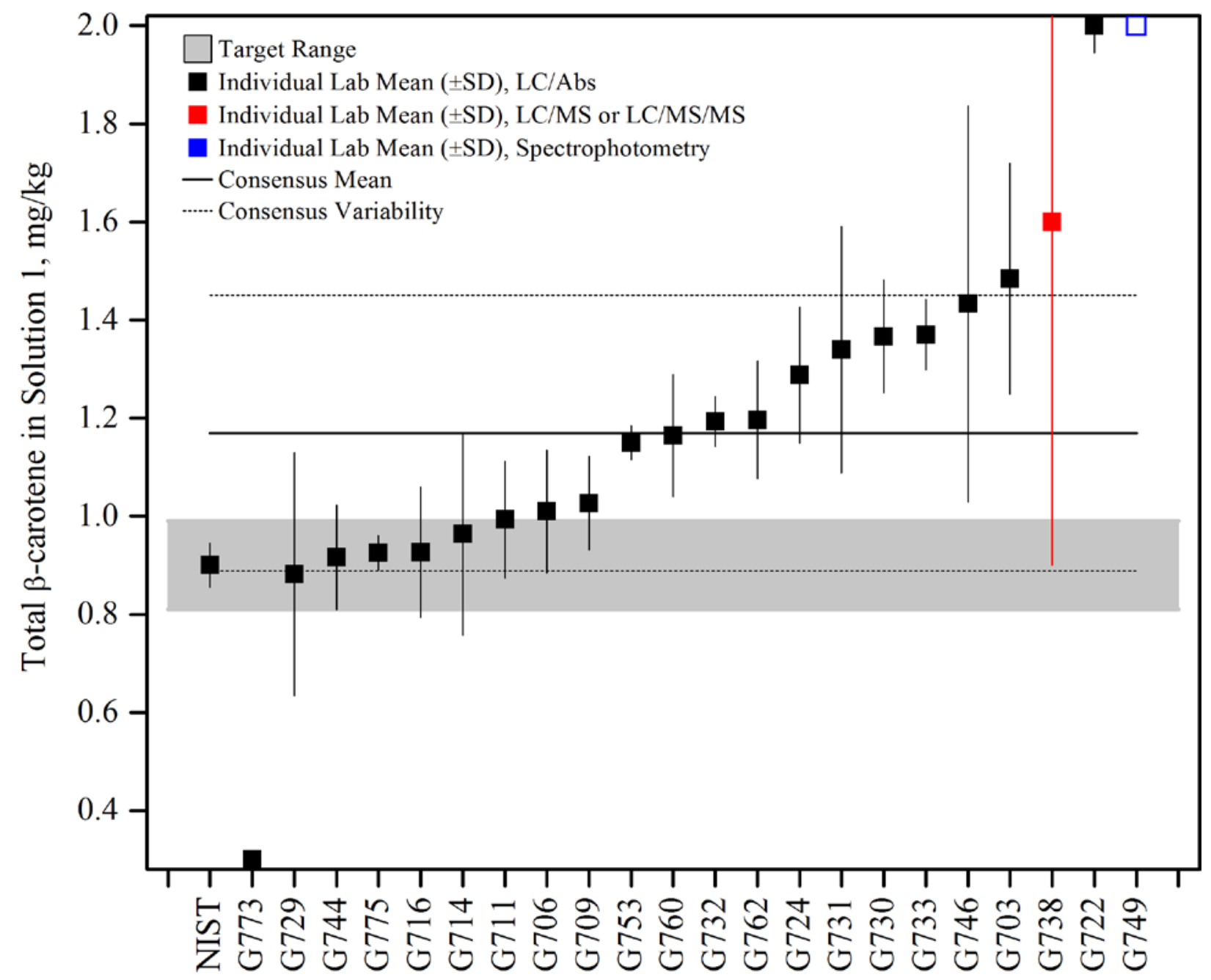

Figure 17. Total $\beta$-carotene in Solution 1 (data summary view - instrumental method). In this view, individual laboratory data are plotted with the individual laboratory standard deviation (error bars). The data are identified by instrumental method in this graph. The black solid line represents the consensus mean, and the black dotted lines represent the consensus variability calculated as one standard deviation about the consensus mean. The gray shaded region represents the target zone for "acceptable” performance, which encompasses the NIST assigned value bounded by twice its standard deviation. 


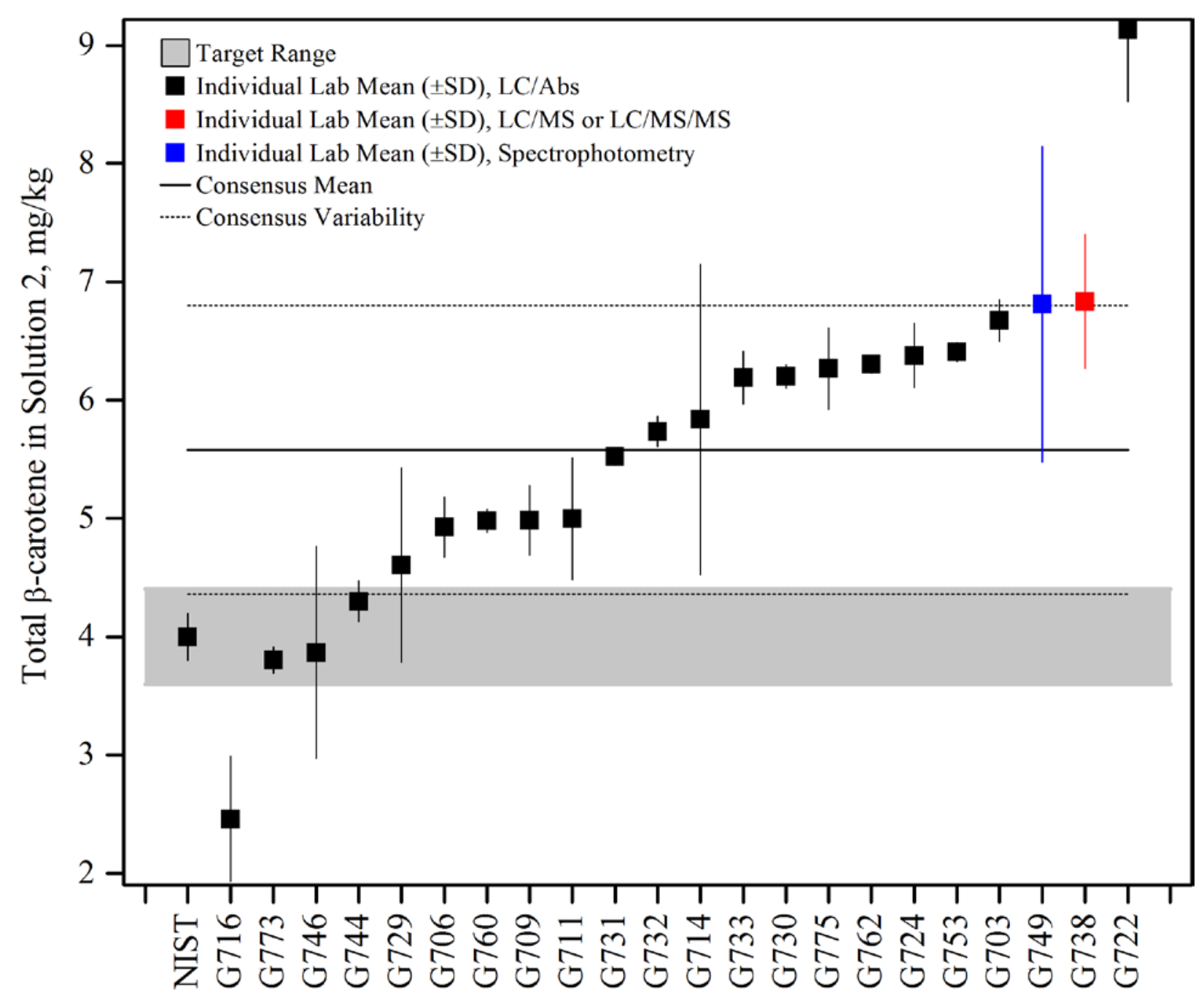

Figure 18. Total $\beta$-carotene in Solution 2 (data summary view - instrumental method). In this view, individual laboratory data are plotted with the individual laboratory standard deviation (error bars). The data are identified by instrumental method in this graph. The black solid line represents the consensus mean, and the black dotted lines represent the consensus variability calculated as one standard deviation about the consensus mean. The gray shaded region represents the target zone for "acceptable" performance, which encompasses the NIST assigned value bounded by twice its standard deviation. 


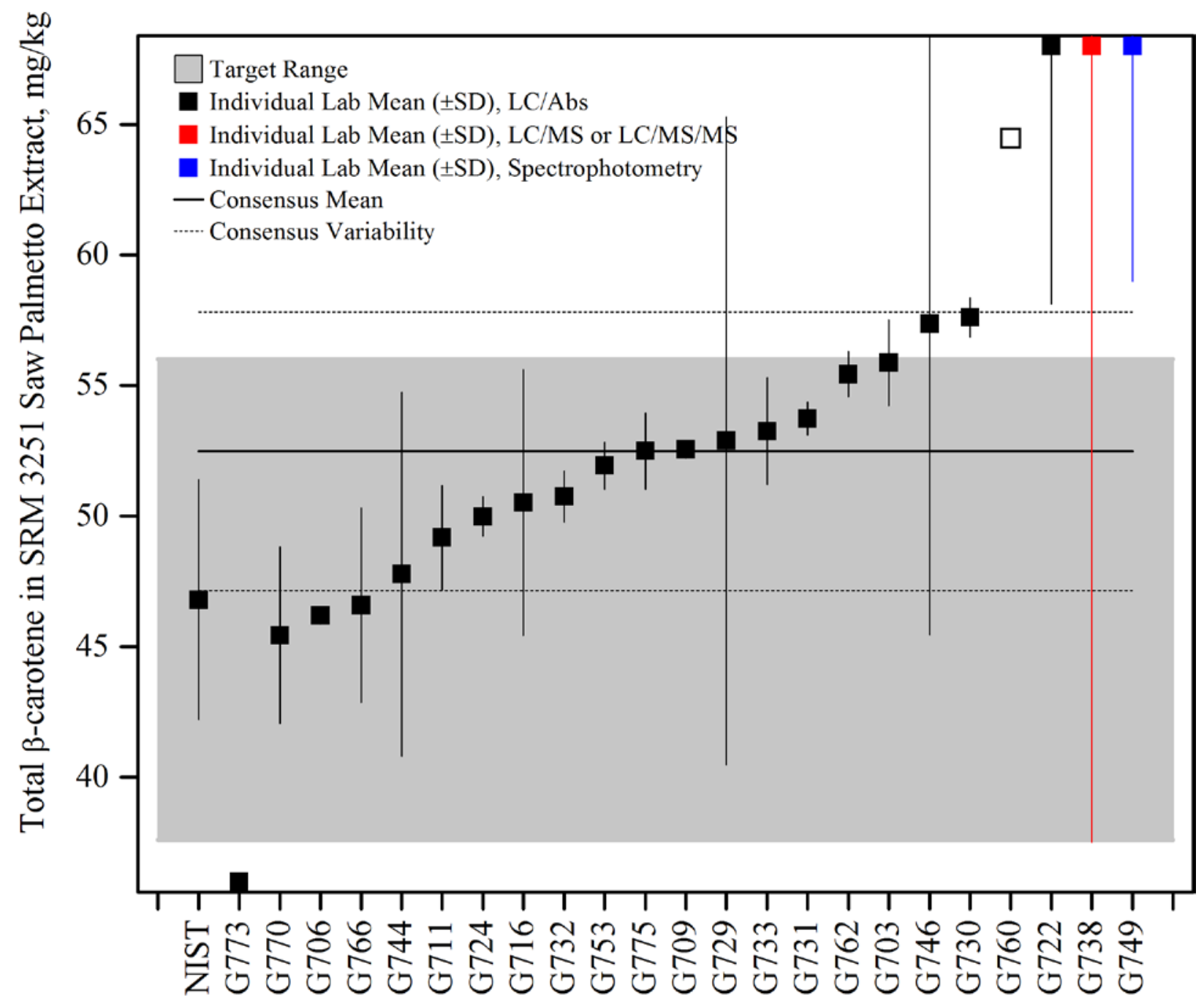

Figure 19. Total $\beta$-carotene in SRM 3251 Serenoa repens Extract (data summary view instrumental method). In this view, individual laboratory data are plotted with the individual laboratory standard deviation (error bars). The data are identified by instrumental method in this graph. The black solid line represents the consensus mean, and the black dotted lines represent the consensus variability calculated as one standard deviation about the consensus mean. The gray shaded region represents the target zone for "acceptable" performance, which encompasses the NIST certified value bounded by twice its uncertainty $\left(U_{95}\right)$. 


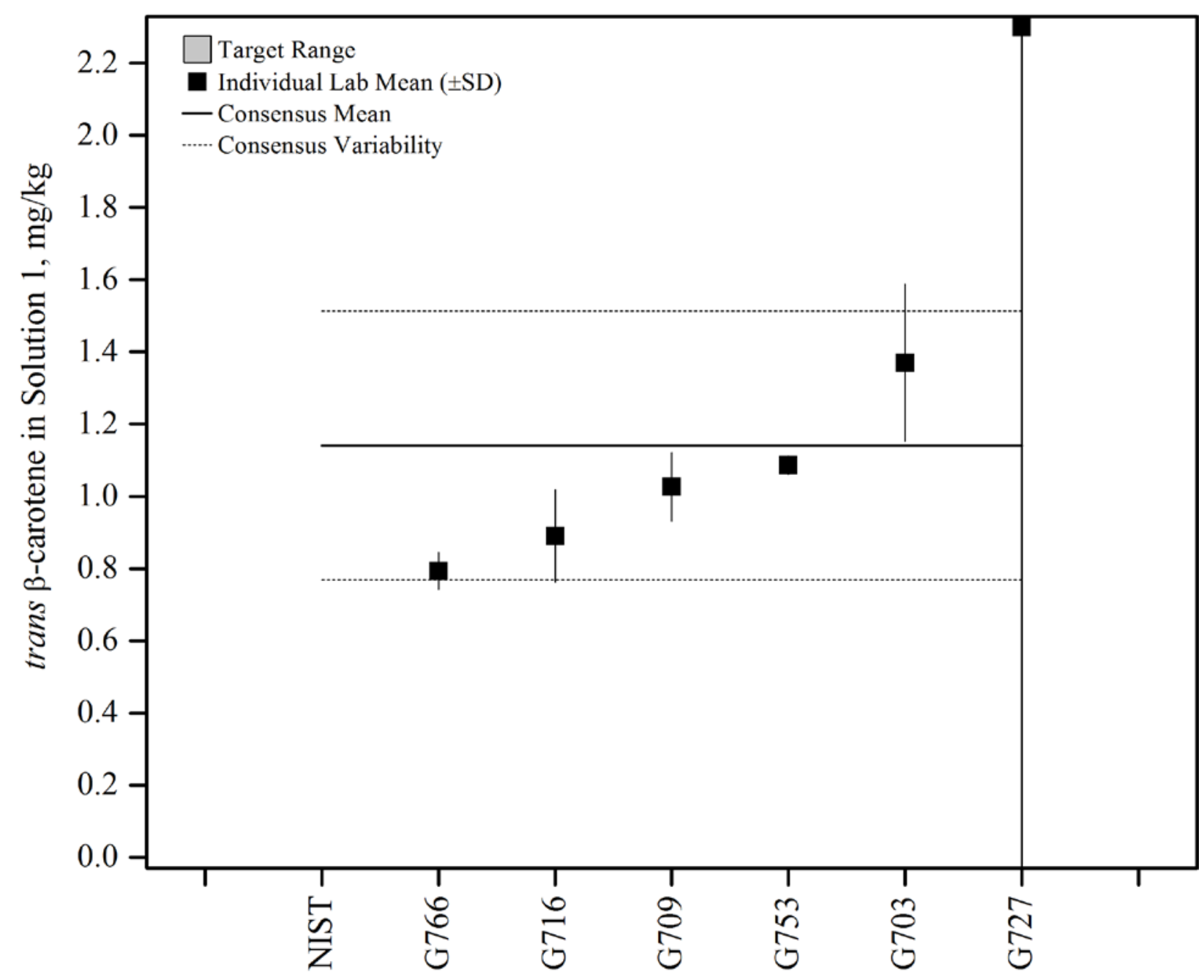

Figure 20. trans- $\beta$-carotene in Solution 1 (data summary view). In this view, individual laboratory data are plotted with the individual laboratory standard deviation (error bars). The black solid line represents the consensus mean, and the black dotted lines represent the consensus variability calculated as one standard deviation about the consensus mean. 


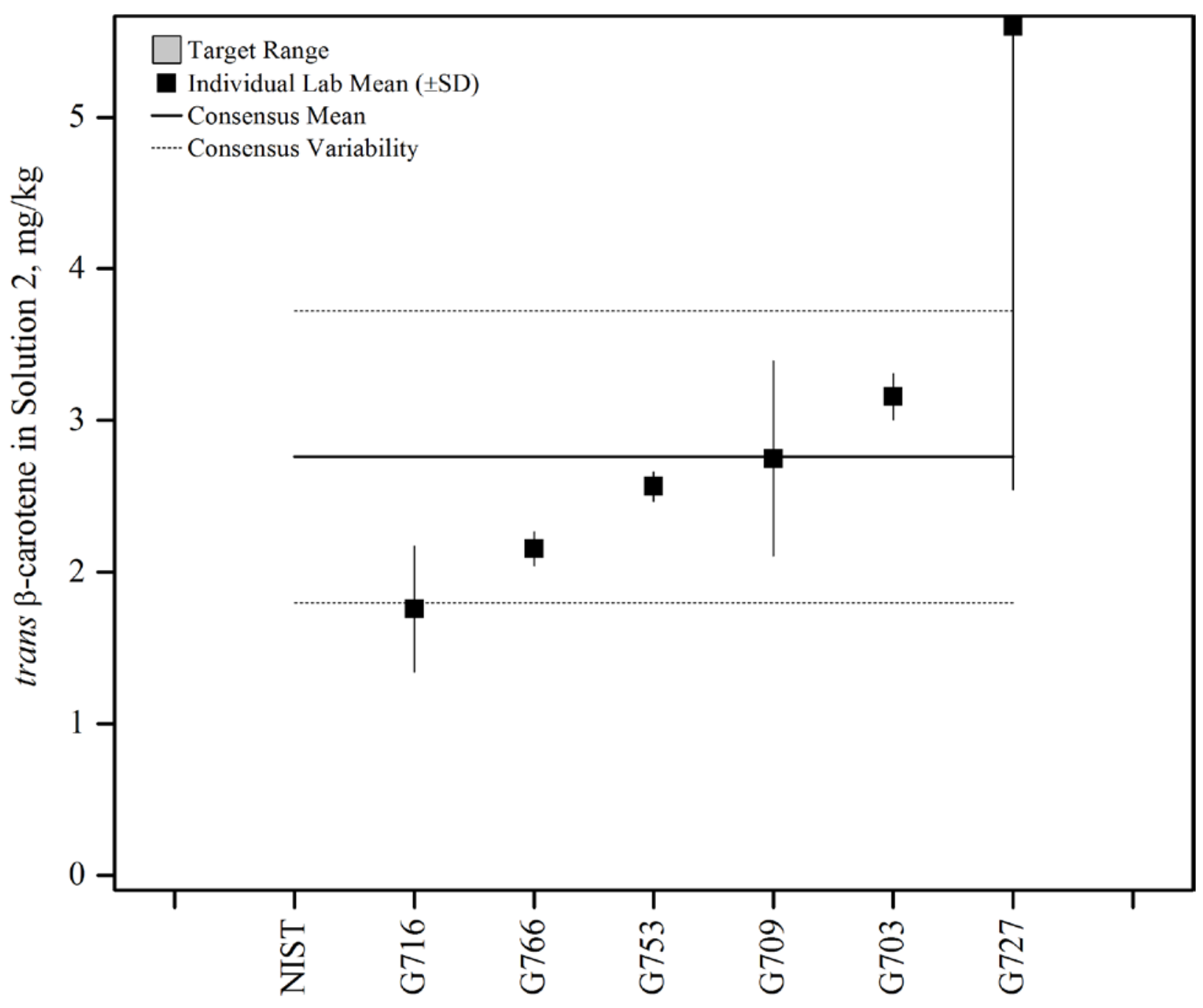

Figure 21. trans- $\beta$-carotene in Solution 2 (data summary view). In this view, individual laboratory data are plotted with the individual laboratory standard deviation (error bars). The black solid line represents the consensus mean, and the black dotted lines represent the consensus variability calculated as one standard deviation about the consensus mean. 


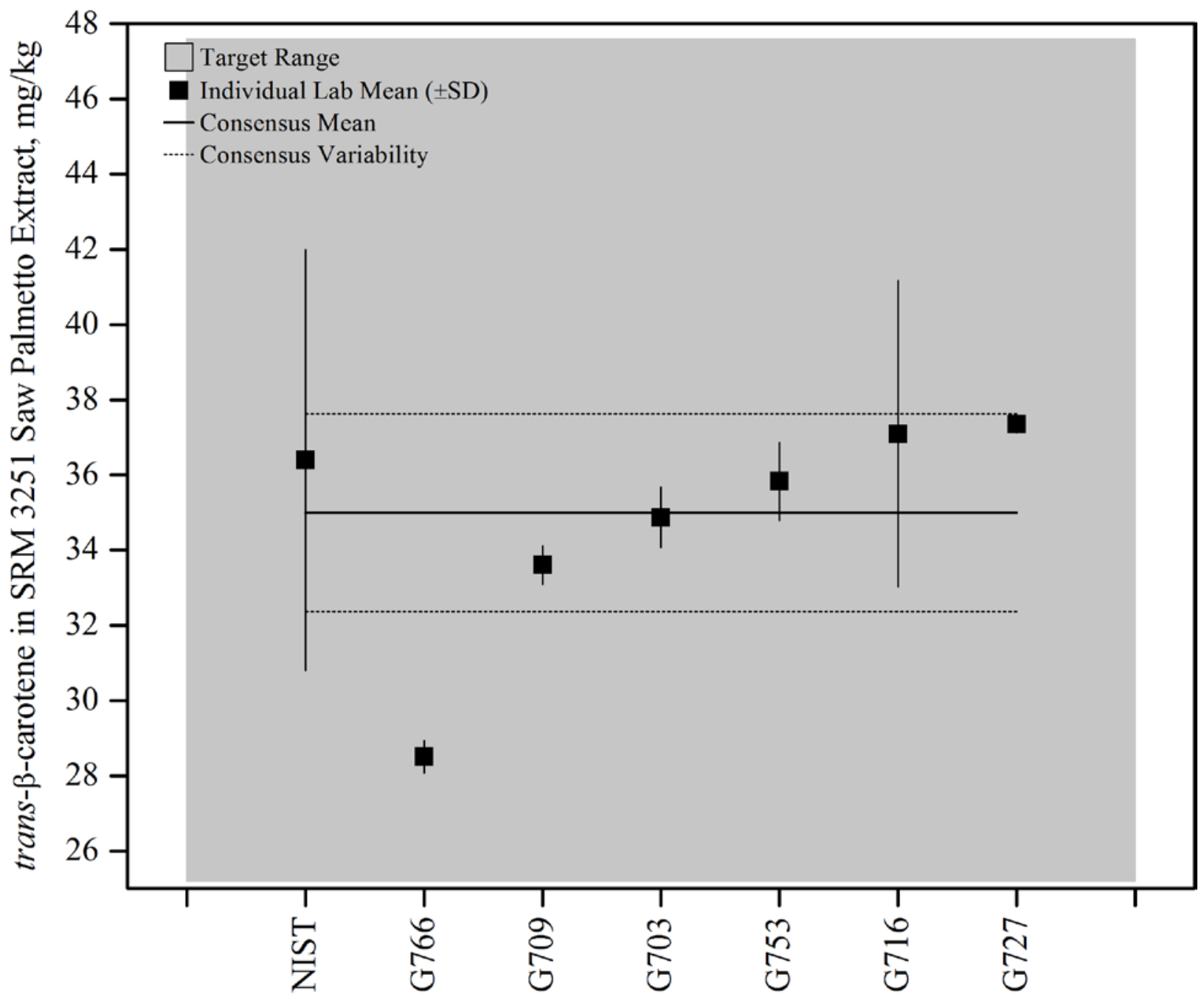

Figure 22. trans- $\beta$-carotene in SRM 3251 Serenoa repens Extract (data summary view). In this view, individual laboratory data are plotted with the individual laboratory standard deviation (error bars). The black solid line represents the consensus mean, and the black dotted lines represent the consensus variability calculated as one standard deviation about the consensus mean. The gray shaded region represents the target zone for "acceptable" performance, which encompasses the NIST certified value bounded by twice its uncertainty $\left(U_{95}\right)$. 


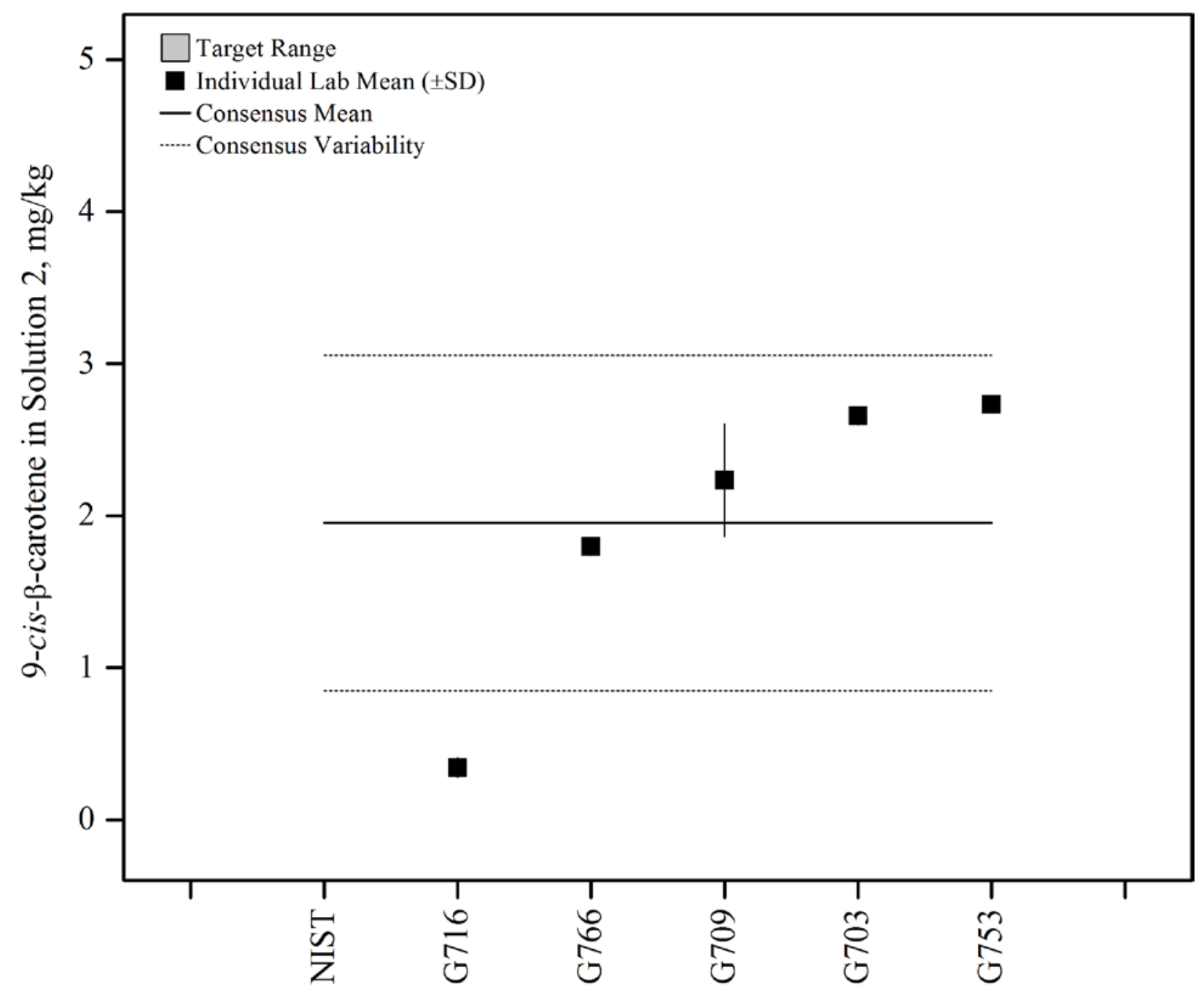

Figure 23. 9-cis- $\beta$-carotene in Solution 2 (data summary view). In this view, individual laboratory data are plotted with the individual laboratory standard deviation (error bars). The black solid line represents the consensus mean, and the black dotted lines represent the consensus variability calculated as one standard deviation about the consensus mean. 


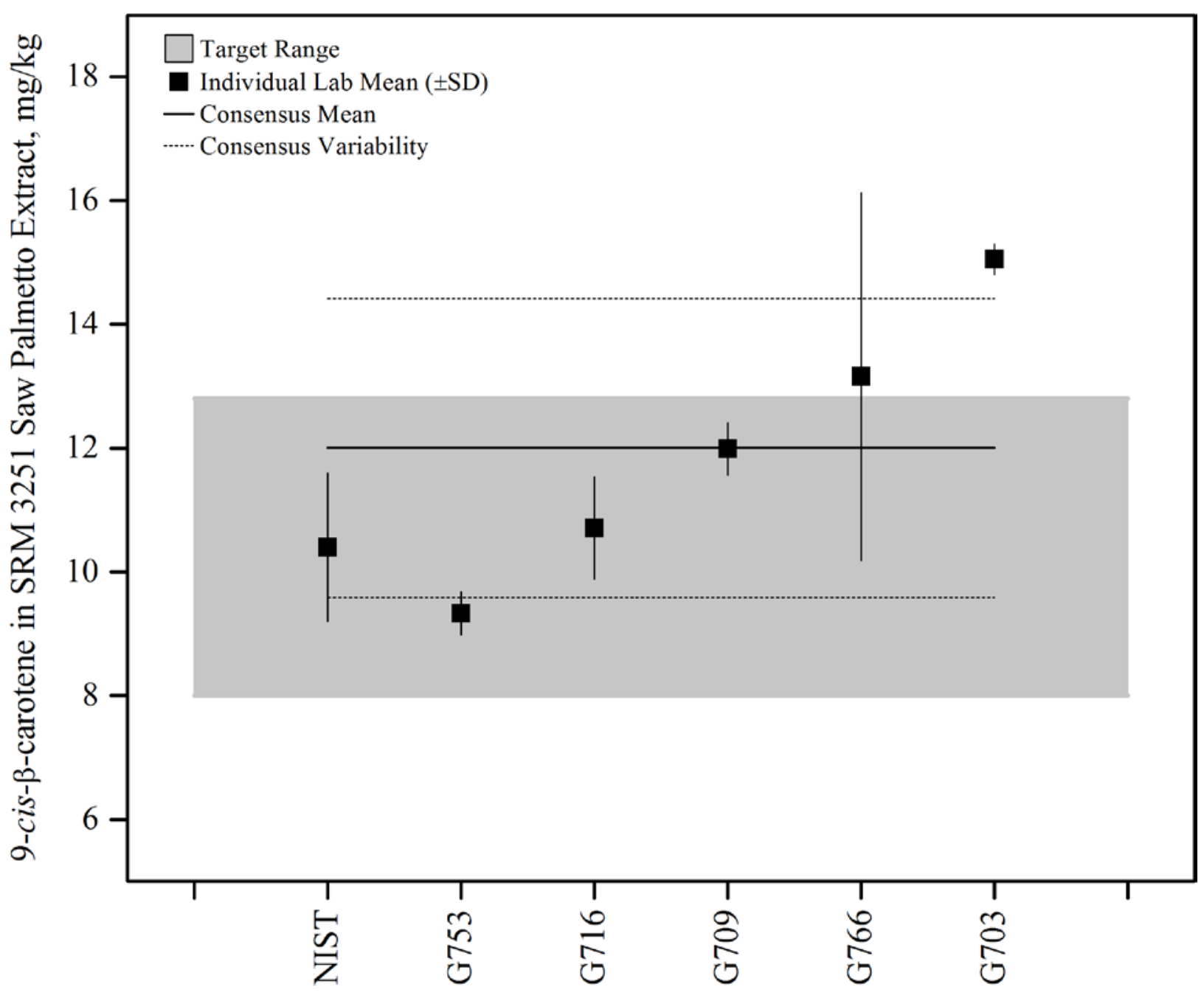

Figure 24. 9-cis-- $\beta$-carotene in SRM 3251 Serenoa repens Extract (data summary view). In this view, individual laboratory data are plotted with the individual laboratory standard deviation (error bars). The black solid line represents the consensus mean, and the black dotted lines represent the consensus variability calculated as one standard deviation about the consensus mean. The gray shaded region represents the target zone for "acceptable" performance, which encompasses the NIST certified value bounded by twice its uncertainty $\left(U_{95}\right)$. 


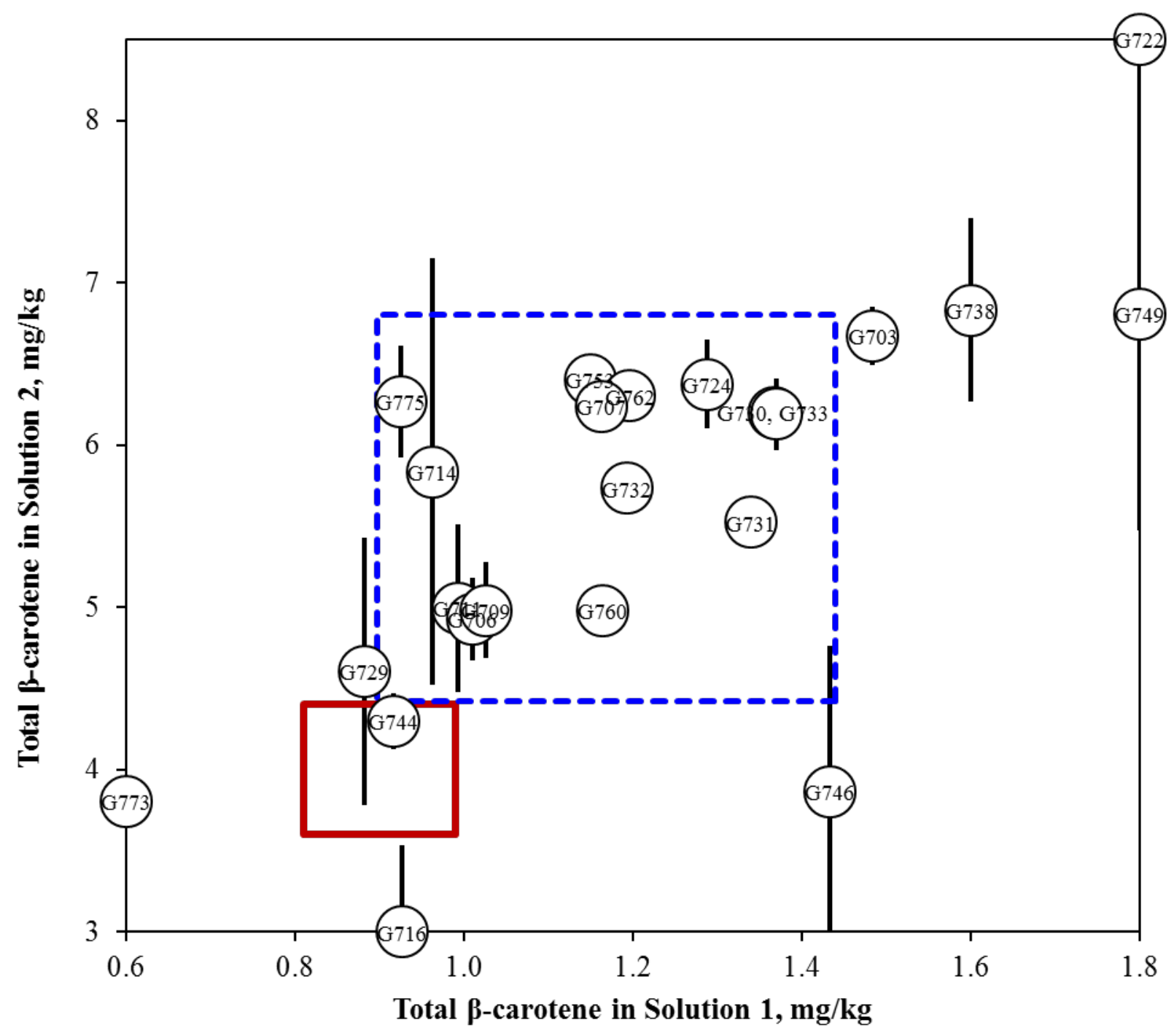

Figure 25. Total $\beta$-carotene in Solution 1 and Solution 2 (sample/sample comparison view). In this view, the individual laboratory results for one sample ( $\beta$-carotene Solution 1$)$ are compared to the results for a second sample ( $\beta$-carotene Solution 2). The solid red box represents the target zone for solution 1 (x-axis) and solution 2 (y-axis). The dotted blue box represents the consensus zone for solution 1 (x-axis) and solution 2 (y-axis). 


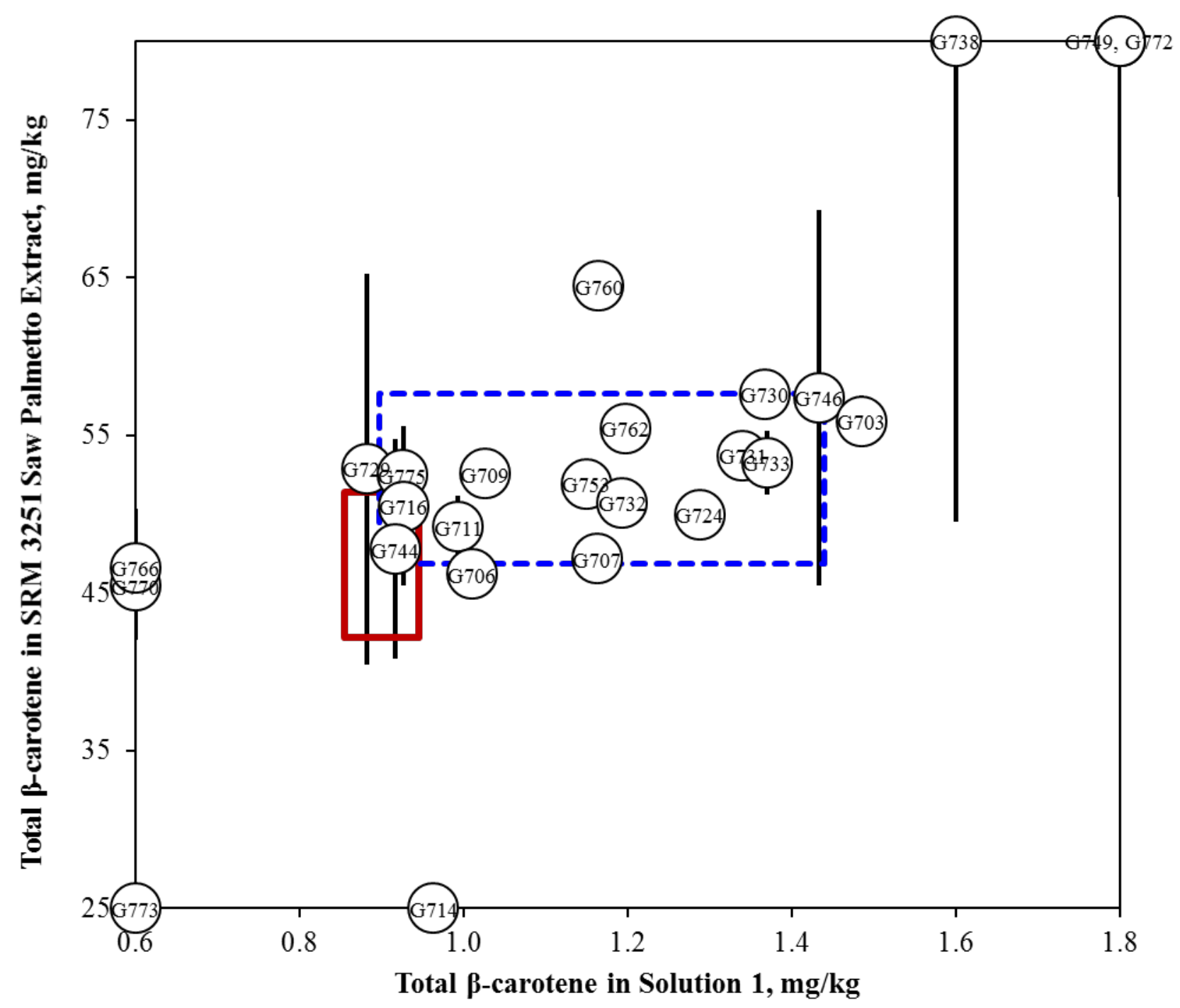

Figure 26. Total $\beta$-carotene in Solution 1 and SRM 3251 Serenoa repens Extract (sample/sample comparison view). In this view, the individual laboratory results for one sample ( $\beta$-carotene Solution 1) are compared to the results for a second sample (saw palmetto extract). The solid red box represents the target zone for solution 1 (x-axis) and saw palmetto extract (y-axis). The dotted blue box represents the consensus zone for solution 1 (x-axis) and saw palmetto extract (y-axis). 


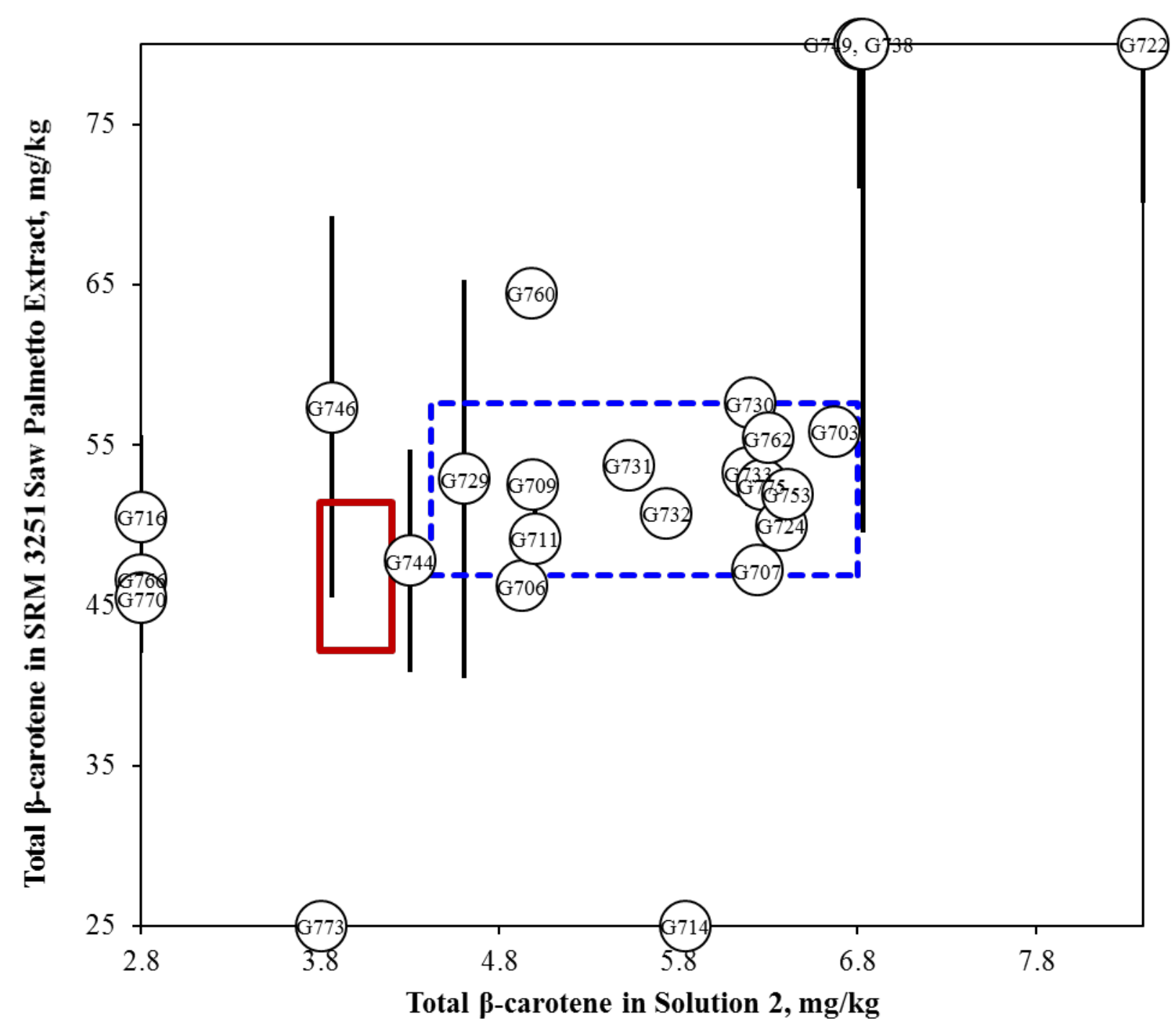

Figure 27. Total $\beta$-carotene in Solution 2 and SRM 3251 Serenoa repens Extract (sample/sample comparison view). In this view, the individual laboratory results for one sample ( $\beta$-carotene Solution 2) are compared to the results for a second sample (saw palmetto extract). The solid red box represents the target zone for solution 2 (x-axis) and saw palmetto extract (y-axis). The dotted blue box represents the consensus zone for solution 2 (x-axis) and saw palmetto extract (y-axis). 


\title{
ANTHOCYANINS \& ANTHOCYANIDINS IN DIETARY SUPPLEMENTS
}

\author{
Study Overview \\ In this study, participants were provided with two NIST SRMs, SRM 3283 Cranberry Extract and \\ SRM 3291 Bilberry Extract. Participants were asked to use in-house analytical methods to \\ determine the mass fractions of anthocyanins and/or anthocyanidins in each of the matrices and \\ report values on an as-received basis.
}

Sample Information

Cranberry Extract. Participants were provided with one packet containing approximately $2.5 \mathrm{~g}$ of cranberry extract. The cranberry extract was heat-sealed inside nitrogen-flushed 4 mil polyethylene bags, which were then sealed inside aluminized plastic bags with 2 packets of silica gel. Before use, participants were instructed to thoroughly mix the contents of the packet and use a sample size of at least $0.1 \mathrm{~g}$. Participants were asked to store the material at controlled room temperature, $20{ }^{\circ} \mathrm{C}$ to $25^{\circ} \mathrm{C}$, and to prepare three samples and report three values from the single packet provided. Prior to the study, the approximate analyte levels were given as $1.8 \mathrm{mg} / \mathrm{g}$ cyanidin, $0.1 \mathrm{mg} / \mathrm{g}$ delphinidin, and $0.7 \mathrm{mg} / \mathrm{g}$ peonidin. NIST assigned values for anthocyanins and anthocyanidins were not available at the time of this report.

Bilberry Extract. Participants were provided with one packet containing approximately $1 \mathrm{~g}$ of bilberry extract. The bilberry extract was heat-sealed inside nitrogen-flushed 4 mil polyethylene bags, which were then sealed inside aluminized plastic bags with 2 packets of silica gel. Before use, participants were instructed to thoroughly mix the contents of the packet and use a sample size of at least $0.1 \mathrm{~g}$. Participants were asked to store the material at controlled room temperature, $20{ }^{\circ} \mathrm{C}$ to $25{ }^{\circ} \mathrm{C}$, and to prepare three samples and report three values from the single packet provided. Prior to the study, the approximate analyte levels were given as $40 \mathrm{mg} / \mathrm{g}$ cyanidin, 45 mg/g delphinidin, $25 \mathrm{mg} / \mathrm{g}$ malvidin, $10 \mathrm{mg} / \mathrm{g}$ peonidin, and $15 \mathrm{mg} / \mathrm{g}$ petunidin. NIST assigned values for anthocyanins and anthocyanidins were not available at the time of this report.

\section{Study Results}

- Thirty-four laboratories enrolled in this exercise and received samples.

- Five to ten laboratories reported results for anthocyanidins in both the cranberry extract and the bilberry extract ( $21 \%$ to $38 \%$ participation). One laboratory reported a single value for anthocyanidins in both samples and was therefore excluded from calculation of summary statistics. ${ }^{2}$ Further discussion will only include studies in which at least eight laboratories reported data.

- The consensus ranges for anthocyanidins in both matrices were wide (46\% to over 100 $\%$ RSD).

- The consensus means were very low compared to the expected values reported prior to the study.

- Nine to fourteen laboratories reported results for anthocyanins in both the cranberry extract and the bilberry extract (27\% to $41 \%$ participation).

- The consensus ranges for anthocyanins in the cranberry extract ranged from acceptable (21\% RSD) to wide (29\% to over $100 \%$ RSD).

- The consensus ranges for anthocyanins in the bilberry extract ranged from acceptable (13\% to $23 \% \mathrm{RSD}$ ) to wide (38\% to $56 \% \mathrm{RSD}$ ). 
- Nineteen laboratories reported results for total anthocyanins in both the cranberry extract and the bilberry extract (56 \% participation). One laboratory reported a single value for total anthocyanins in both samples and was therefore excluded from calculation of summary statistics. ${ }^{2}$

- The consensus range for total anthocyanins in the cranberry extract was wide (38 \% RSD).

- The consensus range for total anthocyanins in the bilberry extract was acceptable (22 \% RSD).

- A majority of the laboratories reported using a solvent extraction approach (50 \%) or a shaking or sonication extraction approach (39\%). Hydrolysis was also reported as a method of sample preparation by two laboratories (11\%).

- Most laboratories reported using LC with absorbance detection as the analytical method for analysis (78 \%). Laboratories also reported using spectrophotometry (17\%) and a microbiological assay (6\%) as the instrumental approach.

- Most laboratories reported the use of an external standard approach to quantitation (89 \%), while two laboratories reported calibration against a molar absorptivity.

\section{Technical Recommendations}

The following are recommendations based on results obtained from the participants in this study.

- The wide consensus ranges for the anthocyanidins may be related to the extraction approach utilized.

- Laboratories using a hydrolysis approach were not included in the consensus calculations.

- The variability in the data could be attributed to the extraction approach. The glycosides can be broken down into the aglycones, and differences in the extraction time, temperature, or solvent used could result in increased variability in the amount of glycosides converted to aglycones.

- Many laboratories are not calibrating using reference standards for each of these compounds, and are instead using a single compound (e.g. cyanidin) for calibration of all five aglycones. If this were a major factor, the variability in the cyanidin consensus should be lower than that for the other aglycones, which was not observed.

- The wide consensus ranges for the anthocyanins may also be related to the extraction approach utilized.

- Laboratories using a hydrolysis approach were not included in the consensus calculations.

- As described above, the variability in the data could be attributed to the extraction approach. The glycosides can be broken down into the aglycones, and differences in the extraction time, temperature, or solvent used could result in increased variability in the amount of glycosides converted to aglycones.

- Many laboratories are not calibrating using reference standards for each of these compounds, and are instead using a single compound (e.g. cyanidin glucoside) or a small subset of the glycosides for calibration of all fifteen glycosides. If this were a major factor, the variability in the cyanidin consensus should be lower than that for the other aglycones, which was not observed. 
- After molar mass conversion to totals for each aglycone, the data for both hydrolysis and extraction approaches could be compared. In many cases, the consensus variability for a total aglycone was decreased compared to that for any of the other forms individually.

- The value reported for each of the three glycosides was converted to the aglycone equivalent and summed, along with the value reported for the aglycone, to give a value for total aglycone.

- The decrease in variability using this approach is further evidence in support of the theory provided above, of the differences in extraction procedure leading to increased variability. By reducing all forms to the base aglycone yields a sum that has a tighter consensus.

- Figure 73 does not reflect an obvious calibration error. Some laboratories reported values that were high for the one sample but were within range for the other sample. This type of trend may indicate individualized problems with the extraction or separation from one matrix compared to another.

- The consistency of the data is improved when all values are converted to a value for "equivalents" of each compound, and even further improved when converted to a value for total anthocyanidins.

- The degree of sample pretreatment may affect the individual compounds measured, but would affect the total less. Harsher extraction conditions (elevated temperature, high acid content, etc.) could cause increased, unintended hydrolysis. Extraction conditions should be thoroughly optimized to ensure that conversion is not occurring unintentionally during the extraction process.

- Lack of authentic standards for the large number of compounds may cause difficulties in chromatographic peak identification and quantitation. The best solution is to acquire as many standards as possible and use retention time (and $\mathrm{m} / \mathrm{z}$ ) to confirm peak identifications. Relying on literature or official methods has limitations, as variations in column chemistry, mobile phase composition, and temperature can all affect the chromatographic selectivity and therefore the retention times of all compounds. 
Table 13. Individual data table (NIST) for anthocyanins and anthocyanidins in dietary supplements.

\section{National Institute of Standards \& Technology}

\begin{tabular}{|c|c|c|c|c|c|c|}
\hline \multirow{3}{*}{ Analyte } & \multirow{3}{*}{$\begin{array}{c}\text { Lab Code: } \\
\text { Sample } \\
\end{array}$} & \multicolumn{5}{|c|}{ Exercise G - July 2011 - Anthocyanins and Anth } \\
\hline & & \multirow{2}{*}{$\begin{array}{c}\text { NIST } \\
\text { Units } \\
\end{array}$} & \multicolumn{4}{|c|}{ 1. Your Results } \\
\hline & & & Mean & $S_{\text {total }}$ & $Z_{\text {comm }}$ & $Z_{\text {NIST }}$ \\
\hline Cyanidin & Cranberry & $\mathrm{mg} / \mathrm{g}$ & & & & \\
\hline Cyanidin & Bilberry & $\mathrm{mg} / \mathrm{g}$ & & & & \\
\hline Delphinidin & Cranberry & $\mathrm{mg} / \mathrm{g}$ & & & & \\
\hline Delphinidin & Bilberry & $\mathrm{mg} / \mathrm{g}$ & & & & \\
\hline Malvidin & Cranberry & $\mathrm{mg} / \mathrm{g}$ & & & & \\
\hline Malvidin & Bilberry & $\mathrm{mg} / \mathrm{g}$ & & & & \\
\hline Peonidin & Cranberry & $\mathrm{mg} / \mathrm{g}$ & & & & \\
\hline Peonidin & Bilberry & $\mathrm{mg} / \mathrm{g}$ & & & & \\
\hline Petunidin & Cranberry & $\mathrm{mg} / \mathrm{g}$ & & & & \\
\hline Petunidin & Bilberry & $\mathrm{mg} / \mathrm{g}$ & & & & \\
\hline Cyanidin Ara & Cranberry & $\mathrm{mg} / \mathrm{g}$ & & & & \\
\hline Cyanidin Ara & Bilberry & $\mathrm{mg} / \mathrm{g}$ & & & & \\
\hline Cyanidin Gal & Cranberry & $\mathrm{mg} / \mathrm{g}$ & & & & \\
\hline Cyanidin Gal & Bilberry & $\mathrm{mg} / \mathrm{g}$ & & & & \\
\hline Cyanidin Glu & Cranberry & $\mathrm{mg} / \mathrm{g}$ & & & & \\
\hline Cyanidin Glu & Bilberry & $\mathrm{mg} / \mathrm{g}$ & & & & \\
\hline Delphinidin Ara & Cranberry & $\mathrm{mg} / \mathrm{g}$ & & & & \\
\hline Delphinidin Ara & Bilberry & $\mathrm{mg} / \mathrm{g}$ & & & & \\
\hline Delphinidin Gal & Cranberry & $\mathrm{mg} / \mathrm{g}$ & & & & \\
\hline Delphinidin Gal & Bilberry & $\mathrm{mg} / \mathrm{g}$ & & & & \\
\hline Delphinidin Glu & Cranberry & $\mathrm{mg} / \mathrm{g}$ & & & & \\
\hline Delphinidin Glu & Bilberry & $\mathrm{mg} / \mathrm{g}$ & & & & \\
\hline Malvidin Ara & Cranberry & $\mathrm{mg} / \mathrm{g}$ & & & & \\
\hline Malvidin Ara & Bilberry & $\mathrm{mg} / \mathrm{g}$ & & & & \\
\hline Malvidin Gal & Cranberry & $\mathrm{mg} / \mathrm{g}$ & & & & \\
\hline Malvidin Gal & Bilberry & $\mathrm{mg} / \mathrm{g}$ & & & & \\
\hline Malvidin Glu & Cranberry & $\mathrm{mg} / \mathrm{g}$ & & & & \\
\hline Malvidin Glu & Bilberry & $\mathrm{mg} / \mathrm{g}$ & & & & \\
\hline Peonidin Ara & Cranberry & $\mathrm{mg} / \mathrm{g}$ & & & & \\
\hline Peonidin Ara & Bilberry & $\mathrm{mg} / \mathrm{g}$ & & & & \\
\hline Peonidin Gal & Cranberry & $\mathrm{mg} / \mathrm{g}$ & & & & \\
\hline Peonidin Gal & Bilberry & $\mathrm{mg} / \mathrm{g}$ & & & & \\
\hline Peonidin Glu & Cranberry & $\mathrm{mg} / \mathrm{g}$ & & & & \\
\hline Peonidin Glu & Bilberry & $\mathrm{mg} / \mathrm{g}$ & & & & \\
\hline Petunidin Ara & Cranberry & $\mathrm{mg} / \mathrm{g}$ & & & & \\
\hline Petunidin Ara & Bilberry & $\mathrm{mg} / \mathrm{g}$ & & & & \\
\hline Petunidin Gal & Cranberry & $\mathrm{mg} / \mathrm{g}$ & & & & \\
\hline Petunidin Gal & Bilberry & $\mathrm{mg} / \mathrm{g}$ & & & & \\
\hline Petunidin Glu & Cranberry & $\mathrm{mg} / \mathrm{g}$ & & & & \\
\hline Petunidin Glu & Bilberry & $\mathrm{mg} / \mathrm{g}$ & & & & \\
\hline Total Anthocyanins & Cranberry & $\mathrm{mg} / \mathrm{g}$ & & & & \\
\hline Total Anthocyanins & Bilberry & $\mathrm{mg} / \mathrm{g}$ & & & & \\
\hline Cyanidin & Cranberry & $\mathrm{mg} / \mathrm{g}$ & & & & \\
\hline Cyanidin & Bilberry & $\mathrm{mg} / \mathrm{g}$ & & & & \\
\hline Delphinidin & Cranberry & $\mathrm{mg} / \mathrm{g}$ & & & & \\
\hline Delphinidin & Bilberry & $\mathrm{mg} / \mathrm{g}$ & & & & \\
\hline Malvidin & Cranberry & $\mathrm{mg} / \mathrm{g}$ & & & & \\
\hline Malvidin & Bilberry & $\mathrm{mg} / \mathrm{g}$ & & & & \\
\hline Peonidin & Cranberry & $\mathrm{mg} / \mathrm{g}$ & & & & \\
\hline Peonidin & Bilberry & $\mathrm{mg} / \mathrm{g}$ & & & & \\
\hline Petunidin & Cranberry & $\mathrm{mg} / \mathrm{g}$ & & & & \\
\hline Petunidin & Bilberry & $\mathrm{mg} / \mathrm{g}$ & & & & \\
\hline
\end{tabular}

\begin{tabular}{|c|c|c|}
\hline $\mathrm{N}$ & Mean & Std Dev \\
\hline 8 & 0.0859 & 0.0504 \\
\hline 12 & 3.08 & 2.68 \\
\hline 6 & 0.116 & 0.18 \\
\hline 12 & 4.23 & 4.64 \\
\hline 2 & 0.0493 & 0.0269 \\
\hline 10 & 1.11 & 0.823 \\
\hline 6 & 0.0505 & 0.0045 \\
\hline 10 & 0.669 & 0.608 \\
\hline 2 & 0.133 & 0.0589 \\
\hline 11 & 0.757 & 0.348 \\
\hline 11 & 0.198 & 0.0574 \\
\hline 14 & 29.9 & 11.3 \\
\hline 13 & 0.132 & 0.0394 \\
\hline 14 & 35.5 & 7.32 \\
\hline 8 & 0.0586 & 0.0778 \\
\hline 13 & 43.2 & 13.3 \\
\hline 2 & 0.0615 & 0.0815 \\
\hline 13 & 37.3 & 7.64 \\
\hline 3 & 0.0187 & 0.029 \\
\hline 13 & 41.9 & 6.45 \\
\hline 4 & 0.0568 & 0.0621 \\
\hline 14 & 45.8 & 7.8 \\
\hline 2 & 0.0514 & 0.0776 \\
\hline 13 & 8.19 & 3.22 \\
\hline 3 & 0.0595 & 0.0865 \\
\hline 13 & 18.4 & 8.76 \\
\hline 4 & 0.0881 & 0.0908 \\
\hline 12 & 29.7 & 13.4 \\
\hline 11 & 0.148 & 0.0479 \\
\hline 12 & 2.44 & 0.921 \\
\hline 12 & 0.201 & 0.0428 \\
\hline 14 & 5.29 & 2.96 \\
\hline 9 & 0.0467 & 0.0454 \\
\hline 13 & 17.5 & 2.96 \\
\hline 0 & & \\
\hline 12 & 10.3 & 1.31 \\
\hline 2 & 0.0993 & 0.109 \\
\hline 11 & 16.8 & 3.84 \\
\hline 4 & 0.0618 & 0.0998 \\
\hline 14 & 32.7 & 5.96 \\
\hline 18 & 0.934 & 0.358 \\
\hline 18 & 354 & 78.2 \\
\hline 15 & 0.259 & 0.103 \\
\hline 15 & 76.5 & 23.7 \\
\hline 9 & 0.134 & 0.166 \\
\hline 15 & 84.7 & 14.4 \\
\hline 8 & 0.0624 & 0.0576 \\
\hline 15 & 34.2 & 12.7 \\
\hline 15 & 0.252 & 0.118 \\
\hline 15 & 17.6 & 4.37 \\
\hline 6 & 0.0942 & 0.0979 \\
\hline 15 & 38.4 & 7.06 \\
\hline
\end{tabular}

\begin{tabular}{|c|c|}
\hline \multicolumn{2}{|c|}{ 3. Target Value } \\
\hline Value & $U_{95}$ \\
\hline NR & NR \\
\hline NR & NR \\
\hline NR & NR \\
\hline NR & NR \\
\hline NR & NR \\
\hline NR & NR \\
\hline NR & NR \\
\hline NR & NR \\
\hline NR & NR \\
\hline NR & NR \\
\hline NR & NR \\
\hline NR & NR \\
\hline NR & NR \\
\hline NR & NR \\
\hline NR & NR \\
\hline NR & NR \\
\hline NR & NR \\
\hline NR & NR \\
\hline NR & NR \\
\hline NR & NR \\
\hline NR & NR \\
\hline NR & NR \\
\hline NR & NR \\
\hline NR & NR \\
\hline NR & NR \\
\hline NR & NR \\
\hline NR & NR \\
\hline NR & NR \\
\hline NR & NR \\
\hline NR & NR \\
\hline NR & NR \\
\hline NR & NR \\
\hline NR & NR \\
\hline NR & NR \\
\hline NR & NR \\
\hline NR & NR \\
\hline NR & NR \\
\hline NR & NR \\
\hline NR & NR \\
\hline NR & NR \\
\hline NR & NR \\
\hline NR & NR \\
\hline NR & NR \\
\hline NR & NR \\
\hline NR & NR \\
\hline NR & NR \\
\hline NR & NR \\
\hline NR & NR \\
\hline NR & NR \\
\hline NR & NR \\
\hline NR & NR \\
\hline NR & NR \\
\hline
\end{tabular}

Mean Average of reported values

$S_{\text {total }}$ Standard deviation of reported values

$\mathrm{Z}_{\text {comm }}$ Z-score: (Lab Mean - Consensus Mean)/ Consensus Standard Deviation

$\mathrm{Z}_{\text {NIST }}$ Z-score: (Lab Mean - NIST Value or Label Claim) NIST or Label Claim Standard Deviation
$\mathrm{N}$ Number of quantitative values reported Mean Robust mean of the reported values Std Dev Robust standard deviation

$$
\begin{aligned}
\text { Value } & \text { NIST-assessed value } \\
U_{95} & \pm 95 \% \text { confidence interval about the } \\
& \text { assessed value }
\end{aligned}
$$

NR No data reported 
Table 14. Data summary table for cyanidin in dietary supplements.

\begin{tabular}{|c|c|c|c|c|c|c|c|c|c|c|c|}
\hline & \multirow[b]{3}{*}{ Lab } & \multicolumn{10}{|c|}{ Cyanidin } \\
\hline & & \multicolumn{10}{|c|}{ SRM 3283 Cranberry Extract (mg/g) } \\
\hline & & \multicolumn{2}{|c|}{ A $\quad$ B } & $\mathbf{C}$ & Avg & SD & A & B & $\mathrm{C}$ & Avg & SD \\
\hline \multirow{35}{*}{ 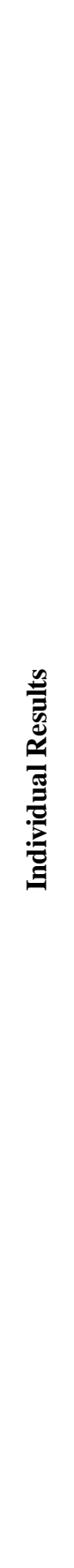 } & NIST & & & & & & & & & & \\
\hline & G701 & & & & & & & & & & \\
\hline & G702 & & & & & & & & & & \\
\hline & G703 & 0.068 & 0.067 & 0.069 & 0.068 & 0.001 & 3.33 & 3.31 & 3.36 & 3.33 & 0.03 \\
\hline & G704 & & & & & & & & & & \\
\hline & G705 & 0.039 & 0.043 & 0.038 & 0.040 & 0.003 & 25.60 & 25.40 & 25.50 & 25.50 & 0.10 \\
\hline & G707 & & & & & & & & & & \\
\hline & G708 & & & & & & & & & & \\
\hline & G715 & 0.095 & 0.098 & & 0.097 & 0.002 & 1.81 & 1.75 & & 1.78 & 0.05 \\
\hline & G716 & & & & & & & & & & \\
\hline & G717 & 0.053 & 0.051 & 0.048 & 0.050 & 0.002 & 0.25 & 0.25 & 0.25 & 0.25 & 0.00 \\
\hline & G718 & 0.060 & 0.059 & 0.057 & 0.059 & 0.002 & 0.74 & 0.64 & 0.67 & 0.68 & 0.05 \\
\hline & G722 & & & & & & & & & & \\
\hline & G724 & & & & & & & & & & \\
\hline & G728 & & & & & & 2.10 & 1.83 & 1.82 & 1.92 & 0.16 \\
\hline & G729 & & & & & & & & & & \\
\hline & G738 & & & & & & & & & & \\
\hline & G739 & & & & & & & & & & \\
\hline & G740 & & & & & & & & & & \\
\hline & G749 & & & & & & & & & & \\
\hline & G752 & & & & & & & & & & \\
\hline & G753 & & & & & & & & & & \\
\hline & G757 & & & & & & & & & & \\
\hline & G760 & & & & & & & & & & \\
\hline & G762 & 0.126 & 0.128 & 0.126 & 0.127 & 0.001 & 3.88 & 3.60 & 3.41 & 3.63 & 0.24 \\
\hline & G765 & & & & & & 1.26 & 1.20 & 1.30 & 1.25 & 0.05 \\
\hline & G766 & & & & & & & & & & \\
\hline & G767 & & & & & & & & & & \\
\hline & G771 & & & & & & & & & & \\
\hline & G772 & & & & & & & & & & \\
\hline & G773 & & & & & & 4.73 & 4.86 & 4.47 & 4.69 & 0.20 \\
\hline & G774 & & & & & & & & & & \\
\hline & G775 & & & & & & 2.22 & 2.23 & 2.28 & 2.25 & 0.03 \\
\hline & G776 & & & & & & & & & & \\
\hline & G777 & 0.173 & 0.169 & 0.172 & 0.171 & 0.002 & 48.45 & 48.35 & 48.58 & 48.46 & 0.11 \\
\hline \multirow{5}{*}{ 忌 } & & \multirow{5}{*}{\multicolumn{3}{|c|}{$\begin{array}{l}\text { Consensus Mean } \\
\text { Consensus Standard Deviation } \\
\text { Maximum } \\
\text { Minimum } \\
\mathrm{N}\end{array}$}} & \multicolumn{2}{|l|}{0.0859} & \multirow{4}{*}{\multicolumn{3}{|c|}{$\begin{array}{l}\text { Consensus Mean } \\
\text { Consensus Standard Deviation } \\
\text { Maximum } \\
\text { Minimum }\end{array}$}} & 3.08 & \\
\hline & & & & & 0.0504 & & & & & 2.68 & \\
\hline & & & & & 0.1713 & & & & & 48.46 & \\
\hline & & & & & 0.0402 & & & & & 0.25 & \\
\hline & & & & & 8 & & $\mathrm{~N}$ & & & 12 & \\
\hline
\end{tabular}


Table 15. Data summary table for cyanidin-3-arabinoside in dietary supplements.

\begin{tabular}{|c|c|c|c|c|c|c|c|c|c|c|c|}
\hline & \multirow[b]{3}{*}{ Lab } & \multicolumn{10}{|c|}{ Cyanidin-3-Arabinoside } \\
\hline & & \multicolumn{5}{|c|}{ SRM 3283 Cranberry Extract (mg/g) } & \multicolumn{5}{|c|}{ SRM 3291 Bilberry Extract (mg/g) } \\
\hline & & A & B & C & Avg & SD & A & B & C & Avg & SD \\
\hline \multirow{35}{*}{ 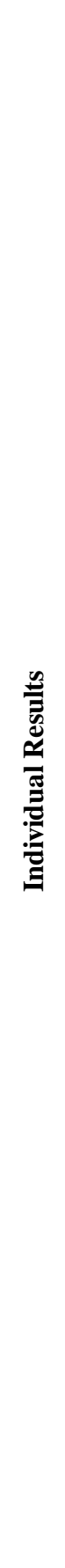 } & NIST & & & & & & & & & & \\
\hline & G701 & 0.150 & 0.160 & 0.160 & 0.157 & 0.006 & 53.2 & 53.1 & 48.4 & 51.6 & 2.7 \\
\hline & G702 & & & & & & & & & & \\
\hline & G703 & 0.134 & 0.132 & 0.133 & 0.133 & 0.001 & 20.0 & 20.3 & 20.3 & 20.2 & 0.2 \\
\hline & G704 & & & & & & & & & & \\
\hline & G705 & 0.157 & 0.175 & 0.154 & 0.162 & 0.011 & 42.8 & 42.5 & 42.5 & 42.6 & 0.2 \\
\hline & G707 & & & & & & & & & & \\
\hline & G708 & 0.217 & 0.211 & 0.217 & 0.215 & 0.003 & 26.7 & 26.5 & 26.6 & 26.6 & 0.1 \\
\hline & G715 & & & & & & 20.9 & 19.5 & & 20.2 & 0.9 \\
\hline & G716 & & & & & & & & & & \\
\hline & G717 & 0.210 & 0.211 & 0.215 & 0.212 & 0.003 & 21.5 & 20.9 & 19.3 & 20.6 & 1.2 \\
\hline & G718 & 0.235 & 0.236 & 0.235 & 0.235 & 0.001 & 25.2 & 24.2 & 25.1 & 24.8 & 0.6 \\
\hline & G722 & & & & & & & & & & \\
\hline & G724 & & & & & & & & & & \\
\hline & G728 & 0.362 & 0.283 & 0.369 & 0.338 & 0.048 & 34.5 & 39.0 & 32.7 & 35.4 & 3.2 \\
\hline & G729 & & & & & & & & & & \\
\hline & G738 & & & & & & & & & & \\
\hline & G739 & & & & & & & & & & \\
\hline & G740 & & & & & & & & & & \\
\hline & G749 & & & & & & & & & & \\
\hline & G752 & & & & & & & & & & \\
\hline & G753 & & & & & & & & & & \\
\hline & G757 & & & & & & & & & & \\
\hline & G760 & & & & & & & & & & \\
\hline & G762 & 0.162 & 0.175 & 0.171 & 0.169 & 0.007 & 28.5 & 28.4 & 26.0 & 27.6 & 1.4 \\
\hline & G765 & 0.231 & 0.237 & 0.253 & 0.240 & 0.011 & 43.7 & 41.9 & 42.5 & 42.7 & 0.9 \\
\hline & G766 & 0.242 & 0.240 & 0.228 & 0.237 & 0.008 & 27.5 & 26.6 & 26.7 & 26.9 & 0.5 \\
\hline & G767 & & & & & & & & & & \\
\hline & G771 & & & & & & & & & & \\
\hline & G772 & & & & & & & & & & \\
\hline & G773 & & 0.130 & 0.130 & 0.130 & 0.000 & 19.7 & 19.7 & 17.5 & 19.0 & 1.3 \\
\hline & G774 & & & & & & & & & & \\
\hline & G775 & & & & & & 23.0 & 23.0 & 23.0 & 23.0 & 0.0 \\
\hline & G776 & & & & & & & & & & \\
\hline & G777 & & & & & & 42.3 & 42.4 & 42.3 & 42.3 & 0.1 \\
\hline \multirow{5}{*}{ 竭 } & & \multicolumn{3}{|c|}{ Consensus Mean } & \multicolumn{2}{|l|}{0.198} & \multicolumn{3}{|c|}{ Consensus Mean } & 29.9 & \\
\hline & & \multicolumn{3}{|c|}{ Consensus Standard Deviation } & \multicolumn{2}{|l|}{0.057} & \multicolumn{3}{|c|}{ Consensus Standard Deviation } & 11.3 & \\
\hline & & \multicolumn{3}{|c|}{ Maximum } & \multicolumn{2}{|l|}{0.338} & \multicolumn{3}{|c|}{ Maximum } & 51.6 & \\
\hline & & \multicolumn{3}{|c|}{ Minimum } & \multicolumn{2}{|l|}{0.130} & \multicolumn{3}{|c|}{ Minimum } & 19.0 & \\
\hline & & \multicolumn{3}{|l|}{$\mathrm{N}$} & 11 & & $\mathrm{~N}$ & & & 14 & \\
\hline
\end{tabular}


Table 16. Data summary table for cyanidin-3-galactoside in dietary supplements.

\begin{tabular}{|c|c|c|c|c|c|c|c|c|c|c|c|}
\hline & \multirow[b]{3}{*}{ Lab } & \multicolumn{10}{|c|}{ Cyanidin-3-Galactoside } \\
\hline & & \multicolumn{5}{|c|}{ SRM 3283 Cranberry Extract (mg/g) } & \multicolumn{5}{|c|}{ SRM 3291 Bilberry Extract (mg/g) } \\
\hline & & A & B & C & Avg & SD & A & B & C & Avg & SD \\
\hline \multirow{35}{*}{ 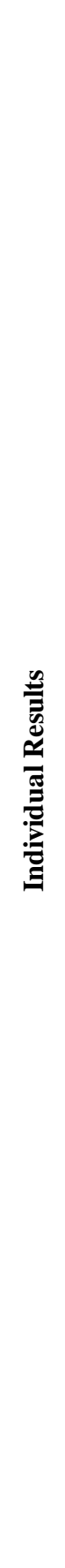 } & NIST & & & & & & & & & & \\
\hline & G701 & 0.090 & 0.087 & 0.090 & 0.089 & 0.002 & 58.9 & 50.5 & 48.1 & 52.5 & 5.7 \\
\hline & G702 & & & & & & & & & & \\
\hline & G703 & 0.099 & 0.099 & 0.097 & 0.098 & 0.001 & 27.5 & 27.9 & 27.6 & 27.7 & 0.2 \\
\hline & G704 & & & & & & & & & & \\
\hline & G705 & 0.022 & 0.024 & 0.020 & 0.022 & 0.002 & 36.8 & 36.4 & 36.3 & 36.5 & 0.3 \\
\hline & G707 & & & & & & & & & & \\
\hline & G708 & 0.149 & 0.150 & 0.155 & 0.151 & 0.003 & 26.3 & 27.1 & 27.0 & 26.8 & 0.4 \\
\hline & G715 & 0.140 & 0.148 & & 0.144 & 0.006 & 35.0 & 35.0 & & 35.0 & 0.0 \\
\hline & G716 & & & & & & & & & & \\
\hline & G717 & 0.149 & 0.144 & 0.145 & 0.146 & 0.002 & 34.3 & 34.0 & 33.7 & 34.0 & 0.3 \\
\hline & G718 & 0.152 & 0.159 & 0.159 & 0.157 & 0.004 & 34.3 & 33.2 & 34.5 & 34.0 & 0.7 \\
\hline & G722 & & & & & & & & & & \\
\hline & G724 & & & & & & & & & & \\
\hline & G728 & 0.207 & 0.164 & 0.189 & 0.187 & 0.022 & 43.8 & 42.9 & 44.6 & 43.7 & 0.9 \\
\hline & G729 & & & & & & & & & & \\
\hline & G738 & & & & & & & & & & \\
\hline & G739 & & & & & & & & & & \\
\hline & G740 & & & & & & & & & & \\
\hline & G749 & & & & & & & & & & \\
\hline & G752 & & & & & & & & & & \\
\hline & G753 & & & & & & & & & & \\
\hline & G757 & & & & & & & & & & \\
\hline & G760 & & & & & & & & & & \\
\hline & G762 & 0.110 & 0.113 & 0.111 & 0.111 & 0.002 & 37.4 & 37.2 & 34.4 & 36.3 & 1.7 \\
\hline & G765 & 0.155 & 0.159 & 0.178 & 0.164 & 0.012 & 58.5 & 55.8 & 56.7 & 57.0 & 1.4 \\
\hline & G766 & 0.173 & 0.152 & 0.156 & 0.160 & 0.011 & 38.1 & 37.7 & 37.8 & 37.9 & 0.2 \\
\hline & G767 & & & & & & & & & & \\
\hline & G771 & & & & & & & & & & \\
\hline & G772 & & & & & & & & & & \\
\hline & G773 & 0.130 & 0.140 & 0.160 & 0.143 & 0.015 & 27.3 & 28.3 & 25.4 & 27.0 & 1.5 \\
\hline & G774 & & & & & & & & & & \\
\hline & G775 & & & & & & 31.1 & 31.1 & 31.1 & 31.1 & 0.0 \\
\hline & G776 & & & & & & & & & & \\
\hline & G777 & 0.094 & 0.092 & 0.096 & 0.094 & 0.002 & 34.7 & 34.9 & 34.8 & 34.8 & 0.1 \\
\hline \multirow{5}{*}{ 竭 } & & \multicolumn{3}{|c|}{ Consensus Mean } & \multicolumn{2}{|l|}{0.132} & \multicolumn{2}{|c|}{ Consensus Mean } & & 35.5 & \\
\hline & & \multicolumn{3}{|c|}{ Consensus Standard Deviation } & \multicolumn{2}{|l|}{0.039} & \multicolumn{3}{|c|}{ Consensus Standard Deviation } & 7.3 & \\
\hline & & \multicolumn{3}{|c|}{ Maximum } & \multicolumn{2}{|l|}{0.187} & \multicolumn{3}{|l|}{ Maximu } & 57.0 & \\
\hline & & \multicolumn{3}{|c|}{ Minimum } & \multicolumn{2}{|l|}{0.022} & \multicolumn{3}{|c|}{ Minimum } & 26.8 & \\
\hline & & \multicolumn{3}{|l|}{$\mathrm{N}$} & 13 & & $\mathrm{~N}$ & & & 14 & \\
\hline
\end{tabular}


Table 17. Data summary table for cyanidin-3-glucoside in dietary supplements.

\begin{tabular}{|c|c|c|c|c|c|c|c|c|c|c|c|}
\hline & \multirow[b]{3}{*}{ Lab } & \multicolumn{10}{|c|}{ Cyanidin-3-Glucoside } \\
\hline & & \multicolumn{5}{|c|}{ SRM 3283 Cranberry Extract (mg/g) } & \multicolumn{5}{|c|}{ SRM 3291 Bilberry Extract (mg/g) } \\
\hline & & A & B & C & Avg & SD & A & B & C & Avg & SD \\
\hline \multirow{35}{*}{ 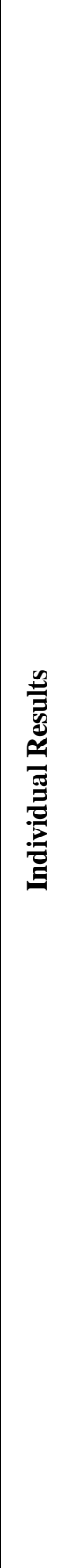 } & NIST & & & & & & & & & & \\
\hline & G701 & 0.0086 & 0.0062 & 0.0068 & 0.0072 & 0.0012 & 93.4 & 83.5 & 88.0 & 88.3 & 4.9 \\
\hline & G702 & & & & & & & & & & \\
\hline & G703 & 0.0136 & & & 0.0136 & & 31.1 & 31.5 & 31.5 & 31.4 & 0.2 \\
\hline & G704 & & & & & & & & & & \\
\hline & G705 & & & & & & & & & & \\
\hline & G707 & & & & & & & & & & \\
\hline & G708 & 0.0102 & 0.0100 & 0.0100 & 0.0101 & 0.0001 & 38.6 & 38.4 & 38.5 & 38.5 & 0.1 \\
\hline & G715 & & & & & & 38.0 & 37.8 & & 37.9 & 0.1 \\
\hline & G716 & & & & & & & & & & \\
\hline & G717 & 0.0111 & 0.0108 & 0.0116 & 0.0112 & 0.0004 & 38.1 & 37.6 & 37.3 & 37.7 & 0.4 \\
\hline & G718 & 0.1110 & 0.1110 & 0.0930 & 0.1050 & 0.0104 & 93.1 & 90.0 & 93.3 & 92.1 & 1.9 \\
\hline & G722 & & & & & & & & & & \\
\hline & G724 & & & & & & & & & & \\
\hline & G728 & & & & & & 47.2 & 46.0 & 48.3 & 47.2 & 1.1 \\
\hline & G729 & & & & & & & & & & \\
\hline & G738 & & & & & & & & & & \\
\hline & G739 & & & & & & & & & & \\
\hline & G740 & & & & & & & & & & \\
\hline & G749 & & & & & & & & & & \\
\hline & G752 & & & & & & & & & & \\
\hline & G753 & & & & & & & & & & \\
\hline & G757 & & & & & & & & & & \\
\hline & G760 & & & & & & & & & & \\
\hline & G762 & 0.0064 & 0.0068 & 0.0080 & 0.0071 & 0.0008 & 40.9 & 40.8 & 37.7 & 39.8 & 1.8 \\
\hline & G765 & 0.0180 & 0.0180 & 0.0160 & 0.0173 & 0.0012 & 62.8 & 60.1 & 60.7 & 61.2 & 1.4 \\
\hline & G766 & & & & & & 42.0 & 41.0 & 41.1 & 41.4 & 0.5 \\
\hline & G767 & & & & & & & & & & \\
\hline & G771 & & & & & & & & & & \\
\hline & G772 & & & & & & & & & & \\
\hline & G773 & & & & & & 30.3 & 30.2 & 27.2 & 29.2 & 1.8 \\
\hline & G774 & & & & & & & & & & \\
\hline & G775 & 0.1711 & 0.1740 & 0.1643 & 0.1698 & 0.0050 & 33.9 & 34.0 & 34.0 & 34.0 & 0.1 \\
\hline & G776 & & & & & & & & & & \\
\hline & G777 & 0.1400 & 0.1390 & 0.1440 & 0.1410 & 0.0026 & 38.1 & 38.2 & 38.2 & 38.2 & 0.0 \\
\hline \multirow{5}{*}{ 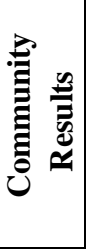 } & & \multicolumn{3}{|c|}{ Consensus Mean } & \multicolumn{2}{|l|}{0.0586} & \multicolumn{3}{|c|}{ Consensus Mean } & 43.2 & \\
\hline & & \multicolumn{3}{|c|}{ Consensus Standard Deviation } & \multicolumn{2}{|l|}{0.0778} & \multicolumn{3}{|c|}{ Consensus Standard Deviation } & 13.3 & \\
\hline & & \multicolumn{3}{|c|}{ Maximum } & \multicolumn{2}{|l|}{0.1698} & \multicolumn{3}{|c|}{ Maximum } & 92.1 & \\
\hline & & \multicolumn{3}{|l|}{ Minimum } & \multicolumn{2}{|l|}{0.0071} & \multicolumn{3}{|c|}{ Minimum } & 29.2 & \\
\hline & & \multicolumn{3}{|l|}{$\mathrm{N}$} & 8 & & $\mathrm{~N}$ & & & 13 & \\
\hline
\end{tabular}


Table 18. Data summary table for cyanidin equivalents in dietary supplements.

\begin{tabular}{|c|c|c|c|c|c|c|c|c|c|c|c|}
\hline & \multirow[b]{3}{*}{ Lab } & \multicolumn{10}{|c|}{ Cyanidin Equivalents } \\
\hline & & \multicolumn{5}{|c|}{ SRM 3283 Cranberry Extract (mg/g) } & \multicolumn{5}{|c|}{ SRM 3291 Bilberry Extract (mg/g) } \\
\hline & & A & B & C & Avg & SD & A & B & C & Avg & SD \\
\hline \multirow{35}{*}{ 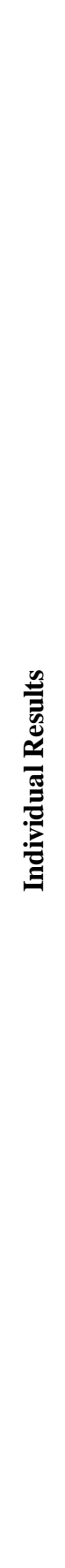 } & NIST & & & & & & & & & & \\
\hline & G701 & 0.166 & 0.169 & 0.171 & 0.169 & 0.003 & 133.7 & 122.0 & 120.1 & 125.3 & 7.4 \\
\hline & G702 & & & & & & & & & & \\
\hline & G703 & 0.232 & 0.221 & 0.222 & 0.225 & 0.006 & 54.5 & 55.2 & 55.0 & 54.9 & 0.4 \\
\hline & G704 & & & & & & & & & & \\
\hline & G705 & 0.161 & 0.179 & 0.156 & 0.165 & 0.012 & 78.4 & 77.8 & 77.8 & 78.0 & 0.4 \\
\hline & G707 & & & & & & & & & & \\
\hline & G708 & 0.250 & 0.247 & 0.254 & 0.250 & 0.004 & 59.8 & 60.0 & 60.1 & 60.0 & 0.2 \\
\hline & G715 & 0.184 & 0.193 & & 0.189 & 0.006 & 62.7 & 61.7 & & 62.2 & 0.8 \\
\hline & G716 & & & & & & & & & & \\
\hline & G717 & 0.299 & 0.294 & 0.295 & 0.296 & 0.002 & 61.3 & 60.3 & 58.8 & 60.1 & 1.2 \\
\hline & G718 & 0.389 & 0.393 & 0.379 & 0.387 & 0.007 & 99.4 & 95.9 & 99.6 & 98.3 & 2.1 \\
\hline & G722 & & & & & & & & & & \\
\hline & G724 & & & & & & & & & & \\
\hline & G728 & 0.380 & 0.299 & 0.374 & 0.351 & 0.045 & 83.9 & 85.3 & 83.6 & 84.3 & 0.9 \\
\hline & G729 & & & & & & & & & & \\
\hline & G738 & 0.297 & & & 0.297 & & 34.5 & & & 34.5 & \\
\hline & G739 & & & & & & & & & & \\
\hline & G740 & & & & & & & & & & \\
\hline & G749 & & & & & & & & & & \\
\hline & G752 & & & & & & & & & & \\
\hline & G753 & & & & & & & & & & \\
\hline & G757 & & & & & & & & & & \\
\hline & G760 & & & & & & & & & & \\
\hline & G762 & 0.311 & 0.325 & 0.319 & 0.318 & 0.007 & 73.5 & 72.9 & 67.3 & 71.2 & 3.4 \\
\hline & G765 & 0.269 & 0.275 & 0.297 & 0.281 & 0.015 & 108.7 & 104.0 & 105.4 & 106.1 & 2.4 \\
\hline & G766 & 0.276 & 0.262 & 0.256 & 0.265 & 0.011 & 70.0 & 68.5 & 68.7 & 69.1 & 0.8 \\
\hline & G767 & & & & & & & & & & \\
\hline & G771 & & & & & & & & & & \\
\hline & G772 & 1.174 & 1.172 & 1.133 & 1.160 & 0.023 & 64.2 & 67.5 & 67.7 & 66.5 & 2.0 \\
\hline & G773 & 0.083 & 0.179 & 0.191 & 0.151 & 0.059 & 55.0 & 55.7 & 50.1 & 53.6 & 3.1 \\
\hline & G774 & & & & & & & & & & \\
\hline & G775 & 0.109 & 0.111 & 0.105 & 0.109 & 0.003 & 59.5 & 59.6 & 59.7 & 59.6 & 0.1 \\
\hline & G776 & & & & & & & & & & \\
\hline & G777 & 0.323 & 0.317 & 0.325 & 0.322 & 0.004 & 124.0 & 124.1 & 124.2 & 124.1 & 0.1 \\
\hline \multirow{5}{*}{ 竭 } & & \multicolumn{3}{|c|}{ Consensus Mean } & \multicolumn{2}{|l|}{0.259} & \multicolumn{3}{|c|}{ Consensus Mean } & 76.5 & \\
\hline & & \multicolumn{3}{|c|}{ Consensus Standard Deviation } & \multicolumn{2}{|l|}{0.103} & \multicolumn{3}{|c|}{ Consensus Standard Deviation } & 23.7 & \\
\hline & & \multicolumn{3}{|c|}{ Maximum } & \multicolumn{2}{|l|}{1.160} & \multicolumn{3}{|c|}{ Maximum } & 125.3 & \\
\hline & & \multicolumn{3}{|c|}{ Minimum } & \multicolumn{2}{|l|}{0.109} & \multicolumn{3}{|c|}{ Minimum } & 34.5 & \\
\hline & & \multicolumn{3}{|l|}{$\mathrm{N}$} & 15 & & $\mathrm{~N}$ & & & 15 & \\
\hline
\end{tabular}


Table 19. Data summary table for delphinidin in dietary supplements.

\begin{tabular}{|c|c|c|c|c|c|c|c|c|c|c|c|}
\hline & \multirow[b]{3}{*}{ Lab } & \multicolumn{10}{|c|}{ Delphinidin } \\
\hline & & \multicolumn{5}{|c|}{ SRM 3283 Cranberry Extract (mg/g) } & \multicolumn{5}{|c|}{ SRM 3291 Bilberry Extract (mg/g) } \\
\hline & & A & B & C & Avg & SD & A & B & C & Avg & SD \\
\hline \multirow{35}{*}{ 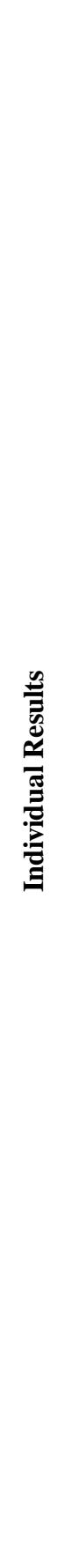 } & NIST & & & & & & & & & & \\
\hline & G701 & & & & & & & & & & \\
\hline & G702 & & & & & & & & & & \\
\hline & G703 & 0.011 & 0.015 & & 0.013 & 0.003 & 4.50 & 4.39 & 4.48 & 4.46 & 0.06 \\
\hline & G704 & & & & & & & & & & \\
\hline & G705 & & & & & & 4.08 & 3.36 & 3.29 & 3.58 & 0.44 \\
\hline & G707 & & & & & & & & & & \\
\hline & G708 & & & & & & & & & & \\
\hline & G715 & & & & & & 0.63 & 1.33 & & 0.98 & 0.49 \\
\hline & G716 & & & & & & & & & & \\
\hline & G717 & 0.007 & 0.007 & 0.006 & 0.007 & 0.000 & 0.91 & 0.83 & 0.92 & 0.89 & 0.05 \\
\hline & G718 & & & & & & 0.97 & 0.92 & 0.96 & 0.95 & 0.03 \\
\hline & G722 & & & & & & & & & & \\
\hline & G724 & & & & & & & & & & \\
\hline & G728 & & & & & & 1.17 & 1.21 & 1.23 & 1.20 & 0.03 \\
\hline & G729 & & & & & & & & & & \\
\hline & G738 & & & & & & & & & & \\
\hline & G739 & & & & & & & & & & \\
\hline & G740 & & & & & & & & & & \\
\hline & G749 & & & & & & & & & & \\
\hline & G752 & & & & & & & & & & \\
\hline & G753 & & & & & & & & & & \\
\hline & G757 & & & & & & & & & & \\
\hline & G760 & & & & & & & & & & \\
\hline & G762 & 0.038 & 0.039 & 0.037 & 0.038 & 0.001 & 3.38 & 3.54 & 3.12 & 3.35 & 0.21 \\
\hline & G765 & & & & & & 0.47 & 0.43 & 0.45 & 0.45 & 0.02 \\
\hline & G766 & & & & & & & & & & \\
\hline & G767 & & & & & & & & & & \\
\hline & G771 & & & & & & & & & & \\
\hline & G772 & & & & & & & & & & \\
\hline & G773 & 0.150 & 0.130 & & 0.140 & 0.014 & 10.30 & 10.60 & 7.98 & 9.63 & 1.43 \\
\hline & G774 & & & & & & & & & & \\
\hline & G775 & & & & & & 2.92 & 3.00 & 3.01 & 2.97 & 0.05 \\
\hline & G776 & & & & & & & & & & \\
\hline & G777 & 0.557 & 0.547 & 0.573 & 0.559 & 0.013 & 17.37 & 17.36 & 17.20 & 17.31 & 0.10 \\
\hline \multirow{5}{*}{ 龍 } & & \multicolumn{3}{|c|}{ Consensus Mean } & \multicolumn{2}{|l|}{0.116} & \multicolumn{3}{|c|}{ Consensus Mean } & 4.23 & \\
\hline & & \multicolumn{3}{|c|}{ Consensus Standard Deviation } & \multicolumn{2}{|l|}{0.180} & \multicolumn{3}{|c|}{ Consensus Standard Deviation } & 4.64 & \\
\hline & & \multicolumn{3}{|c|}{ Maximum } & \multicolumn{2}{|l|}{0.559} & \multicolumn{3}{|c|}{ Maximum } & 17.31 & \\
\hline & & \multicolumn{3}{|c|}{ Minimum } & \multicolumn{2}{|l|}{0.007} & \multicolumn{3}{|c|}{ Minimum } & 0.45 & \\
\hline & & \multicolumn{3}{|l|}{$\mathrm{N}$} & 6 & & $\mathrm{~N}$ & & & 12 & \\
\hline
\end{tabular}


Table 20. Data summary table for delphinidin-3-arabinoside in dietary supplements.

\begin{tabular}{|c|c|c|c|c|c|c|c|c|c|c|c|}
\hline & \multirow[b]{3}{*}{ Lab } & \multicolumn{10}{|c|}{ Cyanidin Equivalents } \\
\hline & & \multicolumn{5}{|c|}{ SRM 3283 Cranberry Extract (mg/g) } & \multicolumn{5}{|c|}{ SRM 3291 Bilberry Extract (mg/g) } \\
\hline & & A & B & C & Avg & SD & A & B & C & Avg & SD \\
\hline \multirow{35}{*}{ 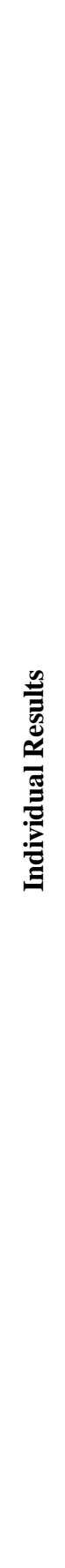 } & NIST & & & & & & & & & & \\
\hline & G701 & 0.166 & 0.169 & 0.171 & 0.169 & 0.003 & 133.7 & 122.0 & 120.1 & 125.3 & 7.4 \\
\hline & G702 & & & & & & & & & & \\
\hline & G703 & 0.232 & 0.221 & 0.222 & 0.225 & 0.006 & 54.5 & 55.2 & 55.0 & 54.9 & 0.4 \\
\hline & G704 & & & & & & & & & & \\
\hline & G705 & 0.161 & 0.179 & 0.156 & 0.165 & 0.012 & 78.4 & 77.8 & 77.8 & 78.0 & 0.4 \\
\hline & G707 & & & & & & & & & & \\
\hline & G708 & 0.250 & 0.247 & 0.254 & 0.250 & 0.004 & 59.8 & 60.0 & 60.1 & 60.0 & 0.2 \\
\hline & G715 & 0.184 & 0.193 & & 0.189 & 0.006 & 62.7 & 61.7 & & 62.2 & 0.8 \\
\hline & G716 & & & & & & & & & & \\
\hline & G717 & 0.299 & 0.294 & 0.295 & 0.296 & 0.002 & 61.3 & 60.3 & 58.8 & 60.1 & 1.2 \\
\hline & G718 & 0.389 & 0.393 & 0.379 & 0.387 & 0.007 & 99.4 & 95.9 & 99.6 & 98.3 & 2.1 \\
\hline & G722 & & & & & & & & & & \\
\hline & G724 & & & & & & & & & & \\
\hline & G728 & 0.380 & 0.299 & 0.374 & 0.351 & 0.045 & 83.9 & 85.3 & 83.6 & 84.3 & 0.9 \\
\hline & G729 & & & & & & & & & & \\
\hline & G738 & 0.297 & & & 0.297 & & 34.5 & & & 34.5 & \\
\hline & G739 & & & & & & & & & & \\
\hline & G740 & & & & & & & & & & \\
\hline & G749 & & & & & & & & & & \\
\hline & G752 & & & & & & & & & & \\
\hline & G753 & & & & & & & & & & \\
\hline & G757 & & & & & & & & & & \\
\hline & G760 & & & & & & & & & & \\
\hline & G762 & 0.311 & 0.325 & 0.319 & 0.318 & 0.007 & 73.5 & 72.9 & 67.3 & 71.2 & 3.4 \\
\hline & G765 & 0.269 & 0.275 & 0.297 & 0.281 & 0.015 & 108.7 & 104.0 & 105.4 & 106.1 & 2.4 \\
\hline & G766 & 0.276 & 0.262 & 0.256 & 0.265 & 0.011 & 70.0 & 68.5 & 68.7 & 69.1 & 0.8 \\
\hline & G767 & & & & & & & & & & \\
\hline & G771 & & & & & & & & & & \\
\hline & G772 & 1.174 & 1.172 & 1.133 & 1.160 & 0.023 & 64.2 & 67.5 & 67.7 & 66.5 & 2.0 \\
\hline & G773 & 0.083 & 0.179 & 0.191 & 0.151 & 0.059 & 55.0 & 55.7 & 50.1 & 53.6 & 3.1 \\
\hline & G774 & & & & & & & & & & \\
\hline & G775 & 0.109 & 0.111 & 0.105 & 0.109 & 0.003 & 59.5 & 59.6 & 59.7 & 59.6 & 0.1 \\
\hline & G776 & & & & & & & & & & \\
\hline & G777 & 0.323 & 0.317 & 0.325 & 0.322 & 0.004 & 124.0 & 124.1 & 124.2 & 124.1 & 0.1 \\
\hline \multirow{5}{*}{ 竭 } & & \multicolumn{3}{|c|}{ Consensus Mean } & \multicolumn{2}{|l|}{0.259} & \multicolumn{3}{|c|}{ Consensus Mean } & 76.5 & \\
\hline & & \multicolumn{3}{|c|}{ Consensus Standard Deviation } & \multicolumn{2}{|l|}{0.103} & \multicolumn{3}{|c|}{ Consensus Standard Deviation } & 23.7 & \\
\hline & & \multicolumn{3}{|c|}{ Maximum } & \multicolumn{2}{|l|}{1.160} & \multicolumn{3}{|c|}{ Maximum } & 125.3 & \\
\hline & & \multicolumn{3}{|c|}{ Minimum } & \multicolumn{2}{|l|}{0.109} & \multicolumn{3}{|c|}{ Minimum } & 34.5 & \\
\hline & & \multicolumn{3}{|l|}{$\mathrm{N}$} & 15 & & $\mathrm{~N}$ & & & 15 & \\
\hline
\end{tabular}


Table 21. Data summary table for delphinidin-3-galactoside in dietary supplements.

\begin{tabular}{|c|c|c|c|c|c|c|c|c|c|c|c|}
\hline & \multirow[b]{3}{*}{ Lab } & \multicolumn{10}{|c|}{ Delphinidin-3-Galactoside } \\
\hline & & \multicolumn{5}{|c|}{ SRM 3283 Cranberry Extract (mg/g) } & \multicolumn{5}{|c|}{ SRM 3291 Bilberry Extract (mg/g) } \\
\hline & & A & B & $\mathrm{C}$ & Avg & SD & A & $\mathbf{B}$ & $\mathrm{C}$ & Avg & SD \\
\hline \multirow{35}{*}{ 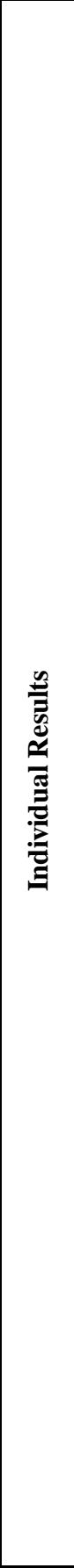 } & NIST & & & & & & & & & & \\
\hline & G701 & & & & & & & & & & \\
\hline & G702 & & & & & & & & & & \\
\hline & G703 & & & & & & 35.2 & 35.7 & 35.6 & 35.5 & 0.3 \\
\hline & G704 & & & & & & & & & & \\
\hline & G705 & & & & & & 47.5 & 47.0 & 47.2 & 47.2 & 0.3 \\
\hline & G707 & & & & & & & & & & \\
\hline & G708 & & & & & & 43.6 & 43.6 & 43.7 & 43.6 & 0.1 \\
\hline & G715 & & & & & & 42.2 & 42.5 & & 42.4 & 0.2 \\
\hline & G716 & & & & & & & & & & \\
\hline & G717 & & & & & & 44.4 & 43.9 & 43.6 & 44.0 & 0.4 \\
\hline & G718 & & & & & & 42.7 & 41.4 & 43.0 & 42.3 & 0.9 \\
\hline & G722 & & & & & & & & & & \\
\hline & G724 & & & & & & & & & & \\
\hline & G728 & & & & & & 48.7 & 47.7 & 48.3 & 48.2 & 0.5 \\
\hline & G729 & & & & & & & & & & \\
\hline & G738 & & & & & & & & & & \\
\hline & G739 & & & & & & & & & & \\
\hline & G740 & & & & & & & & & & \\
\hline & G749 & & & & & & & & & & \\
\hline & G752 & & & & & & & & & & \\
\hline & G753 & & & & & & & & & & \\
\hline & G757 & & & & & & & & & & \\
\hline & G760 & & & & & & & & & & \\
\hline & G762 & 0.0020 & 0.0069 & 0.0030 & 0.0040 & 0.0026 & 45.1 & 45.3 & 41.6 & 44.0 & 2.1 \\
\hline & G765 & & & & & & 61.1 & 58.4 & 59.2 & 59.6 & 1.4 \\
\hline & G766 & & & & & & 31.0 & 30.9 & 31.0 & 30.9 & 0.1 \\
\hline & G767 & & & & & & & & & & \\
\hline & G771 & & & & & & & & & & \\
\hline & G772 & & & & & & & & & & \\
\hline & G773 & & & & & & 34.7 & 34.8 & 31.4 & 33.6 & 1.9 \\
\hline & G774 & & & & & & & & & & \\
\hline & G775 & 0.0488 & 0.0495 & 0.0464 & 0.0482 & 0.0016 & 38.0 & 38.3 & 38.3 & 38.2 & 0.2 \\
\hline & G776 & & & & & & & & & & \\
\hline & G777 & 0.0040 & 0.0040 & 0.0040 & 0.0040 & 0.0000 & 42.1 & 42.1 & 42.1 & 42.1 & 0.0 \\
\hline \multirow{5}{*}{ 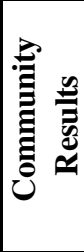 } & & \multicolumn{3}{|c|}{ Consensus Mean } & \multicolumn{2}{|l|}{0.0187} & \multicolumn{2}{|c|}{ Consensus Mean } & & 41.9 & \\
\hline & & \multicolumn{3}{|c|}{ Consensus Standard Deviation } & \multicolumn{2}{|l|}{0.0290} & \multicolumn{3}{|c|}{ Consensus Standard Deviation } & 6.4 & \\
\hline & & \multicolumn{3}{|c|}{ Maximum } & \multicolumn{2}{|l|}{0.0482} & \multicolumn{3}{|c|}{ Maximum } & 59.6 & \\
\hline & & \multicolumn{3}{|l|}{ Minimum } & \multicolumn{2}{|l|}{0.0040} & \multicolumn{3}{|c|}{ Minimum } & 30.9 & \\
\hline & & $\mathrm{N}$ & & & 3 & & $\mathrm{~N}$ & & & 13 & \\
\hline
\end{tabular}


Table 22. Data summary table for delphinidin-3-glucoside in dietary supplements.

\begin{tabular}{|c|c|c|c|c|c|c|c|c|c|c|c|}
\hline & \multirow[b]{3}{*}{ Lab } & \multicolumn{10}{|c|}{ Delphinidin-3-Glucoside } \\
\hline & & \multicolumn{5}{|c|}{ SRM 3283 Cranberry Extract (mg/g) } & \multicolumn{5}{|c|}{ SRM 3291 Bilberry Extract (mg/g) } \\
\hline & & A & B & C & Avg & SD & A & B & C & Avg & SD \\
\hline \multirow{35}{*}{ 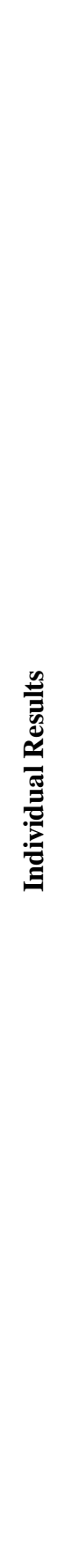 } & NIST & & & & & & & & & & \\
\hline & G701 & & & & & & 64.7 & 52.3 & 53.2 & 56.7 & 6.9 \\
\hline & G702 & & & & & & & & & & \\
\hline & G703 & & & & & & 38.1 & 38.6 & 38.6 & 38.4 & 0.3 \\
\hline & G704 & & & & & & & & & & \\
\hline & G705 & & & & & & 50.9 & 50.5 & 50.6 & 50.7 & 0.2 \\
\hline & G707 & & & & & & & & & & \\
\hline & G708 & & & & & & 46.5 & 46.2 & 46.5 & 46.4 & 0.2 \\
\hline & G715 & & & & & & 45.2 & 45.2 & & 45.2 & 0.0 \\
\hline & G716 & & & & & & & & & & \\
\hline & G717 & & & & & & 47.0 & 46.4 & 46.2 & 46.5 & 0.4 \\
\hline & G718 & 0.0530 & 0.0510 & 0.0570 & 0.0537 & 0.0031 & 45.7 & 44.2 & 45.9 & 45.2 & 0.9 \\
\hline & G722 & & & & & & & & & & \\
\hline & G724 & & & & & & & & & & \\
\hline & G728 & & & & & & 52.2 & 51.1 & 51.3 & 51.5 & 0.6 \\
\hline & G729 & & & & & & & & & & \\
\hline & G738 & & & & & & & & & & \\
\hline & G739 & & & & & & & & & & \\
\hline & G740 & & & & & & & & & & \\
\hline & G749 & & & & & & & & & & \\
\hline & G752 & & & & & & & & & & \\
\hline & G753 & & & & & & & & & & \\
\hline & G757 & & & & & & & & & & \\
\hline & G760 & & & & & & & & & & \\
\hline & G762 & 0.0242 & 0.0202 & 0.0198 & 0.0214 & 0.0024 & 48.3 & 48.4 & 44.5 & 47.1 & 2.2 \\
\hline & G765 & & & & & & 64.7 & 61.8 & 62.7 & 63.1 & 1.5 \\
\hline & G766 & & & & & & 33.1 & 32.8 & 33.0 & 33.0 & 0.1 \\
\hline & G767 & & & & & & & & & & \\
\hline & G771 & & & & & & & & & & \\
\hline & G772 & & & & & & & & & & \\
\hline & G773 & & & & & & 36.7 & 36.9 & 33.4 & 35.7 & 2.0 \\
\hline & G774 & & & & & & & & & & \\
\hline & G775 & 0.1363 & 0.1370 & 0.1324 & 0.1352 & 0.0025 & 40.3 & 40.7 & 40.7 & 40.6 & 0.2 \\
\hline & G776 & & & & & & & & & & \\
\hline & G777 & 0.0170 & 0.0160 & 0.0180 & 0.0170 & 0.0010 & 44.9 & 45.1 & 45.1 & 45.1 & 0.1 \\
\hline \multirow{5}{*}{ 龍 } & & \multicolumn{3}{|c|}{ Consensus Mean } & \multicolumn{2}{|l|}{0.0568} & \multicolumn{2}{|c|}{ Consensus Mean } & & 45.8 & \\
\hline & & \multicolumn{3}{|c|}{ Consensus Standard Deviation } & \multicolumn{2}{|l|}{0.0621} & \multicolumn{4}{|c|}{ Consensus Standard Deviation $\quad 7.8$} & \\
\hline & & \multicolumn{3}{|c|}{ Maximum } & \multicolumn{2}{|l|}{0.1352} & \multicolumn{3}{|c|}{ Maximum } & 63.1 & \\
\hline & & \multicolumn{3}{|c|}{ Minimum } & \multicolumn{2}{|l|}{0.0170} & \multicolumn{3}{|c|}{ Minimum } & 33.0 & \\
\hline & & \multicolumn{3}{|l|}{$\mathrm{N}$} & 4 & & $\mathrm{~N}$ & & & 14 & \\
\hline
\end{tabular}


Table 23. Data summary table for delphinidin equivalents in dietary supplements.

\begin{tabular}{|c|c|c|c|c|c|c|c|c|c|c|c|}
\hline & \multirow[b]{3}{*}{ Lab } & \multicolumn{10}{|c|}{ Delphinidin Equivalents } \\
\hline & & \multicolumn{5}{|c|}{ SRM 3283 Cranberry Extract (mg/g) } & \multicolumn{5}{|c|}{ SRM 3291 Bilberry Extract (mg/g) } \\
\hline & & A & B & C & Avg & SD & A & B & C & Avg & SD \\
\hline \multirow{35}{*}{ 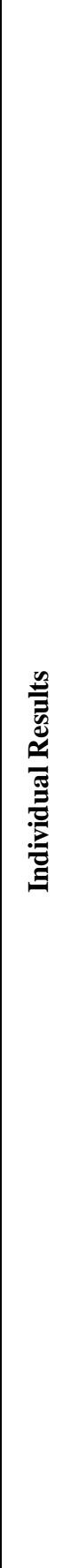 } & NIST & & & & & & & & & & \\
\hline & G701 & & & & & & 42.2 & 34.0 & 34.7 & 37.0 & 4.5 \\
\hline & G702 & & & & & & & & & & \\
\hline & G703 & 0.011 & 0.015 & & 0.013 & 0.003 & 72.8 & 73.6 & 73.8 & 73.4 & 0.5 \\
\hline & G704 & & & & & & & & & & \\
\hline & G705 & 0.076 & 0.085 & 0.074 & 0.078 & 0.006 & 96.8 & 95.2 & 95.5 & 95.9 & 0.8 \\
\hline & G707 & & & & & & & & & & \\
\hline & G708 & & & & & & 92.3 & 91.3 & 91.9 & 91.8 & 0.5 \\
\hline & G715 & & & & & & 83.5 & 84.5 & & 84.0 & 0.7 \\
\hline & G716 & & & & & & & & & & \\
\hline & G717 & 0.007 & 0.007 & 0.006 & 0.007 & 0.000 & 87.3 & 86.0 & 85.7 & 86.3 & 0.8 \\
\hline & G718 & 0.035 & 0.033 & 0.037 & 0.035 & 0.002 & 83.8 & 81.1 & 84.2 & 83.0 & 1.7 \\
\hline & G722 & & & & & & & & & & \\
\hline & G724 & & & & & & & & & & \\
\hline & G728 & & & & & & 96.9 & 94.6 & 95.3 & 95.6 & 1.2 \\
\hline & G729 & & & & & & & & & & \\
\hline & G738 & 0.087 & & & 0.087 & & 41.7 & & & 41.7 & \\
\hline & G739 & & & & & & & & & & \\
\hline & G740 & & & & & & & & & & \\
\hline & G749 & & & & & & & & & & \\
\hline & G752 & & & & & & & & & & \\
\hline & G753 & & & & & & & & & & \\
\hline & G757 & & & & & & & & & & \\
\hline & G760 & & & & & & & & & & \\
\hline & G762 & 0.055 & 0.056 & 0.052 & 0.054 & 0.002 & 92.2 & 92.4 & 84.9 & 89.8 & 4.3 \\
\hline & G765 & & & & & & 120.4 & 114.9 & 116.6 & 117.3 & 2.8 \\
\hline & G766 & & & & & & 60.0 & 59.5 & 59.8 & 59.7 & 0.2 \\
\hline & G767 & & & & & & & & & & \\
\hline & G771 & & & & & & & & & & \\
\hline & G772 & 0.384 & 0.383 & 0.369 & 0.379 & 0.008 & 83.3 & 86.8 & 86.9 & 85.7 & 2.0 \\
\hline & G773 & 0.150 & 0.130 & & 0.140 & 0.014 & 77.5 & 77.7 & 68.5 & 74.6 & 5.2 \\
\hline & G774 & & & & & & & & & & \\
\hline & G775 & 0.121 & 0.122 & 0.117 & 0.120 & 0.003 & 76.8 & 77.5 & 77.6 & 77.3 & 0.4 \\
\hline & G776 & & & & & & & & & & \\
\hline & G777 & 0.580 & 0.566 & 0.594 & 0.580 & 0.014 & 100.4 & 100.6 & 100.3 & 100.4 & 0.1 \\
\hline \multirow{5}{*}{ 象 } & & \multirow{5}{*}{\multicolumn{3}{|c|}{$\begin{array}{l}\text { Consensus Mean } \\
\text { Consensus Standard Deviation } \\
\text { Maximum } \\
\text { Minimum } \\
\mathrm{N}\end{array}$}} & 0.134 & & \multirow{5}{*}{\multicolumn{3}{|c|}{$\begin{array}{l}\text { Consensus Mean } \\
\text { Consensus Standard Deviation } \\
\text { Maximum } \\
\text { Minimum } \\
\mathrm{N} \\
\end{array}$}} & 84.7 & \\
\hline & & & & & 0.166 & & & & & 14.4 & \\
\hline & & & & & 0.580 & & & & & 117.3 & \\
\hline & & & & & 0.007 & & & & & 37.0 & \\
\hline & & & & & 9 & & & & & 15 & \\
\hline
\end{tabular}


Table 24. Data summary table for malvidin in dietary supplements.

\begin{tabular}{|c|c|c|c|c|c|c|c|c|c|c|c|}
\hline & \multirow[b]{3}{*}{ Lab } & \multicolumn{10}{|c|}{ Malvidin } \\
\hline & & \multicolumn{5}{|c|}{ SRM 3283 Cranberry Extract (mg/g) } & \multicolumn{5}{|c|}{ SRM 3291 Bilberry Extract (mg/g) } \\
\hline & & A & B & C & Avg & SD & A & B & C & Avg & SD \\
\hline \multirow{35}{*}{ 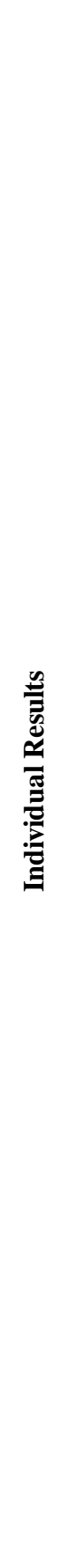 } & NIST & & & & & & & & & & \\
\hline & G701 & & & & & & & & & & \\
\hline & G702 & & & & & & & & & & \\
\hline & G703 & & & & & & 1.19 & 1.19 & 1.21 & 1.20 & 0.01 \\
\hline & G704 & & & & & & & & & & \\
\hline & G705 & & & & & & 0.99 & 0.90 & 0.93 & 0.94 & 0.04 \\
\hline & G707 & & & & & & & & & & \\
\hline & G708 & & & & & & & & & & \\
\hline & G715 & 0.0300 & 0.0350 & & 0.0325 & 0.0035 & 0.75 & 0.71 & & 0.73 & 0.03 \\
\hline & G716 & & & & & & & & & & \\
\hline & G717 & & & & & & 0.34 & 0.34 & 0.32 & 0.33 & 0.01 \\
\hline & G718 & 0.0680 & 0.0640 & 0.0660 & 0.0660 & 0.0020 & 0.26 & 0.25 & 0.25 & 0.25 & 0.00 \\
\hline & G722 & & & & & & & & & & \\
\hline & G724 & & & & & & & & & & \\
\hline & G728 & & & & & & 0.76 & 0.64 & 0.62 & 0.67 & 0.08 \\
\hline & G729 & & & & & & & & & & \\
\hline & G738 & & & & & & & & & & \\
\hline & G739 & & & & & & & & & & \\
\hline & G740 & & & & & & & & & & \\
\hline & G749 & & & & & & & & & & \\
\hline & G752 & & & & & & & & & & \\
\hline & G753 & & & & & & & & & & \\
\hline & G757 & & & & & & & & & & \\
\hline & G760 & & & & & & & & & & \\
\hline & G762 & & & & & & & & & & \\
\hline & G765 & & & & & & & & & & \\
\hline & G766 & & & & & & & & & & \\
\hline & G767 & & & & & & & & & & \\
\hline & G771 & & & & & & & & & & \\
\hline & G772 & & & & & & & & & & \\
\hline & G773 & & & & & & 2.06 & 1.60 & 2.51 & 2.06 & 0.46 \\
\hline & G774 & & & & & & & & & & \\
\hline & G775 & & & & & & 1.57 & 1.57 & 1.24 & 1.46 & 0.19 \\
\hline & G776 & & & & & & & & & & \\
\hline & G777 & & & & & & 4.72 & 4.68 & 4.81 & 4.74 & 0.07 \\
\hline \multirow{5}{*}{ 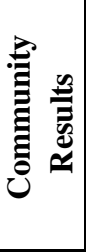 } & & \multirow{5}{*}{\multicolumn{3}{|c|}{$\begin{array}{l}\text { Consensus Mean } \\
\text { Consensus Standard Deviation } \\
\text { Maximum } \\
\text { Minimum } \\
\mathrm{N}\end{array}$}} & 0.0493 & & \multirow{5}{*}{\multicolumn{3}{|c|}{$\begin{array}{l}\text { Consensus Mean } \\
\text { Consensus Standard Deviation } \\
\text { Maximum } \\
\text { Minimum } \\
\text { N }\end{array}$}} & 1.11 & \\
\hline & & & & & 0.0269 & & & & & 0.82 & \\
\hline & & & & & 0.0660 & & & & & 4.74 & \\
\hline & & & & & 0.0325 & & & & & 0.25 & \\
\hline & & & & & 2 & & & & & 10 & \\
\hline
\end{tabular}


Table 25. Data summary table for malvidin-3-arabinoside in dietary supplements.

\begin{tabular}{|c|c|c|c|c|c|c|c|c|c|c|c|}
\hline & \multirow[b]{3}{*}{ Lab } & \multicolumn{10}{|c|}{ Malvidin-3-Arabinoside } \\
\hline & & \multicolumn{5}{|c|}{ SRM 3283 Cranberry Extract (mg/g) } & \multicolumn{5}{|c|}{ SRM 3291 Bilberry Extract (mg/g) } \\
\hline & & A & B & C & Avg & SD & A & B & C & Avg & SD \\
\hline \multirow{35}{*}{ 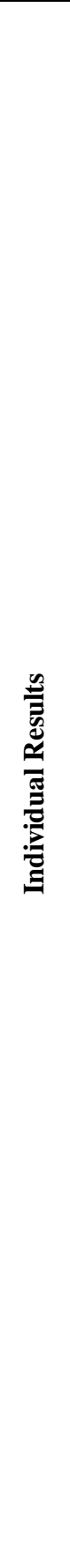 } & NIST & & & & & & & & & & \\
\hline & G701 & & & & & & & & & & \\
\hline & G702 & & & & & & & & & & \\
\hline & G703 & & & & & & 6.89 & 7.12 & 7.08 & 7.03 & 0.12 \\
\hline & G704 & & & & & & & & & & \\
\hline & G705 & & & & & & 9.25 & 9.14 & 9.19 & 9.19 & 0.06 \\
\hline & G707 & & & & & & & & & & \\
\hline & G708 & 0.0959 & 0.0966 & 0.1070 & 0.0998 & 0.0062 & 11.20 & 11.00 & 11.10 & 11.10 & 0.10 \\
\hline & G715 & & & & & & 8.87 & 9.00 & & 8.94 & 0.09 \\
\hline & G716 & & & & & & & & & & \\
\hline & G717 & & & & & & 8.43 & 8.23 & 8.40 & 8.35 & 0.11 \\
\hline & G718 & & & & & & 9.21 & 8.48 & 8.71 & 8.80 & 0.37 \\
\hline & G722 & & & & & & & & & & \\
\hline & G724 & & & & & & & & & & \\
\hline & G728 & & & & & & 12.34 & 11.36 & 12.04 & 11.91 & 0.50 \\
\hline & G729 & & & & & & & & & & \\
\hline & G738 & & & & & & & & & & \\
\hline & G739 & & & & & & & & & & \\
\hline & G740 & & & & & & & & & & \\
\hline & G749 & & & & & & & & & & \\
\hline & G752 & & & & & & & & & & \\
\hline & G753 & & & & & & & & & & \\
\hline & G757 & & & & & & & & & & \\
\hline & G760 & & & & & & & & & & \\
\hline & G762 & & & & & & 10.50 & 10.20 & 9.47 & 10.06 & 0.53 \\
\hline & G765 & & & & & & 11.52 & 11.11 & 11.79 & 11.47 & 0.34 \\
\hline & G766 & & & & & & 5.03 & 4.84 & 4.91 & 4.93 & 0.10 \\
\hline & G767 & & & & & & & & & & \\
\hline & G771 & & & & & & & & & & \\
\hline & G772 & & & & & & & & & & \\
\hline & G773 & & & & & & 1.24 & 1.04 & 0.96 & 1.08 & 0.14 \\
\hline & G774 & & & & & & & & & & \\
\hline & G775 & & & & & & 7.87 & 7.85 & 7.82 & 7.85 & 0.03 \\
\hline & G776 & & & & & & & & & & \\
\hline & G777 & 0.0030 & 0.0030 & 0.0030 & 0.0030 & 0.0000 & 1.50 & 1.49 & 1.52 & 1.50 & 0.01 \\
\hline \multirow{5}{*}{ 串 } & & \multirow{5}{*}{\multicolumn{3}{|c|}{$\begin{array}{l}\text { Consensus Mean } \\
\text { Consensus Standard Deviation } \\
\text { Maximum } \\
\text { Minimum } \\
\mathrm{N}\end{array}$}} & 0.0514 & & \multirow{5}{*}{\multicolumn{3}{|c|}{$\begin{array}{l}\text { Consensus Mean } \\
\text { Consensus Standard Deviation } \\
\text { Maximum } \\
\text { Minimum } \\
\mathrm{N}\end{array}$}} & 8.19 & \\
\hline & & & & & 0.0776 & & & & & 3.22 & \\
\hline & & & & & 0.0998 & & & & & 11.91 & \\
\hline & & & & & 0.0030 & & & & & 1.08 & \\
\hline & & & & & 2 & & & & & 13 & \\
\hline
\end{tabular}


Table 26. Data summary table for malvidin-3-galactoside in dietary supplements.

\begin{tabular}{|c|c|c|c|c|c|c|c|c|c|c|c|}
\hline & \multirow[b]{3}{*}{ Lab } & \multicolumn{10}{|c|}{ Malvidin-3-Galactoside } \\
\hline & & \multicolumn{5}{|c|}{ SRM 3283 Cranberry Extract (mg/g) } & \multicolumn{5}{|c|}{ SRM 3291 Bilberry Extract (mg/g) } \\
\hline & & A & B & C & Avg & SD & A & B & C & Avg & SD \\
\hline \multirow{35}{*}{ 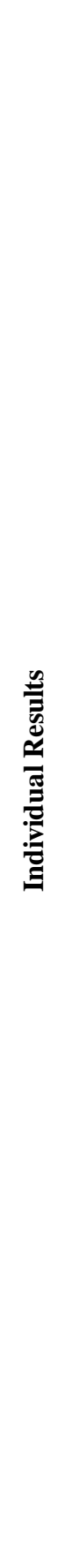 } & NIST & & & & & & & & & & \\
\hline & G701 & 0.1400 & 0.1400 & 0.1600 & 0.1467 & 0.0115 & 26.1 & 23.1 & 21.0 & 23.4 & 2.5 \\
\hline & G702 & & & & & & & & & & \\
\hline & G703 & 0.0125 & & & 0.0125 & & 12.1 & 12.3 & 12.3 & 12.2 & 0.1 \\
\hline & G704 & & & & & & & & & & \\
\hline & G705 & & & & & & 16.3 & 16.1 & 16.2 & 16.2 & 0.1 \\
\hline & G707 & & & & & & & & & & \\
\hline & G708 & & & & & & & & & & \\
\hline & G715 & & & & & & 12.5 & 12.6 & & 12.5 & 0.1 \\
\hline & G716 & & & & & & & & & & \\
\hline & G717 & & & & & & 38.1 & 37.1 & 38.6 & 37.9 & 0.8 \\
\hline & G718 & 0.0520 & & & 0.0520 & & 14.9 & 14.2 & 14.7 & 14.6 & 0.3 \\
\hline & G722 & & & & & & & & & & \\
\hline & G724 & & & & & & & & & & \\
\hline & G728 & & & & & & 19.2 & 18.1 & 19.4 & 18.9 & 0.7 \\
\hline & G729 & & & & & & & & & & \\
\hline & G738 & & & & & & & & & & \\
\hline & G739 & & & & & & & & & & \\
\hline & G740 & & & & & & & & & & \\
\hline & G749 & & & & & & & & & & \\
\hline & G752 & & & & & & & & & & \\
\hline & G753 & & & & & & & & & & \\
\hline & G757 & & & & & & & & & & \\
\hline & G760 & & & & & & & & & & \\
\hline & G762 & 0.0252 & 0.0270 & 0.0270 & 0.0264 & 0.0010 & 14.0 & 14.0 & 13.0 & 13.7 & 0.6 \\
\hline & G765 & & & & & & 18.3 & 17.4 & 17.8 & 17.8 & 0.4 \\
\hline & G766 & & & & & & 6.7 & 6.6 & 6.8 & 6.7 & 0.1 \\
\hline & G767 & & & & & & & & & & \\
\hline & G771 & & & & & & & & & & \\
\hline & G772 & & & & & & & & & & \\
\hline & G773 & & & & & & 27.9 & 27.9 & 25.3 & 27.0 & 1.5 \\
\hline & G774 & & & & & & & & & & \\
\hline & G775 & & & & & & 33.3 & 33.3 & 33.2 & 33.3 & 0.1 \\
\hline & G776 & & & & & & & & & & \\
\hline & G777 & 0.0060 & 0.0050 & 0.0050 & 0.0053 & 0.0006 & 13.3 & 13.3 & 13.3 & 13.3 & 0.0 \\
\hline \multirow{5}{*}{ 竭 } & & \multicolumn{3}{|c|}{ Consensus Mean } & \multicolumn{2}{|l|}{0.0595} & \multicolumn{2}{|c|}{ Consensus Mean } & & 18.4 & \\
\hline & & \multicolumn{4}{|c|}{ Consensus Standard Deviation 0.0865} & & \multicolumn{4}{|c|}{ Consensus Standard Deviation $\quad 8.8$} & \\
\hline & & \multicolumn{2}{|c|}{ Maximum } & & \multicolumn{2}{|l|}{0.1467} & \multicolumn{3}{|c|}{ Maximum } & 37.9 & \\
\hline & & \multicolumn{2}{|c|}{ Minimum } & & \multicolumn{2}{|l|}{0.0053} & \multicolumn{3}{|c|}{ Minimum } & 6.7 & \\
\hline & & \multicolumn{3}{|l|}{$\mathrm{N}$} & 3 & & $\mathrm{~N}$ & & & 13 & \\
\hline
\end{tabular}


Table 27. Data summary table for malvidin-3-glucoside in dietary supplements.

\begin{tabular}{|c|c|c|c|c|c|c|c|c|c|c|c|}
\hline & \multirow[b]{3}{*}{ Lab } & \multicolumn{10}{|c|}{ Malvidin-3-Glucoside } \\
\hline & & \multicolumn{5}{|c|}{ SRM 3283 Cranberry Extract (mg/g) } & \multicolumn{5}{|c|}{ SRM 3291 Bilberry Extract (mg/g) } \\
\hline & & A & B & C & Avg & SD & A & B & C & Avg & SD \\
\hline \multirow{35}{*}{ 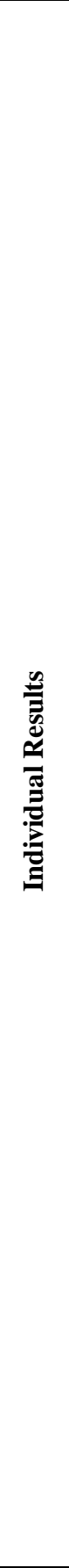 } & NIST & & & & & & & & & & \\
\hline & G701 & & & & & & & & & & \\
\hline & G702 & & & & & & & & & & \\
\hline & G703 & & & & & & 30.2 & 30.6 & 30.6 & 30.5 & 0.2 \\
\hline & G704 & & & & & & & & & & \\
\hline & G705 & & & & & & & & & & \\
\hline & G707 & & & & & & & & & & \\
\hline & G708 & 0.1720 & 0.1780 & 0.1800 & 0.1767 & 0.0042 & 37.3 & 37.0 & 37.2 & 37.2 & 0.2 \\
\hline & G715 & 0.0270 & 0.0320 & & 0.0295 & 0.0035 & 34.7 & 34.8 & & 34.8 & 0.0 \\
\hline & G716 & & & & & & & & & & \\
\hline & G717 & 0.0128 & 0.0110 & 0.0117 & 0.0118 & 0.0009 & 14.5 & 14.3 & 14.2 & 14.3 & 0.2 \\
\hline & G718 & & & & & & 36.5 & 35.4 & 36.6 & 36.2 & 0.7 \\
\hline & G722 & & & & & & & & & & \\
\hline & G724 & & & & & & & & & & \\
\hline & G728 & & & & & & 43.8 & 42.5 & 43.3 & 43.2 & 0.6 \\
\hline & G729 & & & & & & & & & & \\
\hline & G738 & & & & & & & & & & \\
\hline & G739 & & & & & & & & & & \\
\hline & G740 & & & & & & & & & & \\
\hline & G749 & & & & & & & & & & \\
\hline & G752 & & & & & & & & & & \\
\hline & G753 & & & & & & & & & & \\
\hline & G757 & & & & & & & & & & \\
\hline & G760 & & & & & & & & & & \\
\hline & G762 & & & & & & 35.8 & 35.6 & 32.9 & 34.8 & 1.6 \\
\hline & G765 & & & & & & 45.9 & 43.9 & 44.4 & 44.7 & 1.0 \\
\hline & G766 & 0.1323 & 0.1340 & 0.1370 & 0.1344 & 0.0024 & 21.6 & 21.2 & 21.2 & 21.3 & 0.2 \\
\hline & G767 & & & & & & & & & & \\
\hline & G771 & & & & & & & & & & \\
\hline & G772 & & & & & & & & & & \\
\hline & G773 & & & & & & 10.2 & 11.4 & 9.7 & 10.4 & 0.9 \\
\hline & G774 & & & & & & & & & & \\
\hline & G775 & & & & & & 13.4 & 13.5 & 13.5 & 13.4 & 0.0 \\
\hline & G776 & & & & & & & & & & \\
\hline & G777 & & & & & & 35.7 & 35.8 & 35.8 & 35.8 & 0.1 \\
\hline \multirow{5}{*}{ 串 } & & \multicolumn{3}{|c|}{ Consensus Mean } & \multicolumn{2}{|l|}{0.0881} & \multicolumn{3}{|c|}{ Consensus Mean } & 29.7 & \\
\hline & & \multicolumn{3}{|c|}{ Consensus Standard Deviation } & \multicolumn{2}{|l|}{0.0908} & \multicolumn{3}{|c|}{ Consensus Standard Deviation } & 13.4 & \\
\hline & & \multicolumn{3}{|c|}{ Maximum } & \multicolumn{2}{|l|}{0.1767} & \multicolumn{3}{|c|}{ Maximum } & 44.7 & \\
\hline & & \multicolumn{3}{|c|}{ Minimum } & \multicolumn{2}{|l|}{0.0118} & \multicolumn{3}{|c|}{ Minimum } & 10.4 & \\
\hline & & \multicolumn{3}{|l|}{$\mathrm{N}$} & 4 & & $\mathrm{~N}$ & & & 12 & \\
\hline
\end{tabular}


Table 28. Data summary table for malvidin equivalents in dietary supplements.

\begin{tabular}{|c|c|c|c|c|c|c|c|c|c|c|c|}
\hline & \multirow[b]{3}{*}{ Lab } & \multicolumn{10}{|c|}{ Malvidin Equivalents } \\
\hline & & \multicolumn{5}{|c|}{ SRM 3283 Cranberry Extract (mg/g) } & \multicolumn{5}{|c|}{ SRM 3291 Bilberry Extract (mg/g) } \\
\hline & & A & B & C & Avg & SD & A & B & C & Avg & SD \\
\hline \multirow{35}{*}{ 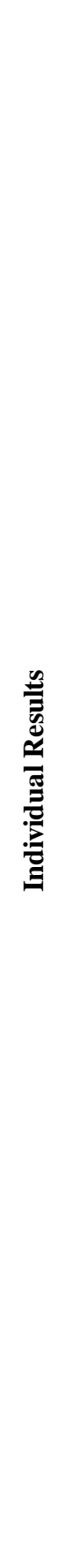 } & NIST & & & & & & & & & & \\
\hline & G701 & 0.0940 & 0.0940 & 0.1074 & 0.0985 & 0.0078 & 17.5 & 15.5 & 14.1 & 15.7 & 1.7 \\
\hline & G702 & & & & & & & & & & \\
\hline & G703 & 0.0084 & & & 0.0084 & & 34.5 & 35.1 & 35.1 & 34.9 & 0.3 \\
\hline & G704 & & & & & & & & & & \\
\hline & G705 & & & & & & 18.5 & 18.2 & 18.4 & 18.4 & 0.1 \\
\hline & G707 & & & & & & & & & & \\
\hline & G708 & 0.1840 & 0.1886 & 0.1974 & 0.1900 & 0.0068 & 33.1 & 32.7 & 32.9 & 32.9 & 0.2 \\
\hline & G715 & 0.0481 & 0.0565 & & 0.0523 & 0.0059 & 38.8 & 38.9 & & 38.9 & 0.1 \\
\hline & G716 & & & & & & & & & & \\
\hline & G717 & 0.0086 & 0.0074 & 0.0079 & 0.0079 & 0.0006 & 41.7 & 40.7 & 41.8 & 41.4 & 0.6 \\
\hline & G718 & 0.1029 & 0.0640 & 0.0660 & 0.0776 & 0.0219 & 41.4 & 39.7 & 40.9 & 40.7 & 0.9 \\
\hline & G722 & & & & & & & & & & \\
\hline & G724 & & & & & & & & & & \\
\hline & G728 & & & & & & 51.8 & 49.4 & 51.3 & 50.9 & 1.3 \\
\hline & G729 & & & & & & & & & & \\
\hline & G738 & & & & & & 6.1 & & & 6.1 & \\
\hline & G739 & & & & & & & & & & \\
\hline & G740 & & & & & & & & & & \\
\hline & G749 & & & & & & & & & & \\
\hline & G752 & & & & & & & & & & \\
\hline & G753 & & & & & & & & & & \\
\hline & G757 & & & & & & & & & & \\
\hline & G760 & & & & & & & & & & \\
\hline & G762 & 0.0169 & 0.0181 & 0.0181 & 0.0177 & 0.0007 & 40.9 & 40.6 & 37.6 & 39.7 & 1.8 \\
\hline & G765 & & & & & & 51.3 & 49.1 & 50.2 & 50.2 & 1.1 \\
\hline & G766 & 0.0888 & 0.0900 & 0.0920 & 0.0903 & 0.0016 & 22.6 & 22.1 & 22.3 & 22.3 & 0.2 \\
\hline & G767 & & & & & & & & & & \\
\hline & G771 & & & & & & & & & & \\
\hline & G772 & & & & & & 38.3 & 41.2 & 42.8 & 40.8 & 2.3 \\
\hline & G773 & & & & & & 28.5 & 28.7 & 26.7 & 28.0 & 1.1 \\
\hline & G774 & & & & & & & & & & \\
\hline & G775 & & & & & & 38.6 & 38.5 & 38.1 & 38.4 & 0.2 \\
\hline & G776 & & & & & & & & & & \\
\hline & G777 & 0.0062 & 0.0055 & 0.0055 & 0.0057 & 0.0004 & 38.7 & 38.8 & 38.9 & 38.8 & 0.1 \\
\hline \multirow{5}{*}{ 竭 } & & \multicolumn{3}{|c|}{ Consensus Mean } & \multicolumn{2}{|l|}{0.0624} & \multicolumn{3}{|c|}{ Consensus Mean } & 34.2 & \\
\hline & & \multicolumn{3}{|c|}{ Consensus Standard Deviation } & \multicolumn{2}{|l|}{0.0576} & \multicolumn{3}{|c|}{ Consensus Standard Deviation } & 12.7 & \\
\hline & & \multicolumn{3}{|c|}{ Maximum } & \multicolumn{2}{|l|}{0.1900} & \multicolumn{3}{|c|}{ Maximum } & 50.9 & \\
\hline & & \multicolumn{3}{|c|}{ Minimum } & \multicolumn{2}{|l|}{0.0057} & \multicolumn{3}{|c|}{ Minimum } & 6.1 & \\
\hline & & \multicolumn{3}{|l|}{$\mathrm{N}$} & 8 & & $\mathrm{~N}$ & & & 15 & \\
\hline
\end{tabular}


Table 29. Data summary table for peonidin in dietary supplements.

\begin{tabular}{|c|c|c|c|c|c|c|c|c|c|c|c|}
\hline & \multirow[b]{3}{*}{ Lab } & \multicolumn{10}{|c|}{ Peonidin } \\
\hline & & \multicolumn{5}{|c|}{ SRM 3283 Cranberry Extract (mg/g) } & \multicolumn{5}{|c|}{ SRM 3291 Bilberry Extract (mg/g) } \\
\hline & & A & B & C & Avg & SD & A & B & C & Avg & SD \\
\hline \multirow{35}{*}{ 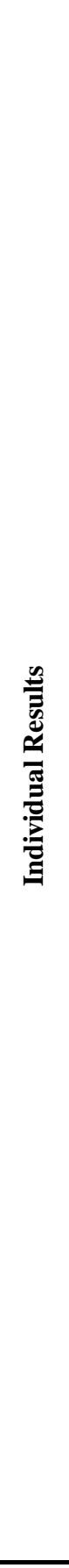 } & NIST & & & & & & & & & & \\
\hline & G701 & & & & & & & & & & \\
\hline & G702 & & & & & & & & & & \\
\hline & G703 & 0.0507 & 0.0526 & 0.0549 & 0.0527 & 0.0021 & 0.468 & 0.479 & 0.491 & 0.479 & 0.012 \\
\hline & G704 & & & & & & & & & & \\
\hline & G705 & 0.0372 & 0.0411 & 0.0355 & 0.0379 & 0.0029 & 0.427 & 0.491 & 0.418 & 0.445 & 0.040 \\
\hline & G707 & & & & & & & & & & \\
\hline & G708 & & & & & & & & & & \\
\hline & G715 & 0.0510 & 0.0460 & & 0.0485 & 0.0035 & 0.234 & 0.234 & & 0.234 & 0.000 \\
\hline & G716 & & & & & & & & & & \\
\hline & G717 & 0.0507 & 0.0507 & 0.0498 & 0.0504 & 0.0005 & 0.200 & 0.206 & 0.223 & 0.210 & 0.012 \\
\hline & G718 & & 0.0510 & & 0.0510 & & 0.242 & 0.229 & 0.229 & 0.233 & 0.008 \\
\hline & G722 & & & & & & & & & & \\
\hline & G724 & & & & & & & & & & \\
\hline & G728 & & & & & & 0.299 & 0.316 & 0.323 & 0.313 & 0.012 \\
\hline & G729 & & & & & & & & & & \\
\hline & G738 & & & & & & & & & & \\
\hline & G739 & & & & & & & & & & \\
\hline & G740 & & & & & & & & & & \\
\hline & G749 & & & & & & & & & & \\
\hline & G752 & & & & & & & & & & \\
\hline & G753 & & & & & & & & & & \\
\hline & G757 & & & & & & & & & & \\
\hline & G760 & & & & & & & & & & \\
\hline & G762 & & & & & & & & & & \\
\hline & G765 & & & & & & & & & & \\
\hline & G766 & & & & & & & & & & \\
\hline & G767 & & & & & & & & & & \\
\hline & G771 & & & & & & & & & & \\
\hline & G772 & & & & & & & & & & \\
\hline & G773 & & & & & & 1.270 & 1.490 & 1.220 & 1.327 & 0.144 \\
\hline & G774 & & & & & & & & & & \\
\hline & G775 & & & & & & 1.307 & 1.082 & 1.452 & 1.280 & 0.186 \\
\hline & G776 & & & & & & & & & & \\
\hline & G777 & 0.1260 & 0.1220 & 0.1320 & 0.1267 & 0.0050 & 1.491 & 1.476 & 1.534 & 1.500 & 0.030 \\
\hline \multirow{5}{*}{ 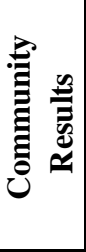 } & & \multicolumn{3}{|c|}{ Consensus Mean } & \multicolumn{2}{|l|}{0.0505} & \multicolumn{3}{|c|}{ Consensus Mean } & 0.669 & \\
\hline & & \multicolumn{3}{|c|}{ Consensus Standard Deviation } & \multicolumn{2}{|l|}{0.0045} & \multicolumn{3}{|c|}{ Consensus Standard Deviation } & 0.608 & \\
\hline & & \multicolumn{3}{|c|}{ Maximum } & \multicolumn{2}{|l|}{0.1267} & \multicolumn{3}{|c|}{ Maximum } & 1.500 & \\
\hline & & \multicolumn{3}{|c|}{ Minimum } & \multicolumn{2}{|l|}{0.0379} & \multicolumn{3}{|c|}{ Minimum } & 0.210 & \\
\hline & & \multicolumn{3}{|l|}{$\mathrm{N}$} & 6 & & $\mathrm{~N}$ & & & 10 & \\
\hline
\end{tabular}


Table 30. Data summary table for peonidin-3-arabinoside in dietary supplements.

\begin{tabular}{|c|c|c|c|c|c|c|c|c|c|c|c|}
\hline & \multirow[b]{3}{*}{ Lab } & \multicolumn{10}{|c|}{ Peonidin-3-Arabinoside } \\
\hline & & \multicolumn{5}{|c|}{ SRM 3283 Cranberry Extract (mg/g) } & \multicolumn{5}{|c|}{ SRM 3291 Bilberry Extract (mg/g) } \\
\hline & & A & B & $\mathbf{C}$ & Avg & SD & A & B & $\mathbf{C}$ & Avg & SD \\
\hline \multirow{35}{*}{ 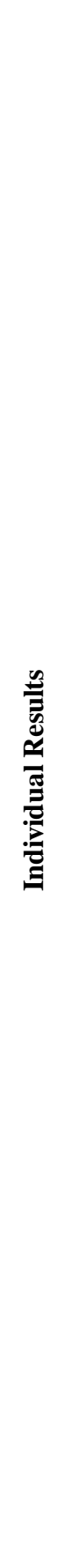 } & NIST & & & & & & & & & & \\
\hline & G701 & 0.168 & 0.163 & 0.174 & 0.168 & 0.006 & 23.97 & 23.36 & 20.93 & 22.75 & 1.61 \\
\hline & G702 & & & & & & & & & & \\
\hline & G703 & 0.103 & 0.101 & 0.107 & 0.104 & 0.003 & 1.63 & 1.67 & 1.65 & 1.65 & 0.02 \\
\hline & G704 & & & & & & & & & & \\
\hline & G705 & 0.129 & 0.138 & 0.123 & 0.130 & 0.008 & 2.54 & 2.46 & 2.50 & 2.50 & 0.04 \\
\hline & G707 & & & & & & & & & & \\
\hline & G708 & & & & & & & & & & \\
\hline & G715 & 0.134 & 0.148 & & 0.141 & 0.010 & 2.12 & 2.15 & & 2.14 & 0.02 \\
\hline & G716 & & & & & & & & & & \\
\hline & G717 & 0.165 & 0.165 & 0.171 & 0.167 & 0.003 & 1.77 & 1.69 & 1.58 & 1.68 & 0.10 \\
\hline & G718 & 0.192 & 0.195 & 0.192 & 0.193 & 0.002 & 2.12 & 2.02 & 2.09 & 2.08 & 0.05 \\
\hline & G722 & & & & & & & & & & \\
\hline & G724 & & & & & & & & & & \\
\hline & G728 & 0.245 & 0.183 & 0.225 & 0.218 & 0.032 & 3.89 & 3.58 & 3.89 & 3.78 & 0.18 \\
\hline & G729 & & & & & & & & & & \\
\hline & G738 & & & & & & & & & & \\
\hline & G739 & & & & & & & & & & \\
\hline & G740 & & & & & & & & & & \\
\hline & G749 & & & & & & & & & & \\
\hline & G752 & & & & & & & & & & \\
\hline & G753 & & & & & & & & & & \\
\hline & G757 & & & & & & & & & & \\
\hline & G760 & & & & & & & & & & \\
\hline & G762 & 0.140 & 0.144 & 0.140 & 0.141 & 0.002 & 2.61 & 2.58 & 2.41 & 2.53 & 0.11 \\
\hline & G765 & 0.176 & 0.179 & 0.182 & 0.179 & 0.003 & 3.37 & 3.40 & 3.51 & 3.43 & 0.07 \\
\hline & G766 & & & & & & & & & & \\
\hline & G767 & & & & & & & & & & \\
\hline & G771 & & & & & & & & & & \\
\hline & G772 & & & & & & & & & & \\
\hline & G773 & & & 0.150 & 0.150 & & 1.61 & 1.54 & 1.35 & 1.50 & 0.13 \\
\hline & G774 & & & & & & & & & & \\
\hline & G775 & 0.045 & 0.045 & 0.050 & 0.046 & 0.003 & 2.01 & 1.99 & 1.93 & 1.98 & 0.04 \\
\hline & G776 & & & & & & & & & & \\
\hline & G777 & 0.108 & 0.106 & 0.112 & 0.109 & 0.003 & 2.21 & 2.23 & 2.24 & 2.23 & 0.01 \\
\hline \multirow{5}{*}{ 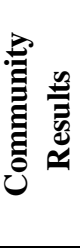 } & & \multirow{5}{*}{\multicolumn{3}{|c|}{$\begin{array}{l}\text { Consensus Mean } \\
\text { Consensus Standard Deviation } \\
\text { Maximum } \\
\text { Minimum } \\
\mathrm{N}\end{array}$}} & 0.148 & & \multirow{5}{*}{\multicolumn{3}{|c|}{$\begin{array}{l}\text { Consensus Mean } \\
\text { Consensus Standard Deviation } \\
\text { Maximum } \\
\text { Minimum } \\
\mathrm{N} \\
\end{array}$}} & 2.44 & \\
\hline & & & & & 0.048 & & & & & 0.92 & \\
\hline & & & & & 0.218 & & & & & 22.75 & \\
\hline & & & & & 0.046 & & & & & 1.50 & \\
\hline & & & & & 11 & & & & & 12 & \\
\hline
\end{tabular}


Table 31. Data summary table for peonidin-3-galactoside in dietary supplements.

\begin{tabular}{|c|c|c|c|c|c|c|c|c|c|c|c|}
\hline & \multirow[b]{3}{*}{ Lab } & \multicolumn{10}{|c|}{ Peonidin-3-Galactoside } \\
\hline & & \multicolumn{5}{|c|}{ SRM 3283 Cranberry Extract (mg/g) } & \multicolumn{5}{|c|}{ SRM 3291 Bilberry Extract (mg/g) } \\
\hline & & A & B & C & Avg & SD & A & B & C & Avg & SD \\
\hline \multirow{35}{*}{ 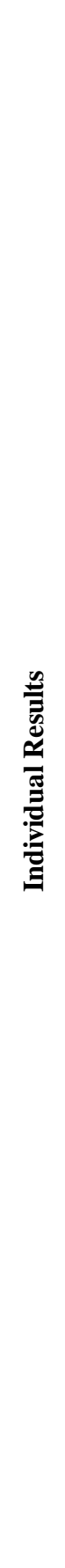 } & NIST & & & & & & & & & & \\
\hline & G701 & 0.177 & 0.173 & 0.177 & 0.176 & 0.002 & 1.67 & 0.76 & 0.82 & 1.08 & 0.51 \\
\hline & G702 & & & & & & & & & & \\
\hline & G703 & 0.156 & 0.157 & 0.160 & 0.158 & 0.002 & 3.73 & 3.81 & 3.80 & 3.78 & 0.04 \\
\hline & G704 & & & & & & & & & & \\
\hline & G705 & 0.178 & 0.199 & 0.176 & 0.184 & 0.013 & 5.72 & 5.70 & 5.68 & 5.70 & 0.02 \\
\hline & G707 & & & & & & & & & & \\
\hline & G708 & 0.211 & 0.211 & 0.218 & 0.213 & 0.004 & 4.56 & 4.49 & 4.54 & 4.53 & 0.04 \\
\hline & G715 & 0.177 & 0.204 & & 0.191 & 0.019 & 8.55 & 8.19 & & 8.37 & 0.25 \\
\hline & G716 & & & & & & & & & & \\
\hline & G717 & 0.221 & 0.223 & 0.224 & 0.223 & 0.002 & 3.76 & 3.78 & 3.97 & 3.84 & 0.12 \\
\hline & G718 & 0.241 & 0.260 & 0.251 & 0.251 & 0.010 & 4.65 & 4.49 & 4.64 & 4.59 & 0.09 \\
\hline & G722 & & & & & & & & & & \\
\hline & G724 & & & & & & & & & & \\
\hline & G728 & 0.456 & 0.211 & 0.404 & 0.357 & 0.129 & 9.67 & 9.08 & 10.32 & 9.69 & 0.62 \\
\hline & G729 & & & & & & & & & & \\
\hline & G738 & & & & & & & & & & \\
\hline & G739 & & & & & & & & & & \\
\hline & G740 & & & & & & & & & & \\
\hline & G749 & & & & & & & & & & \\
\hline & G752 & & & & & & & & & & \\
\hline & G753 & & & & & & & & & & \\
\hline & G757 & & & & & & & & & & \\
\hline & G760 & & & & & & & & & & \\
\hline & G762 & 0.172 & 0.176 & 0.173 & 0.174 & 0.002 & 5.15 & 5.17 & 4.68 & 5.00 & 0.28 \\
\hline & G765 & 0.235 & 0.240 & 0.243 & 0.239 & 0.004 & 7.47 & 7.06 & 7.23 & 7.25 & 0.21 \\
\hline & G766 & 0.197 & 0.218 & 0.199 & 0.205 & 0.012 & 4.40 & 3.98 & 4.00 & 4.13 & 0.24 \\
\hline & G767 & & & & & & & & & & \\
\hline & G771 & & & & & & & & & & \\
\hline & G772 & & & & & & & & & & \\
\hline & G773 & 0.077 & 0.078 & 0.100 & 0.085 & 0.013 & 2.28 & 2.18 & 1.84 & 2.10 & 0.23 \\
\hline & G774 & & & & & & & & & & \\
\hline & G775 & & & & & & 4.25 & 4.25 & 4.20 & 4.23 & 0.03 \\
\hline & G776 & & & & & & & & & & \\
\hline & G777 & & & & & & 13.02 & 13.02 & 13.09 & 13.04 & 0.04 \\
\hline \multirow{5}{*}{ 龍 } & & \multicolumn{3}{|c|}{ Consensus Mean } & \multicolumn{2}{|l|}{0.201} & \multicolumn{3}{|c|}{ Consensus Mean } & 5.29 & \\
\hline & & \multicolumn{3}{|c|}{ Consensus Standard Deviation } & \multicolumn{2}{|l|}{0.043} & \multicolumn{3}{|c|}{ Consensus Standard Deviation } & 2.96 & \\
\hline & & \multicolumn{3}{|c|}{ Maximum } & \multicolumn{2}{|l|}{0.357} & \multicolumn{3}{|c|}{ Maximum } & 13.04 & \\
\hline & & \multicolumn{3}{|c|}{ Minimum } & \multicolumn{2}{|l|}{0.085} & \multicolumn{3}{|c|}{ Minimum } & 1.08 & \\
\hline & & \multicolumn{3}{|l|}{$\mathrm{N}$} & 12 & & $\mathrm{~N}$ & & & 14 & \\
\hline
\end{tabular}


Table 32. Data summary table for peonidin-3-glucoside in dietary supplements.

\begin{tabular}{|c|c|c|c|c|c|c|c|c|c|c|c|}
\hline & \multirow[b]{3}{*}{ Lab } & \multicolumn{10}{|c|}{ Peonidin-3-Glucoside } \\
\hline & & \multicolumn{5}{|c|}{ SRM 3283 Cranberry Extract (mg/g) } & \multicolumn{5}{|c|}{ SRM 3291 Bilberry Extract (mg/g) } \\
\hline & & A & B & C & Avg & SD & A & B & C & Avg & SD \\
\hline \multirow{35}{*}{ 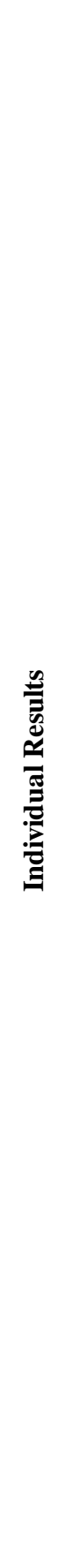 } & NIST & & & & & & & & & & \\
\hline & G701 & & & & & & & & & & \\
\hline & G702 & & & & & & & & & & \\
\hline & G703 & 0.0286 & 0.0267 & 0.0235 & 0.0263 & 0.0026 & 14.2 & 14.4 & 14.4 & 14.3 & 0.1 \\
\hline & G704 & & & & & & & & & & \\
\hline & G705 & 0.0245 & 0.0252 & 0.0224 & 0.0240 & 0.0015 & 18.9 & 18.7 & 18.7 & 18.8 & 0.1 \\
\hline & G707 & & & & & & & & & & \\
\hline & G708 & 0.0367 & 0.0385 & 0.0710 & 0.0487 & 0.0193 & 31.7 & 31.6 & 31.6 & 31.6 & 0.1 \\
\hline & G715 & & & & & & 16.2 & 16.3 & & 16.2 & 0.1 \\
\hline & G716 & & & & & & & & & & \\
\hline & G717 & 0.0298 & 0.0313 & 0.0296 & 0.0302 & 0.0009 & 16.9 & 16.8 & 16.6 & 16.8 & 0.1 \\
\hline & G718 & 0.1290 & 0.1350 & 0.1260 & 0.1300 & 0.0046 & 17.3 & 16.6 & 17.1 & 17.0 & 0.3 \\
\hline & G722 & & & & & & & & & & \\
\hline & G724 & & & & & & & & & & \\
\hline & G728 & & & & & & 23.9 & 23.6 & 24.1 & 23.9 & 0.3 \\
\hline & G729 & & & & & & & & & & \\
\hline & G738 & & & & & & & & & & \\
\hline & G739 & & & & & & & & & & \\
\hline & G740 & & & & & & & & & & \\
\hline & G749 & & & & & & & & & & \\
\hline & G752 & & & & & & & & & & \\
\hline & G753 & & & & & & & & & & \\
\hline & G757 & & & & & & & & & & \\
\hline & G760 & & & & & & & & & & \\
\hline & G762 & 0.0084 & 0.0089 & 0.0080 & 0.0084 & 0.0005 & 18.1 & 18.1 & 16.6 & 17.6 & 0.9 \\
\hline & G765 & 0.0320 & 0.0340 & 0.0450 & 0.0370 & 0.0070 & 28.0 & 26.6 & 27.7 & 27.4 & 0.7 \\
\hline & G766 & & & & & & 16.8 & 16.3 & 16.1 & 16.4 & 0.4 \\
\hline & G767 & & & & & & & & & & \\
\hline & G771 & & & & & & & & & & \\
\hline & G772 & & & & & & & & & & \\
\hline & G773 & & & & & & 15.5 & 14.6 & 13.6 & 14.6 & 1.0 \\
\hline & G774 & & & & & & & & & & \\
\hline & G775 & 0.1090 & 0.1194 & 0.1148 & 0.1144 & 0.0052 & 15.8 & 15.8 & 15.7 & 15.8 & 0.0 \\
\hline & G776 & & & & & & & & & & \\
\hline & G777 & 0.0180 & 0.0160 & 0.0170 & 0.0170 & 0.0010 & 17.0 & 17.1 & 13.0 & 15.7 & 2.3 \\
\hline \multirow{5}{*}{ 竭 } & & \multicolumn{3}{|c|}{ Consensus Mean } & \multicolumn{2}{|l|}{0.0467} & \multicolumn{2}{|c|}{ Consensus Mean } & & 17.5 & \\
\hline & & \multicolumn{3}{|c|}{ Consensus Standard Deviation } & \multicolumn{2}{|l|}{0.0454} & \multicolumn{3}{|c|}{ Consensus Standard Deviation } & 3.0 & \\
\hline & & \multicolumn{3}{|c|}{ Maximum } & \multicolumn{2}{|l|}{0.1300} & \multicolumn{3}{|c|}{ Maximum } & 31.6 & \\
\hline & & \multicolumn{3}{|c|}{ Minimum } & \multicolumn{2}{|l|}{0.0084} & \multicolumn{3}{|c|}{ Minimum } & 14.3 & \\
\hline & & \multicolumn{3}{|l|}{$\mathrm{N}$} & 9 & & $\mathrm{~N}$ & & & 13 & \\
\hline
\end{tabular}


Table 33. Data summary table for peonidin equivalents in dietary supplements.

\begin{tabular}{|c|c|c|c|c|c|c|c|c|c|c|c|}
\hline & \multirow[b]{3}{*}{ Lab } & \multicolumn{10}{|c|}{ Peonidin Equivalents } \\
\hline & & \multicolumn{5}{|c|}{ SRM 3283 Cranberry Extract (mg/g) } & \multicolumn{5}{|c|}{ SRM 3291 Bilberry Extract (mg/g) } \\
\hline & & A & B & C & Avg & SD & A & B & C & Avg & SD \\
\hline \multirow{35}{*}{ 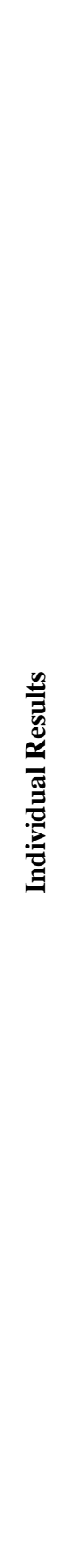 } & NIST & & & & & & & & & & \\
\hline & G701 & 0.232 & 0.226 & 0.236 & 0.231 & 0.005 & 17.7 & 16.7 & 15.1 & 16.5 & 1.3 \\
\hline & G702 & & & & & & & & & & \\
\hline & G703 & 0.242 & 0.242 & 0.249 & 0.244 & 0.004 & 13.3 & 13.5 & 13.5 & 13.4 & 0.1 \\
\hline & G704 & & & & & & & & & & \\
\hline & G705 & 0.259 & 0.283 & 0.250 & 0.264 & 0.017 & 18.2 & 18.1 & 18.0 & 18.1 & 0.1 \\
\hline & G707 & & & & & & & & & & \\
\hline & G708 & 0.161 & 0.162 & 0.188 & 0.170 & 0.015 & 23.6 & 23.5 & 23.5 & 23.5 & 0.1 \\
\hline & G715 & 0.259 & 0.281 & & 0.270 & 0.016 & 17.8 & 17.6 & & 17.7 & 0.1 \\
\hline & G716 & & & & & & & & & & \\
\hline & G717 & 0.328 & 0.331 & 0.333 & 0.331 & 0.003 & 14.9 & 14.7 & 14.7 & 14.8 & 0.1 \\
\hline & G718 & 0.374 & 0.443 & 0.379 & 0.399 & 0.039 & 16.0 & 15.4 & 15.8 & 15.7 & 0.3 \\
\hline & G722 & & & & & & & & & & \\
\hline & G724 & & & & & & & & & & \\
\hline & G728 & 0.467 & 0.264 & 0.419 & 0.383 & 0.106 & 24.8 & 24.0 & 25.4 & 24.8 & 0.7 \\
\hline & G729 & & & & & & & & & & \\
\hline & G738 & \multicolumn{2}{|l|}{0.092} & & \multicolumn{2}{|l|}{0.092} & \multicolumn{2}{|l|}{2.5} & & \multicolumn{2}{|l|}{2.5} \\
\hline & G739 & & & & & & & & & & \\
\hline & G740 & & & & & & & & & & \\
\hline & G749 & & & & & & & & & & \\
\hline & \multicolumn{11}{|l|}{ G752 } \\
\hline & \multicolumn{11}{|l|}{ G753 } \\
\hline & \multicolumn{11}{|l|}{ G757 } \\
\hline & \multicolumn{11}{|l|}{ G760 } \\
\hline & G762 & 0.215 & 0.220 & 0.215 & 0.217 & 0.003 & 16.9 & 16.9 & 15.5 & 16.5 & 0.8 \\
\hline & G765 & 0.296 & 0.303 & 0.314 & 0.304 & 0.009 & 25.4 & 24.2 & 25.1 & 24.9 & 0.6 \\
\hline & G766 & 0.128 & 0.142 & 0.129 & 0.133 & 0.008 & 13.8 & 13.2 & 13.0 & 13.3 & 0.4 \\
\hline & \multicolumn{11}{|l|}{ G767 } \\
\hline & \multicolumn{11}{|l|}{ G771 } \\
\hline & G772 & 0.642 & 0.641 & 0.600 & 0.628 & 0.024 & 15.5 & 16.6 & 17.3 & 16.5 & 0.9 \\
\hline & G773 & 0.050 & 0.051 & 0.169 & 0.090 & 0.069 & 13.9 & 13.5 & 12.2 & 13.2 & 0.9 \\
\hline & \multicolumn{11}{|l|}{ G774 } \\
\hline & G775 & 0.102 & 0.109 & 0.109 & 0.107 & 0.004 & 15.7 & 15.5 & 15.7 & 15.6 & 0.1 \\
\hline & \multicolumn{11}{|l|}{ G776 } \\
\hline & G777 & 0.213 & 0.206 & 0.221 & 0.213 & 0.007 & 22.6 & 22.6 & 20.1 & 21.7 & 1.4 \\
\hline \multirow{5}{*}{ 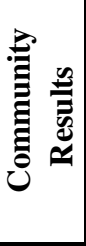 } & & \multirow{5}{*}{\multicolumn{3}{|c|}{$\begin{array}{l}\text { Consensus Mean } \\
\text { Consensus Standard Deviation } \\
\text { Maximum } \\
\text { Minimum } \\
\text { N }\end{array}$}} & 0.252 & & Conser & Mean & & 17.6 & \\
\hline & & & & & 0.118 & & Conser & Stand & eviation & 4.4 & \\
\hline & & & & & 0.628 & & Maxim & & & 24.9 & \\
\hline & & & & & 0.090 & & Minimu & & & 2.5 & \\
\hline & & & & & 15 & & $\mathrm{~N}$ & & & 15 & \\
\hline
\end{tabular}


Table 34. Data summary table for petunidin in dietary supplements.

\begin{tabular}{|c|c|c|c|c|c|c|c|c|c|c|c|}
\hline & \multirow[b]{3}{*}{ Lab } & \multicolumn{10}{|c|}{ Petunidin } \\
\hline & & \multicolumn{5}{|c|}{ SRM 3283 Cranberry Extract (mg/g) } & \multicolumn{5}{|c|}{ SRM 3291 Bilberry Extract (mg/g) } \\
\hline & & A & B & C & Avg & SD & A & B & C & Avg & SD \\
\hline \multirow{35}{*}{ 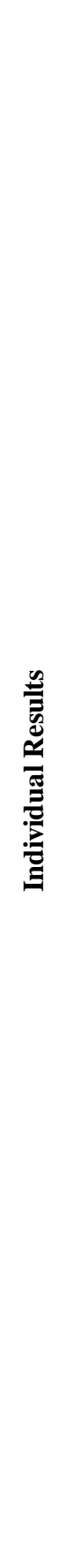 } & NIST & & & & & & & & & & \\
\hline & G701 & & & & & & & & & & \\
\hline & G702 & & & & & & & & & & \\
\hline & G703 & & & & & & 1.230 & 1.210 & 1.230 & 1.223 & 0.012 \\
\hline & G704 & & & & & & & & & & \\
\hline & G705 & & & & & & 0.750 & 0.742 & 0.765 & 0.752 & 0.012 \\
\hline & G707 & & & & & & & & & & \\
\hline & G708 & & & & & & & & & & \\
\hline & G715 & 0.086 & 0.107 & & 0.097 & 0.015 & 0.766 & 0.724 & & 0.745 & 0.030 \\
\hline & G716 & & & & & & & & & & \\
\hline & G717 & & & & & & 0.576 & 0.556 & 0.586 & 0.573 & 0.015 \\
\hline & G718 & & & & & & 0.350 & 0.324 & 0.343 & 0.339 & 0.013 \\
\hline & G722 & & & & & & & & & & \\
\hline & G724 & & & & & & & & & & \\
\hline & G728 & & & & & & 0.724 & 0.562 & 0.531 & 0.606 & 0.104 \\
\hline & G729 & & & & & & & & & & \\
\hline & G738 & & & & & & & & & & \\
\hline & G739 & & & & & & & & & & \\
\hline & G740 & & & & & & & & & & \\
\hline & G749 & & & & & & & & & & \\
\hline & G752 & & & & & & & & & & \\
\hline & G753 & & & & & & & & & & \\
\hline & G757 & & & & & & & & & & \\
\hline & G760 & & & & & & & & & & \\
\hline & G762 & & & & & & & & & & \\
\hline & G765 & & & & & & 0.460 & 0.540 & 0.490 & 0.497 & 0.040 \\
\hline & G766 & & & & & & & & & & \\
\hline & G767 & & & & & & & & & & \\
\hline & G771 & & & & & & & & & & \\
\hline & G772 & & & & & & & & & & \\
\hline & G773 & 0.150 & 0.180 & 0.180 & 0.170 & 0.017 & 0.540 & 0.670 & 0.610 & 0.607 & 0.065 \\
\hline & G774 & & & & & & & & & & \\
\hline & G775 & & & & & & 1.487 & 1.478 & 1.471 & 1.479 & 0.008 \\
\hline & G776 & & & & & & & & & & \\
\hline & G777 & & & & & & 0.961 & 0.959 & 0.941 & 0.954 & 0.011 \\
\hline \multirow{5}{*}{ 离 } & & \multirow{5}{*}{\multicolumn{3}{|c|}{$\begin{array}{l}\text { Consensus Mean } \\
\text { Consensus Standard Deviation } \\
\text { Maximum } \\
\text { Minimum } \\
\mathrm{N}\end{array}$}} & 0.133 & & \multirow{5}{*}{\multicolumn{3}{|c|}{$\begin{array}{l}\text { Consensus Mean } \\
\text { Consensus Standard Deviation } \\
\text { Maximum } \\
\text { Minimum } \\
\text { N }\end{array}$}} & 0.757 & \\
\hline & & & & & 0.059 & & & & & 0.348 & \\
\hline & & & & & 0.170 & & & & & 1.479 & \\
\hline & & & & & 0.097 & & & & & 0.339 & \\
\hline & & & & & 2 & & & & & 11 & \\
\hline
\end{tabular}


Table 35. Data summary table for petunidin-3-arabinoside in dietary supplements.

\begin{tabular}{|c|c|c|c|c|c|c|c|c|c|c|c|}
\hline & \multirow[b]{3}{*}{ Lab } & \multicolumn{10}{|c|}{ Petunidin-3-Arabinoside } \\
\hline & & \multicolumn{5}{|c|}{ SRM 3283 Cranberry Extract (mg/g) } & \multicolumn{5}{|c|}{ SRM 3291 Bilberry Extract (mg/g) } \\
\hline & & $\mathbf{A}$ & $\overline{\mathbf{B}}$ & $\bar{C}$ & Avg & SD & A & B & $\mathrm{C}$ & Avg & SD \\
\hline \multirow{35}{*}{ 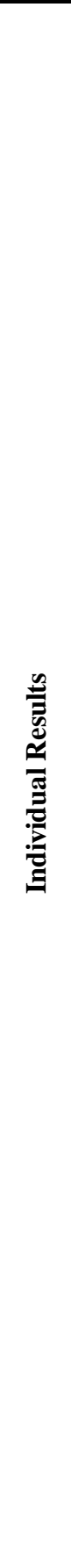 } & \multicolumn{11}{|l|}{ NIST } \\
\hline & \multicolumn{11}{|l|}{ G701 } \\
\hline & \multicolumn{11}{|l|}{ G702 } \\
\hline & G703 & & & & & & 8.3 & 8.3 & 8.4 & 8.3 & 0.1 \\
\hline & \multicolumn{11}{|l|}{ G704 } \\
\hline & G705 & & & & & & 11.1 & 11.0 & 11.1 & 11.1 & 0.1 \\
\hline & \multicolumn{11}{|l|}{ G707 } \\
\hline & G708 & & & & & & 10.9 & 10.8 & 10.8 & 10.8 & 0.1 \\
\hline & G715 & & & & & & 10.3 & 10.3 & & 10.3 & 0.0 \\
\hline & \multicolumn{11}{|l|}{ G716 } \\
\hline & G717 & & & & & & 9.9 & 9.7 & 9.7 & 9.8 & 0.1 \\
\hline & G718 & & & & & & 10.2 & 9.9 & 10.2 & 10.1 & 0.2 \\
\hline & \multicolumn{11}{|l|}{ G722 } \\
\hline & \multicolumn{11}{|l|}{ G724 } \\
\hline & G728 & & & & & & 11.7 & 12.0 & 12.2 & 11.9 & 0.3 \\
\hline & \multicolumn{11}{|l|}{ G729 } \\
\hline & \multicolumn{11}{|l|}{ G738 } \\
\hline & \multicolumn{11}{|l|}{ G739 } \\
\hline & \multicolumn{11}{|l|}{ G740 } \\
\hline & \multicolumn{11}{|c|}{ G749 } \\
\hline & \multicolumn{11}{|c|}{ G752 } \\
\hline & \multicolumn{11}{|c|}{ G753 } \\
\hline & G757 & & & & & & & & & & \\
\hline & G760 & & & & & & & & & & \\
\hline & G762 & & & & & & 10.9 & 10.9 & 10.0 & 10.6 & 0.5 \\
\hline & G765 & & & & & & 14.3 & 13.7 & 13.9 & 14.0 & 0.3 \\
\hline & G766 & & & & & & 11.1 & 10.6 & 10.6 & 10.7 & 0.3 \\
\hline & G767 & & & & & & & & & & \\
\hline & G771 & & & & & & & & & & \\
\hline & G772 & & & & & & & & & & \\
\hline & G773 & & & & & & 9.1 & 9.2 & 7.9 & 8.7 & 0.7 \\
\hline & G774 & & & & & & & & & & \\
\hline & G775 & & & & & & 9.3 & 9.4 & 9.3 & 9.3 & 0.0 \\
\hline & G776 & & & & & & & & & & \\
\hline & G777 & & & & & & & & & & \\
\hline & & Conse & Меa & & & & Conser & Mean & & 10.3 & \\
\hline 音气 & & Conse & $\tan$ & evia & & & Conser & Stand & Deviation & 1.3 & \\
\hline E $\bar{g}$ & & Maxin & & & & & Maxim & & & 14.0 & \\
\hline & & Minim & & & & & Minimı & & & 8.3 & \\
\hline & & $\mathrm{N}$ & & & 0 & & $\mathrm{~N}$ & & & 12 & \\
\hline
\end{tabular}


Table 36. Data summary table for petunidin-3-galactoside in dietary supplements.

\begin{tabular}{|c|c|c|c|c|c|c|c|c|c|c|c|}
\hline & \multirow[b]{3}{*}{ Lab } & \multicolumn{10}{|c|}{ Petunidin-3-Galactoside } \\
\hline & & \multicolumn{5}{|c|}{ SRM 3283 Cranberry Extract (mg/g) } & \multicolumn{5}{|c|}{ SRM 3291 Bilberry Extract (mg/g) } \\
\hline & & A & B & C & Avg & SD & A & B & C & Avg & SD \\
\hline \multirow{35}{*}{ 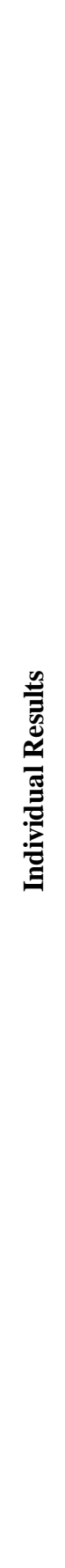 } & NIST & & & & & & & & & & \\
\hline & G701 & & & & & & & & & & \\
\hline & G702 & & & & & & & & & & \\
\hline & G703 & & & & & & 13.1 & 13.3 & 13.3 & 13.2 & 0.1 \\
\hline & G704 & & & & & & & & & & \\
\hline & G705 & & & & & & & & & & \\
\hline & G707 & & & & & & & & & & \\
\hline & G708 & & & & & & 16.7 & 16.5 & 16.7 & 16.6 & 0.1 \\
\hline & G715 & 0.1700 & 0.1640 & & 0.1670 & 0.0042 & 20.5 & 21.9 & & 21.2 & 1.1 \\
\hline & G716 & & & & & & & & & & \\
\hline & G717 & & & & & & 21.2 & 21.3 & 22.7 & 21.7 & 0.9 \\
\hline & G718 & & & & & & 16.2 & 15.6 & 16.2 & 16.0 & 0.3 \\
\hline & G722 & & & & & & & & & & \\
\hline & G724 & & & & & & & & & & \\
\hline & G728 & & & & & & 18.6 & 12.8 & 20.6 & 17.3 & 4.1 \\
\hline & G729 & & & & & & & & & & \\
\hline & G738 & & & & & & & & & & \\
\hline & G739 & & & & & & & & & & \\
\hline & G740 & & & & & & & & & & \\
\hline & G749 & & & & & & & & & & \\
\hline & G752 & & & & & & & & & & \\
\hline & G753 & & & & & & & & & & \\
\hline & G757 & & & & & & & & & & \\
\hline & G760 & & & & & & & & & & \\
\hline & G762 & 0.0297 & 0.0330 & 0.0319 & 0.0315 & 0.0017 & 16.8 & 16.8 & 15.5 & 16.4 & 0.8 \\
\hline & G765 & & & & & & 22.1 & 21.1 & 21.5 & 21.6 & 0.5 \\
\hline & G766 & & & & & & 13.2 & 12.4 & 12.5 & 12.7 & 0.5 \\
\hline & G767 & & & & & & & & & & \\
\hline & G771 & & & & & & & & & & \\
\hline & G772 & & & & & & & & & & \\
\hline & G773 & & & & & & 13.1 & 13.5 & 12.0 & 12.9 & 0.8 \\
\hline & G774 & & & & & & & & & & \\
\hline & G775 & & & & & & 15.2 & 15.2 & 15.2 & 15.2 & 0.0 \\
\hline & G776 & & & & & & & & & & \\
\hline & G777 & & & & & & & & & & \\
\hline \multirow{5}{*}{ 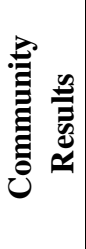 } & & \multicolumn{3}{|c|}{ Consensus Mean } & \multicolumn{2}{|l|}{0.0993} & \multicolumn{3}{|c|}{ Consensus Mean } & 16.8 & \\
\hline & & \multicolumn{3}{|c|}{ Consensus Standard Deviation } & \multicolumn{2}{|l|}{0.1086} & \multicolumn{4}{|c|}{ Consensus Standard Deviation 3.8} & \\
\hline & & \multicolumn{3}{|c|}{ Maximum } & \multicolumn{2}{|l|}{0.1670} & \multicolumn{2}{|c|}{ Maximum } & & 21.7 & \\
\hline & & \multicolumn{3}{|c|}{ Minimum } & \multicolumn{2}{|l|}{0.0315} & \multicolumn{2}{|c|}{ Minimum } & & 12.7 & \\
\hline & & $\mathrm{N}$ & & & 2 & & $\mathrm{~N}$ & & & 11 & \\
\hline
\end{tabular}


Table 37. Data summary table for petunidin-3-glucoside in dietary supplements.

\begin{tabular}{|c|c|c|c|c|c|c|c|c|c|c|c|}
\hline & \multirow[b]{3}{*}{ Lab } & \multicolumn{10}{|c|}{ Petunidin-3-Glucoside } \\
\hline & & \multicolumn{5}{|c|}{ SRM 3283 Cranberry Extract (mg/g) } & \multicolumn{5}{|c|}{ SRM 3291 Bilberry Extract (mg/g) } \\
\hline & & A & B & C & Avg & SD & A & B & C & Avg & SD \\
\hline \multirow{35}{*}{ 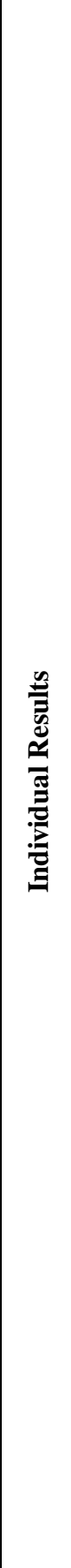 } & NIST & & & & & & & & & & \\
\hline & G701 & & & & & & 57.8 & 49.6 & 53.0 & 53.5 & 4.1 \\
\hline & G702 & & & & & & & & & & \\
\hline & G703 & & & & & & 27.3 & 27.7 & 27.6 & 27.5 & 0.2 \\
\hline & G704 & & & & & & & & & & \\
\hline & G705 & & & & & & 33.5 & 34.5 & 34.6 & 34.2 & 0.6 \\
\hline & G707 & & & & & & & & & & \\
\hline & G708 & & & & & & 34.0 & 34.0 & 34.2 & 34.1 & 0.1 \\
\hline & G715 & & & & & & 29.4 & 30.6 & & 30.0 & 0.8 \\
\hline & G716 & & & & & & & & & & \\
\hline & G717 & & & & & & 32.6 & 33.7 & 33.6 & 33.3 & 0.6 \\
\hline & G718 & 0.0440 & & 0.0440 & 0.0440 & 0.0000 & 33.2 & 32.0 & 33.2 & 32.8 & 0.7 \\
\hline & G722 & & & & & & & & & & \\
\hline & G724 & & & & & & & & & & \\
\hline & G728 & & & & & & 39.9 & 37.5 & 39.6 & 39.0 & 1.3 \\
\hline & G729 & & & & & & & & & & \\
\hline & G738 & & & & & & & & & & \\
\hline & G739 & & & & & & & & & & \\
\hline & G740 & & & & & & & & & & \\
\hline & G749 & & & & & & & & & & \\
\hline & G752 & & & & & & & & & & \\
\hline & G753 & & & & & & & & & & \\
\hline & G757 & & & & & & & & & & \\
\hline & G760 & & & & & & & & & & \\
\hline & G762 & 0.0056 & 0.0057 & 0.0060 & 0.0058 & 0.0002 & 34.0 & 33.9 & 31.0 & 33.0 & 1.7 \\
\hline & G765 & & & & & & 44.3 & 42.3 & 43.0 & 43.2 & 1.0 \\
\hline & G766 & & & & & & 26.2 & 25.2 & 25.3 & 25.6 & 0.6 \\
\hline & G767 & & & & & & & & & & \\
\hline & G771 & & & & & & & & & & \\
\hline & G772 & & & & & & & & & & \\
\hline & G773 & & 0.0180 & & 0.0180 & & 23.8 & 23.0 & 21.5 & 22.8 & 1.2 \\
\hline & G774 & & & & & & & & & & \\
\hline & G775 & 0.1866 & 0.1918 & 0.1945 & 0.1910 & 0.0040 & 30.1 & 30.2 & 30.2 & 30.2 & 0.1 \\
\hline & G776 & & & & & & & & & & \\
\hline & G777 & 0.0070 & 0.0060 & 0.0060 & 0.0063 & 0.0006 & 31.9 & 32.0 & 32.0 & 31.9 & 0.0 \\
\hline \multirow{5}{*}{ 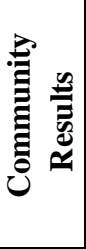 } & & \multirow{5}{*}{\multicolumn{3}{|c|}{$\begin{array}{l}\text { Consensus Mean } \\
\text { Consensus Standard Deviation } \\
\text { Maximum } \\
\text { Minimum } \\
\mathrm{N}\end{array}$}} & 0.0618 & & \multirow{5}{*}{\multicolumn{3}{|c|}{$\begin{array}{l}\text { Consensus Mean } \\
\text { Consensus Standard Deviation } \\
\text { Maximum } \\
\text { Minimum } \\
\mathrm{N}\end{array}$}} & 32.7 & \\
\hline & & & & & 0.0998 & & & & & 6.0 & \\
\hline & & & & & 0.1910 & & & & & 53.5 & \\
\hline & & & & & 0.0058 & & & & & 22.8 & \\
\hline & & & & & 4 & & & & & 14 & \\
\hline
\end{tabular}


Table 38. Data summary table for petunidin equivalents in dietary supplements.

\begin{tabular}{|c|c|c|c|c|c|c|c|c|c|c|c|}
\hline & \multirow[b]{3}{*}{ Lab } & \multicolumn{10}{|c|}{ Petunidin Equivalents } \\
\hline & & \multicolumn{5}{|c|}{ SRM 3283 Cranberry Extract (mg/g) } & \multicolumn{5}{|c|}{ SRM 3291 Bilberry Extract (mg/g) } \\
\hline & & A & B & C & Avg & SD & A & B & C & Avg & SD \\
\hline \multirow{35}{*}{ 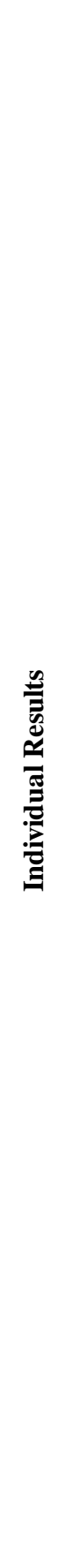 } & NIST & & & & & & & & & & \\
\hline & G701 & & & & & & 38.3 & 32.8 & 35.1 & 35.4 & 2.7 \\
\hline & G702 & & & & & & & & & & \\
\hline & G703 & & & & & & 33.8 & 34.2 & 34.2 & 34.1 & 0.2 \\
\hline & G704 & & & & & & & & & & \\
\hline & G705 & & & & & & 30.8 & 31.3 & 31.5 & 31.2 & 0.4 \\
\hline & G707 & & & & & & & & & & \\
\hline & G708 & & & & & & 41.2 & 41.0 & 41.3 & 41.2 & 0.1 \\
\hline & G715 & 0.1985 & 0.2155 & & 0.2070 & 0.0120 & 41.0 & 42.8 & & 41.9 & 1.2 \\
\hline & G716 & & & & & & & & & & \\
\hline & G717 & & & & & & 43.1 & 43.8 & 44.7 & 43.9 & 0.8 \\
\hline & G718 & 0.0291 & & 0.0291 & 0.0291 & 0.0000 & 40.3 & 38.9 & 40.2 & 39.8 & 0.8 \\
\hline & G722 & & & & & & & & & & \\
\hline & G724 & & & & & & & & & & \\
\hline & G728 & & & & & & 47.7 & 42.3 & 49.0 & 46.3 & 3.6 \\
\hline & G729 & & & & & & & & & & \\
\hline & G738 & & & & & & 12.1 & & & 12.1 & \\
\hline & G739 & & & & & & & & & & \\
\hline & G740 & & & & & & & & & & \\
\hline & G749 & & & & & & & & & & \\
\hline & G752 & & & & & & & & & & \\
\hline & G753 & & & & & & & & & & \\
\hline & G757 & & & & & & & & & & \\
\hline & G760 & & & & & & & & & & \\
\hline & G762 & 0.0233 & 0.0256 & 0.0251 & 0.0247 & 0.0012 & 41.3 & 41.2 & 37.8 & 40.1 & 2.0 \\
\hline & G765 & & & & & & 54.5 & 52.2 & 53.0 & 53.2 & 1.2 \\
\hline & G766 & & & & & & 34.0 & 32.4 & 32.4 & 32.9 & 0.9 \\
\hline & G767 & & & & & & & & & & \\
\hline & G771 & & & & & & & & & & \\
\hline & G772 & & & & & & 41.9 & 44.4 & 45.3 & 43.9 & 1.8 \\
\hline & G773 & 0.1500 & 0.1919 & 0.1800 & 0.1740 & 0.0216 & 31.4 & 31.3 & 28.4 & 30.4 & 1.7 \\
\hline & G774 & & & & & & & & & & \\
\hline & G775 & 0.1235 & 0.1269 & 0.1287 & 0.1264 & 0.0027 & 38.0 & 38.2 & 38.1 & 38.1 & 0.1 \\
\hline & G776 & & & & & & & & & & \\
\hline & G777 & 0.0046 & 0.0040 & 0.0040 & 0.0042 & 0.0004 & 22.1 & 22.1 & 22.1 & 22.1 & 0.0 \\
\hline \multirow{5}{*}{ 竭 } & & \multicolumn{3}{|c|}{ Consensus Mean } & \multicolumn{2}{|l|}{0.0942} & \multicolumn{2}{|c|}{ Consensus Mean } & & 38.4 & \\
\hline & & \multicolumn{3}{|c|}{ Consensus Standard Deviation } & \multicolumn{2}{|l|}{0.0979} & \multicolumn{3}{|c|}{ Consensus Standard Deviation } & 7.1 & \\
\hline & & \multicolumn{3}{|c|}{ Maximum } & \multicolumn{2}{|l|}{0.2070} & \multicolumn{3}{|c|}{ Maximum } & 53.2 & \\
\hline & & \multicolumn{3}{|c|}{ Minimum } & \multicolumn{2}{|l|}{0.0042} & \multicolumn{3}{|c|}{ Minimum } & 12.1 & \\
\hline & & \multicolumn{3}{|l|}{$\mathrm{N}$} & 6 & & $\mathrm{~N}$ & & & 15 & \\
\hline
\end{tabular}


Table 39. Data summary table for total anthocyanins in dietary supplements.

\begin{tabular}{|c|c|c|c|c|c|c|c|c|c|c|c|}
\hline & \multirow[b]{3}{*}{ Lab } & \multicolumn{10}{|c|}{ Total Anthocyanins } \\
\hline & & \multicolumn{5}{|c|}{ SRM 3283 Cranberry Extract (mg/g) } & \multicolumn{5}{|c|}{ SRM 3291 Bilberry Extract (mg/g) } \\
\hline & & A & B & C & Avg & SD & A & B & C & Avg & SD \\
\hline \multirow{35}{*}{ 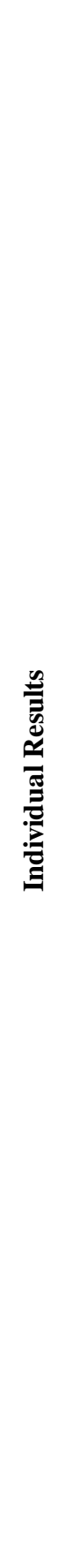 } & NIST & & & & & & & & & & \\
\hline & G701 & 0.734 & 0.729 & 0.768 & 0.744 & 0.021 & 380 & 336 & 334 & 350 & 26 \\
\hline & G702 & & & & & & & & & & \\
\hline & G703 & 0.676 & 0.651 & 0.644 & 0.657 & 0.017 & 310 & 314 & 314 & 313 & 2 \\
\hline & G704 & & & & & & & & & & \\
\hline & G705 & 0.696 & 0.768 & 0.675 & 0.713 & 0.049 & 390 & 387 & 387 & 388 & 2 \\
\hline & G707 & & & & & & & & & & \\
\hline & G708 & 0.891 & 0.895 & 0.958 & 0.915 & 0.038 & 376 & 374 & 376 & 375 & 1 \\
\hline & G715 & 0.910 & 0.982 & & 0.946 & 0.051 & 366 & 368 & & 367 & 2 \\
\hline & G716 & 1.700 & 1.800 & 1.900 & 1.800 & 0.100 & 290 & 280 & 270 & 280 & 10 \\
\hline & G717 & 0.798 & 0.796 & 0.808 & 0.801 & 0.006 & 371 & 367 & 367 & 368 & 2 \\
\hline & G718 & 1.337 & 1.321 & 1.280 & 1.313 & 0.029 & 424 & 409 & 424 & 419 & 9 \\
\hline & G722 & & & & & & & & & & \\
\hline & G724 & 0.730 & 0.770 & 0.770 & 0.757 & 0.023 & 282 & 281 & 282 & 282 & 1 \\
\hline & G728 & 1.270 & 0.841 & 1.187 & 1.099 & 0.228 & 457 & 443 & 457 & 453 & 8 \\
\hline & G729 & & & & & & & & & & \\
\hline & G738 & 0.476 & & & 0.476 & & 97 & & & 97 & \\
\hline & G739 & & & & & & & & & & \\
\hline & G740 & & & & & & & & & & \\
\hline & G749 & & & & & & & & & & \\
\hline & G752 & & & & & & & & & & \\
\hline & G753 & & & & & & & & & & \\
\hline & G757 & 10.100 & 11.100 & 10.200 & 10.467 & 0.551 & 433 & 444 & 419 & 432 & 13 \\
\hline & G760 & & & & & & & & & & \\
\hline & G762 & 0.685 & 0.710 & 0.699 & 0.698 & 0.013 & 388 & 387 & 357 & 377 & 18 \\
\hline & G765 & 0.847 & 0.867 & 0.917 & 0.877 & 0.036 & 543 & 519 & 528 & 530 & 12 \\
\hline & G766 & 0.745 & 0.745 & 0.720 & 0.737 & 0.014 & 303 & 296 & 297 & 298 & 4 \\
\hline & G767 & & & & & & & & & & \\
\hline & G771 & & & & & & & & & & \\
\hline & G772 & 2.200 & 2.196 & 2.102 & 2.166 & 0.055 & 243 & 257 & 260 & 253 & 9 \\
\hline & G773 & 0.507 & 0.676 & 0.720 & 0.634 & 0.112 & 302 & 303 & 272 & 292 & 17 \\
\hline & G774 & & & & & & & & & & \\
\hline & G775 & 0.696 & 0.717 & 0.702 & 0.705 & 0.010 & 340 & 341 & 341 & 340 & 1 \\
\hline & G776 & & & & & & & & & & \\
\hline & G777 & 1.267 & 1.233 & 1.292 & 1.264 & 0.030 & 428 & 428 & 424 & 427 & 2 \\
\hline \multirow{5}{*}{ 竭 } & & \multicolumn{3}{|c|}{ Consensus Mean } & \multicolumn{2}{|l|}{0.934} & \multicolumn{3}{|c|}{ Consensus Mean } & 354 & \\
\hline & & \multicolumn{3}{|c|}{ Consensus Standard Deviation } & \multicolumn{2}{|l|}{0.358} & \multicolumn{3}{|c|}{ Consensus Standard Deviation } & 78 & \\
\hline & & \multicolumn{3}{|c|}{ Maximum } & \multicolumn{2}{|l|}{10.467} & \multicolumn{3}{|c|}{ Maximum } & 530 & \\
\hline & & \multicolumn{3}{|c|}{ Minimum } & \multicolumn{2}{|l|}{0.476} & \multicolumn{3}{|c|}{ Minimum } & 97 & \\
\hline & & \multicolumn{3}{|l|}{$\mathrm{N}$} & 18 & & $\mathrm{~N}$ & & & 18 & \\
\hline
\end{tabular}




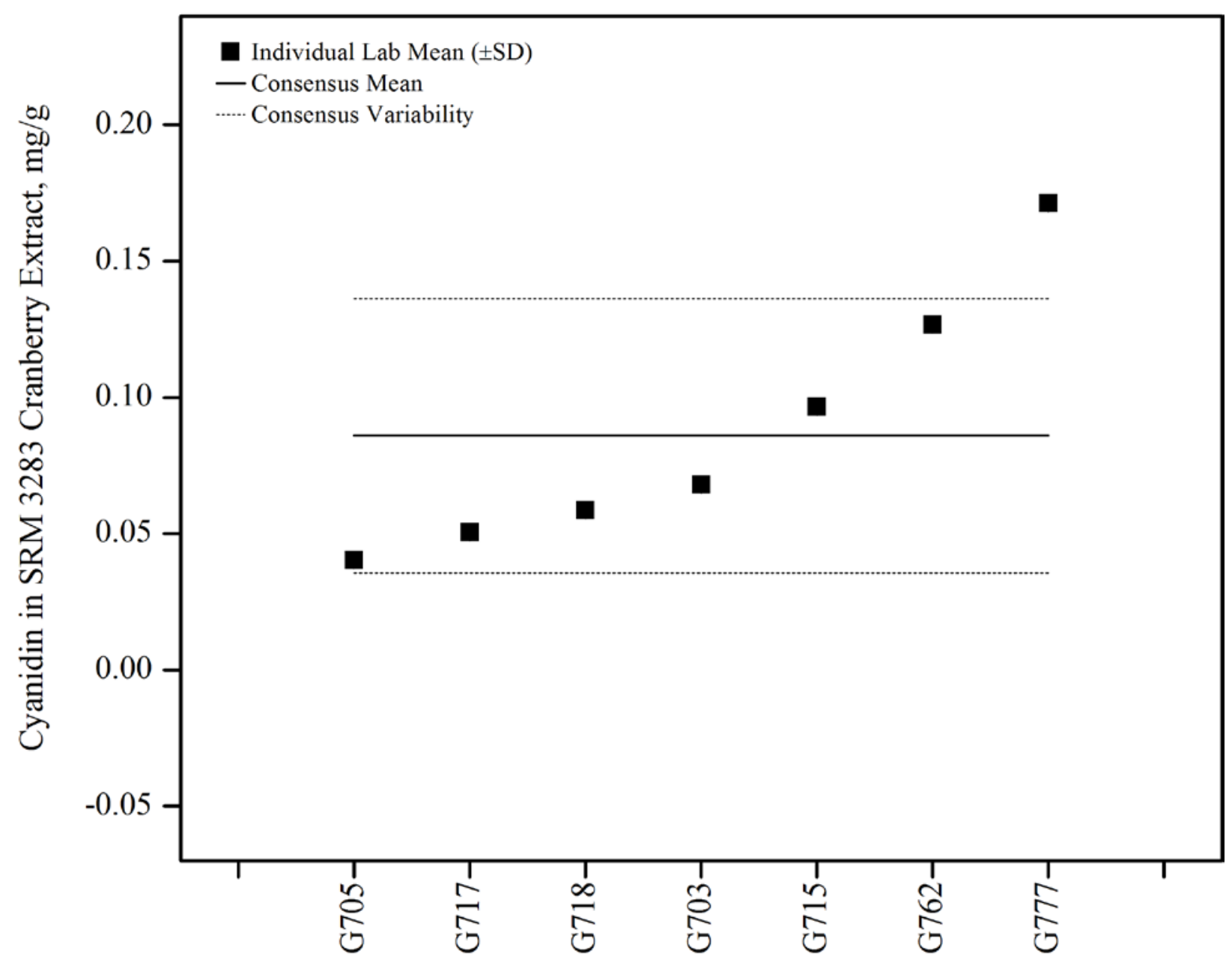

Figure 28. Cyanidin in SRM 3283 Cranberry Extract (data summary view). In this view, individual laboratory data are plotted with the individual laboratory standard deviation (error bars). The black solid line represents the consensus mean, and the black dotted lines represent the consensus variability calculated as one standard deviation about the consensus mean. 


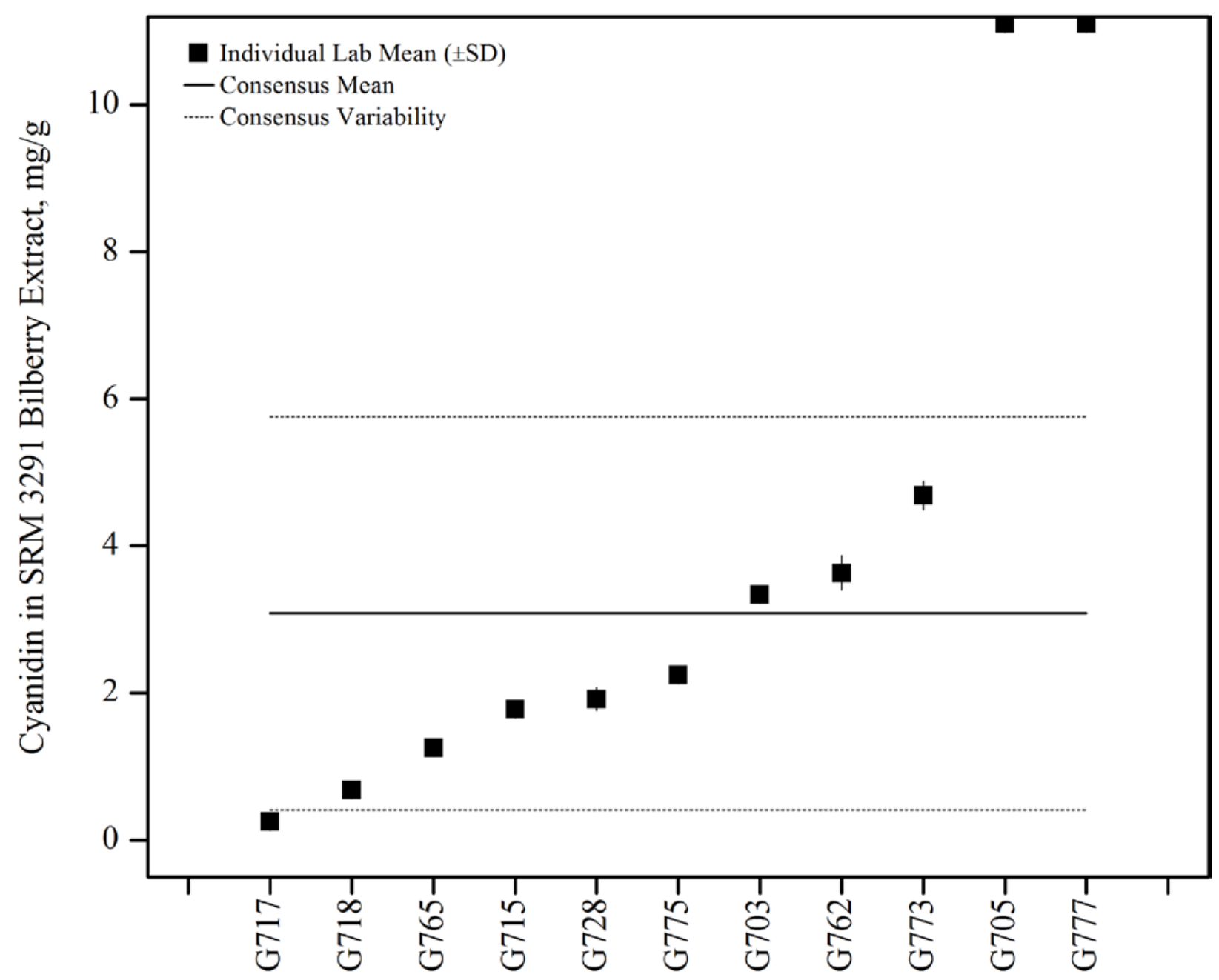

Figure 29. Cyanidin in SRM 3291 Bilberry Extract (data summary view). In this view, individual laboratory data are plotted with the individual laboratory standard deviation (error bars). The black solid line represents the consensus mean, and the black dotted lines represent the consensus variability calculated as one standard deviation about the consensus mean. 


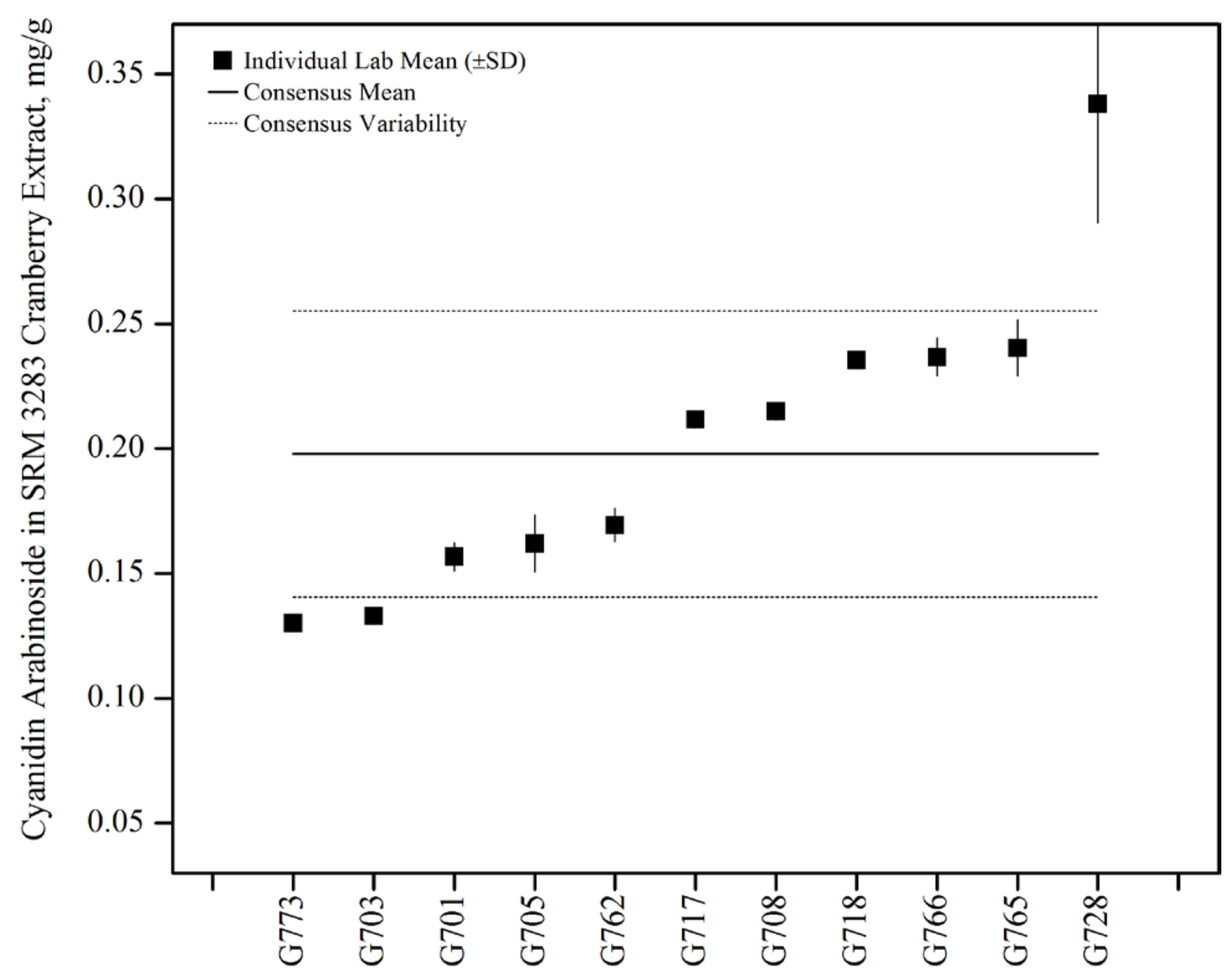

Figure 30. Cyanidin-3-arabinoside in SRM 3283 Cranberry Extract (data summary view). In this view, individual laboratory data are plotted with the individual laboratory standard deviation (error bars). The black solid line represents the consensus mean, and the black dotted lines represent the consensus variability calculated as one standard deviation about the consensus mean. 


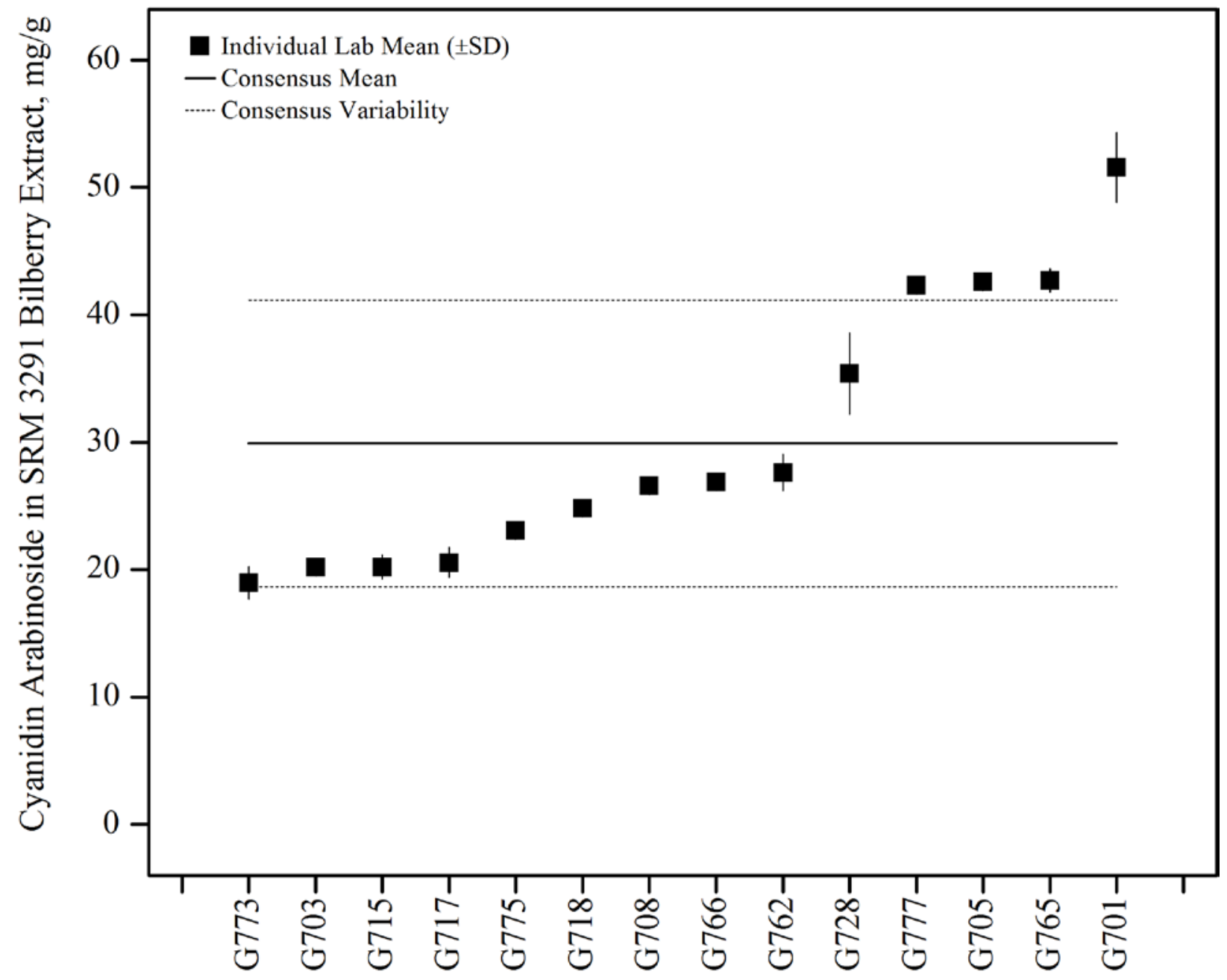

Figure 31. Cyanidin-3-arabinoside in SRM 3291 Bilberry Extract (data summary view). In this view, individual laboratory data are plotted with the individual laboratory standard deviation (error bars). The black solid line represents the consensus mean, and the black dotted lines represent the consensus variability calculated as one standard deviation about the consensus mean. 


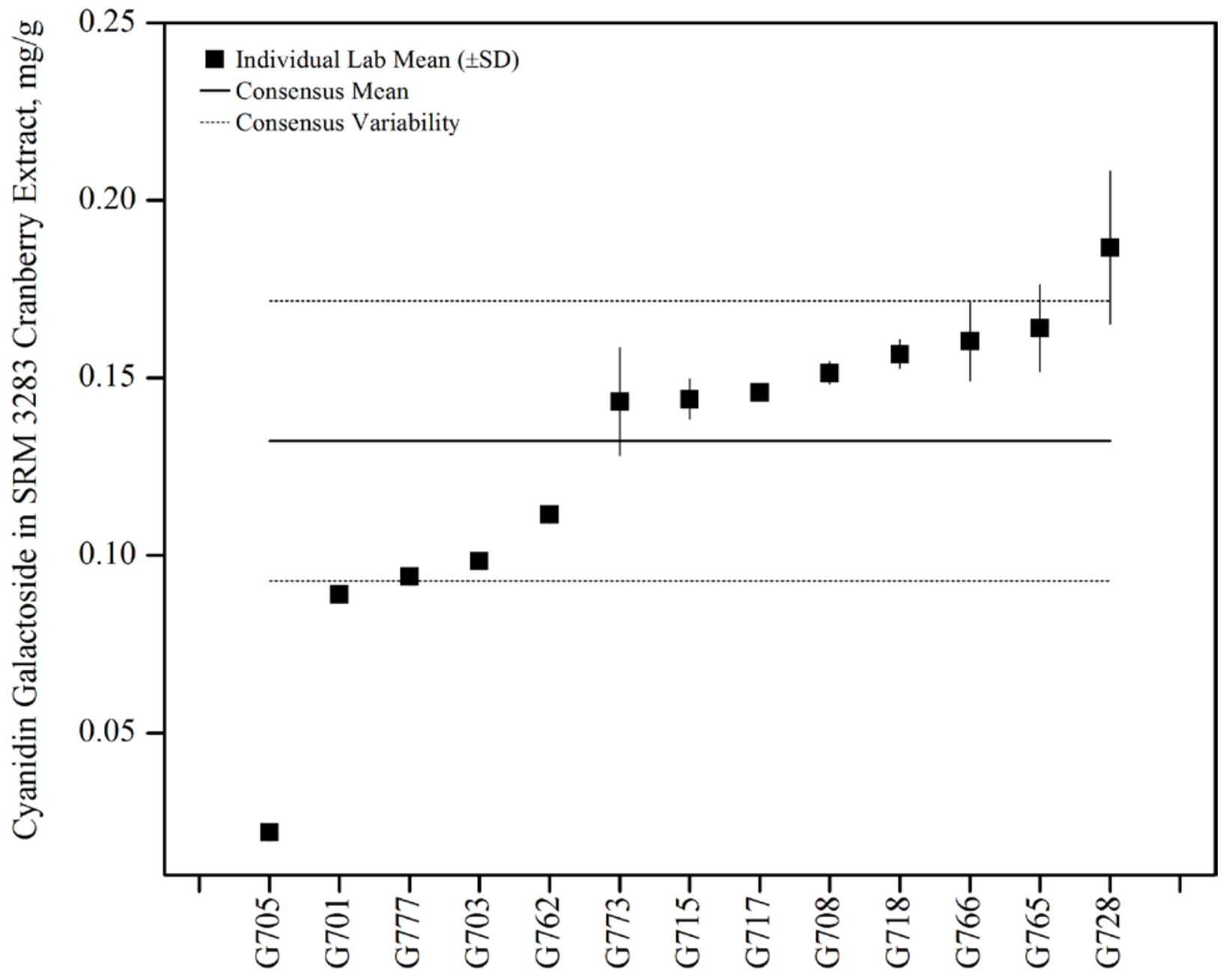

Figure 32. Cyanidin-3-galactoside in SRM 3283 Cranberry Extract (data summary view). In this view, individual laboratory data are plotted with the individual laboratory standard deviation (error bars). The black solid line represents the consensus mean, and the black dotted lines represent the consensus variability calculated as one standard deviation about the consensus mean. 


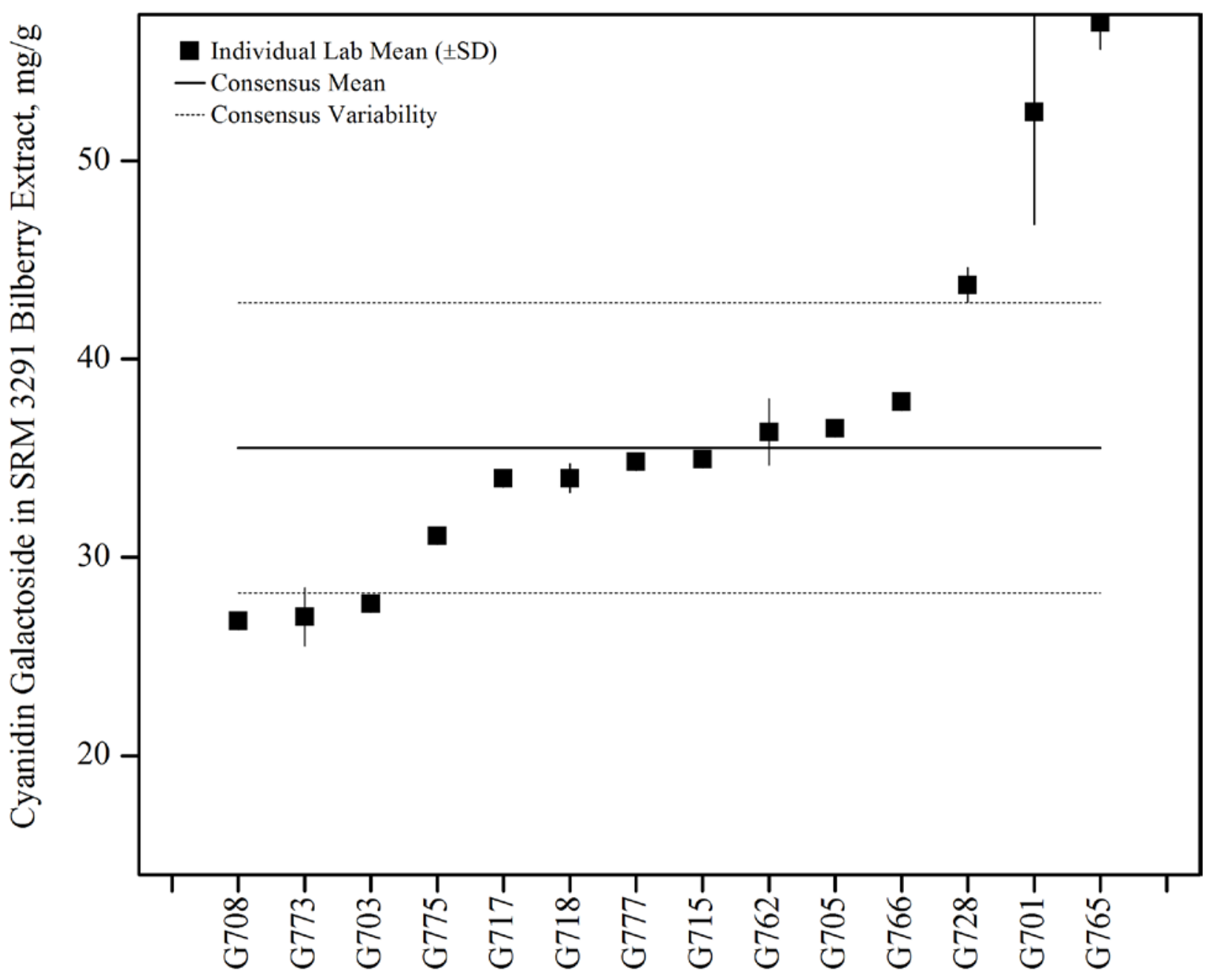

Figure 33. Cyanidin-3-galactoside in SRM 3291 Bilberry Extract (data summary view). In this view, individual laboratory data are plotted with the individual laboratory standard deviation (error bars). The black solid line represents the consensus mean, and the black dotted lines represent the consensus variability calculated as one standard deviation about the consensus mean. 


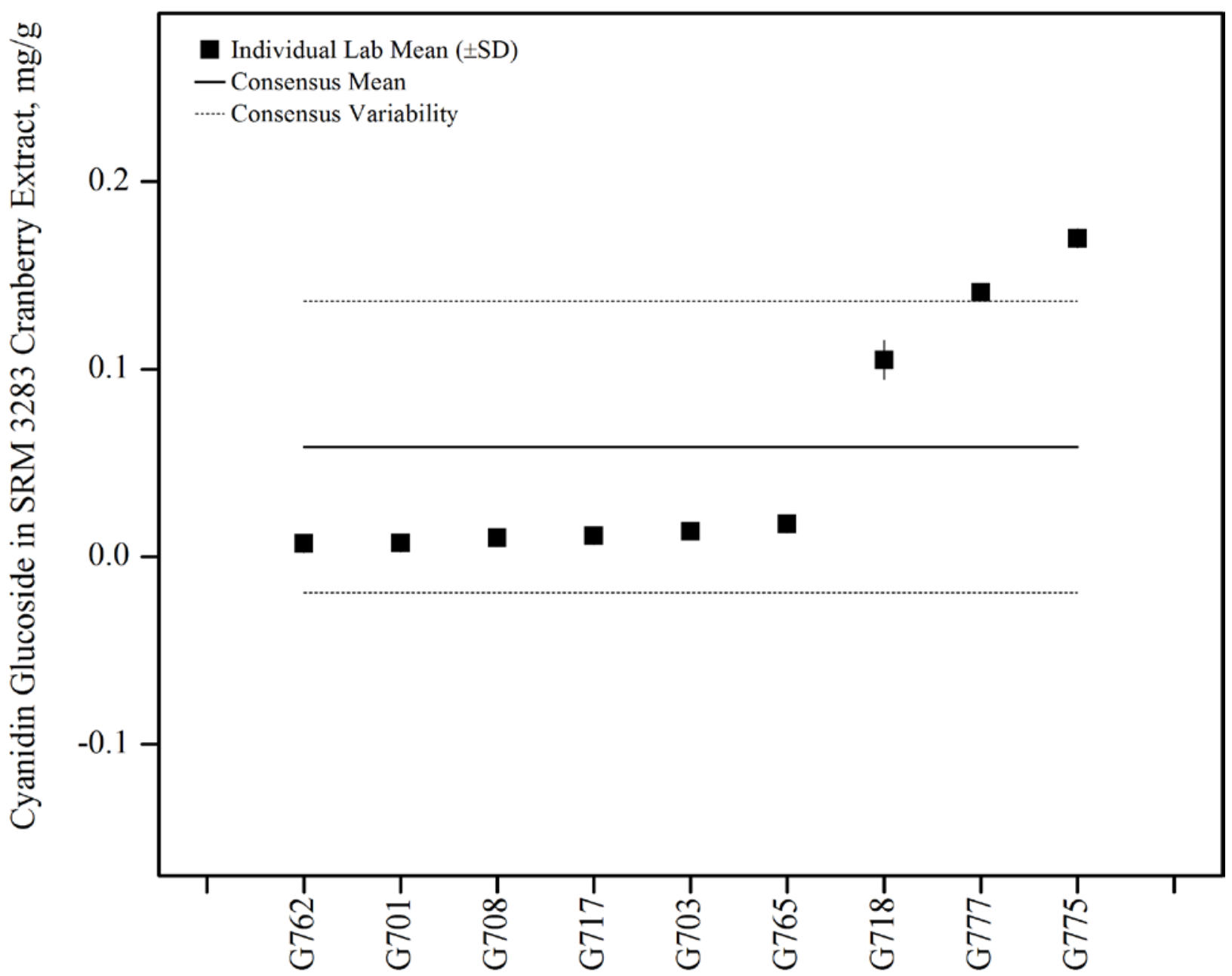

Figure 34. Cyanidin-3-glucoside in SRM 3283 Cranberry Extract (data summary view). In this view, individual laboratory data are plotted with the individual laboratory standard deviation (error bars). The black solid line represents the consensus mean, and the black dotted lines represent the consensus variability calculated as one standard deviation about the consensus mean. 


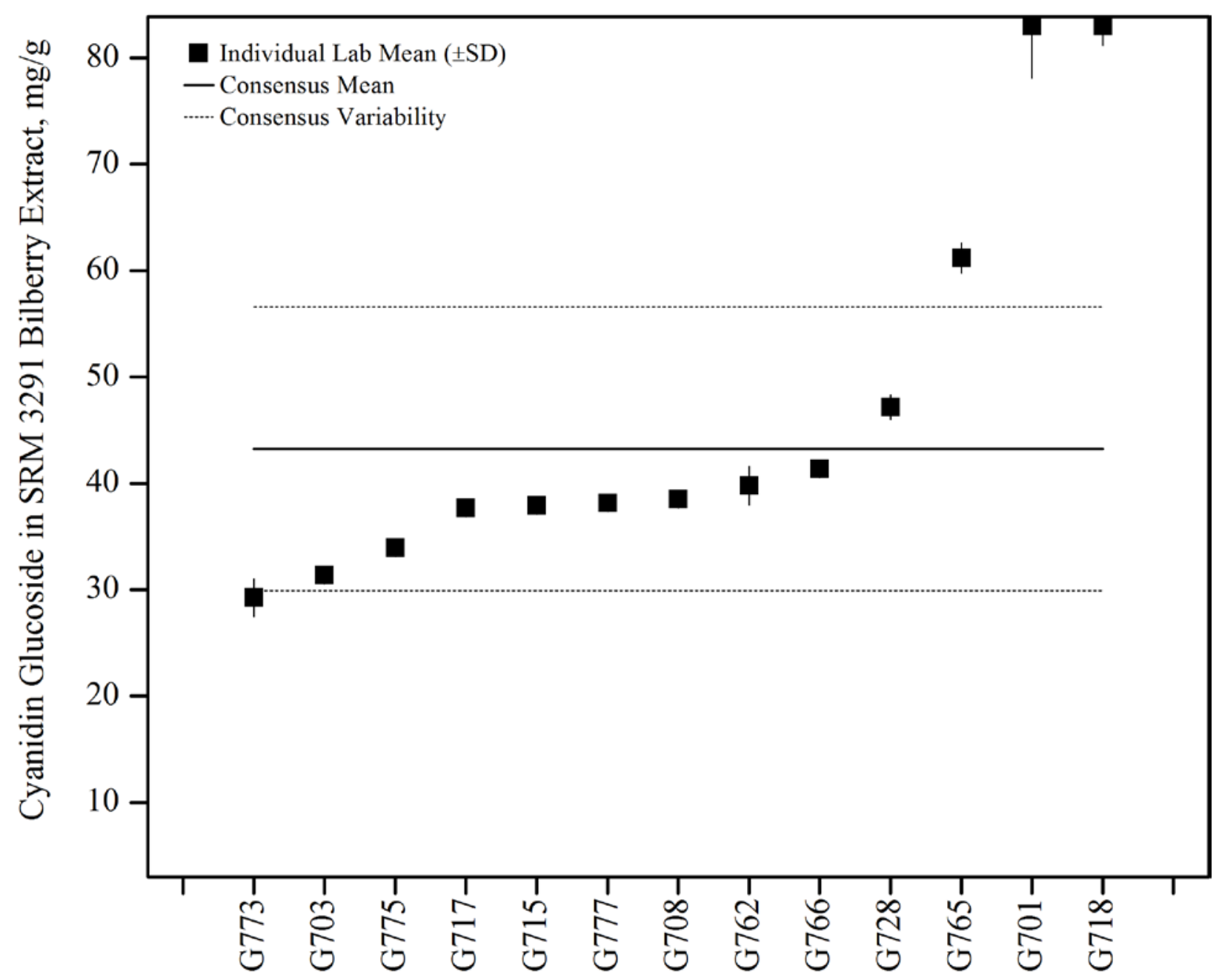

Figure 35. Cyanidin-3-glucoside in SRM 3291 Bilberry Extract (data summary view). In this view, individual laboratory data are plotted with the individual laboratory standard deviation (error bars). The black solid line represents the consensus mean, and the black dotted lines represent the consensus variability calculated as one standard deviation about the consensus mean. 


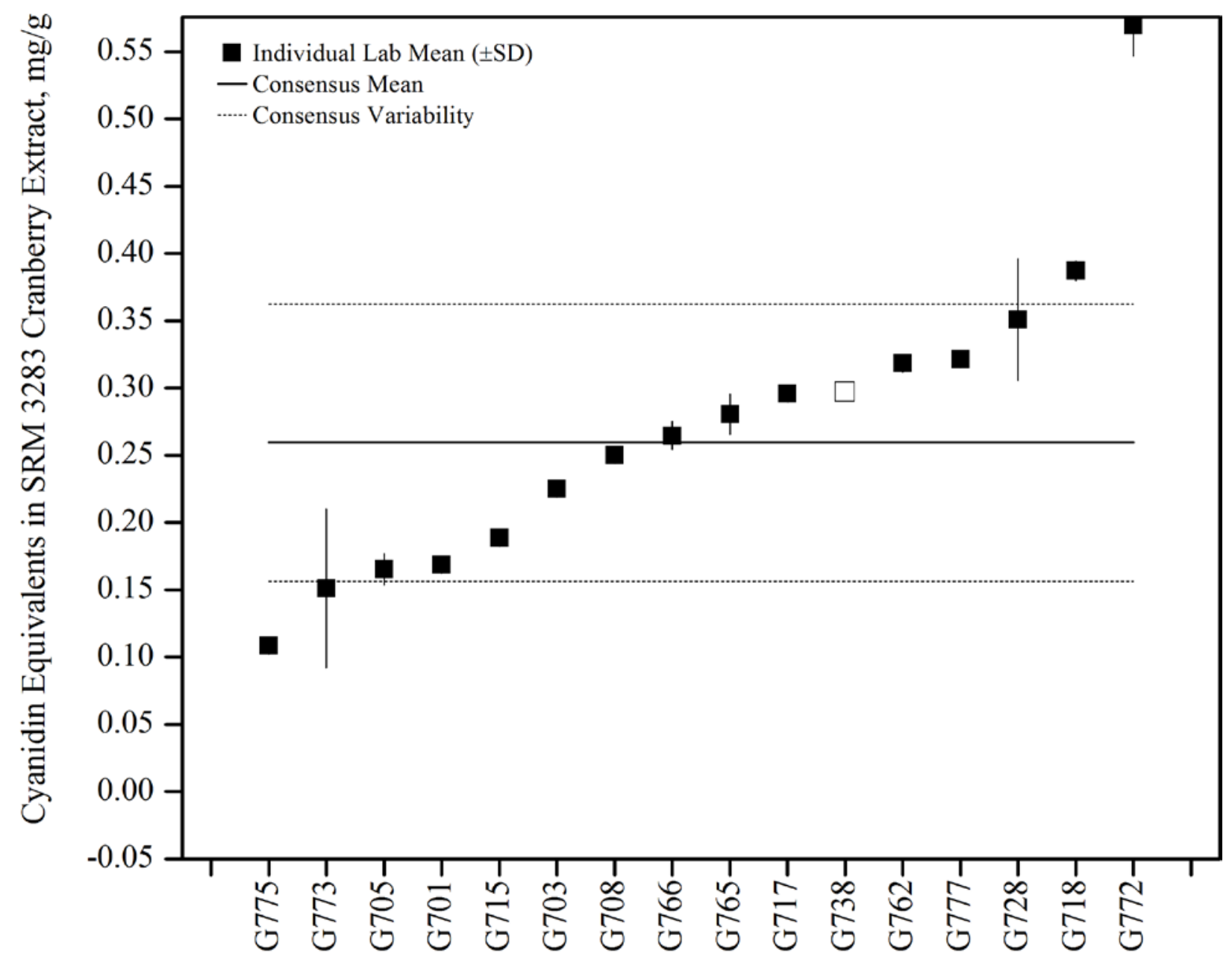

Figure 36. Cyanidin equivalents in SRM 3283 Cranberry Extract (data summary view). In this view, individual laboratory data are plotted with the individual laboratory standard deviation (error bars). The black solid line represents the consensus mean, and the black dotted lines represent the consensus variability calculated as one standard deviation about the consensus mean. 


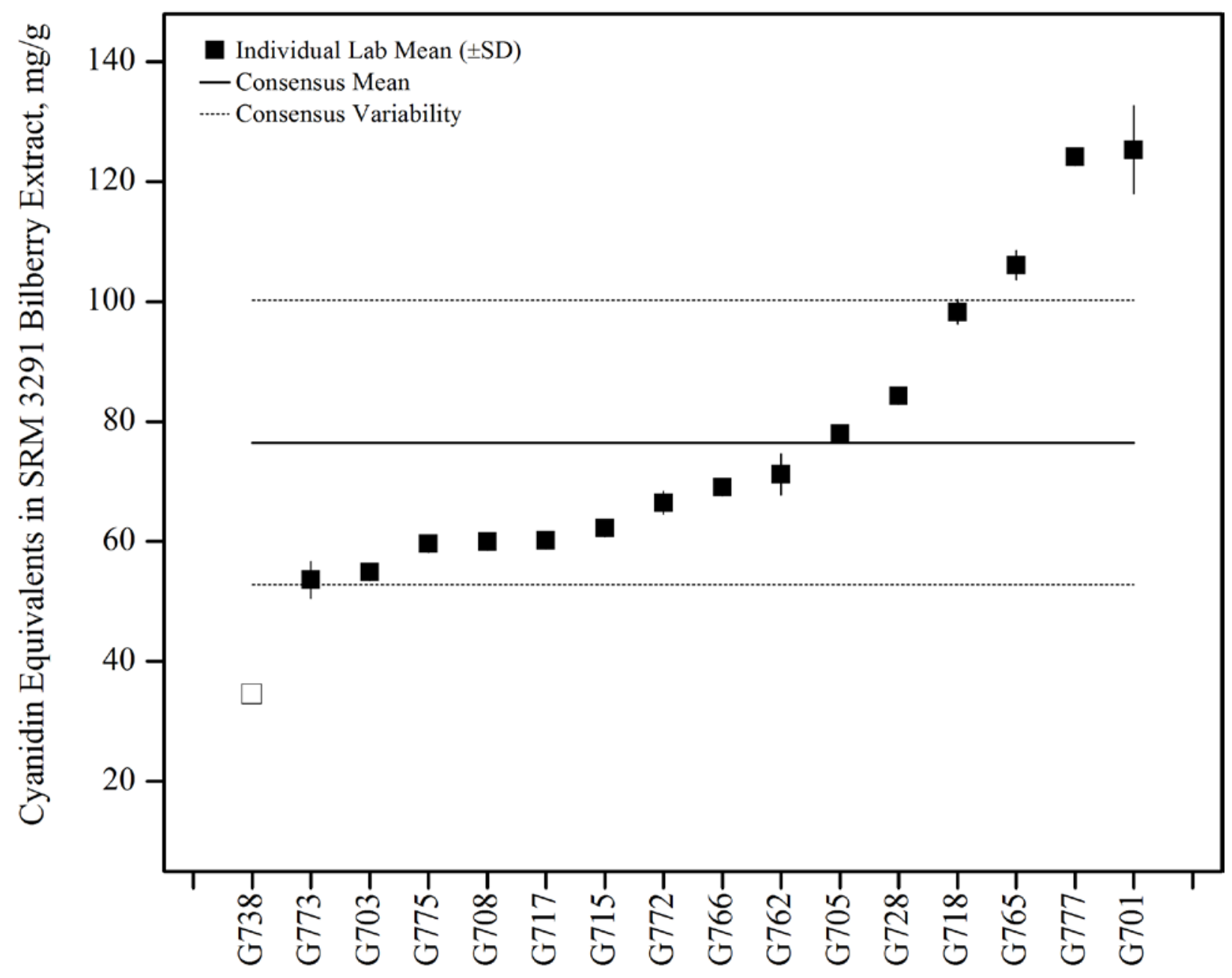

Figure 37. Cyanidin equivalents in SRM 3291 Bilberry Extract (data summary view). In this view, individual laboratory data are plotted with the individual laboratory standard deviation (error bars). The black solid line represents the consensus mean, and the black dotted lines represent the consensus variability calculated as one standard deviation about the consensus mean. 


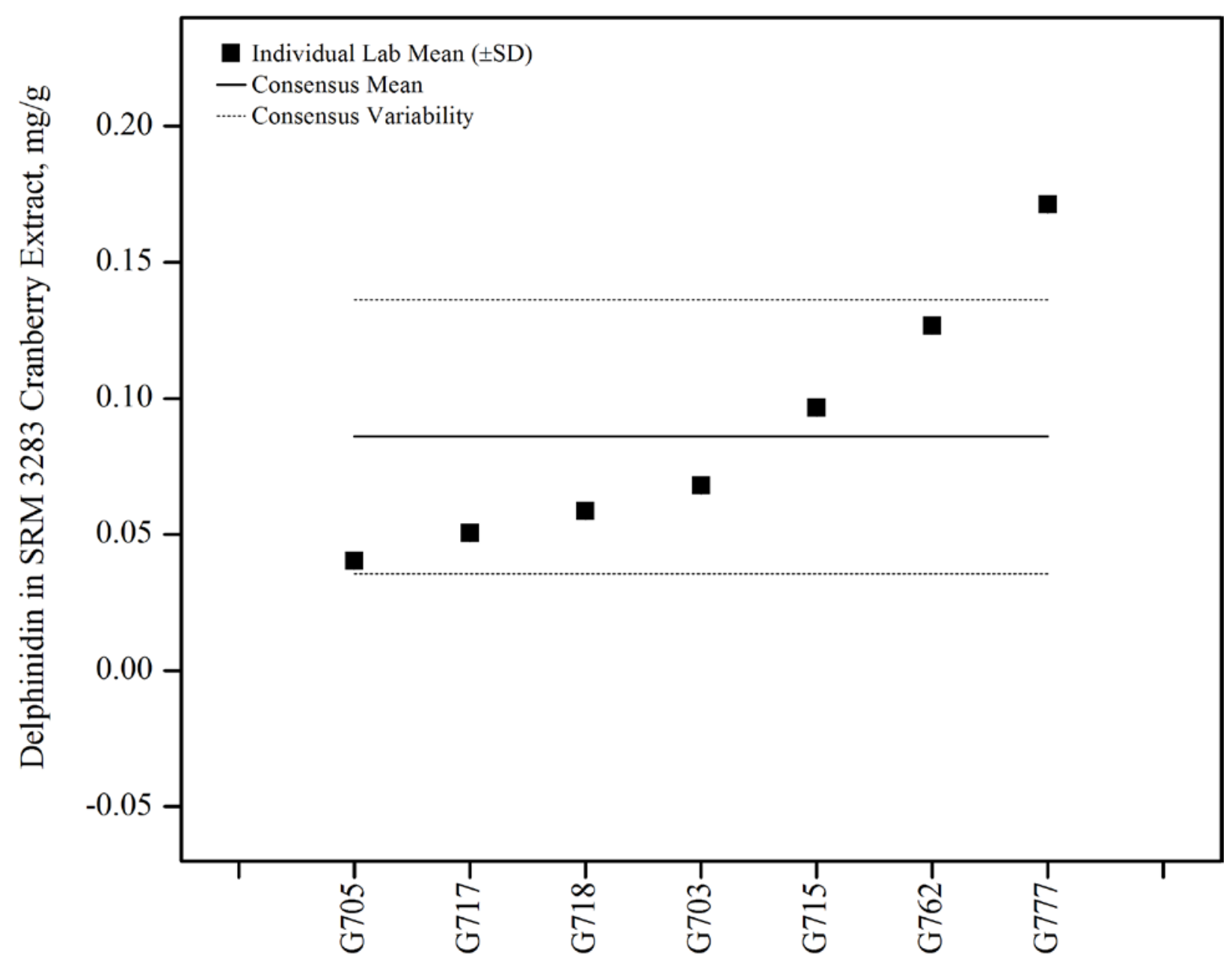

Figure 38. Delphinidin in SRM 3283 Cranberry Extract (data summary view). In this view, individual laboratory data are plotted with the individual laboratory standard deviation (error bars). The black solid line represents the consensus mean, and the black dotted lines represent the consensus variability calculated as one standard deviation about the consensus mean. 


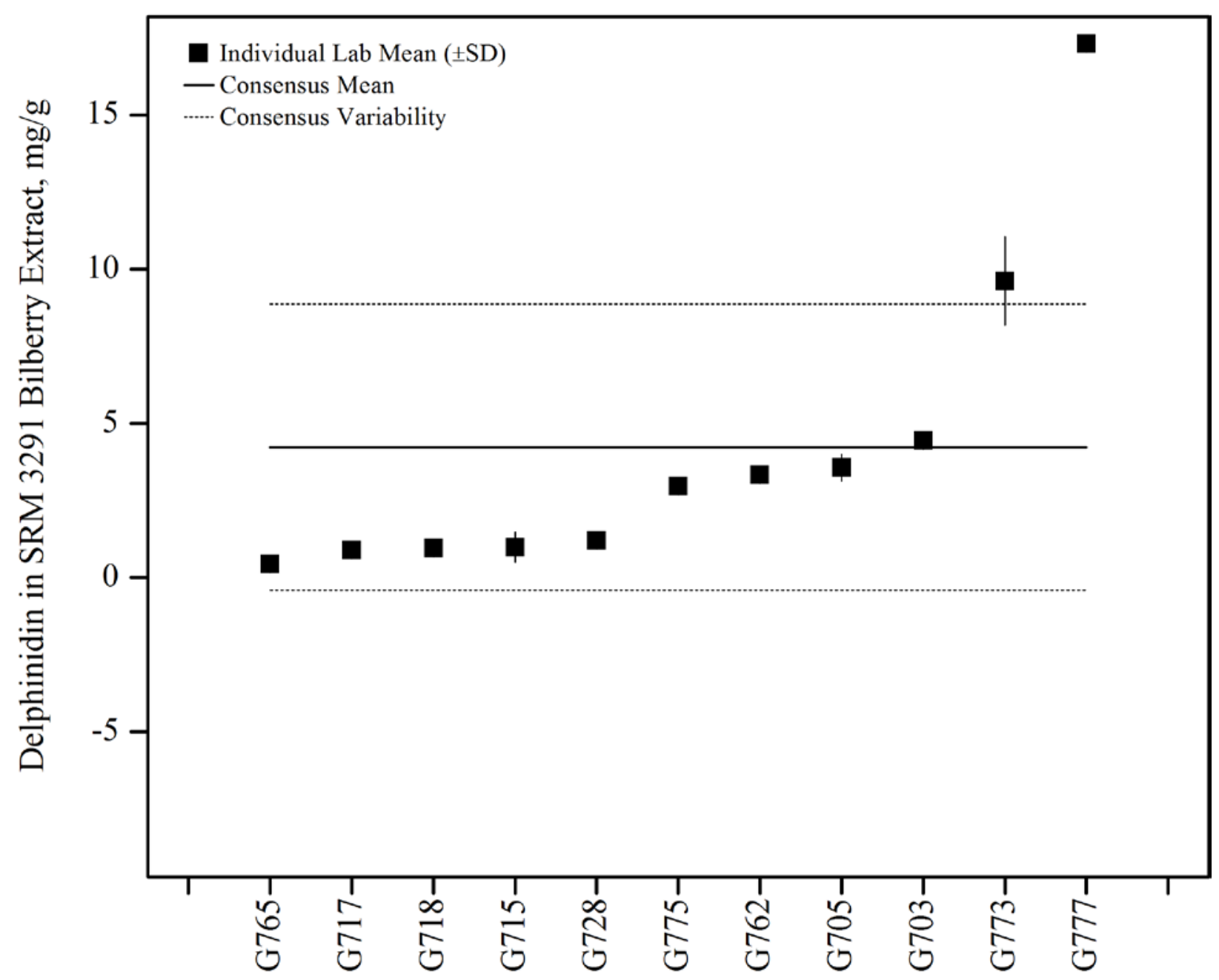

Figure 39. Delphinidin in SRM 3291 Bilberry Extract (data summary view). In this view, individual laboratory data are plotted with the individual laboratory standard deviation (error bars). The black solid line represents the consensus mean, and the black dotted lines represent the consensus variability calculated as one standard deviation about the consensus mean. 


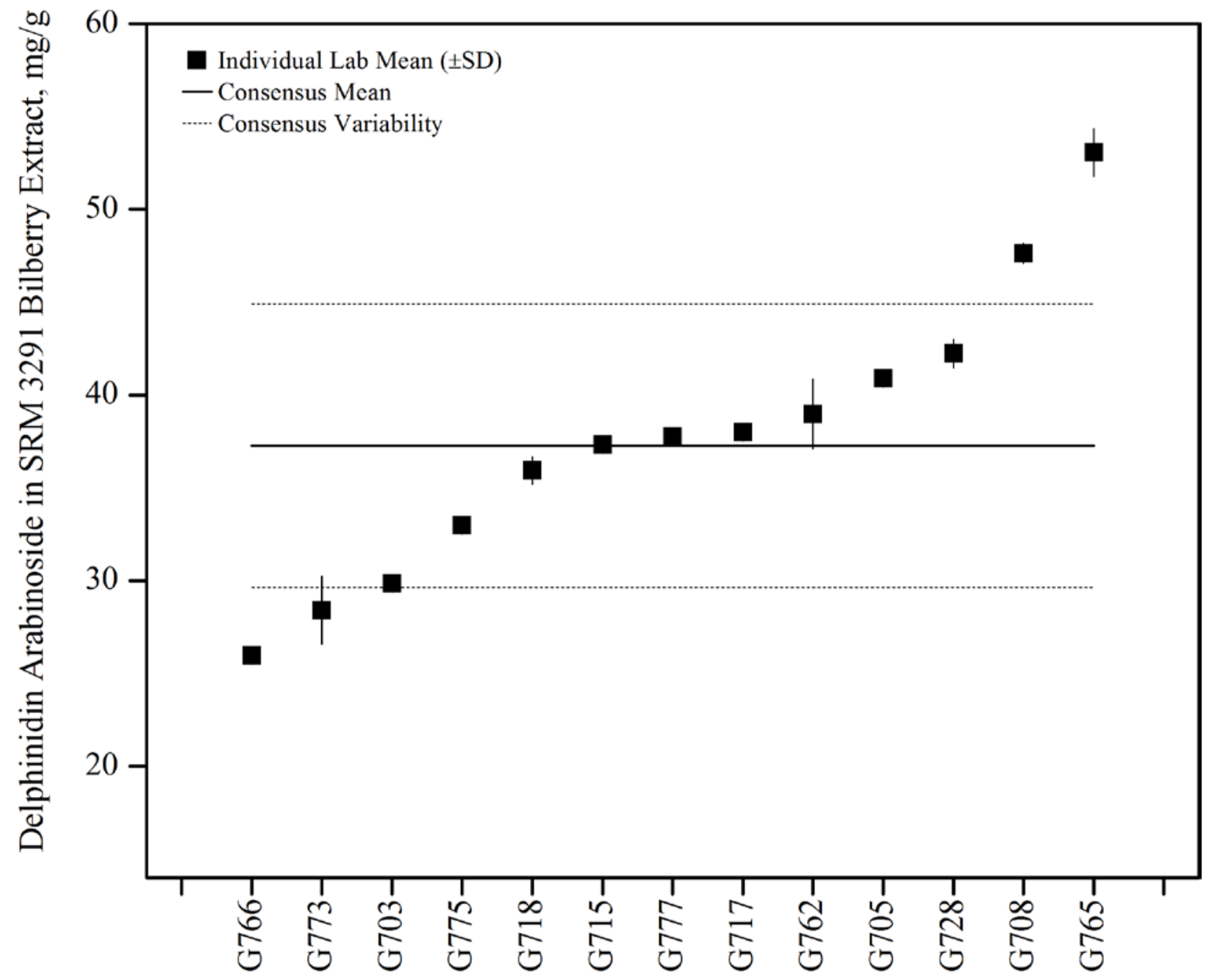

Figure 40. Delphinidin-3-arabinoside in SRM 3291 Bilberry Extract (data summary view). In this view, individual laboratory data are plotted with the individual laboratory standard deviation (error bars). The black solid line represents the consensus mean, and the black dotted lines represent the consensus variability calculated as one standard deviation about the consensus mean. 


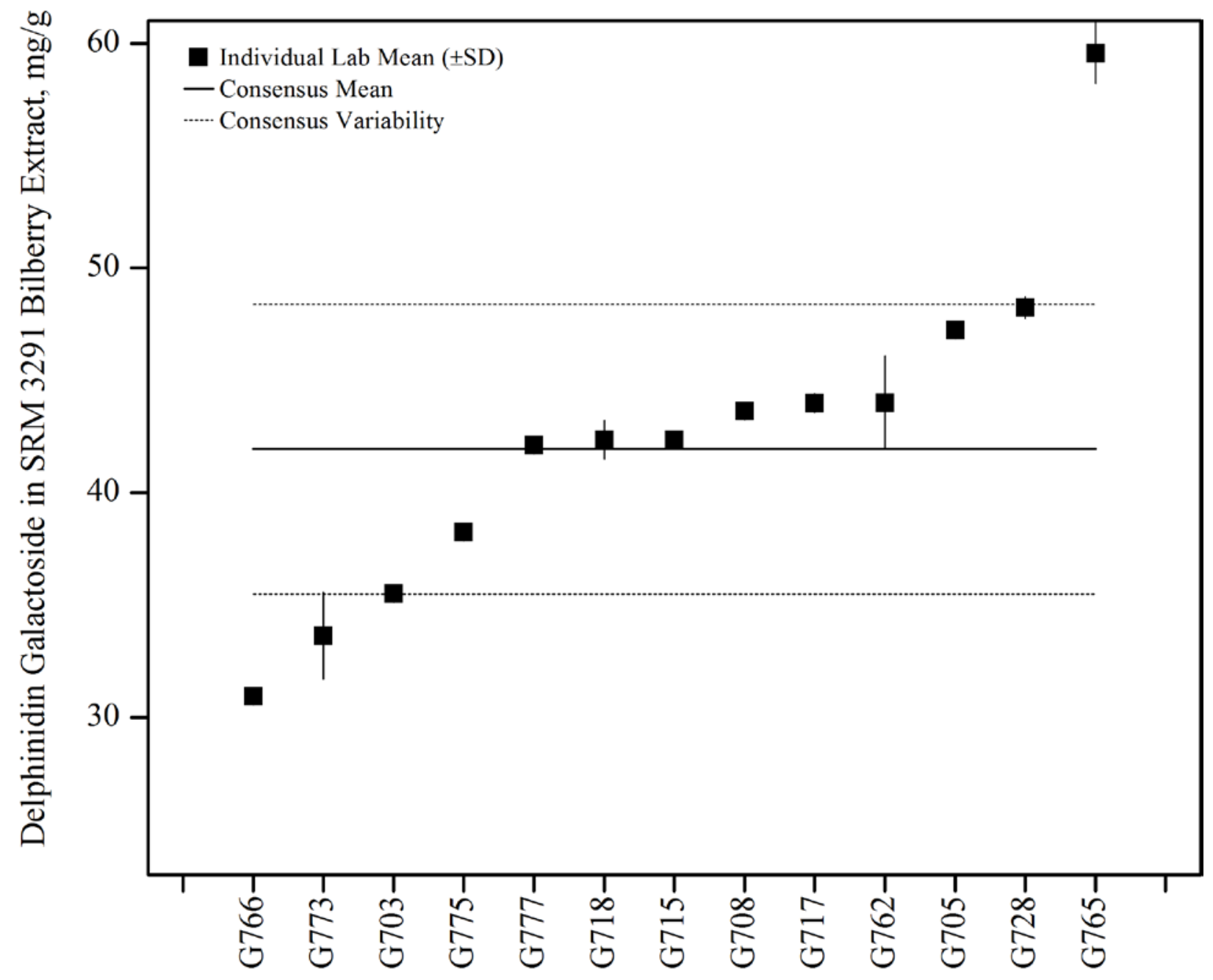

Figure 41. Delphinidin-3-galactoside in SRM 3291 Bilberry Extract (data summary view). In this view, individual laboratory data are plotted with the individual laboratory standard deviation (error bars). The black solid line represents the consensus mean, and the black dotted lines represent the consensus variability calculated as one standard deviation about the consensus mean. 


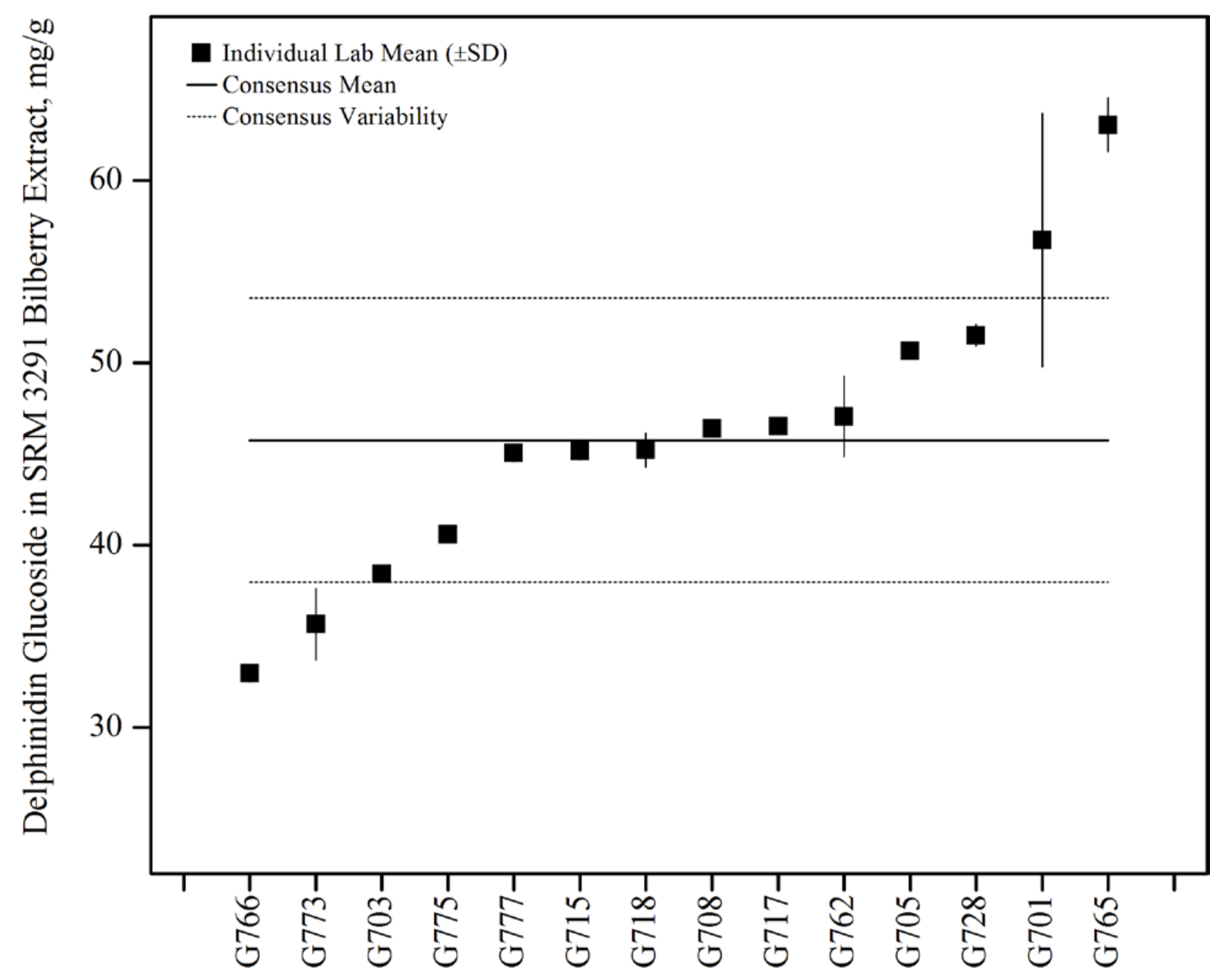

Figure 42. Delphinidin-3-glucoside in SRM 3291 Bilberry Extract (data summary view). In this view, individual laboratory data are plotted with the individual laboratory standard deviation (error bars). The black solid line represents the consensus mean, and the black dotted lines represent the consensus variability calculated as one standard deviation about the consensus mean. 


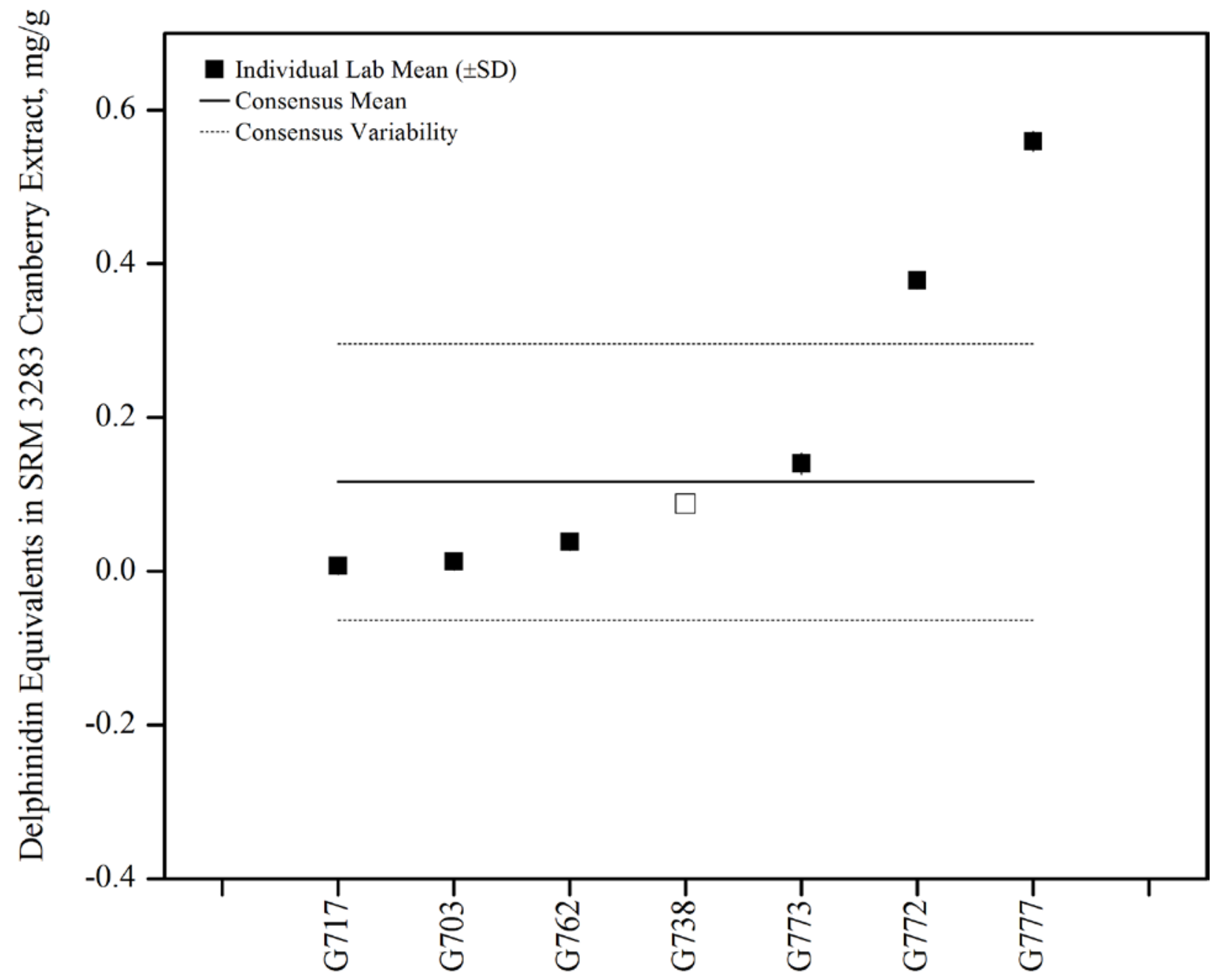

Figure 43. Delphinidin equivalents in SRM 3283 Cranberry Extract (data summary view). In this view, individual laboratory data are plotted with the individual laboratory standard deviation (error bars). The black solid line represents the consensus mean, and the black dotted lines represent the consensus variability calculated as one standard deviation about the consensus mean. 


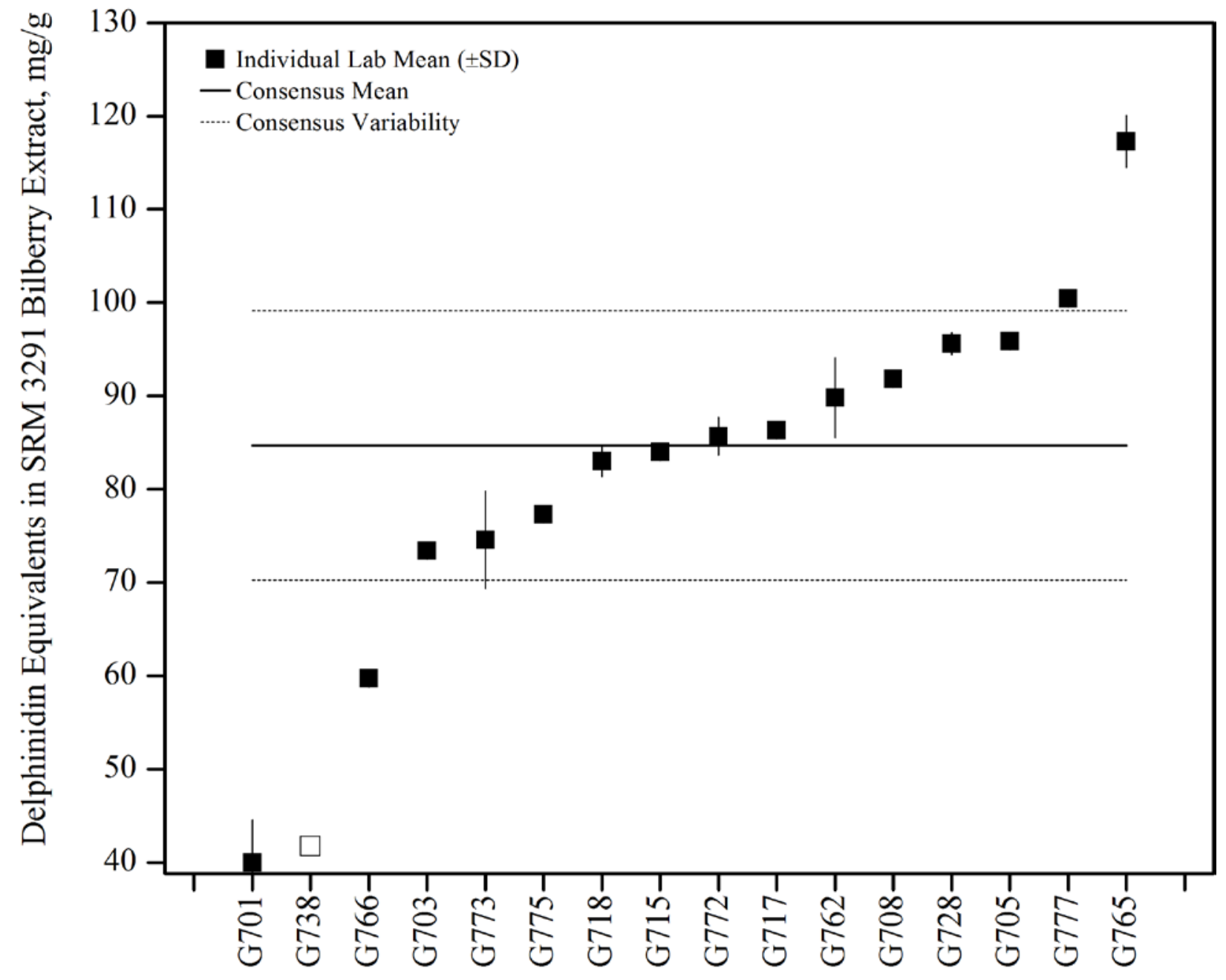

Figure 44. Delphinidin equivalents in SRM 3291 Bilberry Extract (data summary view). In this view, individual laboratory data are plotted with the individual laboratory standard deviation (error bars). The black solid line represents the consensus mean, and the black dotted lines represent the consensus variability calculated as one standard deviation about the consensus mean. 


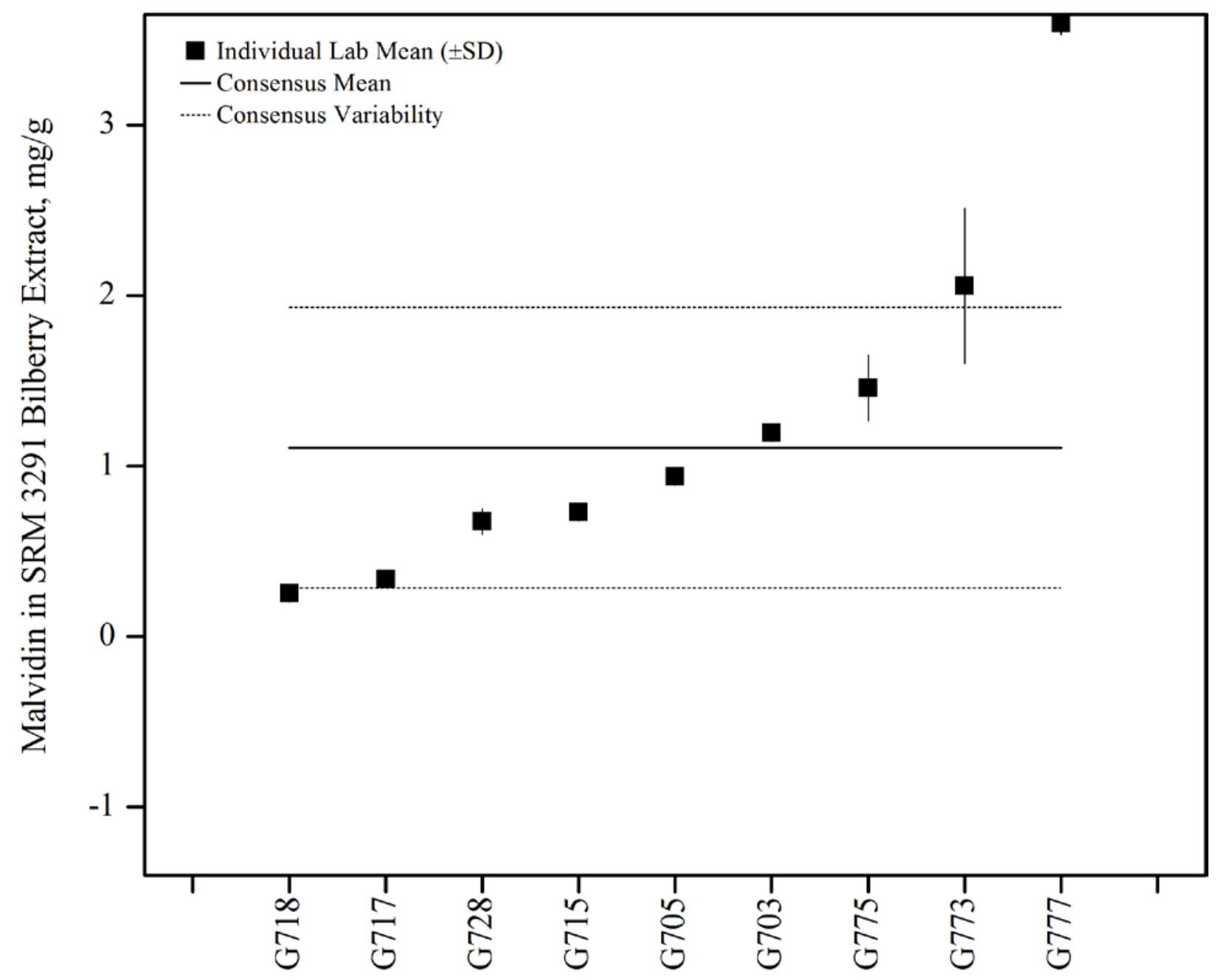

Figure 45. Malvidin in SRM 3291 Bilberry Extract (data summary view). In this view, individual laboratory data are plotted with the individual laboratory standard deviation (error bars). The black solid line represents the consensus mean, and the black dotted lines represent the consensus variability calculated as one standard deviation about the consensus mean. 


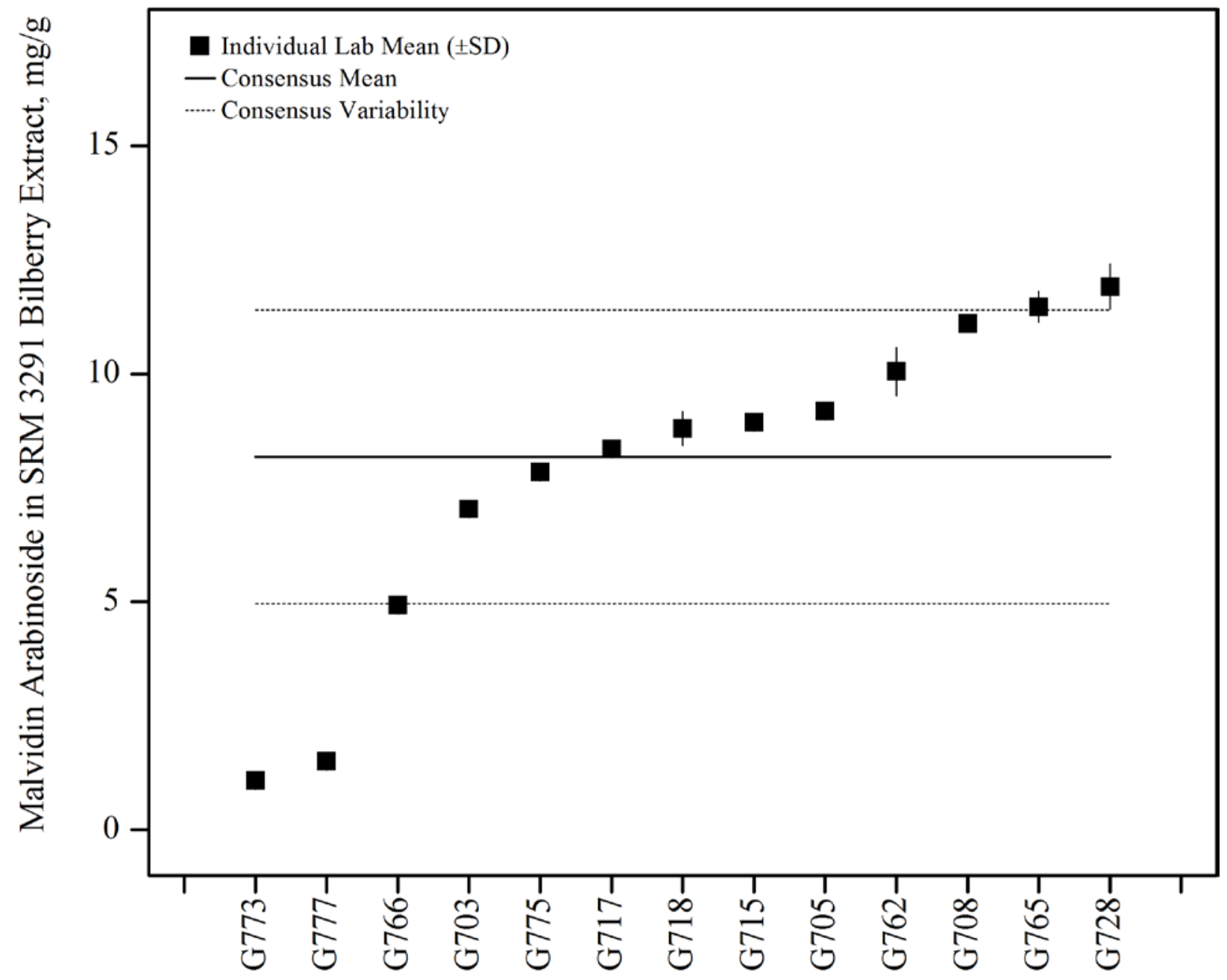

Figure 46. Malvidin-3-arabinoside in SRM 3291 Bilberry Extract (data summary view). In this view, individual laboratory data are plotted with the individual laboratory standard deviation (error bars). The black solid line represents the consensus mean, and the black dotted lines represent the consensus variability calculated as one standard deviation about the consensus mean. 


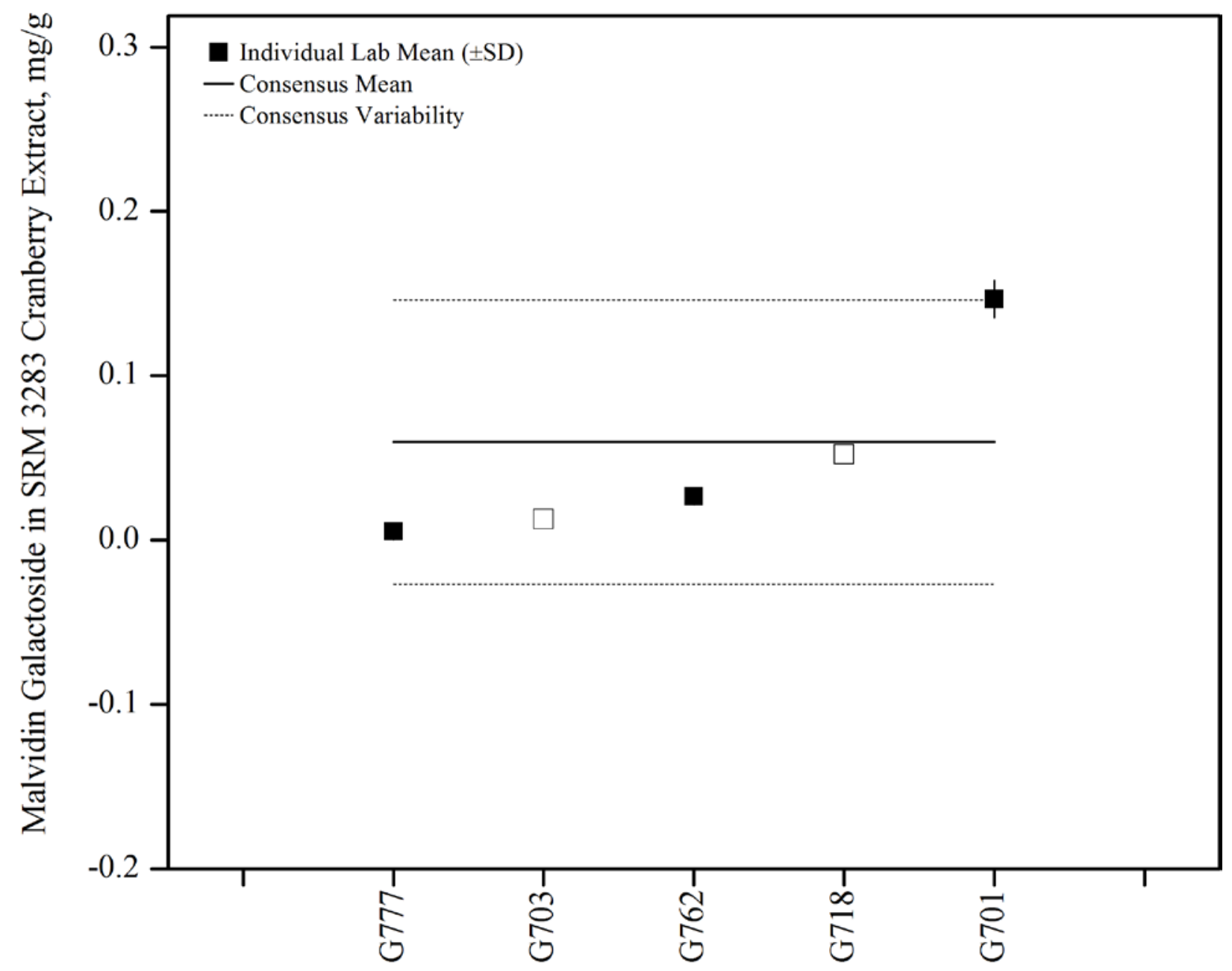

Figure 47. Malvidin-3-galactoside in SRM 3283 Cranberry Extract (data summary view). In this view, individual laboratory data are plotted with the individual laboratory standard deviation (error bars). The black solid line represents the consensus mean, and the black dotted lines represent the consensus variability calculated as one standard deviation about the consensus mean. 


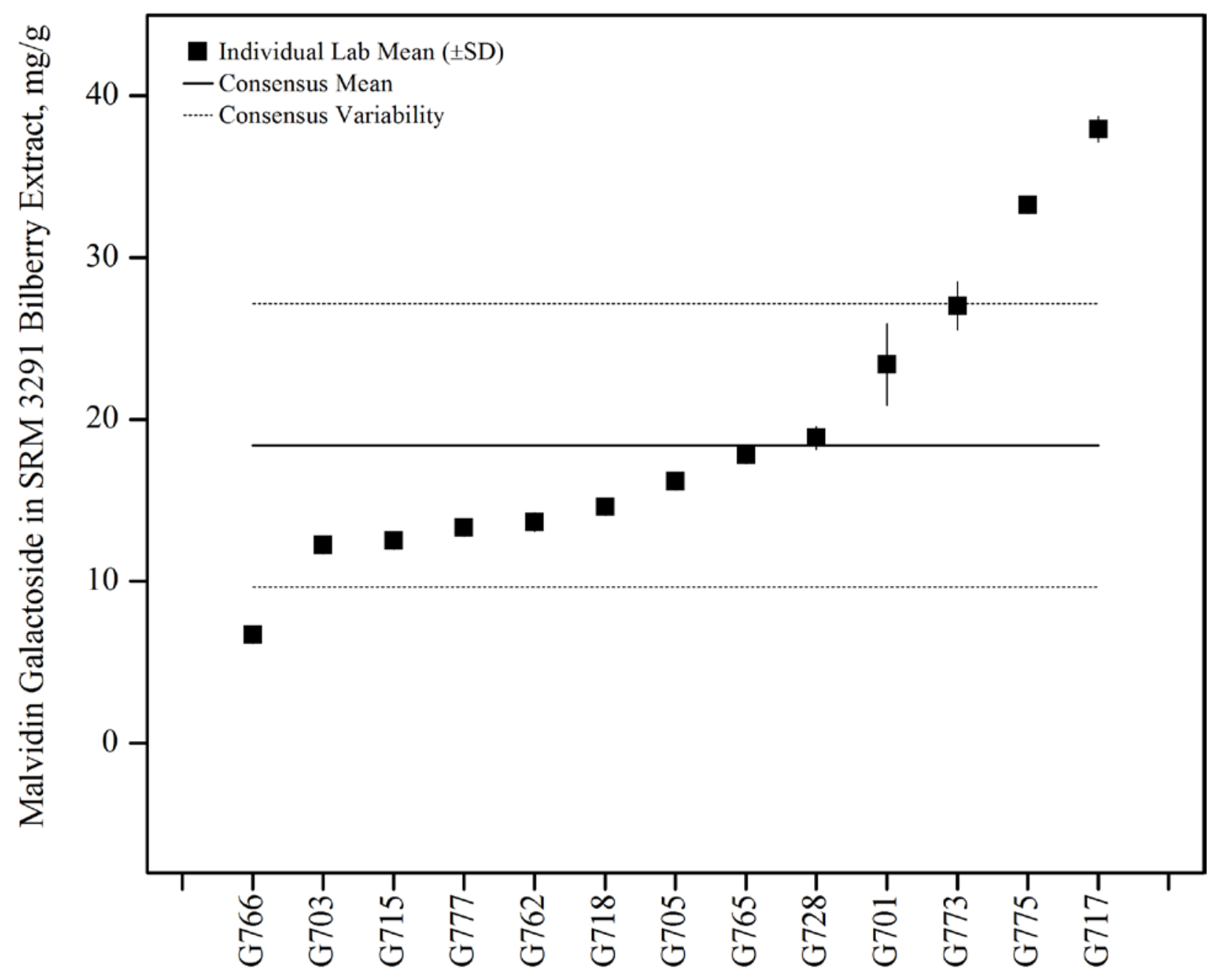

Figure 48. Malvidin-3-galactoside in SRM 3291 Bilberry Extract (data summary view). In this view, individual laboratory data are plotted with the individual laboratory standard deviation (error bars). The black solid line represents the consensus mean, and the black dotted lines represent the consensus variability calculated as one standard deviation about the consensus mean. 


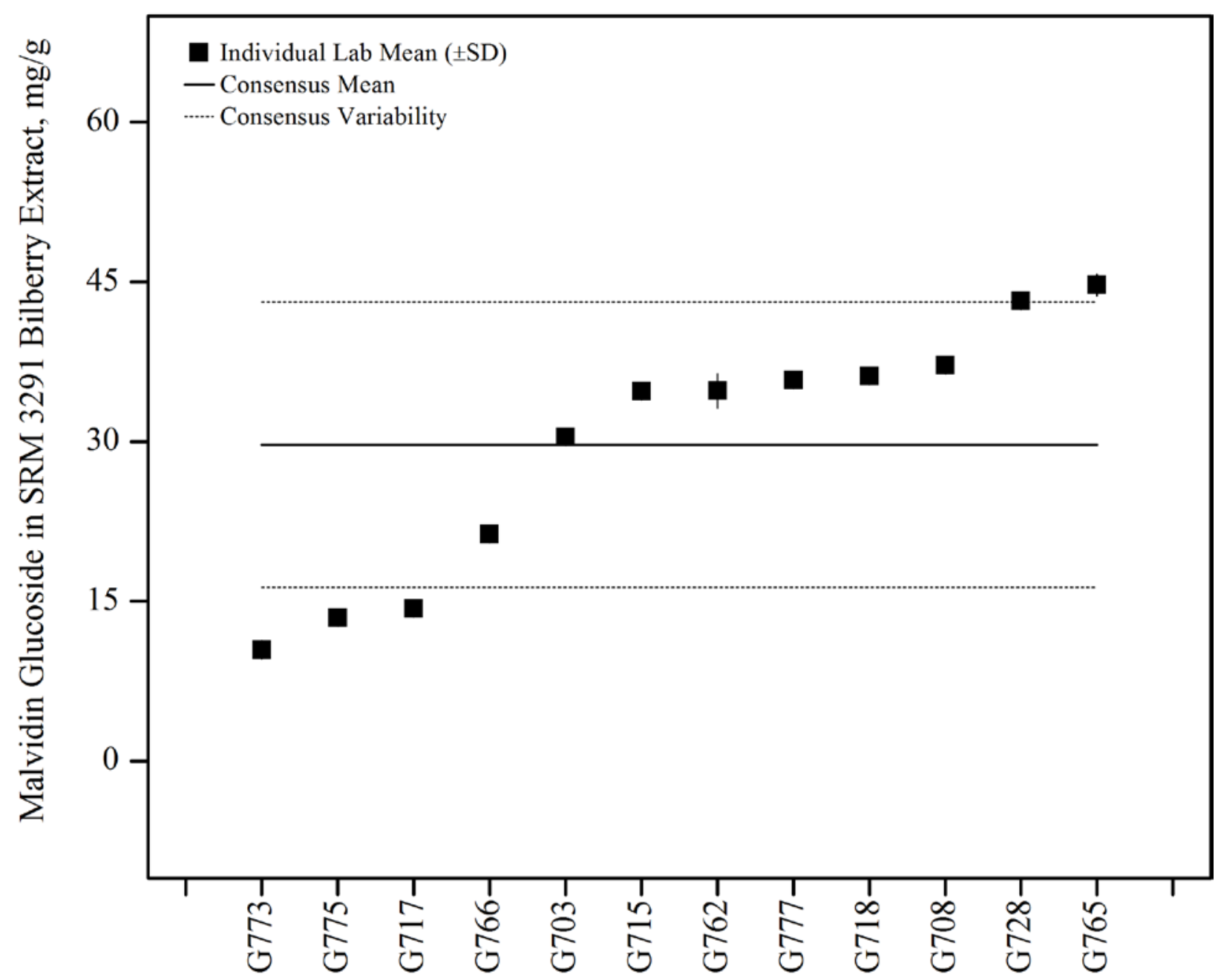

Figure 49. Malvidin-3-glucoside in SRM 3291 Bilberry Extract (data summary view). In this view, individual laboratory data are plotted with the individual laboratory standard deviation (error bars). The black solid line represents the consensus mean, and the black dotted lines represent the consensus variability calculated as one standard deviation about the consensus mean. 


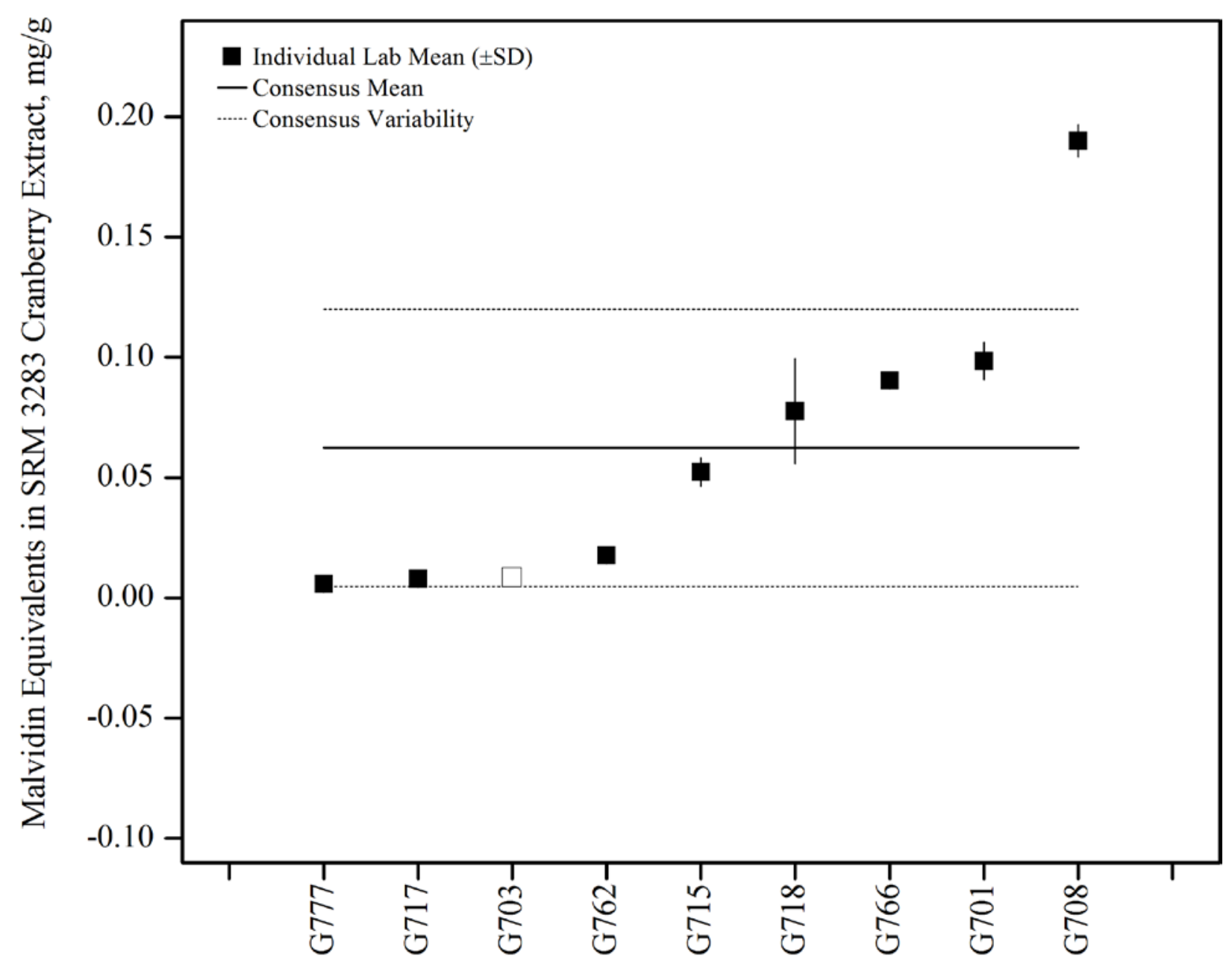

Figure 50. Malvidin equivalents in SRM 3283 Cranberry Extract (data summary view). In this view, individual laboratory data are plotted with the individual laboratory standard deviation (error bars). The black solid line represents the consensus mean, and the black dotted lines represent the consensus variability calculated as one standard deviation about the consensus mean. 


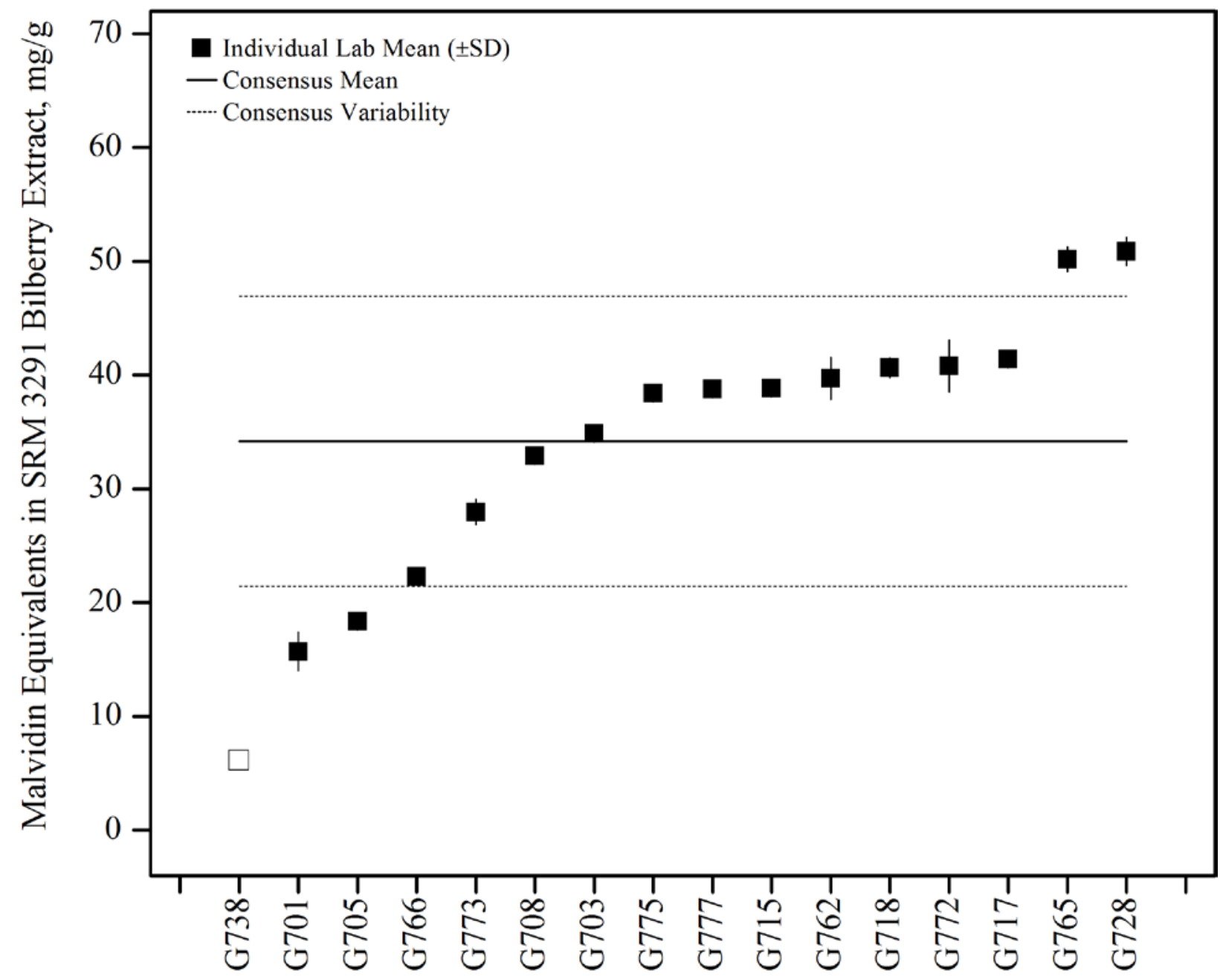

Figure 51. Malvidin equivalents in SRM 3291 Bilberry Extract (data summary view). In this view, individual laboratory data are plotted with the individual laboratory standard deviation (error bars). The black solid line represents the consensus mean, and the black dotted lines represent the consensus variability calculated as one standard deviation about the consensus mean. 


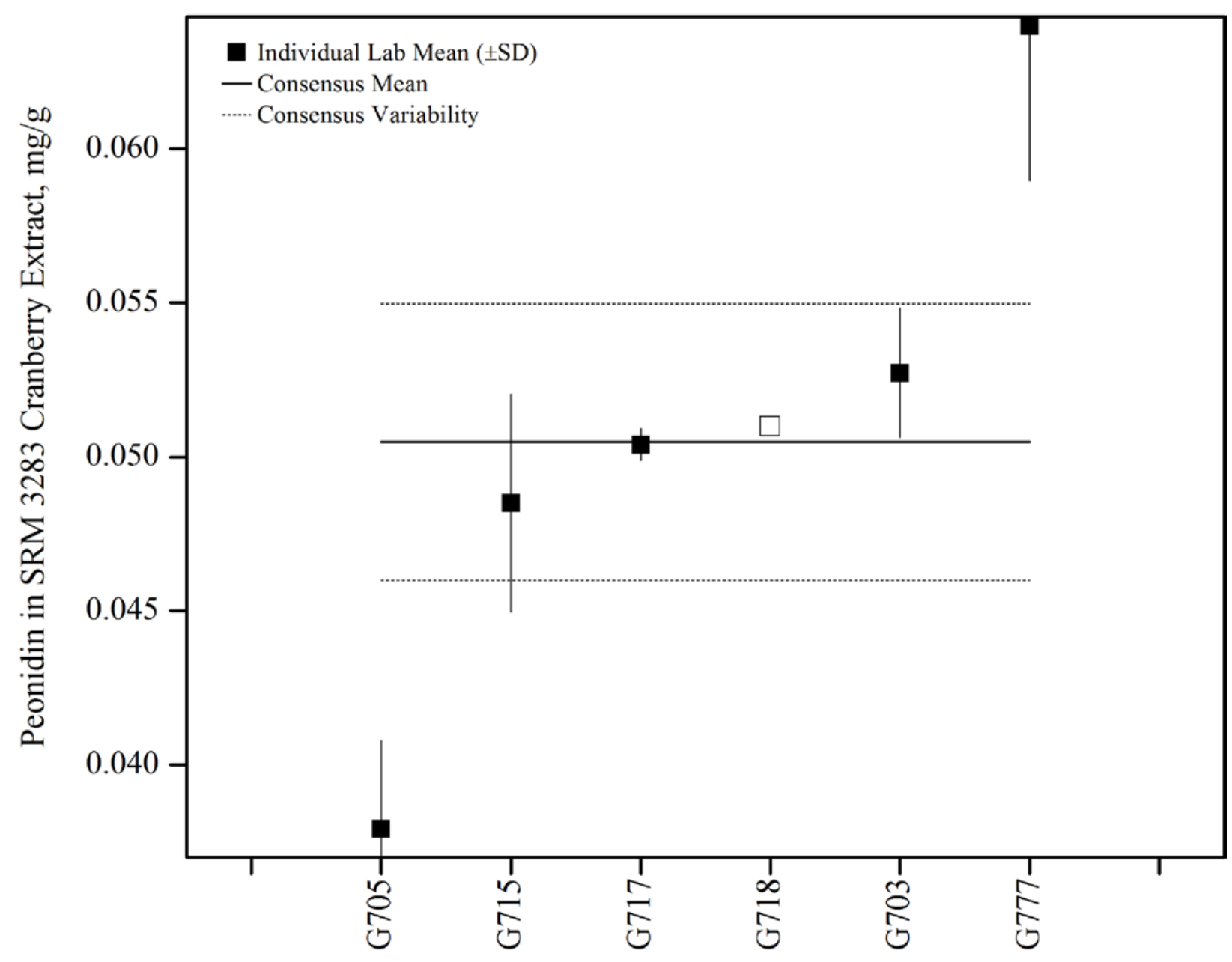

Figure 52. Peonidin in SRM 3283 Cranberry Extract (data summary view). In this view, individual laboratory data are plotted with the individual laboratory standard deviation (error bars). The black solid line represents the consensus mean, and the black dotted lines represent the consensus variability calculated as one standard deviation about the consensus mean. 


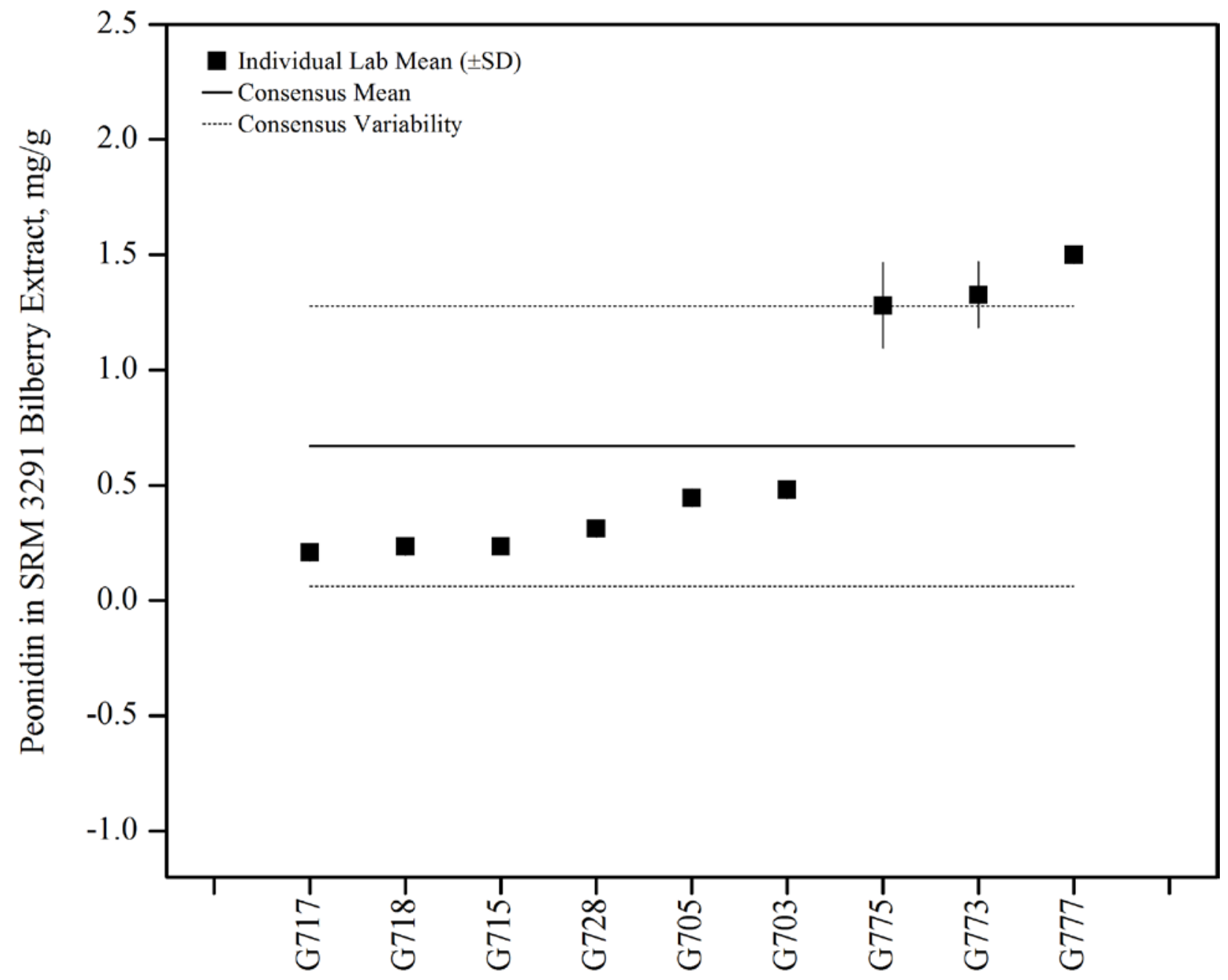

Figure 53. Peonidin in SRM 3291 Bilberry Extract (data summary view). In this view, individual laboratory data are plotted with the individual laboratory standard deviation (error bars). The black solid line represents the consensus mean, and the black dotted lines represent the consensus variability calculated as one standard deviation about the consensus mean. 


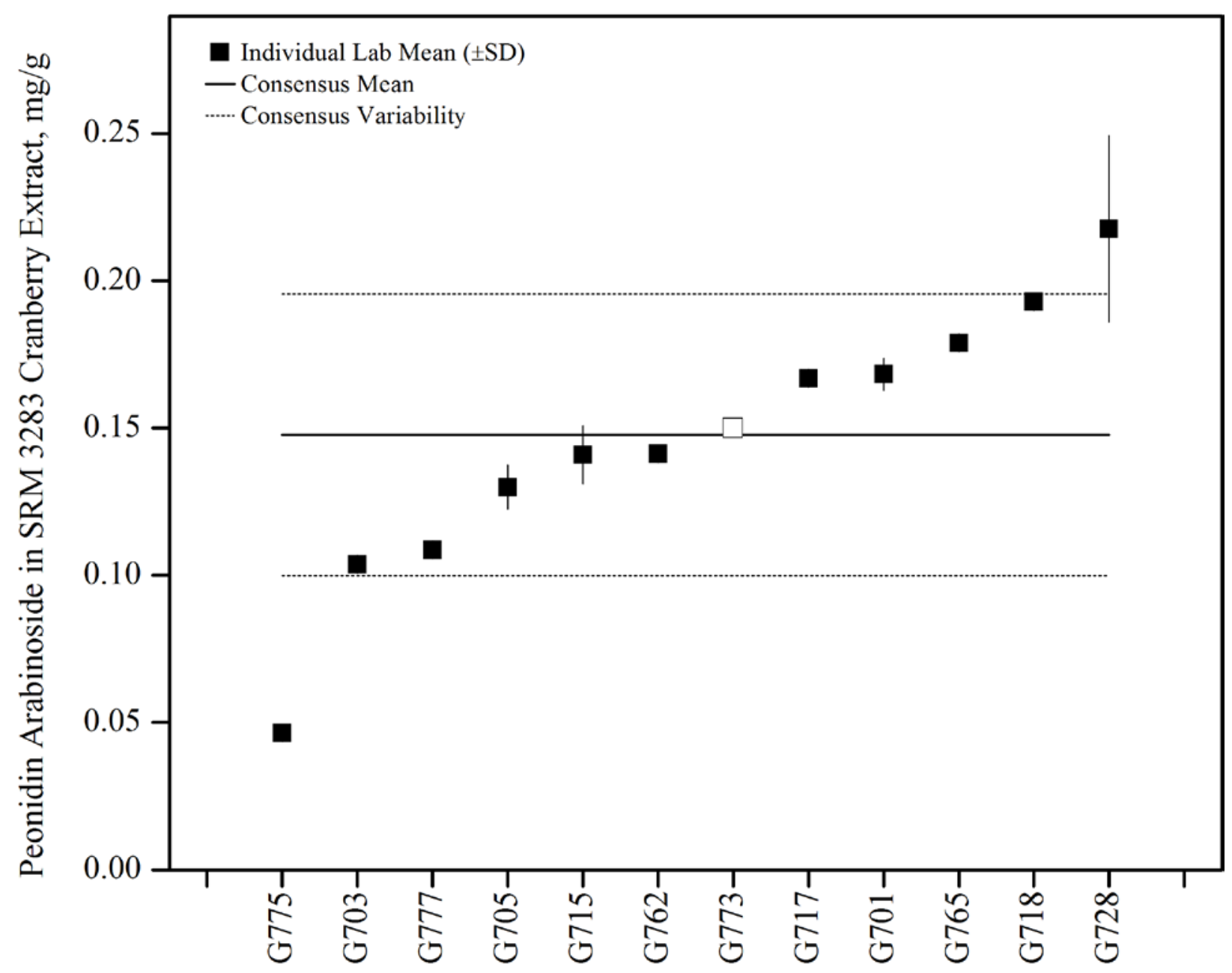

Figure 54. Peonidin-3-arabinoside in SRM 3283 Cranberry Extract (data summary view). In this view, individual laboratory data are plotted with the individual laboratory standard deviation (error bars). The black solid line represents the consensus mean, and the black dotted lines represent the consensus variability calculated as one standard deviation about the consensus mean. 


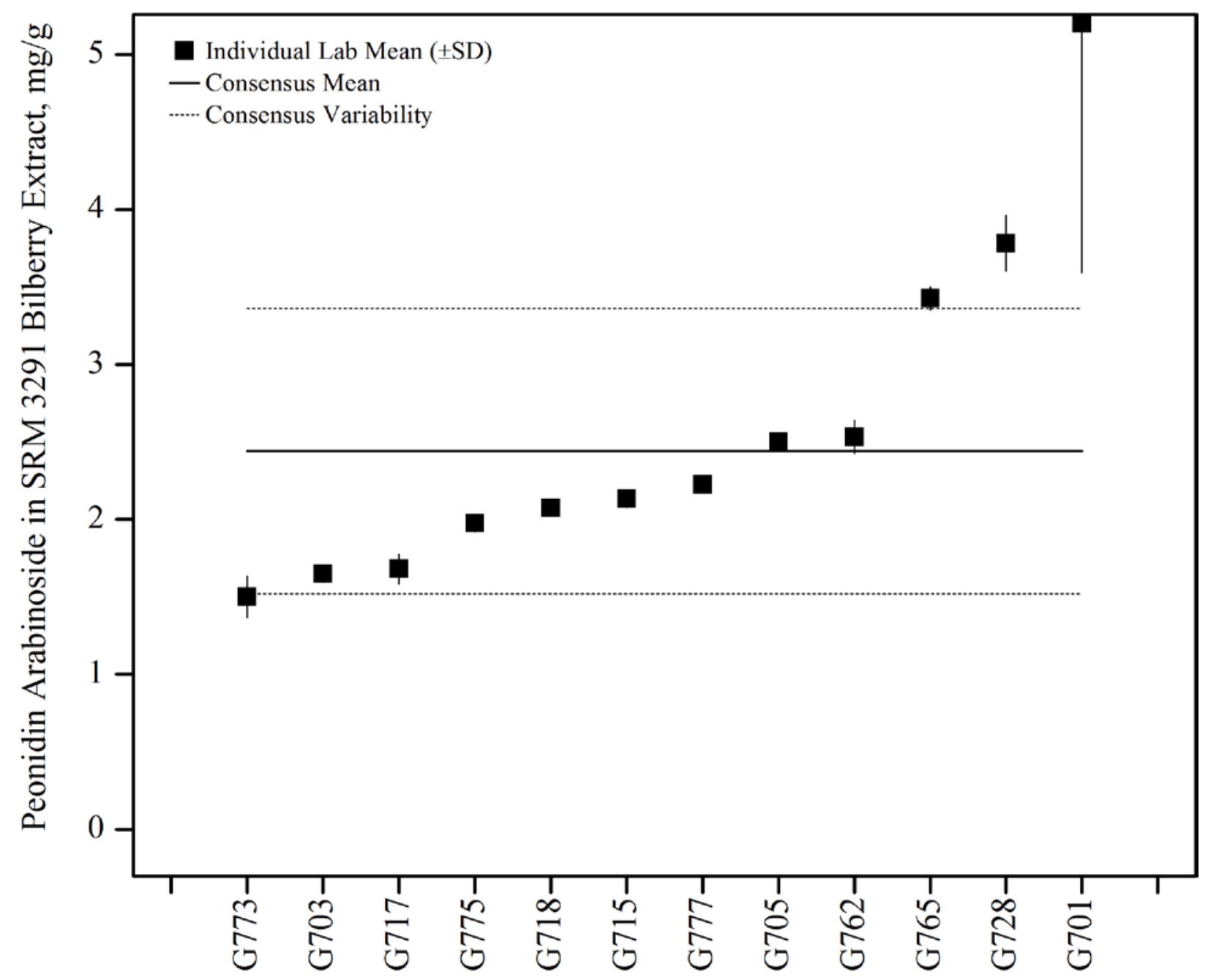

Figure 55. Peonidin-3-arabinoside in SRM 3291 Bilberry Extract (data summary view). In this view, individual laboratory data are plotted with the individual laboratory standard deviation (error bars). The black solid line represents the consensus mean, and the black dotted lines represent the consensus variability calculated as one standard deviation about the consensus mean. 


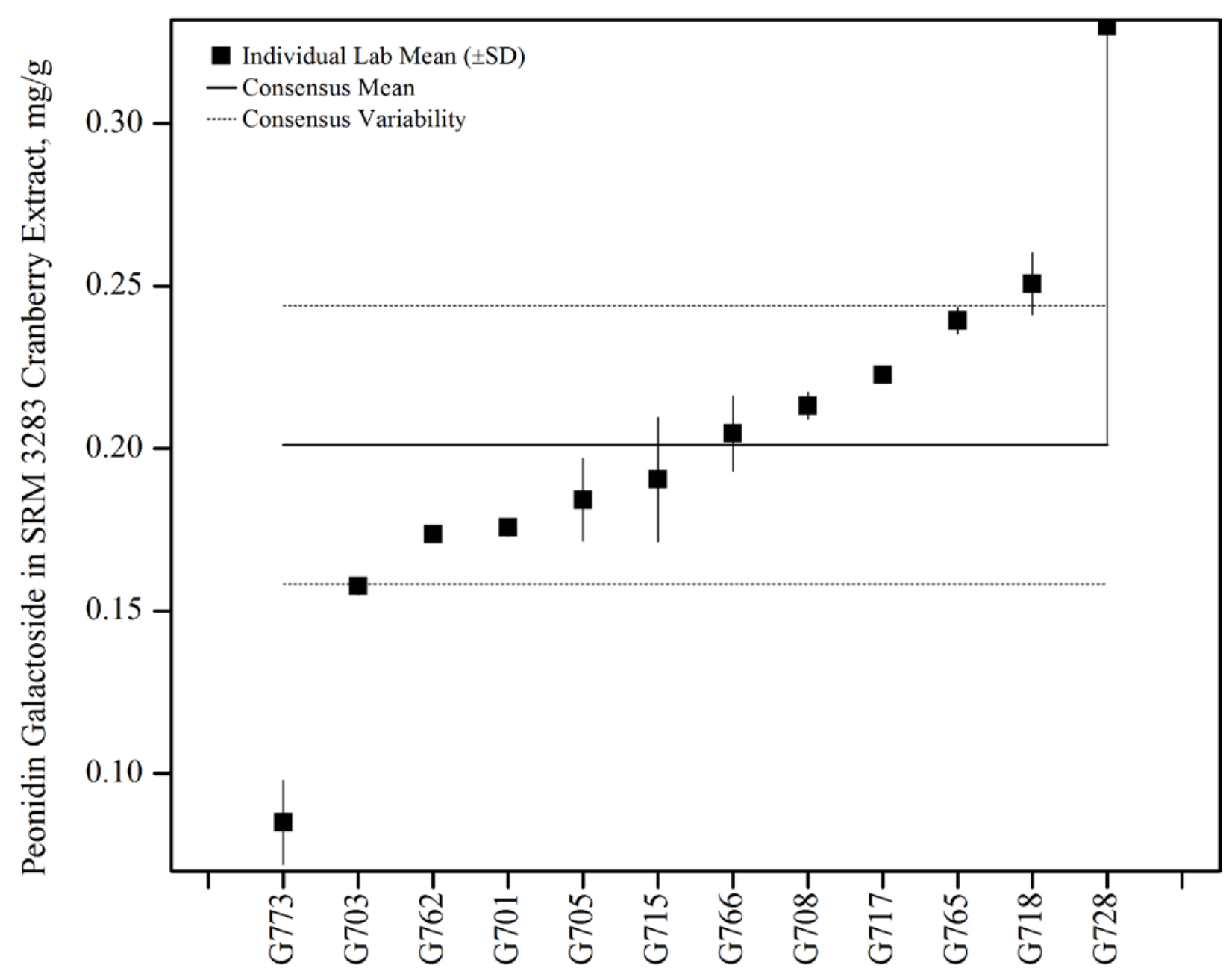

Figure 56. Peonidin-3-galactoside in SRM 3283 Cranberry Extract (data summary view). In this view, individual laboratory data are plotted with the individual laboratory standard deviation (error bars). The black solid line represents the consensus mean, and the black dotted lines represent the consensus variability calculated as one standard deviation about the consensus mean. 


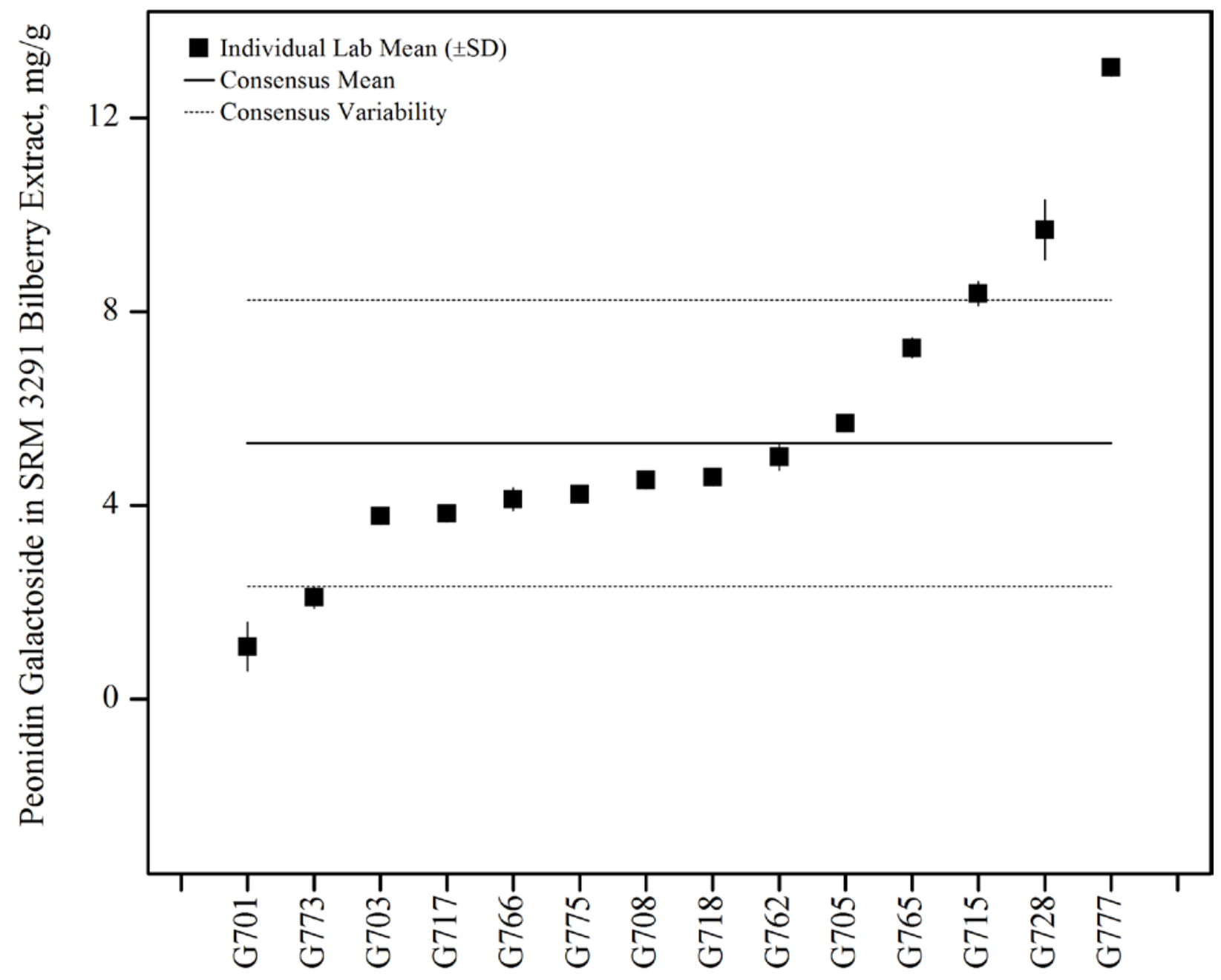

Figure 57. Peonidin-3-galactoside in SRM 3291 Bilberry Extract (data summary view). In this view, individual laboratory data are plotted with the individual laboratory standard deviation (error bars). The black solid line represents the consensus mean, and the black dotted lines represent the consensus variability calculated as one standard deviation about the consensus mean. 


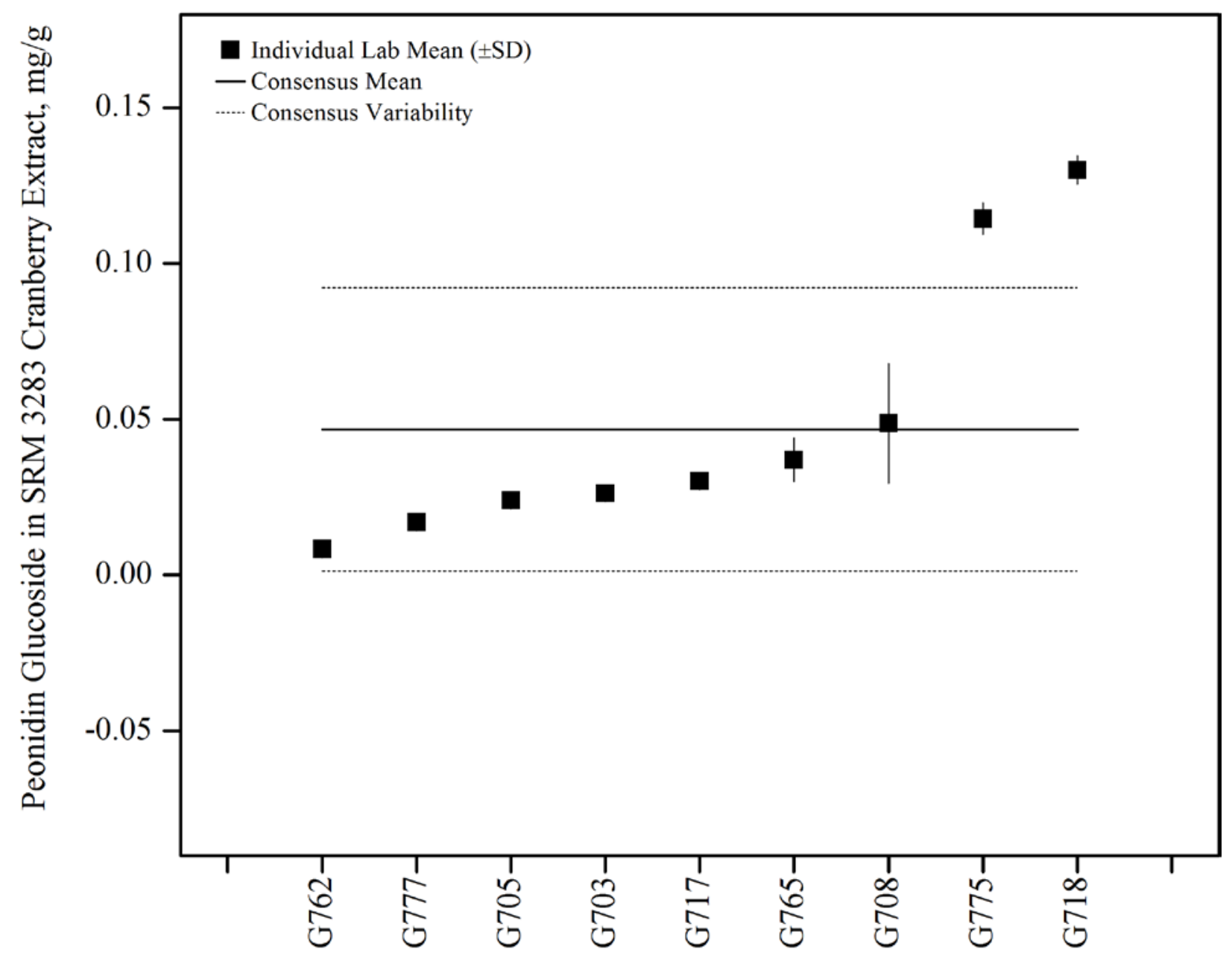

Figure 58. Peonidin-3-glucoside in SRM 3283 Cranberry Extract (data summary view). In this view, individual laboratory data are plotted with the individual laboratory standard deviation (error bars). The black solid line represents the consensus mean, and the black dotted lines represent the consensus variability calculated as one standard deviation about the consensus mean. 


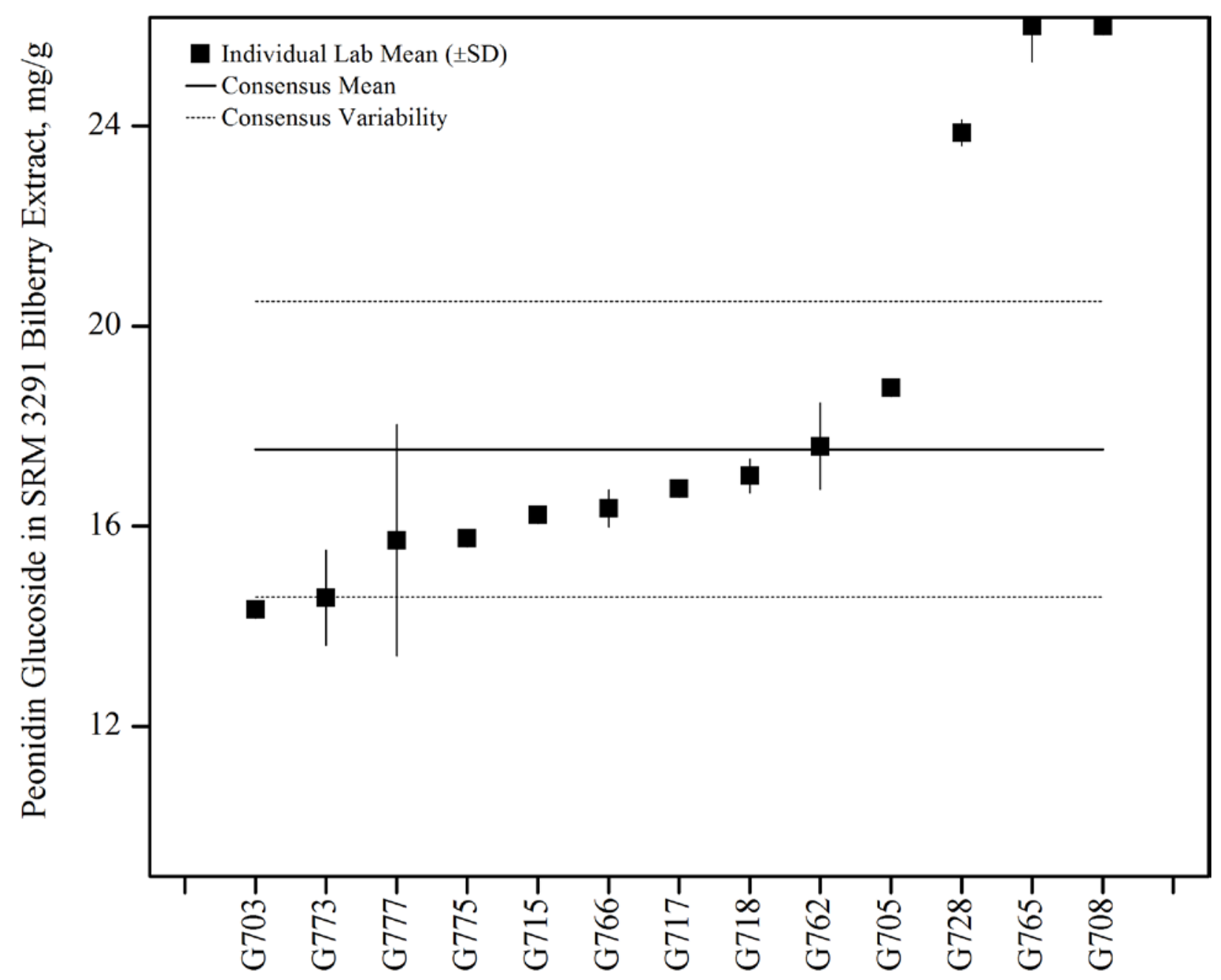

Figure 59. Peonidin-3-glucoside in SRM 3291 Bilberry Extract (data summary view). In this view, individual laboratory data are plotted with the individual laboratory standard deviation (error bars). The black solid line represents the consensus mean, and the black dotted lines represent the consensus variability calculated as one standard deviation about the consensus mean. 


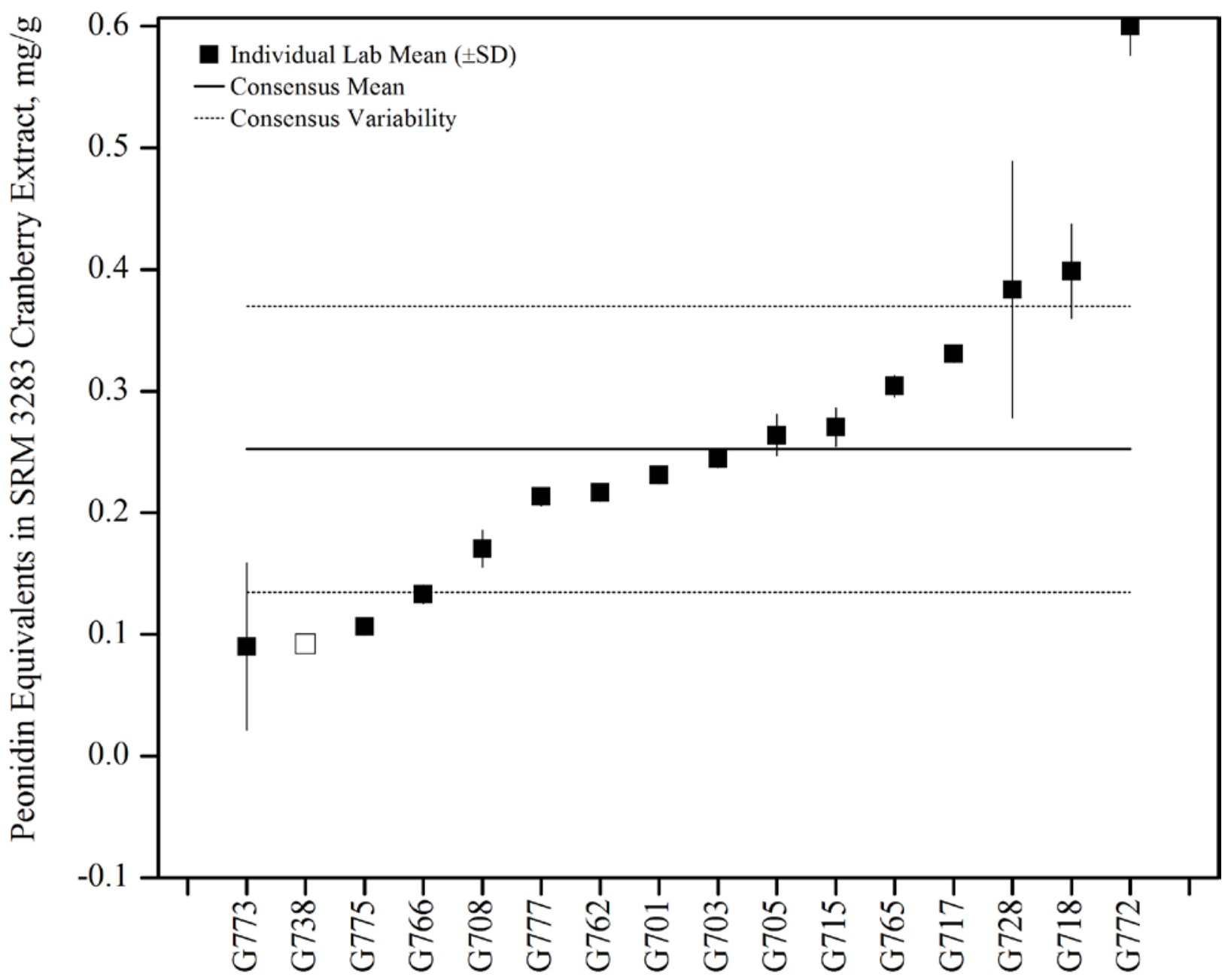

Figure 60. Peonidin equivalents in SRM 3283 Cranberry Extract (data summary view). In this view, individual laboratory data are plotted with the individual laboratory standard deviation (error bars). The black solid line represents the consensus mean, and the black dotted lines represent the consensus variability calculated as one standard deviation about the consensus mean. 


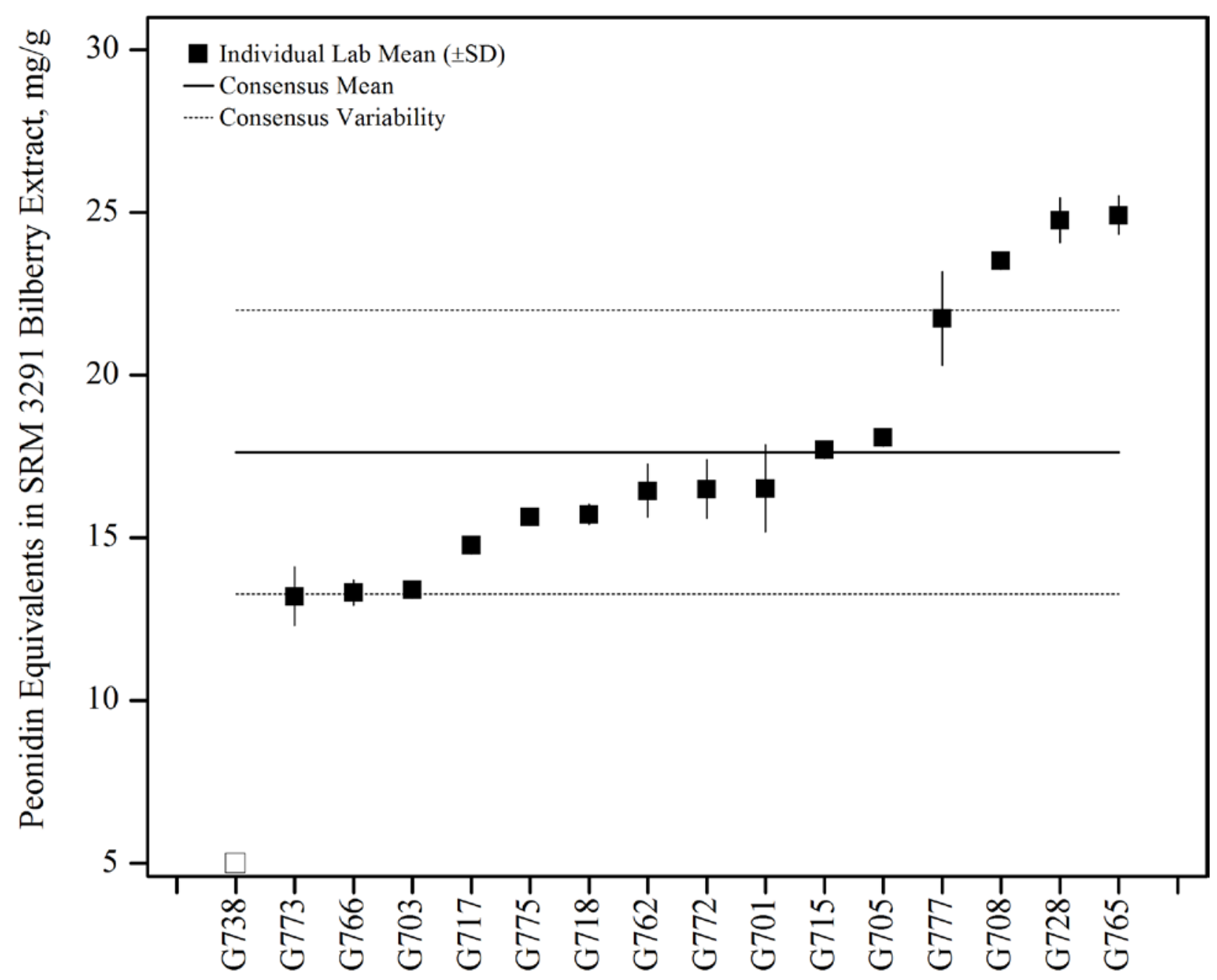

Figure 61. Peonidin equivalents in SRM 3291 Bilberry Extract (data summary view). In this view, individual laboratory data are plotted with the individual laboratory standard deviation (error bars). The black solid line represents the consensus mean, and the black dotted lines represent the consensus variability calculated as one standard deviation about the consensus mean. 


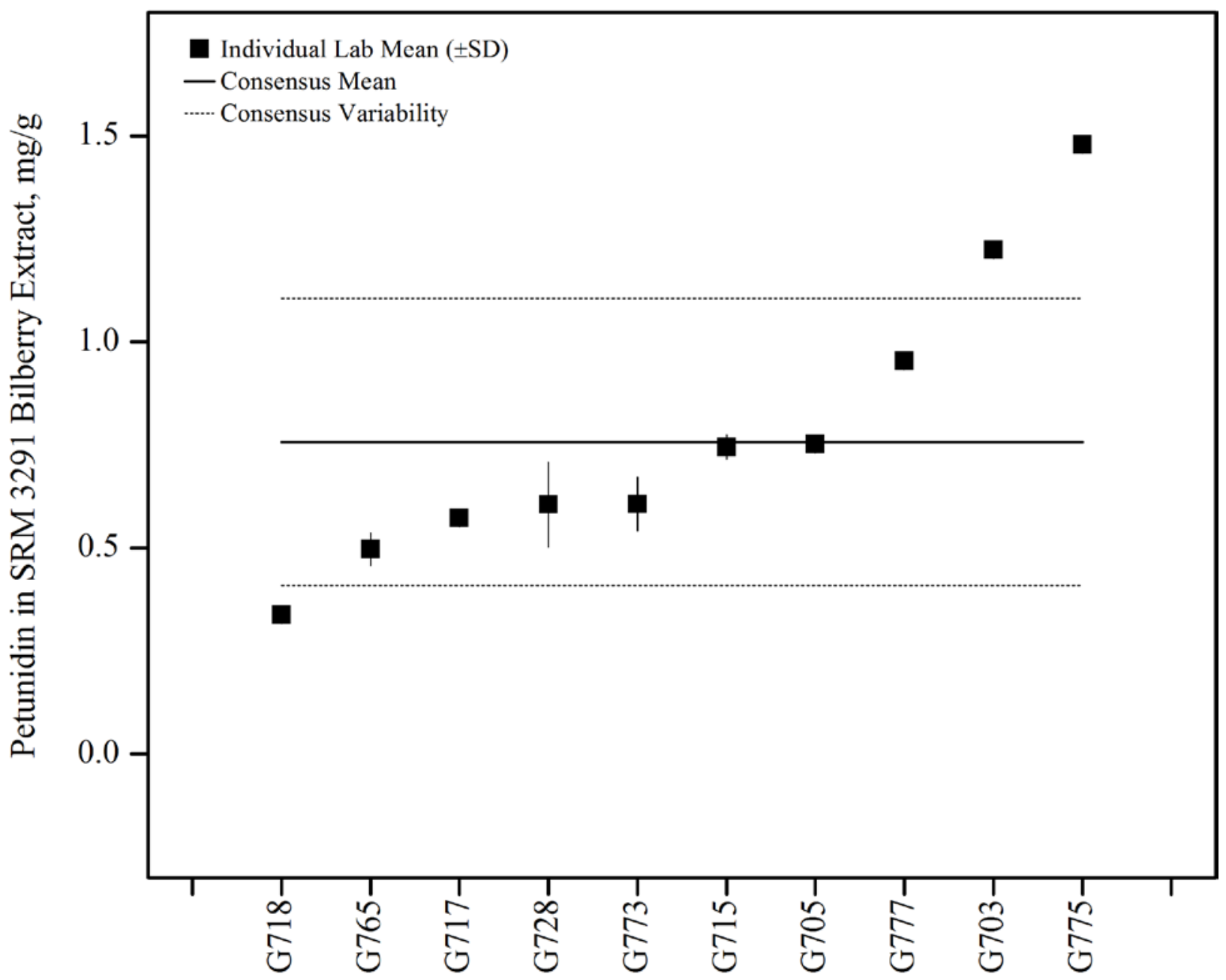

Figure 62. Petunidin in SRM 3291 Bilberry Extract (data summary view). In this view, individual laboratory data are plotted with the individual laboratory standard deviation (error bars). The black solid line represents the consensus mean, and the black dotted lines represent the consensus variability calculated as one standard deviation about the consensus mean. 


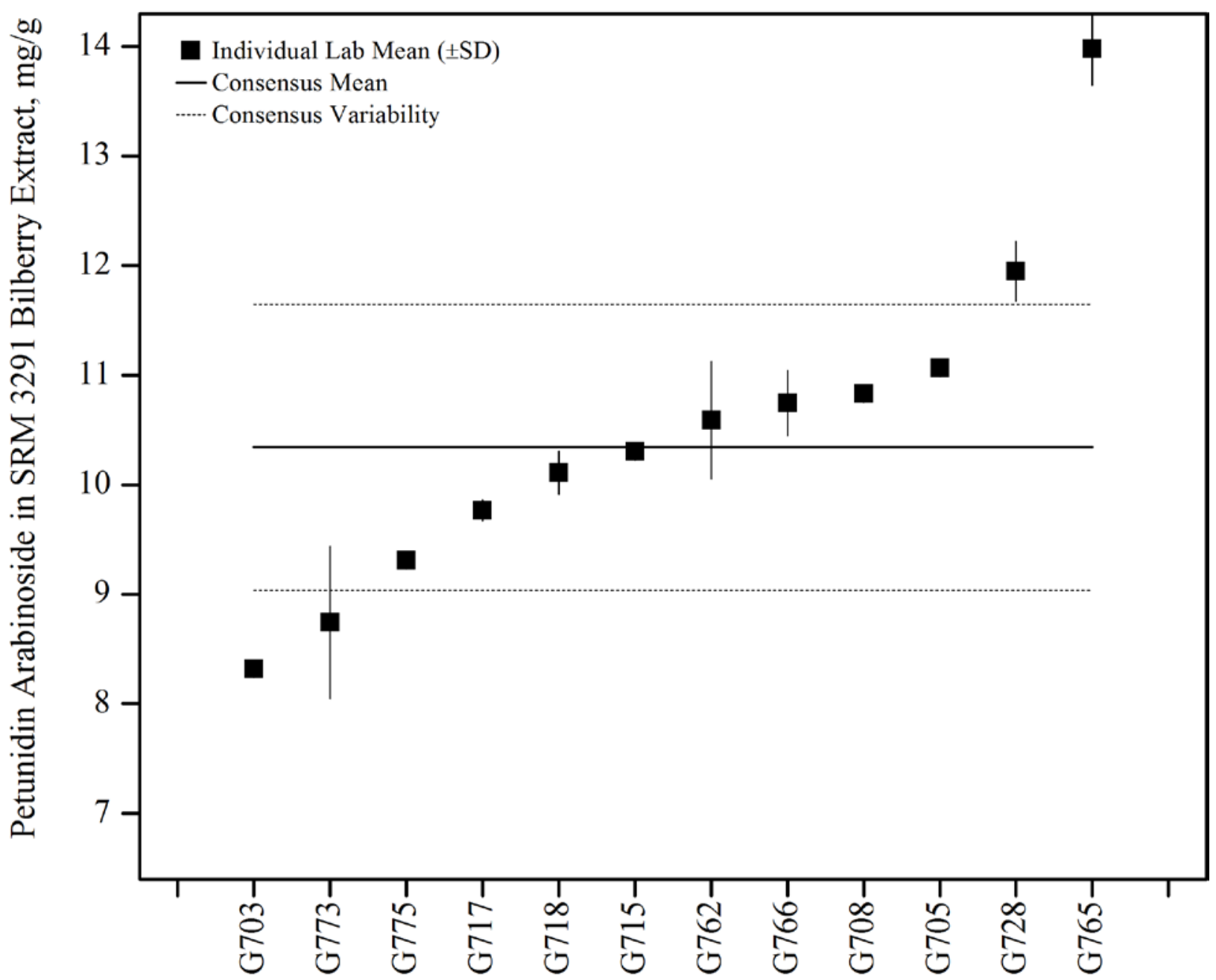

Figure 63. Petunidin-3-arabinoside in SRM 3291 Bilberry Extract (data summary view). In this view, individual laboratory data are plotted with the individual laboratory standard deviation (error bars). The black solid line represents the consensus mean, and the black dotted lines represent the consensus variability calculated as one standard deviation about the consensus mean. 


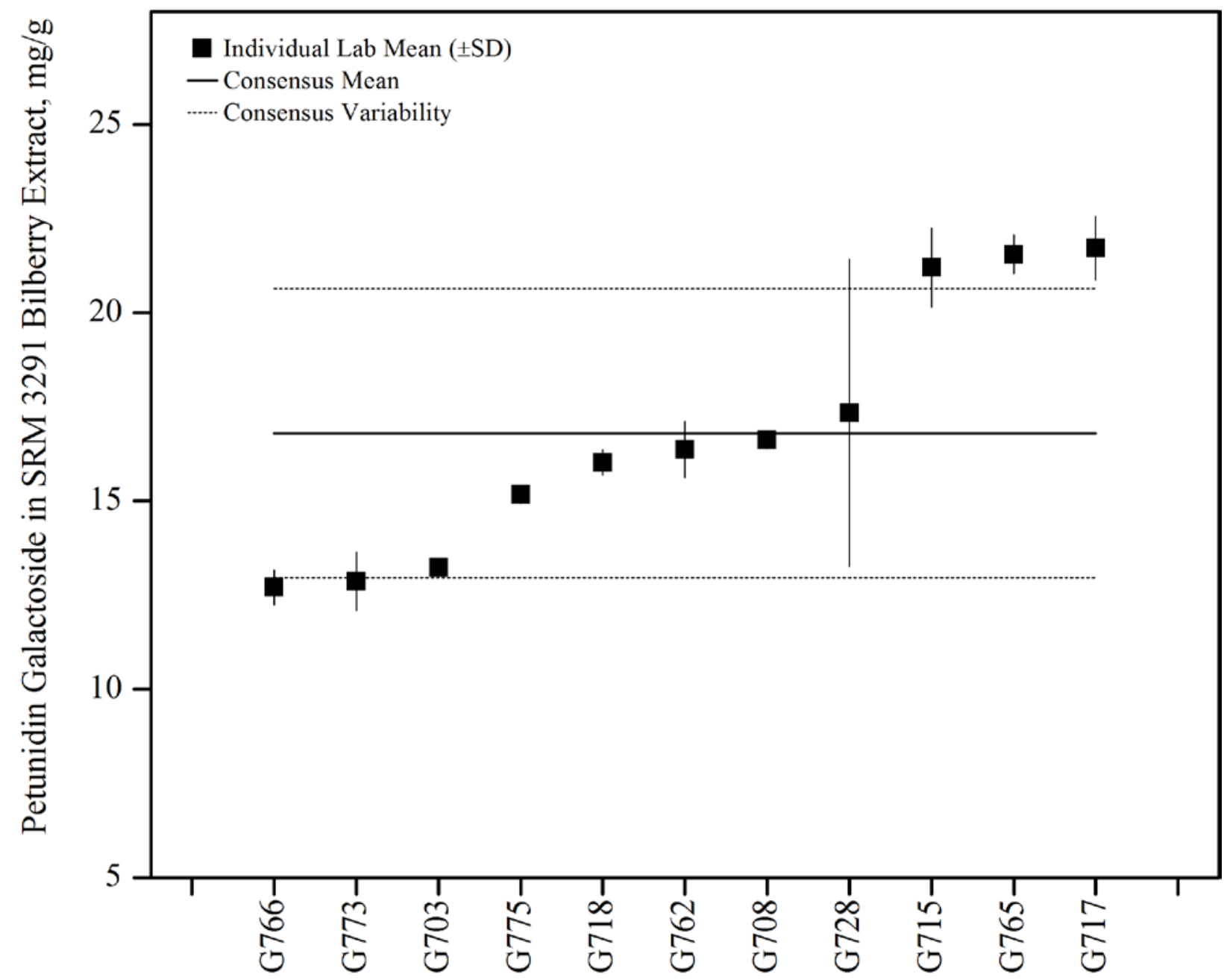

Figure 64. Petunidin-3-galactoside in SRM 3291 Bilberry Extract (data summary view). In this view, individual laboratory data are plotted with the individual laboratory standard deviation (error bars). The black solid line represents the consensus mean, and the black dotted lines represent the consensus variability calculated as one standard deviation about the consensus mean. 


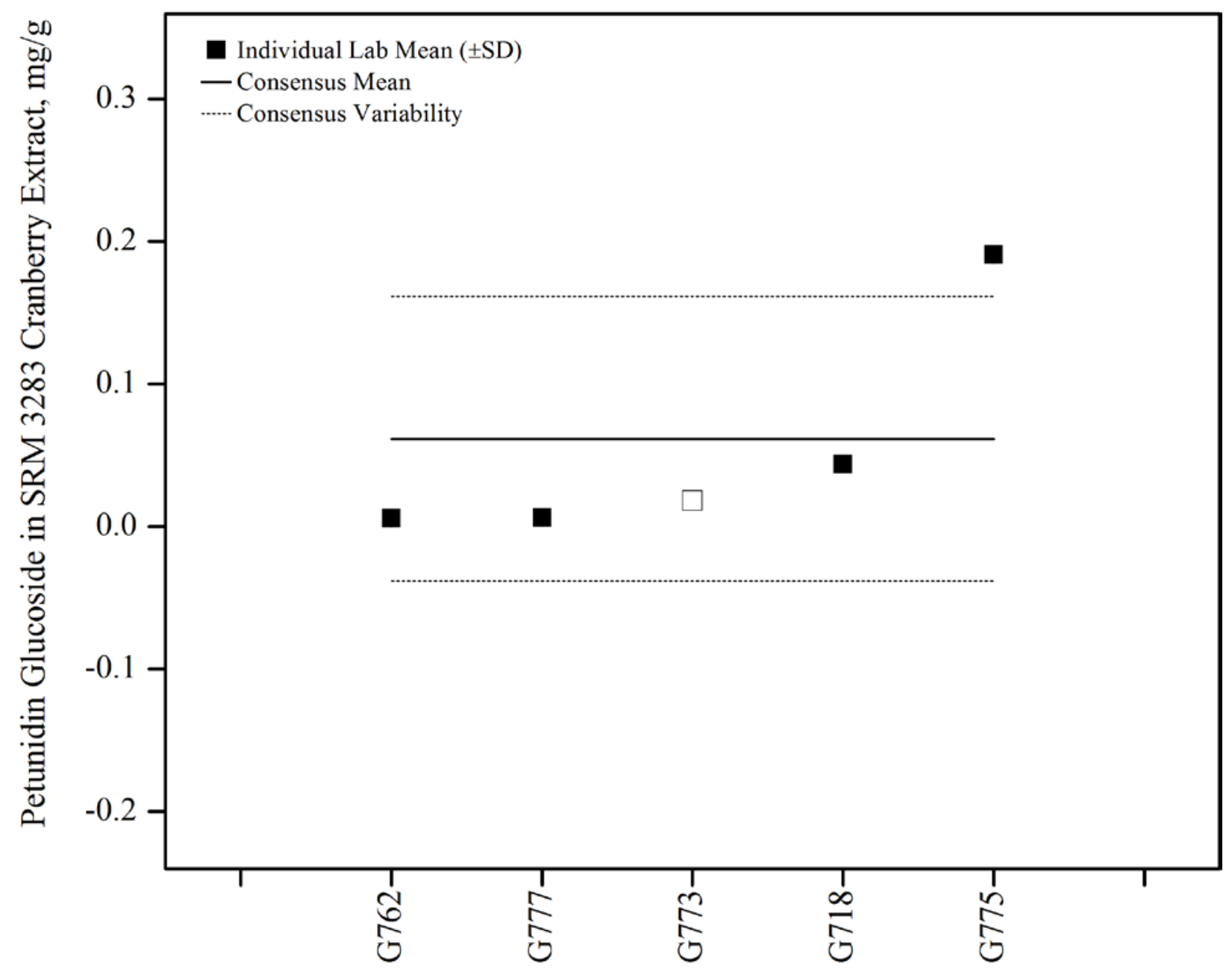

Figure 65. Petunidin-3-glucoside in SRM 3283 Cranberry Extract (data summary view). In this view, individual laboratory data are plotted with the individual laboratory standard deviation (error bars). The black solid line represents the consensus mean, and the black dotted lines represent the consensus variability calculated as one standard deviation about the consensus mean. 


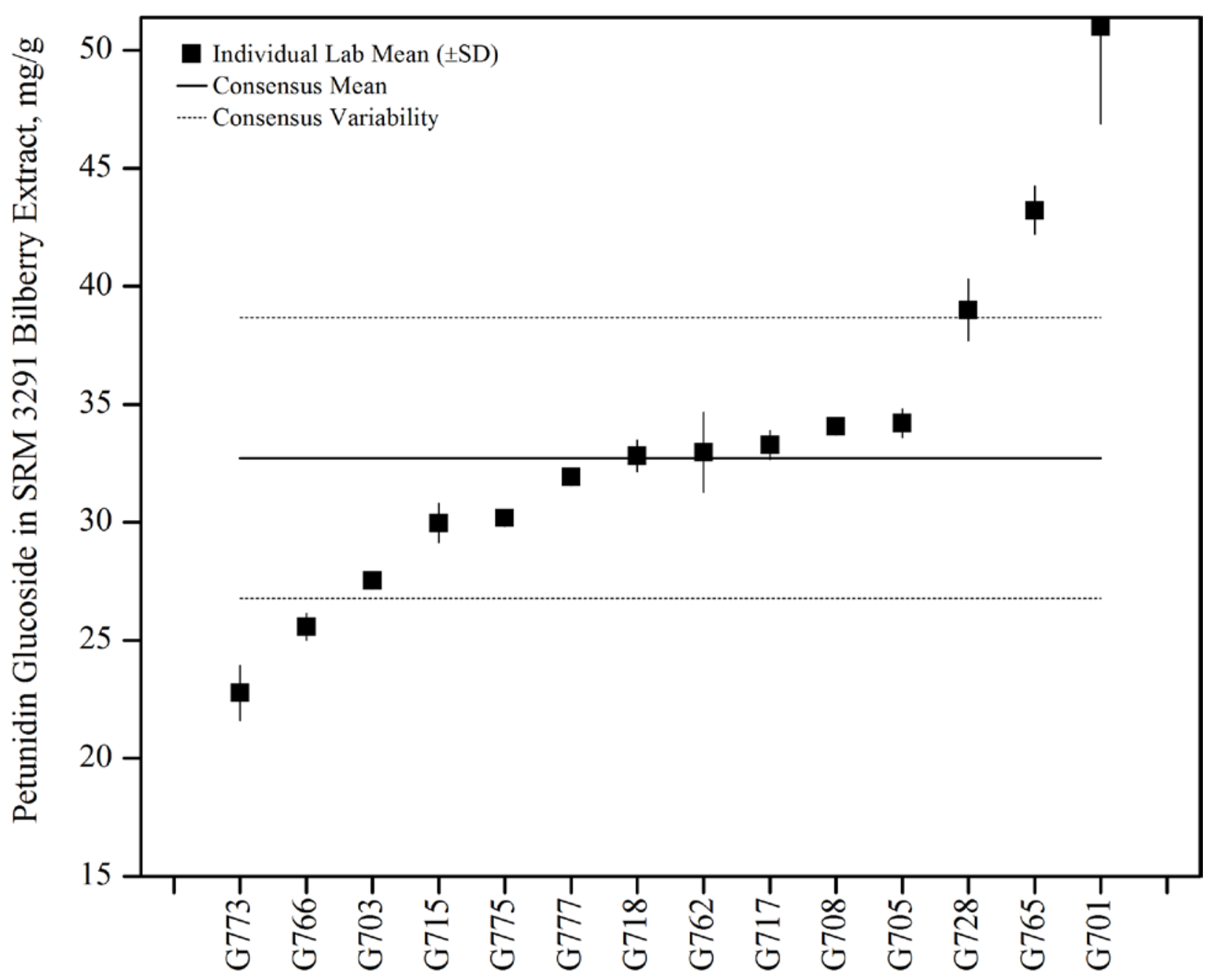

Figure 66. Petunidin-3-glucoside in SRM 3291 Bilberry Extract (data summary view). In this view, individual laboratory data are plotted with the individual laboratory standard deviation (error bars). The black solid line represents the consensus mean, and the black dotted lines represent the consensus variability calculated as one standard deviation about the consensus mean. 


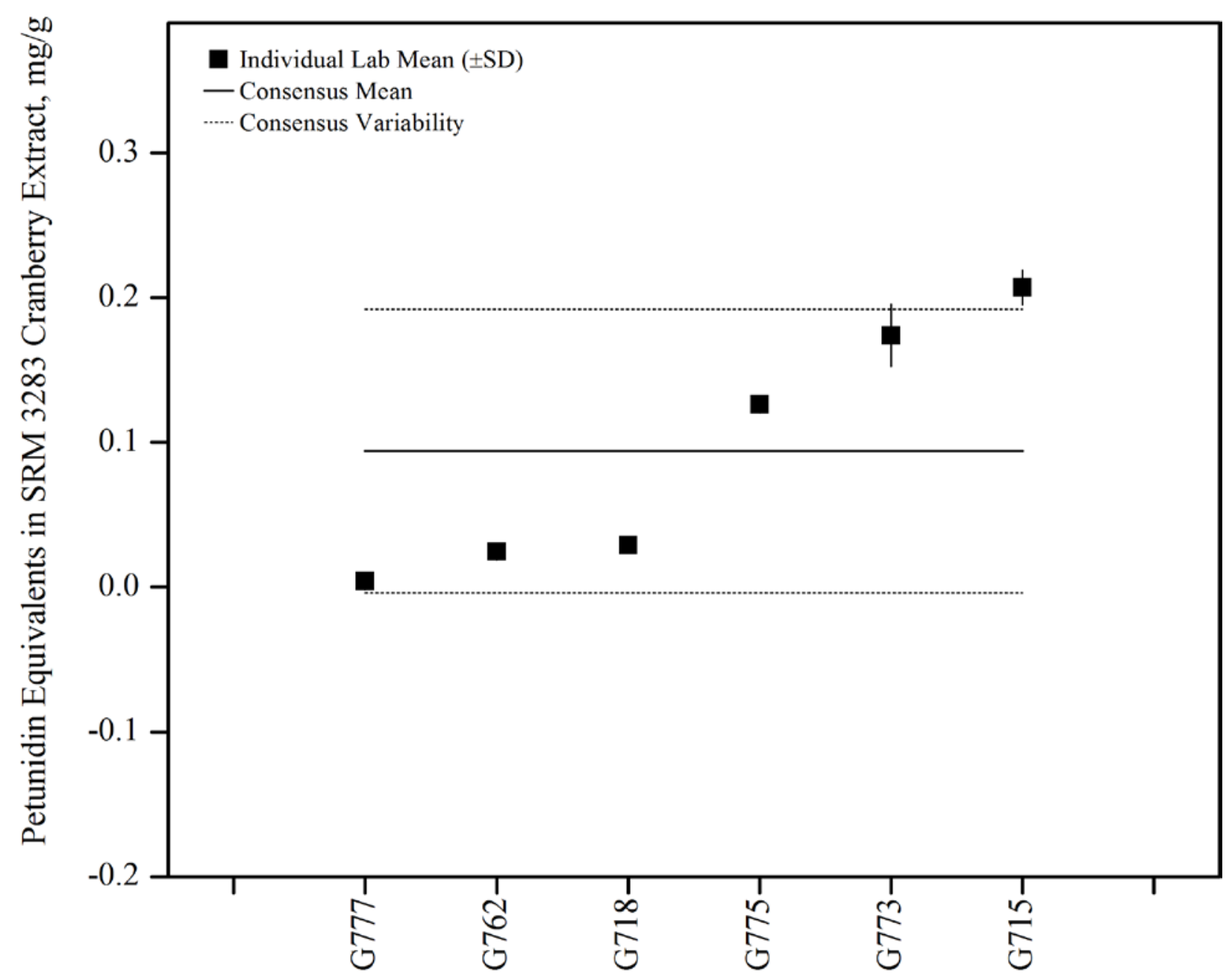

Figure 67. Petunidin equivalents in SRM 3283 Cranberry Extract (data summary view). In this view, individual laboratory data are plotted with the individual laboratory standard deviation (error bars). The black solid line represents the consensus mean, and the black dotted lines represent the consensus variability calculated as one standard deviation about the consensus mean. 


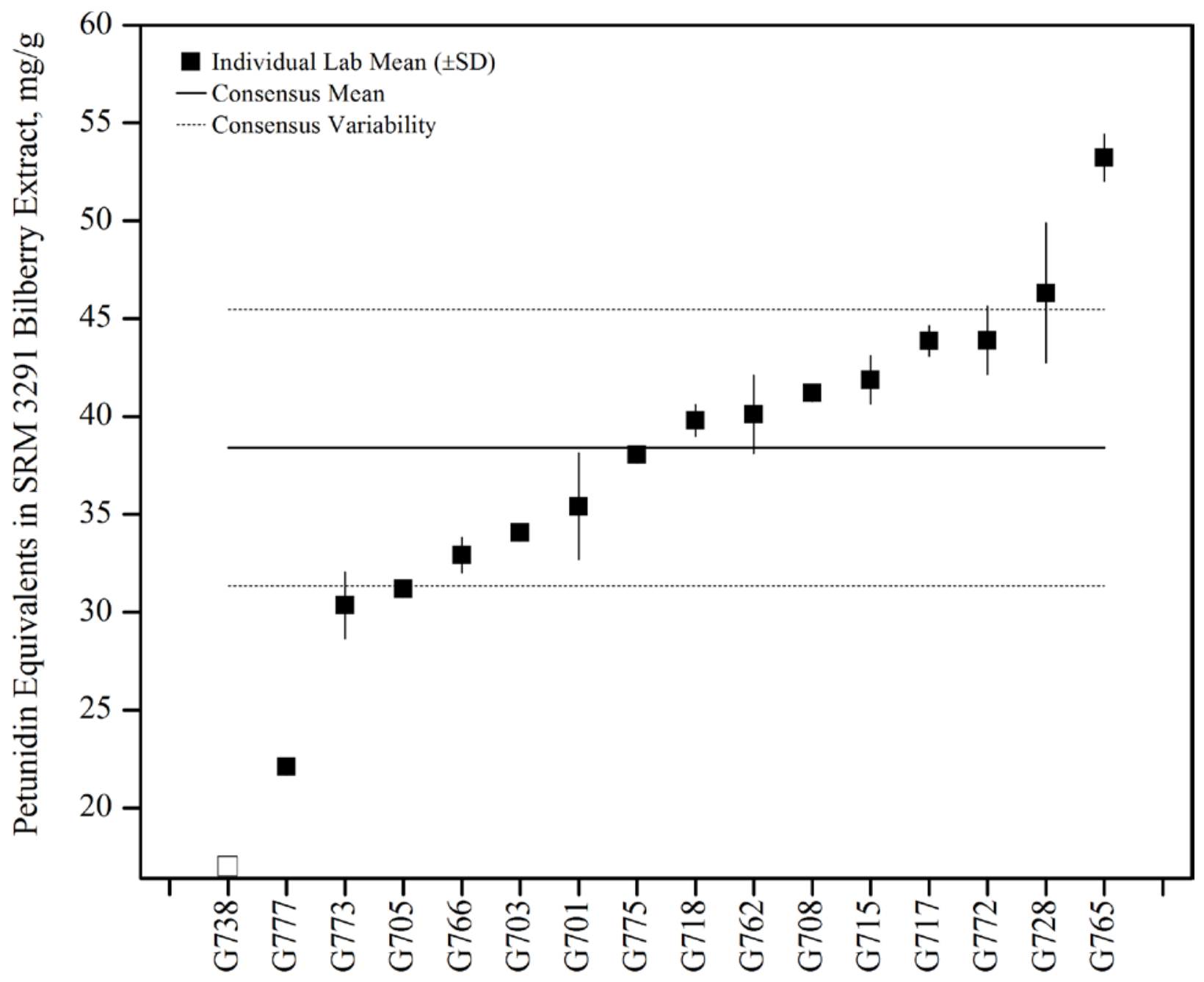

Figure 68. Petunidin equivalents in SRM 3291 Bilberry Extract (data summary view). In this view, individual laboratory data are plotted with the individual laboratory standard deviation (error bars). The black solid line represents the consensus mean, and the black dotted lines represent the consensus variability calculated as one standard deviation about the consensus mean. 


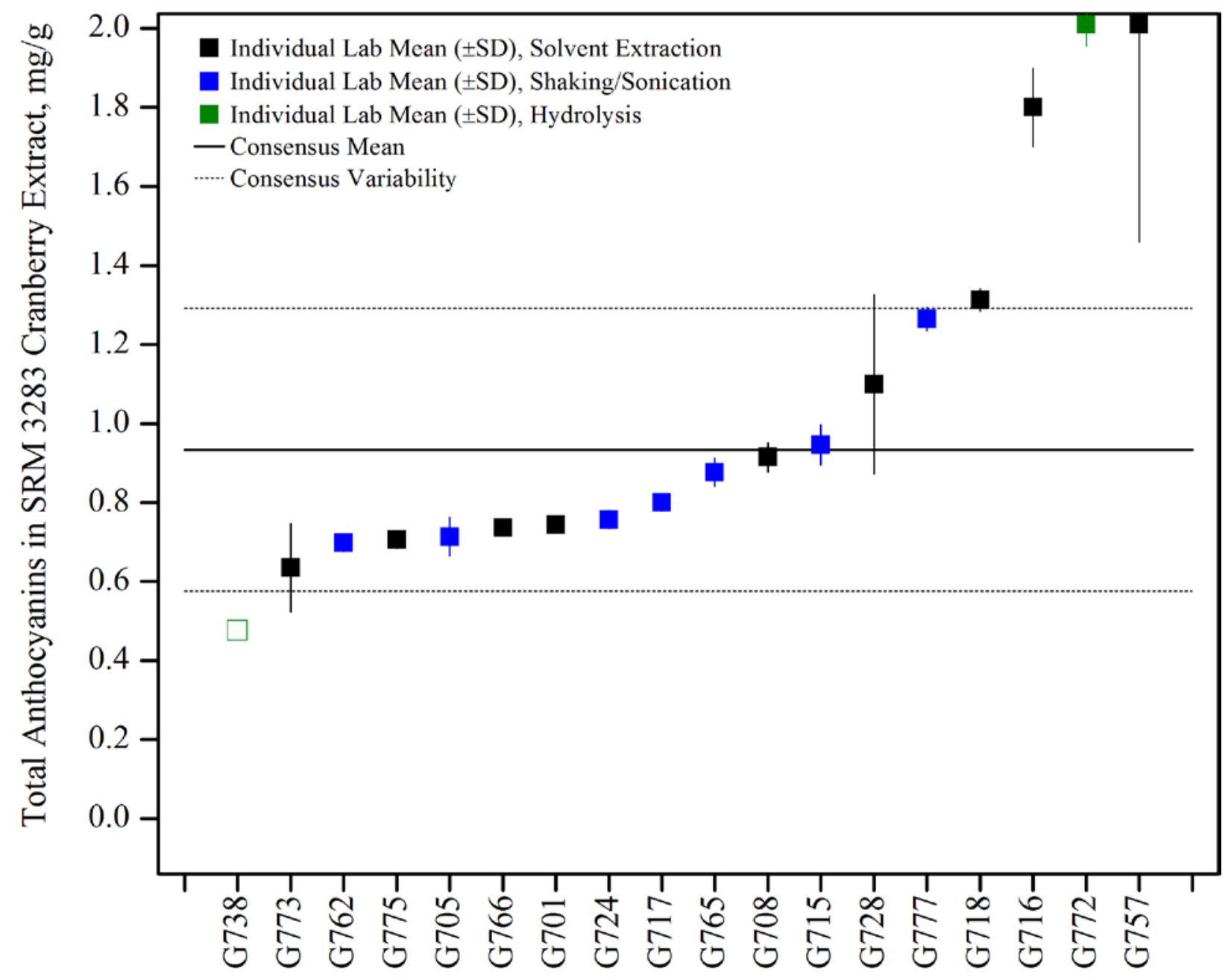

Figure 69. Total anthocyanins in SRM 3283 Cranberry Extract (data summary view - sample preparation method). In this view, individual laboratory data are plotted with the individual laboratory standard deviation (error bars). The data are identified by sample preparation method in this graph. The black solid line represents the consensus mean, and the black dotted lines represent the consensus variability calculated as one standard deviation about the consensus mean. 


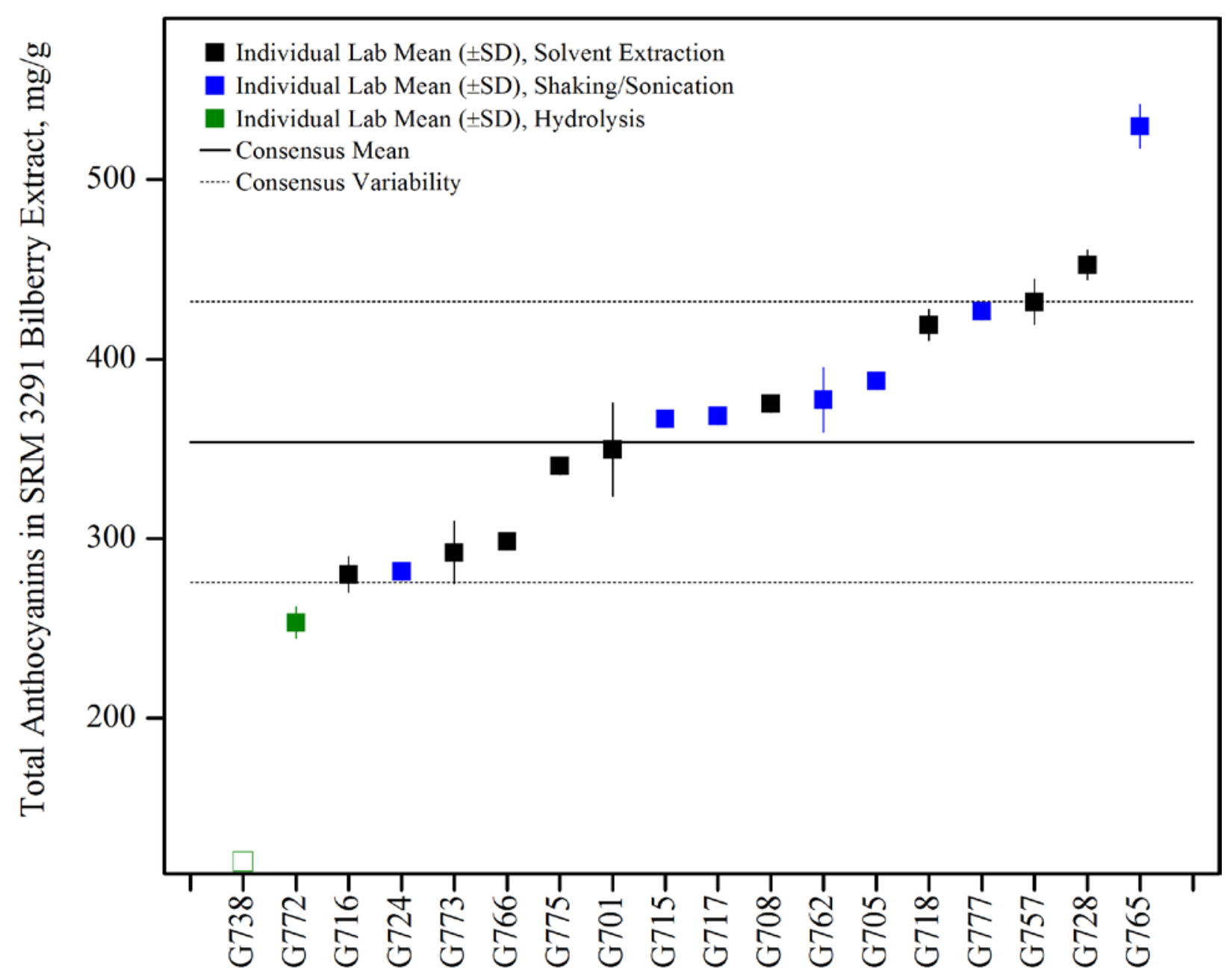

Figure 70. Total anthocyanins in SRM 3291 Bilberry Extract (data summary view - sample preparation method). In this view, individual laboratory data are plotted with the individual laboratory standard deviation (error bars). The data are identified by sample preparation method in this graph. The black solid line represents the consensus mean, and the black dotted lines represent the consensus variability calculated as one standard deviation about the consensus mean. 


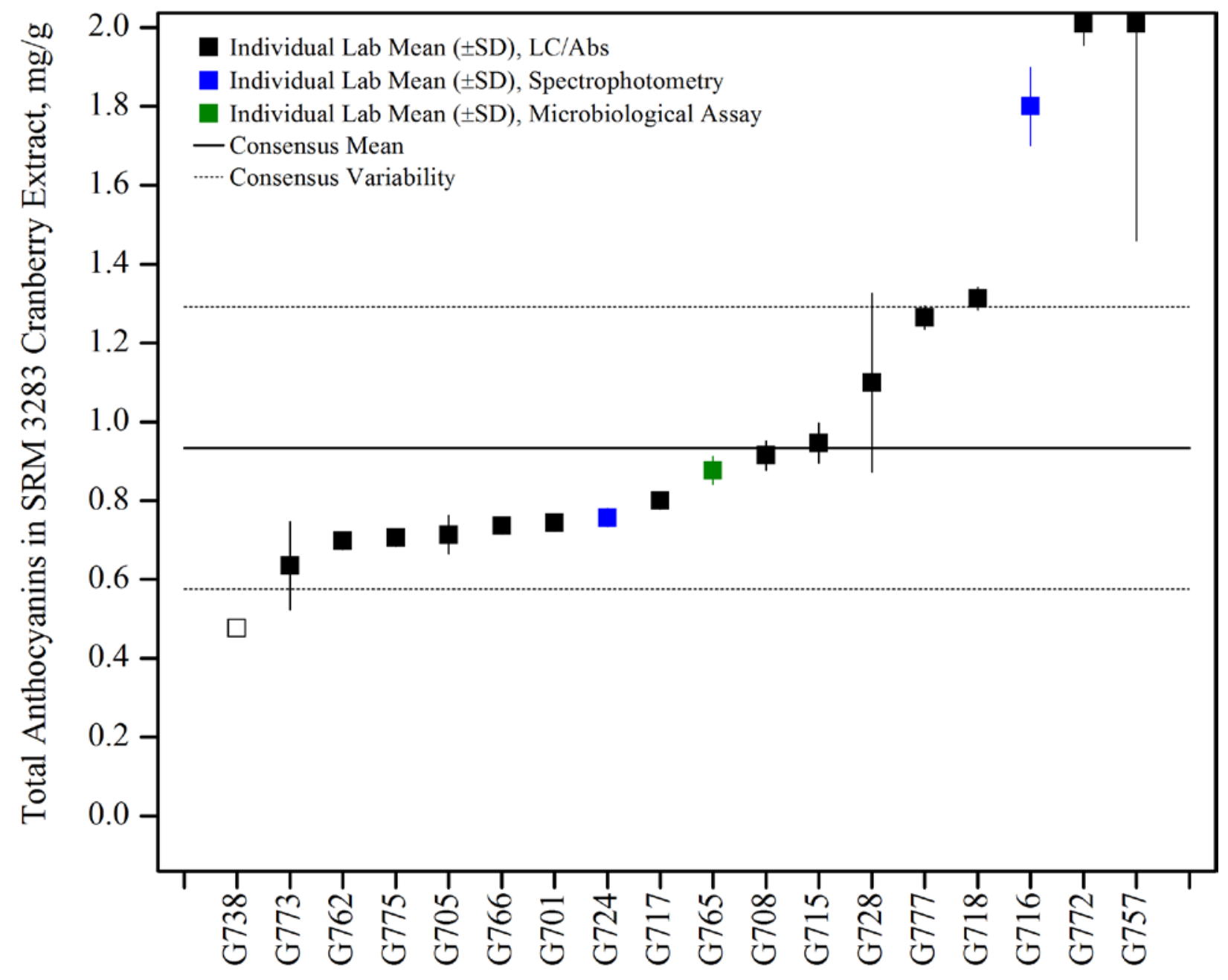

Figure 71. Total anthocyanins in SRM 3283 Cranberry Extract (data summary view instrumental method). In this view, individual laboratory data are plotted with the individual laboratory standard deviation (error bars). The data are identified by instrumental method in this graph. The black solid line represents the consensus mean, and the black dotted lines represent the consensus variability calculated as one standard deviation about the consensus mean. 


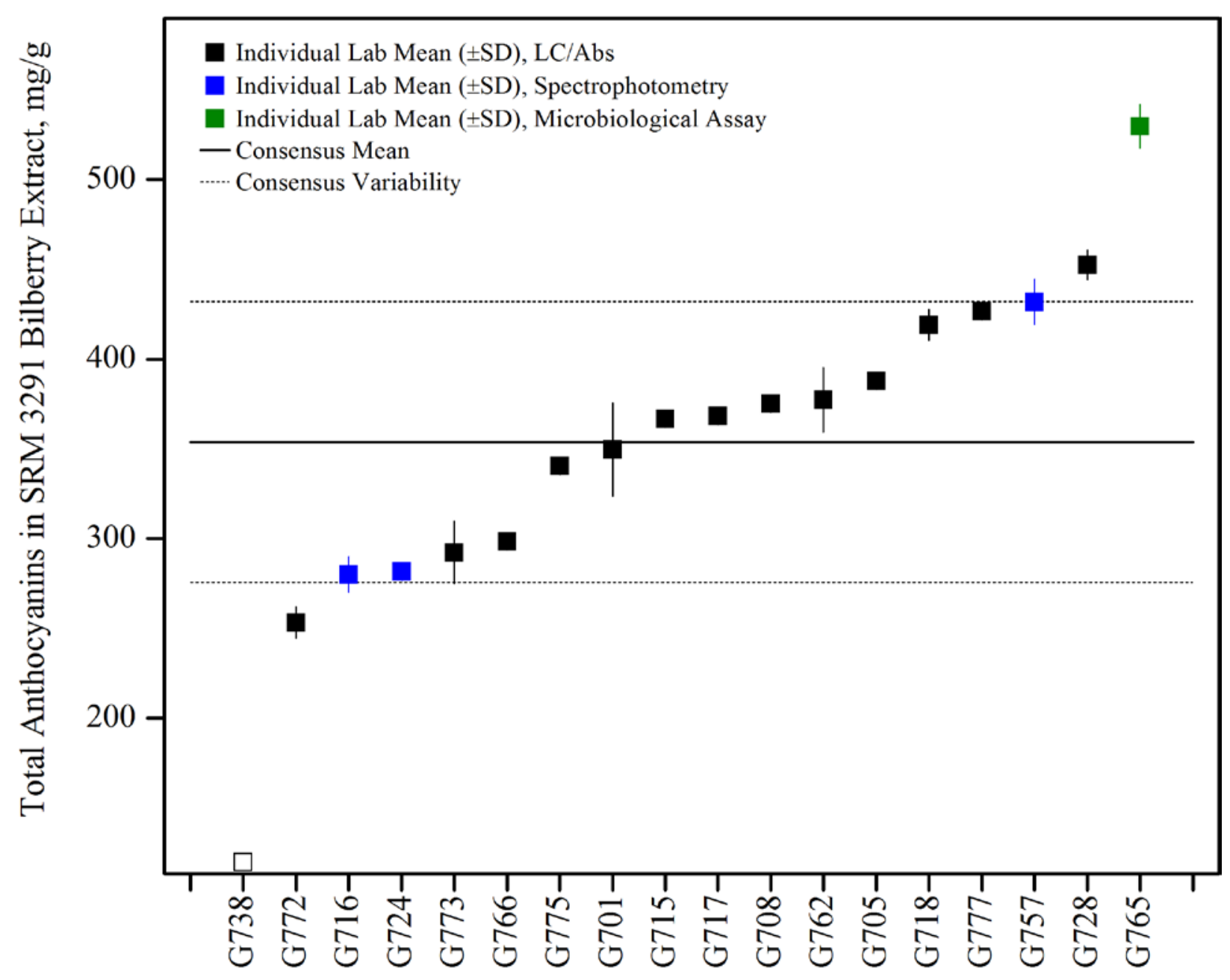

Figure 72. Total anthocyanins in SRM 3291 Bilberry Extract (data summary view - instrumental method). In this view, individual laboratory data are plotted with the individual laboratory standard deviation (error bars). The data are identified by instrumental method in this graph. The black solid line represents the consensus mean, and the black dotted lines represent the consensus variability calculated as one standard deviation about the consensus mean. 


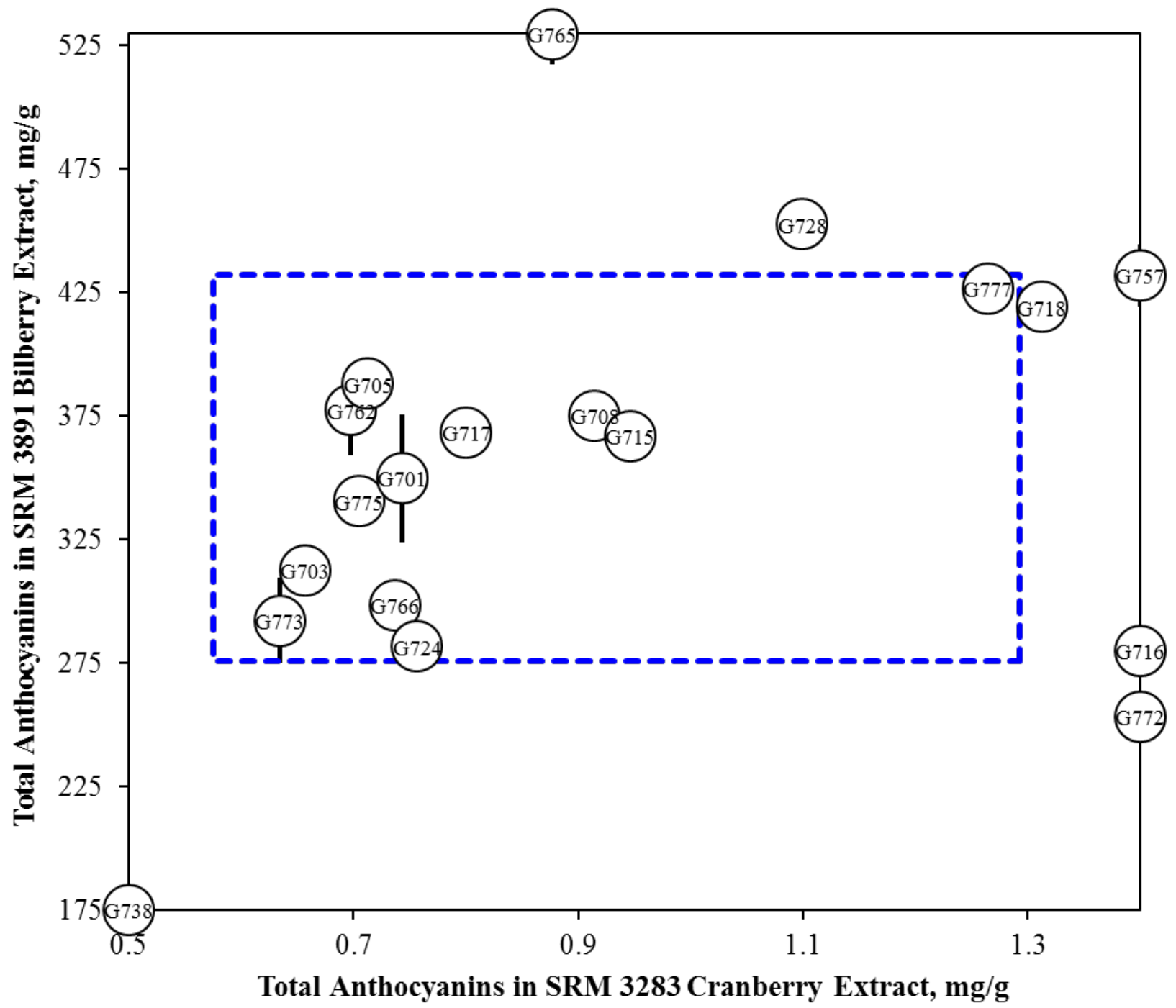

Figure 73. Total anthocyanins in SRM 3283 Cranberry Extract and SRM 3291 Bilberry Extract (sample/sample comparison view). In this view, the individual laboratory results for one sample (SRM 3283 Cranberry Extract) are compared to the results for a second sample (SRM 3291 Bilberry Extract). The dotted blue box represents the consensus zone for the cranberry extract (xaxis) and the bilberry extract (y-axis). 